\title{
Política
}

industrial rural y fortalecimiento

de cadenas

de valor

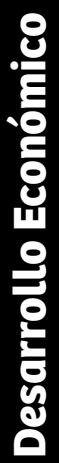

RAMÓN PADILLA PÉREZ

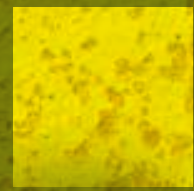

Editor
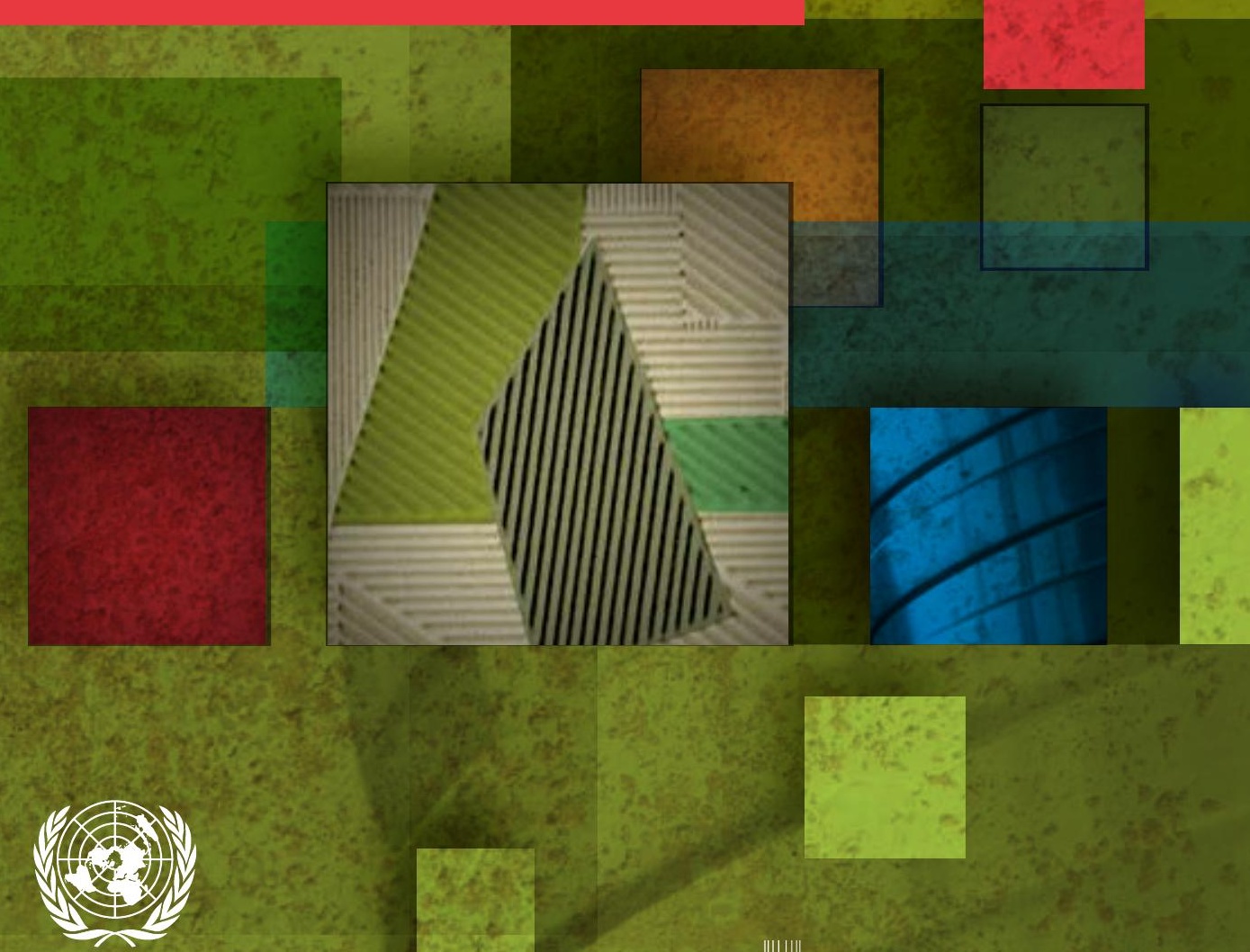

NACIONES UNIDAS

CEPA L

ЛFIDA

Invertir en la población rural 


\section{Política industrial rural y fortalecimiento de cadenas de valor}

Ramón Padilla Pérez

Editor
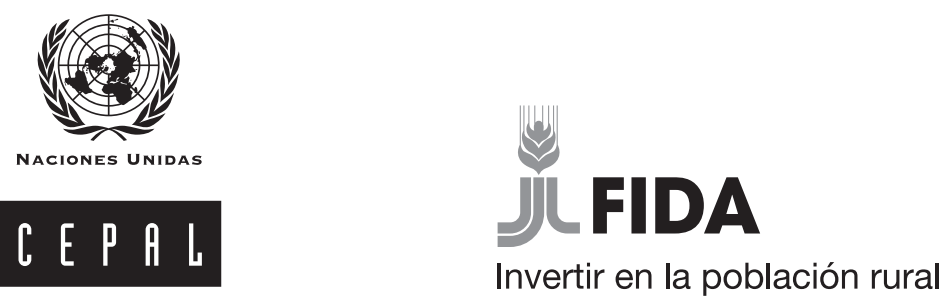

Comisión Económica para América Latina y el Caribe (CEPAL) Santiago de Chile, junio de 2017 


\section{Libros de la CEPAL}

\section{5}

Alicia Bárcena

Secretaria Ejecutiva

Antonio Prado

Secretario Ejecutivo Adjunto

Hugo Eduardo Beteta

Director de la sede subregional de la CEPAL en México

\section{Ricardo Pérez}

Director de la División de Publicaciones y Servicios Web

Este libro fue editado por Ramón Padilla Pérez, Jefe de la Unidad de Desarrollo Económico de la sede subregional de la Comisión Económica para América Latina y el Caribe (CEPAL) en México. La elaboración de los capítulos del libro estuvo a cargo de los siguientes funcionarios de la sede subregional de la CEPAL en México: Stefanie Garry, Caroline Gomes, Ramón Padilla Pérez y Francisco Villarreal. También estuvo a cargo de los siguientes consultores: Verónica Díaz y Nahuel Oddone.

La CEPAL agradece el apoyo financiero del Fondo Internacional de Desarrollo Agrícola (FIDA) para los procesos de fortalecimiento de cadenas de valor rurales y la publicación de este libro.

Diseño de portada: María Luisa Avaria

Publicación de las Naciones Unidas

ISBN: 978-92-1-121952-4 (versión impresa)

ISBN: 978-92-1-058589-7 (versión pdf)

ISBN: 978-92-1-358056-1 (versión ePub)

Número de venta: S.17.II.G.13

LC/PUB.2017/11-P

Distr.: General

Copyright (C) Naciones Unidas, 2017

Todos los derechos reservados

Impreso en Naciones Unidas, Santiago

S.17-00275

Esta publicación debe citarse como: Ramón Padilla Pérez (ed.), Política industrial rural y fortalecimiento de cadenas de valor, Libros de la CEPAL, N 145 (LC/PUB.2017/11-P), Santiago, Comisión Económica para América Latina y el Caribe (CEPAL), 2017.

La autorización para reproducir total o parcialmente esta obra debe solicitarse a la Comisión Económica para América Latina y el Caribe (CEPAL), División de Publicaciones y Servicios Web, publicaciones@cepal.org. Los Estados Miembros de las Naciones Unidas y sus instituciones gubernamentales pueden reproducir esta obra sin autorización previa. Solo se les solicita que mencionen la fuente e informen a la CEPAL de tal reproducción. 


\section{Índice}

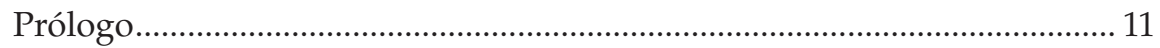

Introducción

Ramón Padilla Pérez...................................................................................... 15

Capítulo I

Desafíos en materia de desarrollo productivo en el espacio

rural de Centroamérica y la República Dominicana

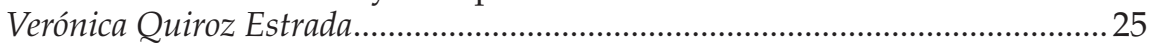

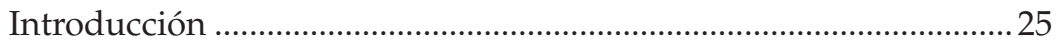

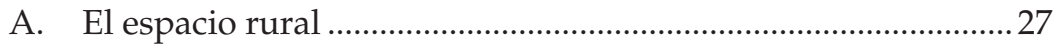

1. Definición de lo rural .............................................................22

2. Características del espacio rural en Centroamérica y la República Dominicana .....................................................2 29

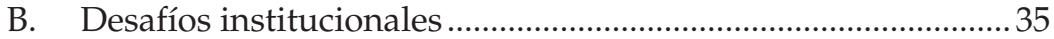

1. Reglas, convenciones y formas de coordinación ...................35

2. Políticas y estrategias .................................................................. 37

C. Desafíos de sostenibilidad ambiental.............................................38

1. Adaptación al cambio climático ..................................................38

2. Mitigación del cambio climático .............................................. 41

D. Desafíos de comercialización............................................................ 43

1. Volatilidad en los precios internacionales de productos primarios ……………………………................... 43

2. Acceso a mercados y papel de los intermediarios ................. 44

3. Comercio extrarregional e intrarregional.................................45 
E. Desafíos de productividad e innovación ………………………....4 47

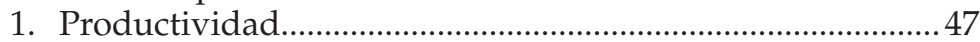

2. Tamaño y desempeño tecnológico ........................................49

3. Educación y capacitación ..........................................................51

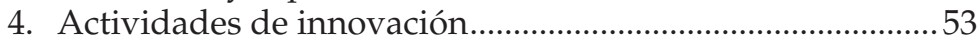

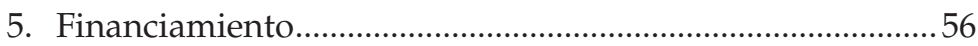

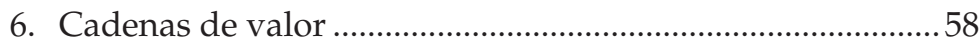

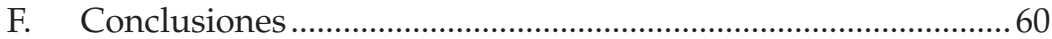

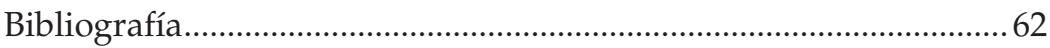

Capítulo II

Política industrial rural

Ramón Padilla Pérez, Verónica Quiroz Estrada .....................................................69

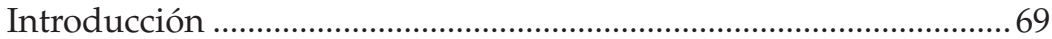

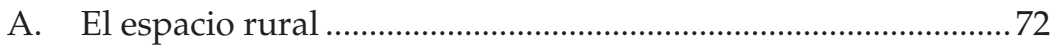

1. Definición del espacio rural ...................................................72

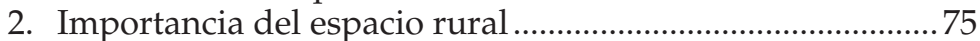

3. Interdependencia y complementariedad

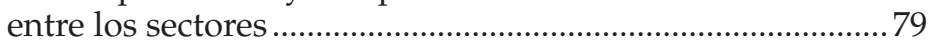

B. Definición y alcance de la política industrial rural......................83

1. ¿Qué es la política industrial rural? .......................................... 83

C. Instrumentos de política industrial rural.....................................8 87

1. Políticas comerciales, de competitividad

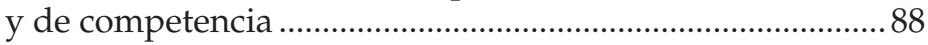

2. Políticas para el fomento productivo........................................90

3. Políticas ambientales ..................................................................96

D. Experiencias en la aplicación de instrumentos coincidentes con la política industrial rural ................................97

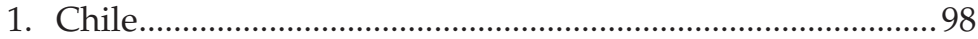

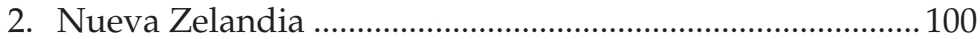

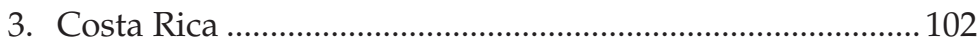

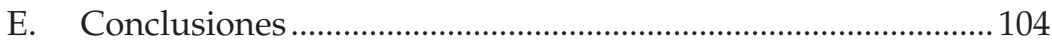

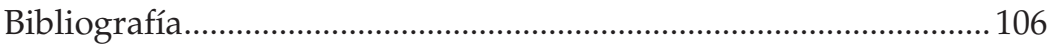

\section{Capítulo III}

Metodología para el fortalecimiento de cadenas de valor

Ramón Padilla Pérez, Nahuel Oddone ............................................................ 113

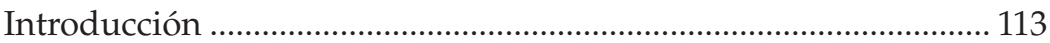

A. Las cadenas de valor y el cambio estructural............................. 114

B. Definiciones y conceptos clave ..................................................... 116

1. Las cadenas de valor ............................................................. 116

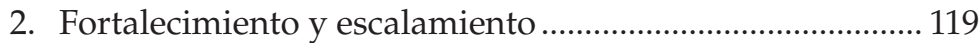

C. La metodología para el fortalecimiento

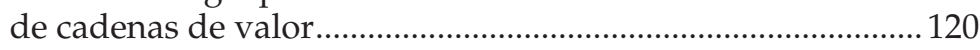

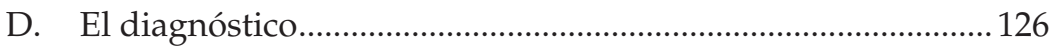




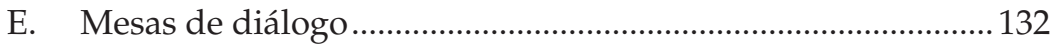

F. Las buenas prácticas ................................................................... 134

G. Las estrategias, el apoyo a la implementación y el lanzamiento

1. La elaboración de estrategias ...............................................137

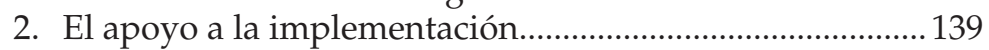

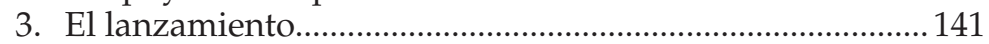

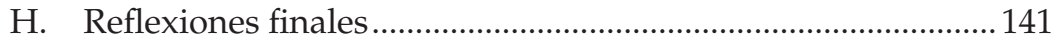

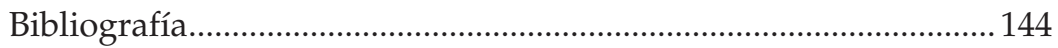

Capítulo IV

La selección de cadenas de valor en el contexto de una política industrial

Caroline Gomes Nogueira, Ramón Padilla Pérez, Francisco G. Villarreal......... 149

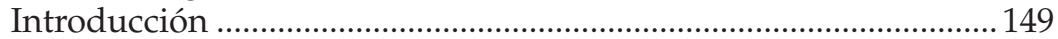

A. ¿Por qué seleccionar cadenas?..................................................150

1. ¿Existen realmente las políticas industriales horizontales?.

2. La existencia de fallas de mercado........................................ 152

3. El desafío de las ventajas comparativas y la creación de ganadores ...................................................152

4. El aprovechamiento de ventanas de oportunidad..............153

5. El cambio estructural ...........................................................154

B. La selección de sectores en la práctica: herramientas y estrategias.

1. Identificación de conglomerados (clusters) de alto potencial en Centroamérica: Instituto Centroamericano de Administración de Empresas (INCAE) e Instituto de Desarrollo Internacional de Harvard....

2. Selección de sectores prioritarios en México en términos de productividad y potencial de crecimiento.

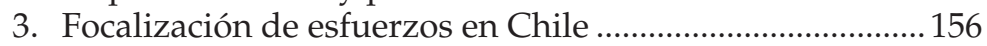

C. La metodología de selección de cadenas ..................................... 158

D. El desarrollo de indicadores a partir de los metaobjetivos propuestos

E. La aplicación de la metodología: la selección de cadenas en México

F. Reflexiones finales: fortalezas y desafíos de la selección de cadenas.

Bibliografía.

\section{Capítulo V}

El fortalecimiento de cadenas de valor de productos

primarios y agroindustriales

Ramón Padilla Pérez

Introducción

A. La definición de metaobjetivos 


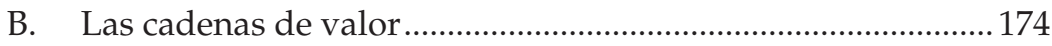

1. Los eslabones de las cadenas de valor..................................174

2. La gobernanza de las cadenas de valor ...............................182

3. Estimación de costos y márgenes............................................183

4. Instituciones y organizaciones que apoyan y regulan las cadenas ............................................................. 185

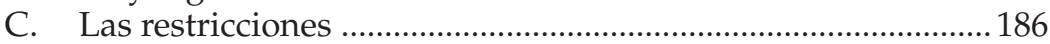

D. Las estrategias para el fortalecimiento de cadenas de valor rurales

1. Fortalecimiento institucional .................................................. 192

2. Política de desarrollo agropecuario para el fortalecimiento de cadenas.

3. Política industrial rural para el fortalecimiento de cadenas.

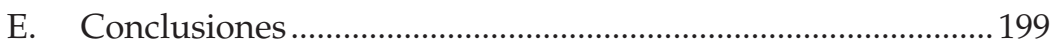

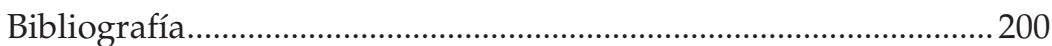

Capítulo VI

El fortalecimiento de las cadenas de valor turísticas en los espacios rurales

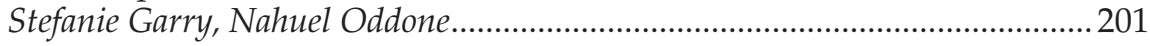

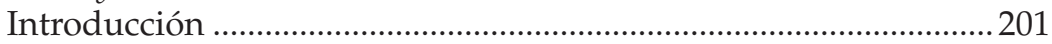

A. Contexto regional del turismo.........................................................203

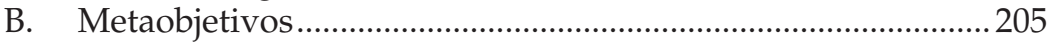

C. Las cadenas de valor turísticas..................................................208

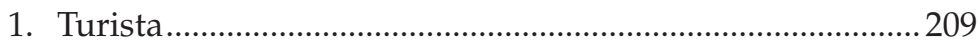

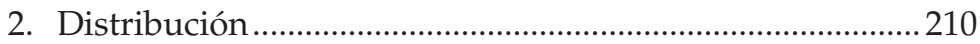

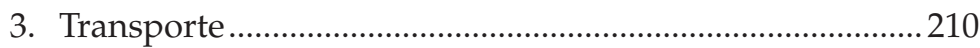

4. Alojamiento y servicios gastronómicos................................. 211

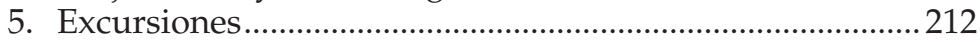

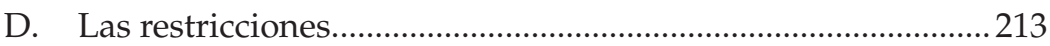

E. Estrategias y recomendaciones de política pública

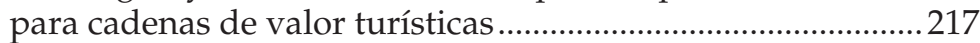

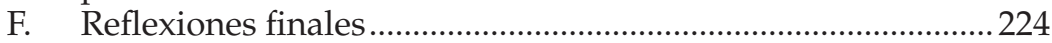

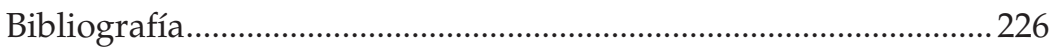

Capítulo VII

Conclusiones

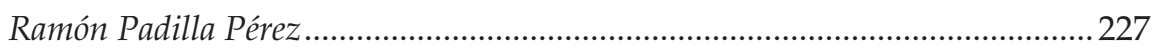

A. Fortalecimiento de cadenas de valor, política industrial rural y cambio estructural progresivo..........................................228

B. La creación de cadenas de valor................................................231

C. Fortalezas, retos y líneas de trabajo futuro.....................................2234

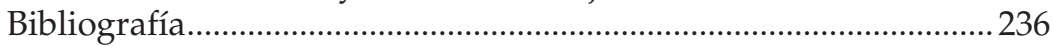

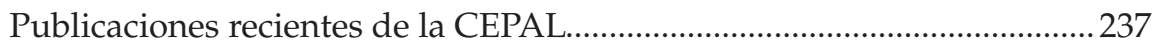




\section{Cuadros}

I.1 Centroamérica y la República Dominicana: distribución del ingreso de las personas por quintiles, según área geográfica, 2014 o último año disponible.

I.2 Centroamérica y la República Dominicana: distribución de la población ocupada rural por tipo de inserción laboral, 2000 y 2014.

I.3 Centroamérica y la República Dominicana: limitaciones a la implementación de reformas agrarias

I.4 Centroamérica y la República Dominicana: rendimiento medio de los granos básicos, 1980-2013.

I.5 Centroamérica y la República Dominicana: indicadores de ciencia y tecnología en el sector agropecuario

I.6 Centroamérica y la República Dominicana: participación del crédito rural en el crédito total de las organizaciones de microfinanzas, 2014

I.7 Centroamérica y la República Dominicana: ejemplos de restricciones por eslabón en cadenas de valor rurales

II.1 Principales criterios para definir el espacio rural .................................72

II.2 Cambios recientes en el paradigma rural.............................................. 74

II.3 América Latina y el Caribe (8 países): PIB agropecuario como porcentaje del PIB total, a precios constantes, 1990-1995, 2000-2005 y 2010-2015.

II.4 América Latina (8 países): población económicamente activa rural como porcentaje de la población económicamente activa total, 1990 y 2015.

II.5 América Latina y el Caribe: contribución del valor agregado al PIB por sector de actividad económica, años seleccionados

II.6 Definición y ejemplos de escalamiento económico en el espacio rural

II.7 Políticas comerciales, de competitividad y de competencia .............88

II.8 Políticas para el fomento productivo ……………………………….........91

II.9 Políticas ambientales .......................................................................96

II.10 Chile: ejemplos de instrumentos y acciones de política industrial rural

II.11 Costa Rica: ejemplos de instrumentos y acciones para fortalecer el turismo rural.

III.1 Cadenas de valor del proyecto CEPAL-FIDA “Crecimiento inclusivo, política industrial rural y cadenas de valor participativas en América Latina y el Caribe", 2014-2016

III.2 Espacios de diálogo: tipos y características ......................................133

IV.1 Centroamérica: clusters de alto potencial .........................................155

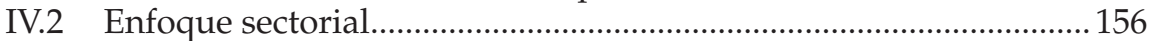

V.1 Estimación de costos y márgenes a lo largo de las cadenas ............ 184 
V.2 Restricciones que enfrentan las cadenas de valor analizadas de productos primarios y agroindustriales.

V.3 Estrategias para el fortalecimiento de las cadenas de valor rurales analizadas.

VI.1 Cadenas de valor de turismo en espacios rurales: restricciones específicas por eslabón.

\section{Gráficos}

I.1 Centroamérica y la República Dominicana: población rural, 1985 y 2015

I.2 Centroamérica y la República Dominicana: población urbana y rural en situación de pobreza e indigencia, 2014 o último año disponible

I.3 Centroamérica y la República Dominicana: participación del PIB agropecuario en el PIB total a precios constantes, 1990-2015.

I.4 Centroamérica y la República Dominicana: población ocupada rural, por gran sector económico, 2014 o último año disponible..... 34

I.5 Centroamérica y la República Dominicana: distribución de los eventos extremos, por tipo de origen, 1990-2015.

I.6 Centroamérica y la República Dominicana: superficie agrícola y de bosques, 1990 y 2015 o último año disponible

I.7 Precios internacionales de granos básicos, promedio anual, 1980-2016.

I.8 Centroamérica y la República Dominicana: exportaciones e importaciones de productos agroalimentarios, 2015 o último año disponible

I.9 Centroamérica y la República Dominicana: tasas de crecimiento medio de la productividad laboral media en el sector agropecuario, 1990-2002 y 2002-2012

I.10 Centroamérica y la República Dominicana: distribución de la población económicamente activa (PEA) rural de 15 años y más, según años de instrucción, 2014 o último año disponible

II.1 Población rural como porcentaje de la población total, 1990 y 2015

II.2 Valor agregado agrícola como porcentaje del PIB total, 1990-2014

II.3 América Latina (países seleccionados): población ocupada rural según actividad económica, 1997, 2005 y 2014 .................................... 78

II.4 América Latina (19 países): población en situación de pobreza e indigencia, por zona geográfica, 1990 y 2014.

V.1 El Salvador: producción nacional e importaciones de tomate, 2000-2013

V.2 México: proporción de unidades económicas dedicadas a la preparación de embutidos y otras conservas de ganado, aves y otros animales comestibles, por tamaño, 2004, 2009 y 2013. 
V.3 República Dominicana: producción estimada de lácteos, 1980-2014

VI.1 Centroamérica y la República Dominicana: llegadas turísticas internacionales, 2007-2014

\section{Recuadros}

III.1 Preguntas base para la elaboración del diagnóstico

IV.1 México: metaobjetivos e indicadores para la cadena de valor de embutidos y otras conservas de cerdo

\section{Diagramas}

III.1 Estructura general de una cadena de valor de bienes ...................... 118

III.2 Metodología para el fortalecimiento de cadenas de valor................121

III.3 Enfoque sistémico de la cadena de valor ............................................124

III.4 Diagnóstico de la cadena ...................................................................126

III.5 Proceso de análisis de buenas prácticas ............................................135

III.6 Proceso de elaboración de estrategias ..................................................137

III.7 Matriz de comparación de costos, plazo de implementación e impactos relativos de las estrategias ................................................ 138

IV.1 Alineación vertical y horizontal ......................................................159

IV.2 Proceso de selección de cadenas......................................................... 160

V.1 El Salvador: cadena de valor de tomate y chile verde dulce........... 175

V.2 México: cadena de valor de los embutidos y otras conservas

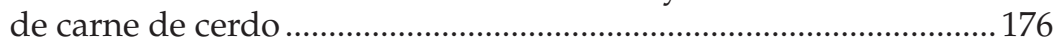

V.3 República Dominicana: cadena de valor de los lácteos .................... 179

V.4 El Salvador: cadena de valor de snacks nutritivos

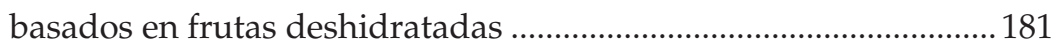

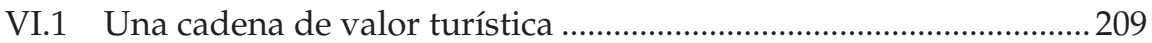

VI.2 Turismo: proceso de certificación .........................................................218

VI.3 Gobernanza en cadenas de valor turísticas: actores clave y su papel en el desarrollo de nuevos destinos o productos...........219

VI.4 Estrategias para el fortalecimiento de las cadenas

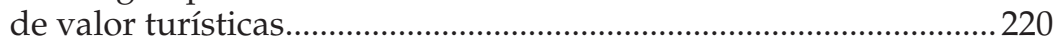

VII.1 Metodología para la creación de cadenas participativas ..................232

\section{Mapas}

VI.1 Guatemala: el departamento de Sacatepéquez ................................. 206

VI.2 República Dominicana: la provincia de Pedernales y su área protegida …………….............................................................206

VI.3 El Salvador: el departamento de La Libertad .................................... 207 



\section{Prólogo}

Después de dos años de contracción económica, se espera que en 2017 los países de América Latina y el Caribe registren un ligero repunte en torno al $1 \%$. La recuperación se da en un contexto externo de creciente incertidumbre y bajo dinamismo. El crecimiento bajo o negativo ha acentuado los retos económicos y sociales que enfrenta la región, como la insuficiencia de la inversión, la baja dinámica de la productividad, el ensanchamiento de las brechas estructurales y el riesgo de deterioro social ante el aumento del desempleo y la reducción del gasto público.

Para enfrentar estos retos, la Comisión Económica para América Latina y el Caribe (CEPAL) ha planteado la necesidad de promover un cambio estructural progresivo, es decir, un proceso de transformación hacia actividades y procesos productivos intensivos en aprendizaje e innovación, que permitan aumentar la producción y que favorezcan la protección del medio ambiente, el empleo con derechos y el mejoramiento de las condiciones sociales de la población.

Un cambio estructural con estas características es un instrumento poderoso para el cumplimiento de la Agenda 2030 para el Desarrollo Sostenible y los 17 Objetivos de Desarrollo Sostenible (ODS) que los 193 países representados en la Asamblea General de las Naciones Unidas aprobaron en septiembre de 2015. De esta manera, la transformación de la estructura productiva iría acompañada de la reducción de la pobreza y de una mejora del bienestar de la población (Objetivos 1, 2 y 3), promovería el trabajo decente, la expansión de la actividad económica y la innovación (Objetivos 8 y 9), reduciría la desigualdad (Objetivo 10) y combatiría de manera decidida el cambio climático y sus efectos (Objetivo 13). 
Los retos para el cumplimiento de los ODS se acrecientan en el espacio rural. Como se muestra en el capítulo I de este libro, la pobreza en las zonas rurales es significativamente mayor que en las urbanas, lo que está muy asociado con otras brechas (por ejemplo, en materia de educación, infraestructura y acceso a servicios). En América Latina el porcentaje de la población rural en situación de pobreza es del 46,2\%, mientras que en el espacio urbano esta cifra se reduce al $23,8 \%$. Para avanzar en el cumplimiento de la Agenda 2030 se requiere un nuevo conjunto de instituciones y políticas y plantear soluciones creativas e innovadoras que lleven a un cambio en el estilo de desarrollo.

La propuesta para abordar los retos del espacio rural que la CEPAL plantea en este libro parte de una nueva perspectiva que reconoce que hay una nueva ruralidad que requiere nuevos instrumentos y enfoques. La transformación estructural del espacio rural debe abordarse con políticas innovadoras, que reconozcan que lo rural no es sinónimo de primario ni de atrasado. Asimismo, debe considerarse que hay una creciente presencia y complementariedad con otras actividades y que la actividad rural incorpora, cada vez más, la innovación y el conocimiento tecnológico.

$\mathrm{Si}$ bien se reconocen los enormes desafíos que enfrenta el espacio rural, que deben ser atendidos con un conjunto integral de políticas, la propuesta se centra en instrumentos dirigidos a la transformación productiva, que se agrupan en lo que aquí se define como una política industrial rural. Esta política comprende la implementación por parte del Estado de instrumentos dirigidos al fortalecimiento de las actividades productivas del espacio rural, con el propósito de lograr un cambio estructural a través de actividades de transformación (manufactura) y de servicios. Es importante señalar que no significa renunciar a las vocaciones productivas de los territorios, sino escalar las capacidades existentes y complementarlas con actividades secundarias (como la agroindustria y las artesanías) y terciarias (como el turismo rural, los servicios ambientales y los servicios profesionales).

Para avanzar en el cumplimiento de la Agenda 2030 también se necesitan nuevas herramientas participativas que involucren al gobierno, el sector privado y la sociedad civil. La metodología de cadenas de valor desarrollada por la CEPAL, que se describe y ejemplifica en esta publicación, ha mostrado ser un instrumento efectivo para sumar los esfuerzos de diversos actores. Por una parte, un pilar central de la metodología es la participación activa del sector público, los actores de la cadena y los organismos de apoyo (asociaciones empresariales, universidades y proveedores de servicios especializados, entre otros) en todas las etapas del proceso, a través de mesas de diálogo, grupos de discusión y ejecución de actividades. La construcción de espacios de 
diálogo permite establecer acuerdos entre actores públicos y privados y también en el seno de dichos actores.

Por otra parte, en la CEPAL creemos en el valor de la polinización cruzada, en la relevancia de exponer a los planificadores del desarrollo social, a los garantes de las normas ambientales y a los promotores del desarrollo productivo a la conversación sobre el desarrollo del espacio rural. Nuestro trabajo con los países de la región para transformar el espacio rural contó con la estrecha colaboración de socios que tradicionalmente habían tenido poca interacción con este espacio, como los ministerios de economía, de comercio y de industria - buscando siempre la complementariedad con los ministerios de agricultura y ganadería-, y con otros cuya esfera de influencia siempre alcanza el espacio rural.

En este libro se expone la propuesta de política industrial rural que surge de la colaboración técnica de los países de la región y de una alianza estratégica con el Fondo Internacional de Desarrollo Agrícola (FIDA). Asimismo, se sintetiza la metodología desarrollada y se extraen lecciones transversales de las diversas cadenas que recibieron apoyo. Con propuestas como la aquí presentada, la CEPAL reitera su compromiso en favor del desarrollo económico inclusivo y sostenible de los países de la región.

\author{
Alicia Bárcena \\ Secretaria Ejecutiva \\ Comisión Económica para \\ América Latina y el Caribe (CEPAL)
}





\section{Introducción}

En años recientes, la CEPAL ha trabajado estrechamente con los países de la región en el diseño de estrategias participativas para el fortalecimiento de las cadenas de valor como un instrumento orientado a impulsar el cambio estructural. Este fortalecimiento permite ampliar la participación en aquellos eslabones de la estructura productiva que tienen mayor intensidad en conocimientos o cuya demanda es más dinámica. Al mismo tiempo, tiende a aminorar la heterogeneidad estructural que caracteriza a las economías latinoamericanas, mediante una mejor distribución de la captura de valor agregado a lo largo de la cadena, así como la incorporación de nuevos productores y prestadores de servicios.

La CEPAL ha encontrado eco y respondido al creciente interés de los Gobiernos de la región por diseñar e implementar políticas más decididas en materia de política industrial o de desarrollo productivo. En efecto, en la última década se ha observado una atención renovada en América Latina y el Caribe por conformar una nueva ecuación entre el Estado, el mercado y la sociedad. Esta nueva ecuación abre espacios para un papel más activo del sector público en la promoción del desarrollo económico y social, al tiempo que demanda un compromiso más activo del sector privado y la sociedad en general. Los acuerdos y las acciones conjuntas entre estos actores son clave en el nuevo modelo.

La crisis financiera internacional de 2008-2009 marcó un punto de inflexión al abrir espacios de discusión que eran considerados anatema 
según el modelo predominante de desarrollo, en particular en materia de aceptación de políticas industriales, orientación de las políticas macroeconómicas al crecimiento y no solo a la estabilidad nominal, y formulación de políticas en favor de la igualdad con base en derechos (CEPAL, 2012). Un Estado más activo debe ir acompañado de la articulación de las políticas públicas en los diversos ámbitos: macroeconomía, desarrollo industrial, ambiental y social, entre otras (CEPAL, 2012).

El presente libro tiene dos objetivos principales. En primer lugar, se sistematiza la experiencia de la sede subregional de la CEPAL en México en lo atinente al diseño de políticas industriales enfocadas en espacios rurales, en particular la colaboración técnica para el fortalecimiento de cadenas de valor en Centroamérica, México y la República Dominicana. Con este trabajo se completa un conjunto de publicaciones que buscar servir de guía e ilustración para organismos públicos o actores privados interesados en llevar a cabo procesos similares. Los documentos se clasifican en dos grupos:

i) Material de corte conceptual y metodológico, integrado por el Manual para el fortalecimiento de cadenas de valor (Padilla y Oddone, 2016); los primeros tres capítulos de Fortalecimiento de las cadenas de valor como instrumento de la política industrial. Metodología y experiencia de la CEPAL en Centroamérica (Padilla, 2014) y el contenido del presente libro.

ii) Material de corte empírico, que sintetiza la experiencia con 12 cadenas de valor y se puede consultar en los capítulos IV al VII de Padilla (2014), y los 8 capítulos de Fortalecimiento de cadenas de valor rurales (Oddone y Padilla, 2017), así como los documentos que detallan los procesos de colaboración técnica con cada cadena² ${ }^{2}$.

El segundo objetivo es reflexionar acerca de la importancia que la política industrial rural reviste para el cambio estructural, sobre la base del trabajo en cadenas de valor. En este libro se ofrece un enfoque novedoso de la política industrial y el desarrollo del espacio rural, temas que tradicionalmente han sido tratados por separado. En la región, la política industrial por lo general se ha enfocado en la promoción de actividades manufactureras de baja, media y alta tecnología (industrias textil, automotriz, electrónica y aeroespacial, entre otras) y los servicios (por ejemplo, software, tecnología de la información y las comunicaciones (TIC), y servicios empresariales), con escaza atención a actividades de transformación y la incorporación de servicios en el sector primario. Por otra parte, el desarrollo

Todos los documentos se encuentran publicados en el sitio web de la CEPAL [en línea] http:/ / www.cepal.org/es.

2 Véanse Antunes y Monge (2013); Oddone y Beltrán (2014); Oddone y Alarcón (2016); Oddone y otros (2016); Garry y Martínez (2016); Alvarado y otros (2016); Romero, Díaz y Aguirre (2016); Cordero y Padilla (2017); Gomes y Oddone (2017); y Alvarado y Oddone (2017). 
productivo del espacio rural se ha concentrado en las actividades primarias y, en algunos casos recientes, en los servicios turísticos.

La colaboración técnica de la CEPAL se dio, sobre todo, con los ministerios que tienen el mandato de fomentar el desarrollo industrial: las carteras de economía, industria y comercio. Pero para cada cadena también se establecieron vínculos con ministerios dedicados al desarrollo de los espacios rurales, como agricultura y ganadería, así como con las carteras de turismo. De este modo se buscó incluir en la agenda de los primeros nuevas actividades y sectores, más allá de la manufactura tradicional y los servicios, mientras que en la agenda del segundo grupo se apuntó a introducir nuevos instrumentos y enfoques a fin de apoyar el desarrollo del espacio rural.

El cambio estructural se entiende como la recomposición de la estructura del valor agregado y el empleo (Krüger, 2008). La transformación de economías predominantemente agrícolas en economías industriales, o de estas últimas en economías basadas en los servicios, puede estar acompañada - o no- de un creciente desarrollo económico y social (Carmignani y Mandeville, 2014; Szirmai, 2012; Lewis, 1954; Kaldor, 1961). Para que esta transformación redunde en un crecimiento sostenido, inclusivo y ambientalmente sostenible - que la CEPAL describe como un cambio estructural progresivo-, se requiere un conjunto integral de políticas públicas (CEPAL, 2016). En las últimas décadas, en América Latina y el Caribe el espacio rural recibió en general poco apoyo para lograr un cambio estructural progresivo, a pesar de que aún mantiene un peso significativo en la economía. Asimismo, la dimensión rural es de vital importancia para el cumplimiento de los Objetivos de Desarrollo Sostenible (ODS).

El espacio rural, por su parte, se define a partir de tres dimensiones principales: i) la económica o sectorial; ii) la demográfica, y iii) la territorial (véase el capítulo II). La primera dimensión se relaciona con las principales actividades productivas, con una participación predominante de la agricultura, la ganadería, la acuicultura, la silvicultura e, incluso, los servicios vinculados con actividades primarias, como el turismo rural. La segunda dimensión toma en cuenta la clasificación de la población en rural y urbana, usando como referencia el tamaño y la densidad de la población, así como la intensidad de los desplazamientos o la lejanía (distancia) de centros urbanos. En la tercera dimensión, la economía de lo rural puede ser entendida desde una lógica de localización de los procesos económicos y sociales donde el eje articulador es el territorio. El trabajo con cadenas adoptó una definición amplia del espacio rural, que combina los tres criterios, de manera que incluye, además de las actividades primarias, la agroindustria, las artesanías y los servicios, como el turismo rural, que tienen lugar en territorios alejados de centros urbanos y con baja densidad demográfica. 
La propuesta de política industrial que aquí se presenta comprende la implementación por parte del Estado de instrumentos encaminados al fortalecimiento de las actividades productivas del espacio rural, con el propósito de lograr un cambio estructural mediante la transformación (manufactura) y los servicios, así como la integración y complementariedad con actividades, mercados y sectores de mayor dinamismo e intensidad de conocimientos. Esta política da respuesta a cambios recientes en el ámbito rural que plantean la necesidad de contar con nuevos enfoques e instrumentos de apoyo. Destaca la disminución de la participación de las actividades primarias en el valor agregado y el empleo rural, de la mano de una contribución creciente de las manufacturas y los servicios (Weller, 2016), una mayor interdependencia entre la actividad agropecuaria y otros sectores, y la creciente importancia de los procesos de aprendizaje e innovación, entre otros (véase el capítulo II).

Aunque se reconoce que el sector agropecuario suele ser la principal actividad del espacio rural, la política industrial rural no es sinónimo de una política agrícola o agropecuaria. La política industrial rural tampoco equivale a la política de desarrollo rural, pues se concentra en el escalamiento y la transformación mediante la integración con la manufactura y los servicios. Ejemplos de ello, tomados de la experiencia práctica de la CEPAL con los países de América Latina, son el desarrollo de las cadenas de valor de turismo rural, la incorporación de tecnologías para el procesamiento y la comercialización de frutas deshidratadas o fritas al vacío, y el fortalecimiento de las cadenas de valor agroindustriales.

El fortalecimiento de cadenas de valor por medio de la metodología participativa desarrollada por la CEPAL es un instrumento útil para avanzar hacia una nueva ecuación entre el Estado, el mercado y la sociedad en torno a productos y territorios específicos ${ }^{3}$. Primero, al seguir un enfoque microeconómico centrado en los actores que componen los eslabones de la cadena de valor y en sus interrelaciones, permite identificar las restricciones y formular estrategias focalizadas. Así, se constituye en una herramienta útil para el diseño de estrategias públicas específicas que proporciona elementos para una acción pública más decidida. Segundo, la metodología comprende el análisis de las instituciones y organizaciones públicas que regulan y apoyan la cadena, por lo que permite coordinar los diversos instrumentos dirigidos a su fortalecimiento en diversas áreas, como la formación de recursos humanos, el fomento de la innovación, la comercialización y el acceso a nuevos mercados, y la protección del medio ambiente. Tercero, un pilar central de la metodología es la participación activa del sector público, los actores de la cadena y los organismos de apoyo (asociaciones empresariales, universidades y proveedores de servicios

Véase Padilla y Oddone (2016). 
especializados, entre otros) en todas las etapas del proceso mediante mesas de diálogo, grupos de discusión y una participación activa en la ejecución de cada etapa. La construcción de espacios de diálogo permite llegar a acuerdos entre los actores públicos y privados, pero también en el seno de los sectores públicos y privados. En el capítulo III se presenta un resumen de esta metodología.

Entre 2014 y 2016, la sede subregional de la CEPAL en México colaboró con Gobiernos de Centroamérica, México y la República Dominicana en el fortalecimiento de ocho cadenas de valor rurales en el marco del proyecto "Crecimiento inclusivo, política industrial rural y cadenas de valor participativas en América Latina y el Caribe", financiado por el Fondo Internacional de Desarrollo Agrícola (FIDA). Los detalles del trabajo con las cadenas pueden encontrarse en las publicaciones anteriormente citadas. En este libro se presentan las reflexiones transversales que surgen en materia de formulación de política pública, la aplicación de la metodología y evidencia empírica comparada.

En el primer capítulo, Verónica Quiroz, consultora de la CEPAL, examina los retos que enfrenta el espacio rural de Centroamérica y la República Dominicana, donde tuvieron lugar siete procesos de fortalecimiento de cadenas. Si bien existen desafíos en distintas áreas, el capítulo se concentra en el desarrollo productivo, en sintonía con el enfoque del resto de los capítulos. La autora empieza por caracterizar el espacio rural, para lo que hace uso de indicadores económicos y sociales. A continuación aborda los desafíos, que divide en cuatro grandes campos:

i) los institucionales, queincluyen las reglas, normas, convenciones, formas de coordinación y políticas públicas;

ii) los ambientales, tanto en lo concerniente a la adaptación a los efectos del cambio climático como a su mitigación;

iii) los de comercialización, que abordan los precios, el acceso a los mercados y el comercio exterior, $y$

iv) los de productividad e innovación, que agrupan diversas áreas, como las capacidades tecnológicas, la educación y la capacitación, el financiamiento y las cadenas de valor.

En el segundo capítulo -elaborado por Ramón Padilla Pérez, funcionario de la CEPAL, y Verónica Quiroz- se presenta una propuesta sobre el concepto y alcance de la política industrial rural. Los insumos para la elaboración del capítulo son la revisión de bibliografía y, sobre todo, la experiencia en el fortalecimiento de cadenas de valor rurales. El capítulo inicia con la definición del espacio rural y luego se identifican los cambios recientes por los que ha pasado. A continuación, se ofrece una definición 
de política industrial rural y se reconoce que esta tiene diversos alcances e instrumentos. Estos últimos se agrupan en tres categorías: i) las políticas comerciales, de competitividad y de competencia; ii) los instrumentos para el fomento productivo, y iii) los instrumentos en materia ambiental. Por último, se brindan ejemplos de instrumentos implementados por el sector público de otros países que, si bien no han sido llamados propiamente política industrial rural, persiguen objetivos similares a los considerados por esta.

En el tercer capítulo, escrito por Ramón Padilla Pérez y Nahuel Oddone, consultor de la CEPAL, se sintetiza la metodología para el fortalecimiento de cadenas de valor como un instrumento de la política industrial rural. Si bien ya se cuenta con un manual que ofrece detalles y ejemplos prácticos, se considera importante incluir en este libro los lineamientos generales, de manera que el lector tenga una adecuada comprensión de la metodología a la que se hace referencia en el resto de la obra.

En el cuarto capítulo, Caroline Gomes, Francisco Villarreal y Ramón Padilla Pérez, funcionarios de la CEPAL, profundizan en un tema que resulta central cuando se trabaja con cadenas y, en general, cuando se formulan políticas industriales: la selección. Entre los encargados del diseño e implementación de políticas públicas en América Latina y el Caribe, es común encontrar cierta resistencia a la selección, debido a las distorsiones que puede causar la incapacidad de los gobiernos para identificar efectivamente las mejores industrias y sectores, y la posibilidad de quedar sujeto a presiones del sector privado en la búsqueda de rentas, entre otras razones. Ante recursos humanos y financieros limitados, y el enorme número de cadenas que conforman el aparato productivo de un país o una región, es necesario escoger las que recibirán apoyo en el corto plazo. Por ello, reviste vital importancia diseñar un proceso transparente y objetivo. En este capítulo se presenta la metodología usada para la selección de las cadenas.

La metodología para el fortalecimiento de cadenas puede adaptarse a diversos sectores y actividades. En los siguientes dos capítulos se analiza de manera transversal su aplicación en distintos contextos, siempre dentro del espacio rural. En el quinto capítulo, Ramón Padilla Pérez presenta reflexiones transversales sobre cuatro cadenas de productos primarios: tomate y chile verde (El Salvador), lácteos (República Dominicana), embutidos de carne de cerdo (México) y snacks nutritivos elaborados con frutas deshidratadas (El Salvador). Los objetivos centrales del proceso de fortalecimiento de estas cadenas fueron elevar la productividad, potenciar los encadenamientos locales, incrementar la participación de pequeños productores y aumentar el valor agregado de los productos primarios mediante la transformación. Las cadenas enfrentan restricciones similares relacionadas con la falta de acceso a nuevas tecnologías, una gran 
heterogeneidad productiva (diferencias significativas entre pequeños y grandes productores), escaso acceso al financiamiento y baja capacidad para comercializar sus productos, entre otras. En este capítulo se presenta un recuento de las estrategias que formarían parte de una política industrial rural.

En el sexto capítulo, Stefanie Garry, funcionaria de la CEPAL, y Nahuel Oddone analizan de manera comparativa tres cadenas de valor de servicios: el turismo rural en el departamento de Sacatepéquez (Guatemala), en La Libertad (El Salvador) y en Pedernales (República Dominicana). El objetivo primordial de estas cadenas consistió en fortalecer la oferta existente de turismo, como una fuente complementaria de ingresos en el espacio rural. Si bien los objetivos específicos varían, los tres casos dan cuenta de la aplicación de la metodología más allá de las cadenas de bienes. Los territorios sufren algunas restricciones comunes para fortalecer las cadenas turísticas: infraestructura insuficiente, falta de capacitación y cultura de oferta turística, escaso desarrollo de productos y destinos turísticos, y limitado desarrollo de estrategias de comercialización. Las estrategias diseñadas para las tres cadenas coinciden en la importancia de desarrollar una oferta turística que brinde mayores ingresos y mejores condiciones de vida a la población, sin renunciar a las vocaciones productivas de los territorios y que garanticen que los productores y oferentes de servicios locales logren una captura justa del valor agregado generado en la cadena.

Con estos dos capítulos empíricos se sintetiza la experiencia que reflejan siete cadenas de valor. Como parte del proyecto CEPAL-FIDA "Crecimiento inclusivo, política industrial rural y cadenas de valor participativas en América Latina y el Caribe" se trabajó con una octava cadena de valor: los chips fritos al vacío (Costa Rica). El objetivo central fue apoyar un proceso de emprendimiento dirigido a transformar productos primarios añadiendo innovación a fin de obtener mayor valor agregado. Se partió de la selección de la nueva tecnología que se deseaba llevar al mercado y fue necesario adaptar la metodología para incluir conceptos y herramientas de emprendimiento: estudio de mercado, estudio de factibilidad técnica y económica, y transferencia y adaptación de nuevas tecnologías. La metodología y los resultados principales de esta cadena se pueden consultar en Cordero y Padilla (2017).

Por último, en el séptimo capítulo Ramón Padilla Pérez presenta las reflexiones finales en torno al argumento esencial del libro: el fortalecimiento de cadenas de valor — un instrumento de la política industrial ruralpermite un cambio estructural progresivo en el espacio rural. Asimismo, se hace un examen crítico de las fortalezas y debilidades de la metodología, y se concluye con la identificación de líneas de trabajo futuro. 


\section{Bibliografía}

Alvarado, J. y N. Oddone (2017), "Fortalecimiento de la cadena de valor de turismo en Pedernales, República Dominicana", Fortalecimiento de cadenas de valor rurales, Documentos de Proyectos (LC/TS.2017/24), Ciudad de México, Comisión Económica para América Latina y el Caribe (CEPAL).

Alvarado, J. y otros (2016), "La cadena de valor de embutidos y otras conservas de carne de cerdo en México", Documentos de Proyectos (LC/MEX/W.17), Ciudad de México, Comisión Económica para América Latina y el Caribe (CEPAL).

Antunes, B. y C. Monge (2013), “Diagnóstico de la cadena de fibras sintéticas-ropa deportiva en El Salvador", Documentos de Proyectos (LC/MEX/L.1119), Ciudad de México, Comisión Económica para América Latina y el Caribe (CEPAL).

Carmignani, F. y T. Mandeville (2014), "Never been industrialized: A tale of African structural change", Structural Change and Economic Dynamics, vol. 31.

CEPAL (Comisión Económica para América Latina y el Caribe) (2016), La matriz de la desigualdad social en América Latina (LC/G.2690 (MDS.1/2)), Santiago. (2012), Cambio estructural para la igualdad: una visión integrada del desarrollo (LC/G.2524), Santiago.

Cordero, M. y R. Padilla (2017), “Creación de una cadena de valor: chips fritos al vacío en Costa Rica", Fortalecimiento de cadenas de valor rurales, Documentos de Proyectos (LC/TS.2017/24), Ciudad de México, Comisión Económica para América Latina y el Caribe (CEPAL).

Garry, S. y R. Martínez (2016), "Fortalecimiento de la cadena de turismo en el Departamento de La Libertad, El Salvador", Documentos de Proyectos (LC/MEX/W.18),Ciudad de México, Comisión Económica para América Latina y el Caribe (CEPAL).

Gomes, C. y N. Oddone (2017), "Fortalecimiento de la cadena de valor de los lácteos en la República Dominicana", Fortalecimiento de cadenas de valor rurales, Documentos de Proyectos (LC/TS.2017/24), Ciudad de México, Comisión Económica para América Latina y el Caribe (CEPAL).

Kaldor, N. (1961), "Capital accumulation and economic growth", The Theory of Capital Proceedings of a Conference Held by the International Economic Association, F. Lutz y D. Hague, Londres, Macmillan.

Krüger, J. (2008), "Productivity and structural change: a review of the literature", Journal of Economic Surveys, vol. 22, No 2.

Lewis, W. (1954), "Economic development with unlimited supplies of labor", Manchester School of Economic and Social Studies, vol. 22.

Oddone, N. y C. Beltrán (2014), “Diagnóstico de la cadena de camarón de cultivo en El Salvador", Documentos de Proyectos (LC/MEX/L.1137), Ciudad de México, Comisión Económica para América Latina y el Caribe (CEPAL).

Oddone, N. y P. Alarcón (2016), "Fortalecimiento de la cadena de turismo de Antigua Guatemala y de los municipios rurales del Departamento de Sacatepéquez", Documentos de Proyectos (LC/MEX/W.15), Ciudad de México, Comisión Económica para América Latina y el Caribe (CEPAL).

Oddone, N. y R. Padilla (2017), "Fortalecimiento de cadenas de valor rurales", Documentos de Proyectos (LC/TS.2017/24), Ciudad de México, Comisión Económica para América Latina y el Caribe (CEPAL). 
Oddone, N. y otros (2016), "Fortalecimiento de la cadena de valor de tomate y chile verde dulce en El Salvador", Documentos de Proyectos (LC/MEX/W.13), Ciudad de México, Comisión Económica para América Latina y el Caribe (CEPAL).

Padilla, R. (ed.) (2014), Fortalecimiento de las cadenas de valor como instrumento de la política industrial. Metodología y experiencia de la CEPAL en Centroamérica, Libros de la CEPAL, No 123 (LC/G.2606-P), Santiago, Comisión Económica para América Latina y el Caribe (CEPAL).

Padilla, R. y N. Oddone (2016), Manual para el fortalecimiento de cadenas de valor (LC/MEX/1.1218), Ciudad de México, Comisión Económica para América Latina y el Caribe (CEPAL).

Romero, I., V. Díaz y A. Aguirre (2016), “Fortalecimiento de la cadena de valor de los snacks nutritivos con base en fruta deshidratada en El Salvador", Documentos de Proyectos (LC/MEX/W.16), Ciudad de México, Comisión Económica para América Latina y el Caribe (CEPAL).

Szirmai, A. (2012), "Industrialization as an engine of growth in developing countries, 1950-2005", Structural Change and Economic Dynamics, vol. 23.

Weller, J. (ed.) (2016), Brechas y transformaciones: la evolución del empleo agropecuario en América Latina, Libros de la CEPAL, No 141 (LC/G.2695-P), Santiago, Comisión Económica para América Latina y el Caribe (CEPAL). 

Capítulo I

\section{Desafíos en materia de desarrollo productivo en el espacio rural de Centroamérica y la República Dominicana}

Verónica Quiroz Estrada

\section{Introducción}

El espacio rural es multisectorial y dinámico, y enfrenta desafíos particulares en materia de desarrollo productivo. En los países en desarrollo los retos son mayores y, debido a la cantidad de población rural, así como a las brechas sociales y económicas entre lo rural y lo urbano, su atención adquiere un carácter inclusivo. En los últimos años, el espacio rural ha sufrido transformaciones significativas que obligan a repensar las estrategias de desarrollo.

En el proyecto conjunto entre el Fondo Internacional de Desarrollo Agrícola (FIDA) y la Comisión Económica para América Latina y el Caribe (CEPAL), "Crecimiento inclusivo, política industrial rural y cadenas de valor participativas en América Latina y el Caribe", se trabajó en estrecha colaboración con los Gobiernos de cinco países de la subregión norte de América Latina y el Caribe (Costa Rica, El Salvador, Guatemala, México y la República Dominicana) en el fortalecimiento de ocho cadenas de valor

La autora de este capítulo agradece los valiosos comentarios realizados por Julie Lennox, Ramón Padilla Pérez y José Manuel Iraheta al primer borrador de este documento. 
rurales ${ }^{2}$. En este primer capítulo se identifican los principales desafíos que enfrentan el espacio rural de Centroamérica y la República Dominicana en materia de desarrollo productivo. Cabe señalar que aunque en México también se llevó a cabo la asistencia técnica en el fortalecimiento de una cadena de valor (embutidos), en este capítulo no se lo incluye en el grupo de países examinados debido a que presenta grandes diferencias con los países de Centroamérica y la República Dominicana en lo que respecta a tamaño, condiciones y problemáticas.

Lo que se pretende no es exponer un análisis exhaustivo de todos los desafíos que enfrenta el espacio rural de Centroamérica y la República Dominicana, sino presentar aquellos que son clave para entender las condiciones actuales de la estructura productiva rural en la subregión y las oportunidades para transformarla.

Los desafíos en materia de desarrollo productivo se han agrupado en cuatro áreas:

i) Desafíos institucionales. Se relacionan con las reglas, convenciones, arreglos o formas de coordinación que tienen un impacto en el desempeño productivo en el espacio rural.

ii) Desafíos de sostenibilidad ambiental. Se asocian a la realización de actividades productivas más sostenibles en el espacio rural, con énfasis en la mitigación y adaptación al cambio climático.

iii) Desafíos de comercialización. Hacen referencia a las condiciones de mercado que tienen efecto en la comercialización de productos y servicios del espacio rural, así como al acceso a mercados locales, intrarregionales y extrarregionales.

iv) Desafíos de productividad e innovación. Se relacionan con los aspectos que inciden en la productividad y la innovación en el espacio rural. Este es el caso del tamaño y desempeño tecnológico, la educación y capacitación, las actividades de innovación y el acceso a financiamiento. En este grupo también se incluyen los desafíos respecto del fortalecimiento de las cadenas de valor, tema central de los siguientes capítulos.

Este capítulo está estructurado en seis secciones además de esta Introducción. En la sección A se exponen los criterios utilizados para definir el espacio rural y sus características generales en Centroamérica y la República Dominicana. En la sección B se presentan los desafíos institucionales, mientras que en la sección $C$ se exponen los desafíos de sostenibilidad ambiental, en la sección D se sintetizan los retos en

La subregión norte de América Latina incluye a Costa Rica, Cuba, El Salvador, Guatemala, Haití, Honduras, México, Nicaragua, Panamá y la República Dominicana. 
materia de comercialización y en la sección E se agrupan los desafíos de productividad e innovación. Por último, en la sección F se presentan las conclusiones.

\section{A. El espacio rural}

\section{Definición de lo rural}

En la bibliografía especializada no existe una definición única y consensuada de lo rural. Un punto de partida vigente es la separación entre lo rural y lo urbano. En los países se aplican diferentes criterios para definir estas categorías. Por otra parte, el espacio rural es dinámico y con características que se modifican en el tiempo, y la conceptualización de lo rural recoge estas transformaciones ${ }^{3}$. A continuación, se examinan tres criterios para definir a las áreas rurales: i) demográfico, ii) sectorial o económico y iii) territorial.

\section{a) Criterio demográfico}

Este criterio se relaciona con el tamaño de la población y el espacio geográfico, y habitualmente es utilizado por las oficinas responsables de generar estadísticas nacionales. Las definiciones usadas varían de un país a otro y se modifican con el transcurso del tiempo. Se consideran dimensiones como: i) el tamaño de la población, ii) la densidad de la población y iii) el acceso a infraestructura o servicios. En la mayoría de los casos, lo rural se toma como una categoría residual, definida como lo que no es urbano (Naciones Unidas, 2007).

Una de las dimensiones más utilizadas para demarcar las áreas rurales es el tamaño de la población. En los países de Centroamérica y la República Dominicana se ha definido a la población rural en contraposición de la población urbana. Aunque los criterios difieren, se considera un tamaño de la población menor al rango de 1.500 a 2.000 habitantes, que vive en espacios geográficos dispersos, por ejemplo, fuera de las cabeceras municipales o los centros administrativos ${ }^{4}$.

El acceso a infraestructura y servicios básicos es otra dimensión utilizada y en ella se contemplan elementos tangibles como aceras, luz eléctrica, alcantarillado, centros de salud y facilidades de comunicación.

Algunos de los cambios han sido reconocidos por organismos internacionales en lo que se ha denominado "nuevo paradigma rural" (OCDE, 2006). En el contexto latinoamericano, otros autores han dado cuenta de una "nueva ruralidad" al reconocer los cambios en la diversificación de las actividades del espacio rural y la importancia de los empleos e ingresos no agropecuarios en las estrategias de sustento de los hogares rurales (Kay, 2009; Bonnal y otros, 2004; Echeverri y Rivero, 2002; Pérez y Farah, 2001).

4 Véanse definiciones para cada país en CELADE (2016). 
Los elementos elegidos por cada país son variables. Por ejemplo, mientras que en Nicaragua la población rural es aquella que reside en localidades de menos de 1.000 habitantes que no tienen una estructura urbanística, como trazado de calles, servicio de luz eléctrica o establecimientos comerciales e industriales, en Panamá, se refiere a la población que vive en localidades con menos de 1.500 habitantes que no reúnen características urbanas, como servicio de luz eléctrica, acueducto y alcantarillado, calles pavimentadas, facilidades de comunicación o escuelas secundarias (CELADE, 2016).

Otra dimensión utilizada, sobre todo por países desarrollados, es la densidad de la población. Con la intención de generar un criterio armonizado, la Organización de Cooperación y Desarrollo Económicos (OCDE) definió a las comunidades rurales como aquellas que tienen una densidad de población menor de 150 habitantes por $\mathrm{km}^{2}$ (500 habitantes por $\mathrm{km}^{2}$ para el caso del Japón) (OCDE, 2006).

Por otra parte, cada vez es más frecuente constatar una disminución de la distancia entre las áreas rurales y urbanas, lo que genera desplazamientos de la población rural hacia los centros urbanos para realizar actividades laborales, aunque esta población continúe pernoctando en áreas rurales. Esto da cuenta de nuevas formas de interacción y de un creciente vínculo entre lo rural y lo urbano (Chomitz, Buys y Thomas, 2005).

\section{b) Criterio sectorial o económico}

En este criterio se define a las áreas rurales a partir de la contribución de las principales actividades económicas. Anteriormente existía una identidad entre el mundo rural y el sector agropecuario (Echeverri, 2011). Hoy esa concepción está cambiando y el espacio rural se define como multisectorial. Aunque las actividades del sector agropecuario siguen siendo cardinales en las áreas rurales del mundo en desarrollo, la participación de este sector tiende a disminuir en términos de su contribución al PIB y al empleo. En el espacio rural, además de la contribución de la agricultura, silvicultura, ganadería y pesca, se observa una creciente presencia de otras actividades, como la agroindustria y las artesanías, y de servicios como el turismo rural y los servicios ambientales.

\section{c) Criterio territorial}

En este criterio, la ruralidad se define más allá de un espacio geográfico delimitado por cuantificaciones en virtud de una o más variables. La definición de lo rural se complementa con una lógica de procesos económicos y sociales, que, si bien están localizados, corresponden a una construcción social donde se establecen relaciones que dan origen y 
expresan una identidad compartida por múltiples actores (Schejtman y Berdegué, 2004). En las áreas rurales, los sectores más importantes son los que operan en torno a los recursos naturales (Echeverri, 2011; Echeverri y Ribero, 2002).

El territorio es el espacio de acción social en el que se hacen explícitos los requerimientos de conectividad, donde se ubican los recursos naturales comunes que es necesario aprovechar y preservar, donde la gobernanza adquiere particularidades según las etnias, estructuras de poder local y rivalidades, y donde se establecen proyectos de desarrollo a partir de la convergencia de intereses y voluntades (Pomareda, 2016; Dirven y otros, 2011).

En este capítulo se entiende al espacio rural en virtud de la recuperación de los tres criterios anteriores: como el espacio geográfico con menor densidad de población, en el que se llevan a cabo interacciones sociales y procesos económicos que dan cuenta de propósitos y una identidad compartida, generalmente en torno a los recursos naturales, y donde convergen, además de las actividades del sector agropecuario, otras actividades de la transformación y los servicios.

Debido a que el espacio rural se ha definido con distintos criterios y a que no hay una identificación agregada de su peso económico, las estadísticas de este capítulo se presentan según la disponibilidad de información. Cuando se muestra información a nivel rural, se recupera la definición de la fuente utilizada. En diversas ocasiones se presenta información divulgada del sector agropecuario, que tiene un peso económico importante en las actividades del espacio rural en la subregión. Las actividades que incluye el sector agropecuario son: agricultura, ganadería, silvicultura, pesca y acuacultura. En algunas fuentes de información se utiliza indistintamente el término agrícola o agropecuario. También se recupera información que da cuenta de la estructura productiva a partir de las características económicas y sociales de la población definida como rural.

\section{Características del espacio rural en Centroamérica y la República Dominicana}

\section{a) Población}

Al igual que en otras latitudes del mundo, la población rural en la subregión ha disminuido en las últimas tres décadas. No obstante, un alto porcentaje de la población de Centroamérica y la República Dominicana aún vive en áreas rurales. En 2015, la población total (en miles de personas) de Centroamérica y la República Dominicana se estimó como sigue: Costa Rica (4.821), El Salvador (6.298), Guatemala (15.920), Honduras (8.075), 
Nicaragua (6.086), Panamá (3.929) y República Dominicana (10.531) (CEPAL, 2015a). A partir de estos totales, como se puede apreciar en el gráfico I.1, los países con mayor presencia relativa de población rural fueron Honduras $(46 \%)$, Guatemala (44\%) y Nicaragua (42\%). En el extremo opuesto se ubicaron Costa Rica (23\%) y la República Dominicana (21\%).

\section{Gráfico I.1}

Centroamérica y la República Dominicana: población rural, 1985 y 2015 (En porcentajes de la población total)

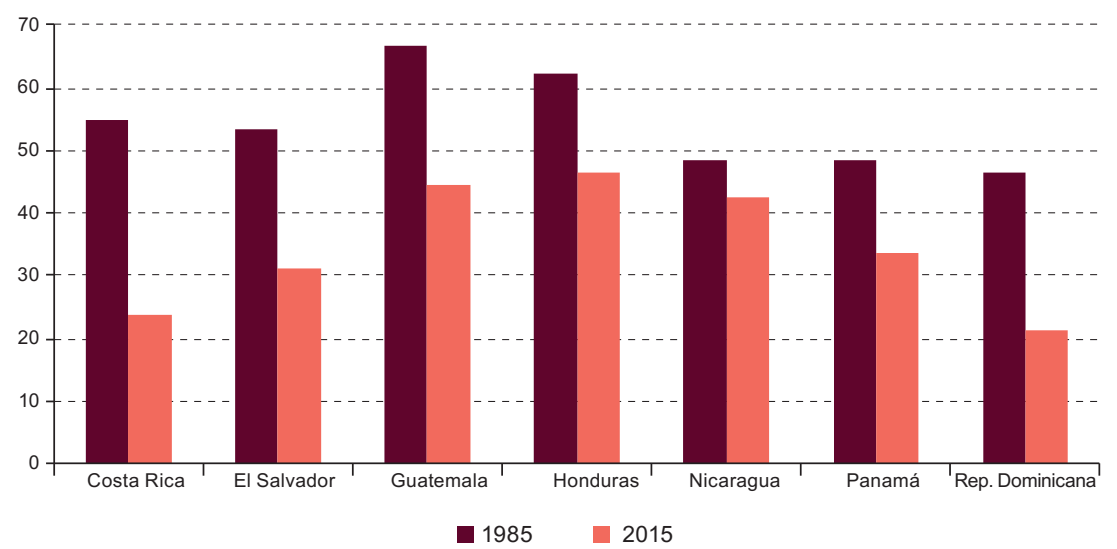

Fuente: Comisión Económica para América Latina y el Caribe (CEPAL), "CEPALSTAT. Bases de Datos y Publicaciones Estadísticas", 2016 [en línea] http://estadisticas.cepal.org/cepalstat/ WEB_CEPALSTAT/Portada.asp.

\section{b) Pobreza}

Una característica del espacio rural en Centroamérica y la República Dominicana es el alto porcentaje de población rural en situación de pobreza e indigencia. En el gráfico I.2 se observa que en todos los países de la subregión hay una mayor cantidad de población rural en situación de pobreza e indigencia que en las áreas urbanas. En Guatemala, el 77,2\% de la población rural contaba con un ingreso medio por debajo de la línea de pobreza en 2014, en Honduras esta cifra alcanzó un 81,8\% en 2013 y en Nicaragua llegó al 65,5\% en 2009. El país de la subregión con menor concentración de población rural en situación de pobreza es Costa Rica (un 22\% en 2014). En el gráfico I.2 también se muestran altos coeficientes de población en situación de indigencia entre la población de Guatemala y Honduras, mientras que en Costa Rica se observa el menor porcentaje.

En cuanto a la distribución del ingreso, los países que registran una mayor concentración de los ingresos de la población rural en el quintil 
más rico son Honduras $(58,2 \%)$ y Panamá $(56,6 \%)$. El país con una mejor distribución de los ingresos en el espacio rural es El Salvador (véase el cuadro I.1). Las diferencias entre la población urbana y la población rural no son tan marcadas como en los indicadores anteriores.

\section{Gráfico I.2}

Centroamérica y la República Dominicana: población urbana y rural en situación de pobreza e indigencia, 2014 o último año disponible

(En porcentajes)

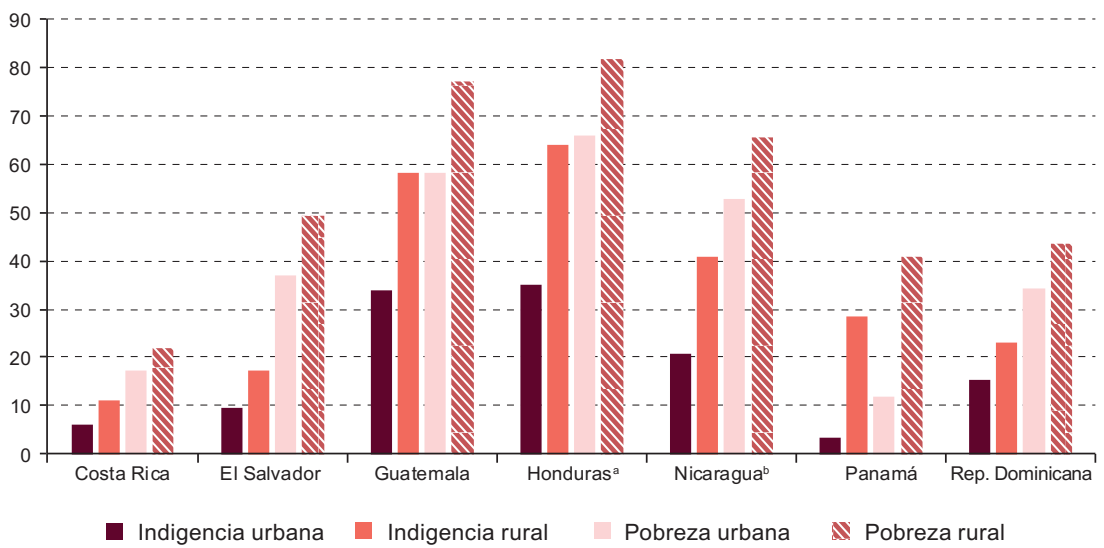

Fuente: Comisión Económica para América Latina y el Caribe (CEPAL), "CEPALSTAT. Bases de Datos y Publicaciones Estadísticas", 2016 [en línea] http://estadisticas.cepal.org/cepalstat/WEB_ CEPALSTAT/Portada.asp.

a El último año disponible para Honduras es 2013.

b El último año disponible para Nicaragua es 2009.

\section{Cuadro I.1}

Centroamérica y la República Dominicana: distribución del ingreso de las personas por quintiles, según área geográfica, 2014 o último año disponible

(En porcentajes del ingreso nacional total)

\begin{tabular}{|c|c|c|c|c|c|c|c|c|c|c|}
\hline \multirow{2}{*}{ País } & \multicolumn{2}{|c|}{ Quintil 1} & \multicolumn{2}{|c|}{ Quintil 2} & \multicolumn{2}{|c|}{ Quintil 3} & \multicolumn{2}{|c|}{ Quintil 4} & \multicolumn{2}{|c|}{ Quintil 5} \\
\hline & Urbana & Rural & Urbana & Rural & Urbana & Rural & Urbana & Rural & Urbana & Rural \\
\hline Costa Rica & 3,8 & 3,8 & 8,0 & 8,6 & 12,8 & 13,2 & 21,0 & 20,8 & 54,4 & 53,8 \\
\hline El Salvador & 6,0 & 5,8 & 10,4 & 10,6 & 14,6 & 15,4 & 21,4 & 22,4 & 47,6 & 45,8 \\
\hline Guatemala & 4,0 & 4,6 & 7,6 & 8,4 & 11,8 & 12,8 & 18,8 & 19,6 & 57,6 & 54,4 \\
\hline Honduras $^{a}$ & 3,6 & 2,8 & 8,2 & 6,8 & 13,2 & 11,8 & 21,2 & 20,4 & 54,0 & 58,2 \\
\hline Nicaraguab $^{b}$ & 5,0 & 4,4 & 9,8 & 9,0 & 14,0 & 14,0 & 21,0 & 21,8 & 50,2 & 50,8 \\
\hline Panamá & 4,6 & 2,4 & 9,0 & 6,6 & 13,6 & 12,6 & 20,8 & 21,8 & 51,8 & 56,6 \\
\hline $\begin{array}{l}\text { República } \\
\text { Dominicana }\end{array}$ & 3,4 & 3,6 & 7,4 & 8,0 & 12,4 & 12,6 & 21,2 & 21,0 & 55,8 & 54,6 \\
\hline
\end{tabular}

Fuente: Comisión Económica para América Latina y el Caribe (CEPAL), "CEPALSTAT. Bases de Datos y Publicaciones Estadísticas", 2016 [en línea] http://estadisticas.cepal.org/cepalstat/WEB_ CEPALSTAT/Portada.asp.

a El último año disponible para Honduras es 2013.

b El último año disponible para Nicaragua es 2009. 
La población del espacio rural de la subregión enfrenta carencias en materia de servicios de infraestructura básica. Estas carencias son mayores que las observadas en las zonas urbanas. De acuerdo con el Quinto Informe Estado de la Región en Desarrollo Humano Sostenible, el 35,5\% de los hogares de la subregión vivía en condiciones de hacinamiento en 2014; con excepción de Costa Rica, Honduras y Panamá, esta situación se eleva hasta el 50\% en zonas rurales. En ese mismo año, dos de cada diez hogares no contaban con una vivienda de calidad, cifra que se triplica en el espacio rural. De igual forma, se estimó que un 13\% de los hogares urbanos no contaba con un abastecimiento de agua potable adecuado, mientras que en las zonas rurales esta cifra alcanzó al 23,6\%. Además, se estimó que un 12,9\% de las viviendas rurales no contaba con servicios de saneamiento. En cuanto a la electricidad, nueve de cada diez hogares que no cuentan con este servicio se ubican en zonas rurales (Programa Estado de la Nación, 2016) ${ }^{5}$.

La incidencia de la pobreza en el espacio rural es resultado, entre otros factores, de la falta de activos y, lo que es aún más importante, de su inadecuada distribución, que se ilustra claramente en la estructura de la propiedad de la tierra. En Centroamérica, más de la mitad de los productores poseen una superficie menor de 5 hectáreas (CEPAL, 2016b). Como se verá más adelante, el tamaño de las unidades de producción es un desafío del desarrollo productivo, ya que las de menores proporciones tienen menos posibilidades de generar economías de escala, reducir costos, acceder a tecnologías y aumentar la productividad.

El acceso desigual a recursos naturales y mercados y las desventajas derivadas de las inequidades sociales y políticas, así como también los bajos niveles en educación, agravan la situación de pobreza rural (FIDA, 2011). La población del espacio rural en Centroamérica y la República Dominicana cuenta con menos años de instrucción que la población urbana. En los países de Centroamérica y la República Dominicana, la media de años de estudio de la población rural de entre 15 y 24 años de edad varía entre 5,2 y 9,2 años, mientras que para la población urbana varía entre 6,9 y 10,5 años. En la población de 25 a 59 años de edad, los años de instrucción de la población rural oscilan entre 3,1 y 7,5 años, mientras que en la población urbana varían entre 6,3 y 12 años. Los países con menos años de instrucción en el espacio rural son Guatemala, Honduras y Nicaragua, mientras que Costa Rica, Panamá y la República Dominicana acumularon más años (CEPAL, 2016a).

En el informe no se incluye a la República Dominicana.

De acuerdo con información de 2014 o el último año disponible. El último año disponible para Honduras es 2013 y para Nicaragua es 2009 (CEPAL, 2016a). 


\section{c) Producción y empleo}

Las actividades del sector agropecuario continúan siendo centrales en el espacio rural de Centroamérica y la República Dominicana. No obstante, la participación del PIB agropecuario en el PIB total ha descendido en los últimos 25 años. En 2015, Panamá (2,9\%), Costa Rica $(5,5 \%)$ y la República Dominicana $(5,6 \%)$ fueron los países con menor participación de este sector, mientras que Nicaragua (14,2\%), Honduras $(12,6 \%)$ y Guatemala $(11,3 \%)$ fueron los que registraron mayor contribución (véase el gráfico I.3). El peso del PIB agropecuario en Centroamérica (con la excepción de Panamá, cuya economía tiene una elevada concentración de actividades en el sector de los servicios, y la República Dominicana se sitúa por encima de la media en América Latina y el Caribe $(4,8 \%)$.

Gráfico I.3

Centroamérica y la República Dominicana: participación del PIB agropecuario en el PIB total a precios constantes, 1990-2015

(En porcentajes)

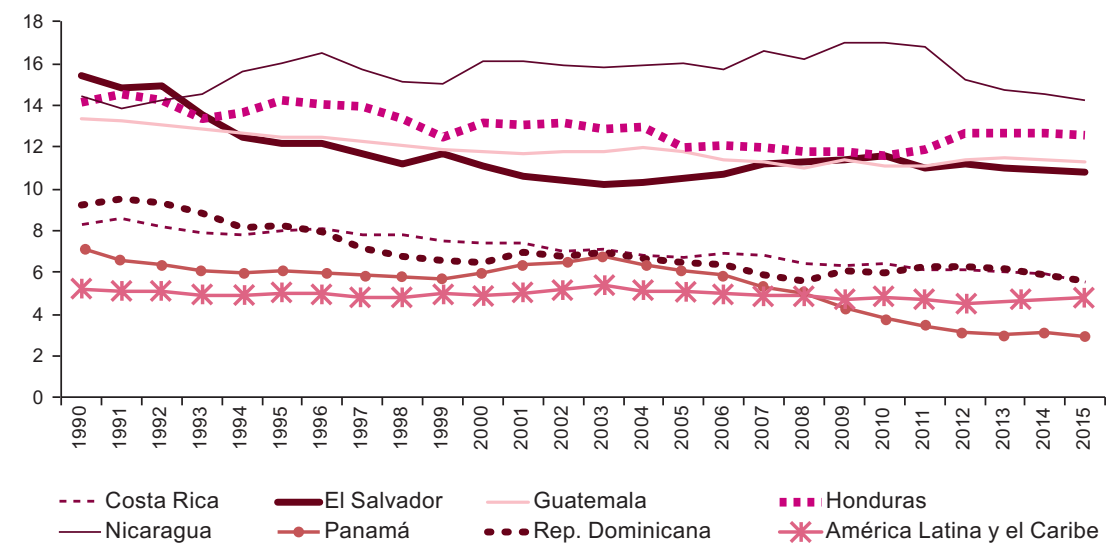

Fuente: Comisión Económica para América Latina y el Caribe (CEPAL), "CEPALSTAT. Bases de Datos y Publicaciones Estadísticas", 2016 [en línea] http://estadisticas.cepal.org/cepalstat/WEB_ CEPALSTAT/Portada.asp.

El sector agropecuario es un importante generador de empleo en el espacio rural, pero hay una tendencia hacia la diversificación. En el gráfico I.4 se muestra que la proporción más alta de población ocupada rural en el sector agropecuario se registró en Nicaragua (70\%), Honduras $(59,2 \%)$ y Guatemala $(57,5 \%)$. Estos tres países se sitúan por encima del promedio de América Latina $(52,8 \%)^{7}$. El menor porcentaje

Promedio ponderado para 16 países: Bolivia (Estado Plurinacional de) (2013), Brasil (2014), Chile (2013), Colombia (2014), Costa Rica (2014), Ecuador (2014), El Salvador (2014), Guatemala (2014), Honduras (2013), México (2014), Nicaragua (2009), Panamá (2014), Paraguay (2014), Perú (2014), República Dominicana (2014) y Uruguay (2014) (CEPAL, 2016a). 
de población ocupada rural en este sector lo registraron Costa Rica $(31,6 \%)$ y la República Dominicana (33,8\%).

\section{Gráfico I.4}

Centroamérica y la República Dominicana: población ocupada rural, por gran sector económico, 2014 o último año disponible ${ }^{a}$

(En porcentajes)

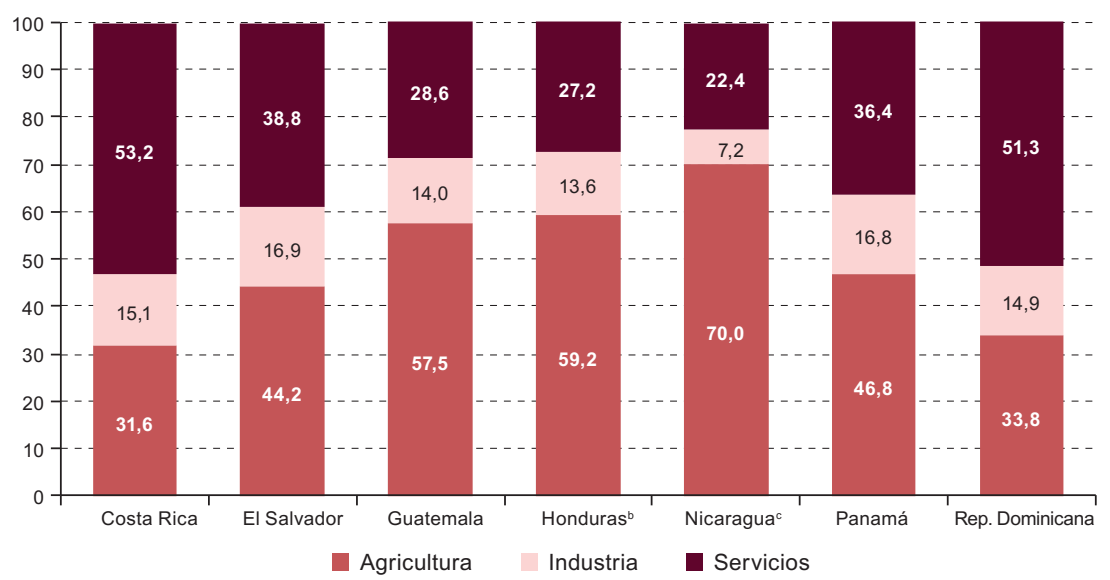

Fuente: Comisión Económica para América Latina y el Caribe (CEPAL), "CEPALSTAT. Bases de Datos y Publicaciones Estadísticas", 2016 [en línea] http://estadisticas.cepal.org/cepalstat/WEB_ CEPALSTAT/Portada.asp.

a De acuerdo con la Clasificación Industrial Internacional Uniforme de Todas las Actividades Económicas, Revisión 2 (CIIU, Rev. 2). En esta clasificación, la gran división Agricultura corresponde a las actividades de agricultura, caza, ganadería, silvicultura y pesca.

b El último año disponible para Honduras es 2013.

c El último año disponible para Nicaragua es 2009.

La población del espacio rural en la subregión está diversificando sus fuentes de empleo con dos realidades. En Guatemala, Honduras y Nicaragua, y en menor medida en El Salvador, prevalece una estructura productiva con una concentración del empleo rural en actividades agropecuarias. En Costa Rica y la República Dominicana, en tanto, sucede lo contrario y más de la mitad de los empleados rurales se ocupan en el sector de los servicios.

Como se observa en el cuadro I.2, en los últimos años, el porcentaje de asalariados rurales, con excepción del caso nicaragüense, se mantiene constante o ha crecido en todos los países. El porcentaje de la población ocupada rural que trabaja por cuenta propia o en actividades familiares que no se remuneran registra un comportamiento en dirección contraria, salvo en Honduras y Nicaragua. 
Cuadro I.2

Centroamérica y la República Dominicana: distribución de la población ocupada rural por tipo de inserción laboral, 2000 y 2014

(En porcentajes)

\begin{tabular}{|c|c|c|c|c|c|c|}
\hline \multirow[t]{2}{*}{ País } & \multicolumn{2}{|c|}{ Empleadores (total) } & \multicolumn{2}{|c|}{ Asalariados (total) } & \multicolumn{2}{|c|}{$\begin{array}{l}\text { Trabajo por cuenta } \\
\text { propia y familiar no } \\
\text { remunerado (total) }\end{array}$} \\
\hline & 2000 & 2014 & 2000 & 2014 & 2000 & 2014 \\
\hline Costa Rica & 5,8 & 4,1 & 66,4 & 72,6 & 27,8 & 23,3 \\
\hline El Salvador & 4,6 & 3,6 & 47,3 & 50,5 & 48,1 & 45,8 \\
\hline Guatemala & $2,0^{\mathrm{a}}$ & 1,3 & $42,9^{\mathrm{a}}$ & 51,0 & $55,1^{\text {a }}$ & 47,7 \\
\hline Honduras & $3,1^{\mathrm{b}}$ & $1,6^{\mathrm{e}}$ & $33,5^{\mathrm{b}}$ & $33,5^{\mathrm{e}}$ & $63,4^{\mathrm{b}}$ & $64,9^{\mathrm{e}}$ \\
\hline Nicaragua & $3,3^{\mathrm{a}}$ & $1,0^{f}$ & $43,7^{\mathrm{a}}$ & $36,0^{f}$ & $53,0^{\mathrm{a}}$ & $62,6^{4}$ \\
\hline Panamá & $1,5^{\mathrm{c}}$ & 2,0 & $39,5^{\circ}$ & 43,7 & $58,9^{c}$ & 54,3 \\
\hline $\begin{array}{l}\text { República } \\
\text { Dominicana }\end{array}$ & $1,7^{\mathrm{d}}$ & 2,7 & $36,6^{d}$ & 41,2 & $61,7^{\mathrm{d}}$ & 56,2 \\
\hline
\end{tabular}

Fuente: Comisión Económica para América Latina y el Caribe (CEPAL), "CEPALSTAT. Bases de Datos y Publicaciones Estadísticas", 2016 [en línea] http://estadisticas.cepal.org/cepalstat/WEB_ CEPALSTAT/Portada.asp.

a Corresponde a 1998.

b Corresponde a 1999.

corresponde a 2001.

d Corresponde a 2002.

e Corresponde a 2013.

Corresponde a 2009.

En las siguientes cuatro secciones se presentan los desafíos del espacio rural identificados en materia de desarrollo productivo.

\section{B. Desafíos institucionales}

\section{Reglas, convenciones y formas de coordinación}

La implementación de reformas agrarias y de un marco normativo que apoye a las unidades de menor tamaño sigue siendo un desafío institucional en Centroamérica y la República Dominicana. Pese a los esfuerzos por introducir programas de tenencia de la tierra y mejorar los que ya existen, el impacto en la disminución de la concentración de la tierra no ha sido sustantivo (CEPAL, 2001). En el cuadro I.3 se sintetizan algunas limitaciones institucionales identificadas en la implementación de las reformas agrarias en Centroamérica y la República Dominicana, sin dejar de reconocer que existen especificidades en cada país. 


\section{Cuadro I.3 \\ Centroamérica y la República Dominicana: limitaciones a la implementación de reformas agrarias}

- Conflictos bélicos y procesos de inestabilidad política

- Politización de las reformas

- Problemas en los procesos de titulación y seguridad jurídica de la propiedad

- Falta de continuidad en los programas de reforma agraria

- Recursos financieros insuficientes

- Carencia de servicios de apoyo (asistencia técnica, capacitación, financiamiento y otros) para los beneficiarios de la transformación agraria

- Poca agilidad en los procesos de transformación agraria

- Desmantelamiento de instituciones para la reforma agraria

- Sistemas legales demasiado complejos sujetos a sucesivas modificaciones y con vacíos jurídicos

- Asimetría en los procesos de tenencia de la tierra y la introducción de cambios tecnológicos

- Extranjerización de tierras

Fuente: Elaboración propia, sobre la base de A. Baumeister, Concentración de tierras y seguridad alimentaria en Centroamérica, Roma, Coalición Internacional para el Acceso a la Tierra (ILC)/ Fondo de Desarrollo Noruego, 2013; F. Edouard, Gobernanza en la tenencia de la tierra y recursos naturales en América Central, Roma, Organización de las Naciones Unidas para la Alimentación y la Agricultura, 2010; Comisión Económica para América Latina y el Caribe (CEPAL), "La estructura agraria y el campesinado en el Salvador, Guatemala y Honduras" (LC/MEX/L.492), Ciudad de México, Sede Subregional de la CEPAL en México, 2001; F. Barea, La reforma agraria en el istmo centroamericano y república dominicana durante el periodo 1986-1991, San José, Instituto Interamericano de Cooperación para la Agricultura (IICA), 1994.

El centralismo pone de manifiesto la incapacidad de las entidades públicas para atender las demandas de la población rural. Las instancias públicas a nivel nacional, ubicadas en centros urbanos, absorben más presupuesto y recursos humanos que las entidades que operan en el espacio rural. Por ejemplo, Jansen y Alwang (2006) estudiaron la concentración de la inversión pública en zonas rurales de Centroamérica y mostraron que en Guatemala, Honduras y Nicaragua la inversión pública es mayor en las zonas más cercanas a las áreas urbanas y menor en las áreas rurales más remotas.

En Centroamérica y la República Dominicana subsisten problemas de gobernabilidad, como los conflictos para el pleno cumplimiento del estado de derecho, los procesos de inclusión ciudadana incompletos, con exclusión de poblaciones indígenas y afrodescendientes, y los problemas de seguridad, debilidad en la capacidad de respuesta y organización de la sociedad civil, entre otros (ECADERT/CAC/SICA, 2010). La población rural confronta estos fenómenos en condiciones distintas a la población urbana, con una mayor incidencia de la pobreza, menores oportunidades económicas, deficiencias en el acceso a activos e información, centralismo y bajos niveles de instrucción.

En cuanto a formas de coordinación, los pequeños productores y las micro y pequeñas empresas del espacio rural tienen capacidades desiguales en términos sociales, económicos y políticos para manifestar las demandas y propuestas de política pública que favorezcan su desarrollo (Flores y Rello, 2002). El fomento de los procesos de asociatividad y la búsqueda de nuevas formas de coordinación entre las unidades productivas de menor tamaño, el Gobierno y otras organizaciones puede ayudar a contrarrestar estas 
limitaciones, haciendo frente a los elevados costos de transacción y superando las restricciones a nivel individual.

\section{Políticas y estrategias}

Las instituciones en el espacio rural son resultado, entre otros factores, de modelos o estrategias de desarrollo nacional y de la implementación de políticas públicas. El reconocimiento por parte del Estado del potencial de las actividades económicas en el espacio rural para contribuir al cambio estructural y al desarrollo económico requiere de su correspondiente asignación en el presupuesto (Pomareda, 2016). En el sector agropecuario, la participación del gasto del gobierno central como porcentaje del gasto público total ha descendido en la mayoría de los países de la subregión. En 2014 y 2015 este porcentaje se sitúo por debajo del 3\% en los países de Centroamérica y la República Dominicana (CEPAL, 2016a).

La ausencia de procesos participativos en la elaboración, implementación y evaluación de políticas públicas para el espacio rural con mecanismos de diálogo entre diversos actores locales, regionales y nacionales es otro desafío institucional. Los procesos participativos consisten en establecer mecanismos de diálogo, concertación y monitoreo del cumplimiento de compromisos. Aunque existen iniciativas vinculadas a este tipo de procesos, la política rural en Centroamérica y la República Dominicana ha sido gestionada con una base social reducida, donde los actores con menos poder tienen una participación limitada (Berdegué y otros, 2013) ${ }^{8}$. El consenso en la implementación de políticas y estrategias para el espacio rural es un desafío en la subregión, ya que, incluso cuando se han generado procesos de participación, los procesos de implementación son complejos. En Guatemala, por ejemplo, se impulsó un proceso para formular de manera participativa la iniciativa de la Ley de Desarrollo Rural Integral discutida desde 2002, formalizada en 2009 y respecto de la cual se iniciaron acciones para implementarla en $2012^{9}$. Sin embargo, el proceso para su aprobación ha sido lento y la implementación se ha retrasado debido a la falta de consenso entre distintos actores (Privado, 2016).

Un ejemplo de estas iniciativas es la Estrategia Centroamericana de Desarrollo Rural Territorial (ECADERT), que surge para incentivar la gestión participativa de políticas públicas territoriales incluyentes y equitativas, con los procesos de formulación y creación de consensos para la planificación y transformación institucional, social, económica, cultural y ambiental del espacio rural centroamericano (ECADERT, 2011). Por otra parte, el Centro Latinoamericano para el Desarrollo Rural (RIMISP) ha puesto en marcha una iniciativa que involucra a actores del nivel subregional y entidades públicas y privadas para reformular un marco conceptual y de acercamiento operativo entre gobiernos y organismos multilaterales en la negociación de préstamos y la implementación de proyectos con influencia en los países de la subregión (Grupos de Diálogo Rural). El proyecto se lleva a cabo en Costa Rica, El Salvador, Guatemala, Nicaragua y Panamá (RIMISP, 2016).

$9 \quad$ Esta ley se centra en la población rural en situación de pobreza y pobreza extrema y da prioridad a los pueblos indígenas y campesinos con tierra insuficiente, tierra improductiva o sin tierra, mujeres indígenas y campesinas, asalariados permanentes o temporales, artesanos, pequeños productores rurales, micro y pequeños empresarios rurales (Privado, 2016). 


\section{Desafíos de sostenibilidad ambiental}

\section{Adaptación al cambio climático}

El cambio climático es resultado de un exceso de emisiones de gases de efecto invernadero (GEI) en la atmósfera y ha sido considerado como la mayor falla de mercado de todos los tiempos (CEPAL, 2016b). Aunque la contribución de los países de Centroamérica y la República Dominicana a estas emisiones es menor en comparación con otras regiones, las zonas rurales de la subregión son de las más vulnerables y amenazadas por eventos extremos. En las últimas décadas, las amenazas de origen meteorológico e hidrológico han sido potenciadas por los efectos del cambio climático. Honduras (1), Nicaragua (4) y Guatemala (10) se han posicionado entre los diez países más afectados por este tipo de eventos a nivel mundial (Kreft y otros, 2015). Según información de The International Disaster Database EM-DAT, en el período 1990-2015, Centroamérica y la República Dominicana fueron afectadas por 382 eventos extremos, mientras que entre 1965 y 1990 se registraron 107. La mayoría de estos eventos son de origen meteorológico e hidrológico (como inundaciones, tormentas, derrumbes y sequías). A su vez, son el tipo de eventos extremos asociados al cambio climático que más pérdidas y daños han generado (véase el gráfico I.5).

\section{Gráfico I.5}

Centroamérica y la República Dominicana: distribución de los eventos extremos, por tipo de origen, 1990-2015

(En porcentajes)

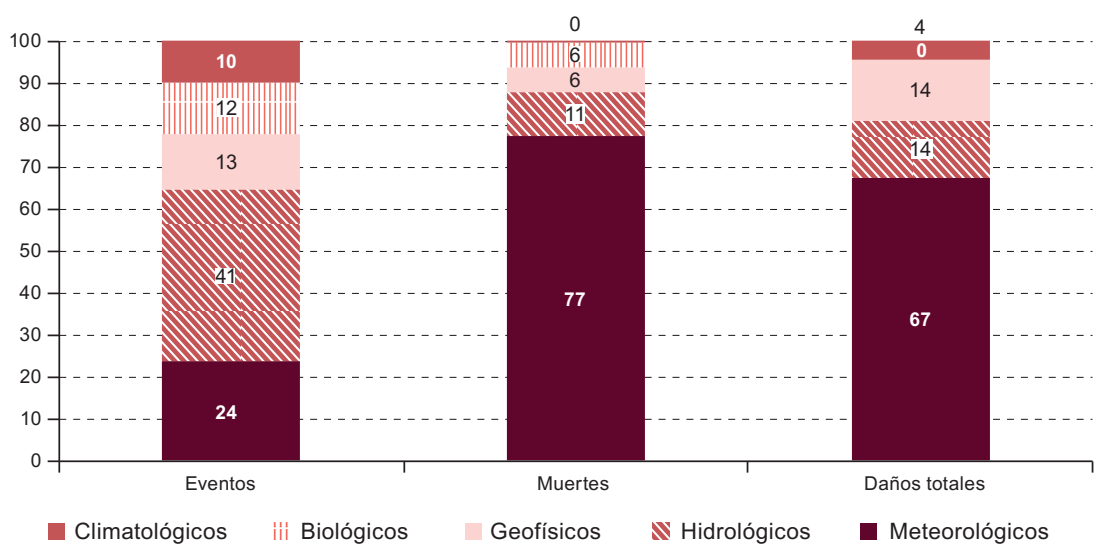

Fuente: Elaboración propia, sobre la base de datos de "EM-DAT Database", 2016 [en línea] www.emdat.be. 
Debido a que las condiciones climatológicas tienen estrecha relación con el desempeño de las actividades rurales, las pérdidas y los daños derivados de eventos extremos han sido mayores en estas áreas. De acuerdo con el informe Gestión integral de riesgos y seguros agropecuarios en Centroamérica y la República Dominicana: situación actual y líneas de acción potenciales, el 67\% de las pérdidas económicas por eventos extremos en Centroamérica y la República Dominicana han afectado al sector agropecuario. En el mismo informe se señala que los principales desastres, ocurridos entre 1970 y 2008, han generado pérdidas por un total de 7.125 millones de dólares a precios de 2008 en la agricultura, mientras que el total de pérdidas en la industria fue de 1.887 millones de dólares, en el sector de comercio alcanzó los 1.256 millones de dólares y en el sector del turismo llegó a 363 millones de dólares (CEPAL/CAC/SICA, 2013). En este escenario se ha sugerido establecer medidas de adaptación y prevención de riesgos para el sector agropecuario y otras actividades del espacio rural. Los seguros agropecuarios son un instrumento para la gestión de los riesgos ${ }^{10}$.

El cambio climático tiene efectos en el uso de los recursos hídricos en las actividades económicas rurales, ya sea por un déficit o por un exceso de agua, como en las inundaciones, tormentas y derrumbes, que afectan las propiedades del suelo y dañan la producción agropecuaria y otras actividades rurales. En 2012, la disponibilidad de los recursos hídricos renovables en Centroamérica y la República Dominicana sumó 686.630 millones de metros cúbicos anuales. Los países con mayor cantidad de agua disponible fueron Nicaragua (23,9\%) y Panamá $(20,3 \%)$, mientras que los países con menor disponibilidad fueron El Salvador (3,8\%) y la República Dominicana (3,4\%). La extracción total de agua en Centroamérica y la República Dominicana se estima en 19.137 millones de metros cúbicos anuales ${ }^{11}$. El sector agropecuario demanda un alto porcentaje del recurso hídrico: aproximadamente el 64\% de la extracción en la subregión (12.214 millones de metros cúbicos por año) (FAO, 2016b). A pesar de que algunos países de la subregión cuentan con

10 La gestión integral de los riesgos divide el riesgo en amenazas y vulnerabilidades, y esto ha sido clave para evaluar el impacto de los eventos extremos o potencialmente desastrosos. Entre los distintos tipos de amenazas hay algunas de origen económico, por ejemplo la volatilidad de los precios, y otras de origen antropogénico y natural, como los eventos extremos. En cuanto a las vulnerabilidades, debido a la posición geográfica de los países de la subregión (en un istmo estrecho que conecta dos continentes y entre dos océanos), las zonas del Atlántico son más afectadas por tormentas y huracanes, y entre las áreas productivas más vulnerables se encuentran las riberas de los ríos y las zonas bajas y costeras (véase CEPAL/CAC/SICA, 2013).

11 Con información del último año disponible para cada país: Costa Rica (2013), El Salvador (2005), Guatemala (2006), Honduras (2003), Nicaragua (2011), Panamá (2010) y República Dominicana (2010) (FAO, 2016b). 
niveles relativamente altos de disponibilidad de agua, en varias zonas hay problemas de escasez del recurso hídrico relacionados con la falta de infraestructura para acceder a dicho recurso y la inestabilidad de las condiciones climáticas (Pomareda, 2016; CEPAL, 2011). Los efectos del cambio climático en los recursos hídricos de Centroamérica han sido analizados en estudios técnicos del proyecto "La economía del cambio climático en Centroamérica" (CEPAL, 2010 y 2011). A partir de la identificación de escenarios de disponibilidad y demanda de agua para los cortes 2000, 2020, 2030, 2050, 2070 y 2100, sin cambio climático y con impacto del cambio climático en los escenarios B2 (escenario de emisiones inferior a la tendencia actual) y A2 (escenario de emisiones crecientes e inacción global), se estimaron aumentos mayores en la demanda de agua y una disminución de la disponibilidad de agua total y per cápita con cambio climático. Así, la demanda de agua podría aumentar alrededor de un 300\% en 2050 y más del $1.600 \%$ en 2100 en un escenario tendencial, mientras que aumenta un $20 \%$ más que el escenario base con un escenario B2 y un $24 \%$ más en A2. La disponibilidad de agua se reduce considerablemente a partir de 2030, sobre todo con el escenario A2 (un 63\% en el año final). De igual forma, se estima una disminución media para Centroamérica en la disponibilidad de agua per cápita al final del período del $90 \%$ en el escenario A2 y del 82\% en un escenario B2 (CEPAL, 2010).

La puesta en práctica de medidas de adaptación frente a fenómenos como la sequía es otro desafío ambiental de Centroamérica y la República Dominicana. La subregión, y en especial la zona designada como el Corredor Seco Centroamericano, es particularmente vulnerable a estos fenómenos ${ }^{12}$. Los fenómenos relacionados con la precipitación pluvial en esta subregión han sido cada vez más variables y extremos. En el Corredor Seco Centroamericano (que incluye un 30\% de los 53 millones de hectáreas que tiene la superficie de Centroamérica), el $42 \%$ de la superficie (6.684.899 hectáreas) enfrenta un grado de sequía bajo, el 50,5\% (8.045.987 hectáreas) muestra un grado moderado y el 7,5\% (1.187.385 hectáreas) tiene un grado severo (FAO, 2012).

A nivel subregional se han incorporado distintas agendas para la adaptación a los riesgos climáticos. La iniciativa del Centro de Coordinación para la Prevención de los Desastres Naturales en América Central (CEPREDENAC) busca gestionar los riesgos a partir de la coordinación y el intercambio de información, experiencias y asesoría técnica y científica en materia de prevención, mitigación, respuesta y recuperación de desastres.

12 El Corredor Seco Centroamericano contempla a un grupo de ecosistemas que se integran en la ecorregión del bosque tropical seco de Centroamérica, comenzando en Chiapas (México), y en una franja abarca las zonas bajas de la vertiente del Pacífico y gran parte de la región central premontañosa (0 a $800 \mathrm{msnm}$ ) de El Salvador, Guatemala, Honduras, Nicaragua y parte de Costa Rica (hasta Guanacaste). En Honduras incluye fragmentos que se aproximan a la costa del Caribe (FAO, 2012). 
Otras iniciativas son la Estrategia Centroamericana de Desarrollo Rural Territorial (ECADERT) y la Política Agrícola Centroamericana (PACA) en materia de adaptación al cambio climático y gestión integral de riesgos del Consejo Agropecuario Centroamericano (CAC). En tanto, la Comisión Centroamericana de Ambiente y Desarrollo (CCAD)-Sistema de la Integración Centroamericana (SICA) ha impulsado la Estrategia Regional de Cambio Climático (ERCC), cuyo objetivo es prevenir y reducir los efectos del cambio climático mediante un aumento de la resiliencia y la capacidad de adaptación.

Por último, en los países centroamericanos se están concretando acuerdos entre diferentes dependencias oficiales a nivel nacional y regional para atender una agenda en investigación, desarrollo e innovación. Algunos ejemplos de los temas tratados por las agendas agroclimáticas en la subregión en materia de adaptación son: programas de investigación y transferencia de tecnología baja en carbono (Costa Rica); vulnerabilidad y estrategias de adaptación para el café (El Salvador); producción de maíz y frijol, material genético resistente a sequía, rescate de conocimiento ancestral, fitomejoramiento participativo y promoción de bancos de semillas comunitarios (Guatemala); la agenda de investigación de la Dirección de Ciencia y Tecnología Agropecuaria (DICTA) orientada a resolver afectaciones del sector ante el cambio climático (Honduras); innovación tecnológica en cadenas productivas para la adaptación (Panamá), y estudio sobre la valorización económica del recurso hídrico (República Dominicana) (Rodríguez, López y Meza, 2015).

\section{Mitigación del cambio climático}

Las emisiones de gases de efecto invernadero en actividades de agricultura y ganadería en Centroamérica y la República Dominicana son menores que las de otras subregiones como América del Norte y América del Sur. No obstante, las emisiones de dióxido de carbono provenientes de actividades agropecuarias en la subregión se han incrementado de 20 millones de toneladas en 1970 a 35,8 millones de toneladas en $2010^{13}$.

El incremento de las emisiones de gases de efecto invernadero puede atribuirse a la expansión agrícola y ganadera y la disminución de los recursos forestales. Como se muestra en el gráfico I.6, en las últimas dos décadas, los países de Centroamérica (con la excepción de Costa Rica) y la República Dominicana registraron una disminución en el porcentaje de área de bosques con respecto a la superficie total. En cuanto a la superficie agrícola, con excepción de Costa Rica, Honduras y la República Dominicana, los países registraron una expansión.

13 No se incluye a Panamá (CEPAL, 2015b). 


\section{Gráfico I.6}

Centroamérica y la República Dominicana: superficie agrícola y de bosques, 1990 y 2015 o último año disponible

(En porcentajes de la superficie total)

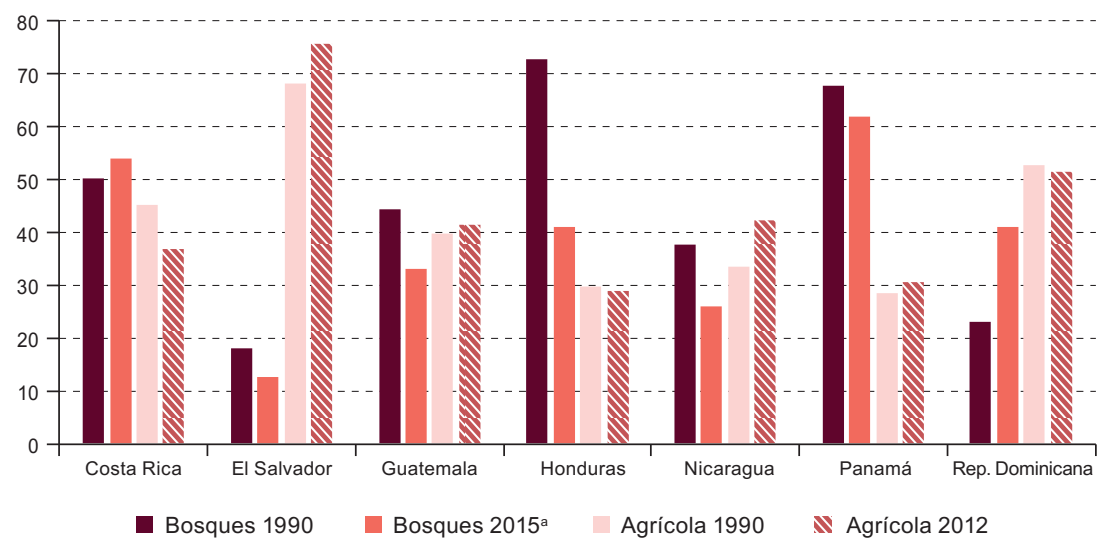

Fuente: Comisión Económica para América Latina y el Caribe (CEPAL), "CEPALSTAT. Bases de Datos y Publicaciones Estadísticas”, 2016 [en línea] http://estadisticas.cepal.org/cepalstat/WEB_ CEPALSTAT/Portada.asp.

a El dato es de FAO (2016a).

El crecimiento del sector agropecuario debe ir acompañado de acciones responsables en materia de conservación y manejo de los bosques y otros recursos naturales. Esto supone enormes desafíos para los países en desarrollo que aún tienen altas brechas de productividad y necesitan aumentar la producción, sin que esto vaya en detrimento de las condiciones ambientales. La conservación y el manejo adecuado de los bosques representa una oportunidad para la mitigación de los efectos del cambio climático en tanto se contribuye a preservar la biodiversidad y al desacoplamiento de las emisiones de carbono.

Las acciones de mitigación también involucran prácticas más sostenibles en diferentes actividades económicas del espacio rural. Se puede minimizar el uso de insumos externos y generar bienes y servicios más eficientes en términos ambientales. En la agricultura orgánica, por ejemplo, se elimina o minimiza el uso de fertilizantes sintéticos, pesticidas, reguladores de crecimiento, antibióticos, organismos genéticamente modificados y otros aditivos que tienen efectos negativos en el ambiente y en la salud de los consumidores. En Centroamérica, así como en otras regiones en desarrollo, este tipo de cultivos como porcentaje del total de la superficie agrícola es bajo (en 2009 significó entre el 0,2 \% y el 0,4\% del total de la superficie cultivable). En cambio, en países desarrollados como Dinamarca y Finlandia este porcentaje fue del 5,62\% y del 7,3\%, respectivamente (FAO, 2016a). Los productos y servicios con etiquetados 
ambientales son una alternativa para las comunidades rurales que necesitan mejorar sus ingresos de forma sostenible.

Los desafíos en materia de mitigación se verán influidos por los compromisos de los países con las contribuciones determinadas a nivel nacional ${ }^{14}$. La mayoría de los países de la subregión, con excepción de Nicaragua, han hecho públicas estas contribuciones. En los compromisos enviados se destaca Costa Rica, que ha renovado su compromiso hacia la neutralidad de carbono para 2021 y ha determinado una meta de emisiones de gases de efecto invernadero en un máximo absoluto (9.374.000 tCO2eq netas para 2030) (CPDN, 2017).

\section{Desafíos de comercialización}

\section{Volatilidad en los precios internacionales de productos primarios}

Entre los principales productos primarios agrícolas de Centroamérica y la República Dominicana se encuentran los granos básicos como maíz, frijol y arroz. En 2014 el principal productor de maíz en la subregión fue Guatemala, con 1.847.214 toneladas, seguido por El Salvador (819.311 toneladas) y Honduras (400.000 toneladas). Guatemala también registró la mayor cantidad de producción de frijol, con 235.029 toneladas, seguido por El Salvador (120.795 toneladas) y Nicaragua (183.600 toneladas). Por su parte, la República Dominicana tuvo la mayor producción de arroz, con 718.237 toneladas (FAO, 2016a).

En el gráfico I.7 se muestra cómo en los últimos 35 años el precio de los granos básicos a nivel internacional ha tenido variaciones significativas. Durante el período 2006-2008 los precios de los granos básicos alcanzaron niveles máximos. Algunos factores identificados como causas de este incremento de precios fueron el aumento del precio de las materias primas (como el petróleo), la mayor demanda de cultivos en el sector de los biocombustibles, la disminución en las reservas alimentarias y la menor producción de cereales, además de otras condiciones y políticas macroeconómicas y de la especulación en los mercados organizados de futuros (FAO, 2010). A partir de la crisis financiera internacional de 20082009 se ha observado una tendencia a la baja de los precios, pero en un contexto de marcada volatilidad.

14 Las contribuciones determinadas a nivel nacional forman parte de los acuerdos de la Convención Marco de las Naciones Unidas sobre el Cambio Climático para mitigar los efectos del cambio climático a fin de reducir las emisiones de gases de efecto invernadero y mantener el aumento de la temperatura mundial por debajo de los $2{ }^{\circ} \mathrm{C}$. Estas contribuciones son los compromisos que cada país asume, de acuerdo con sus capacidades y necesidades, para hacer frente al cambio climático. 
Gráfico 1.7

Precios internacionales de granos básicos, promedio anual, 1980-2016 (En dólares por tonelada métrica)

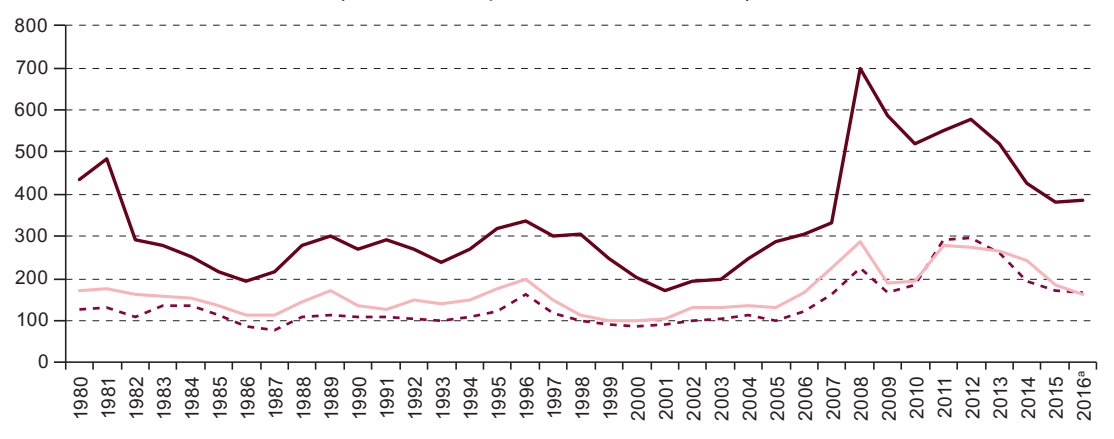

Fuente: Comisión Económica para América Latina y el Caribe (CEPAL), "CEPALSTAT. Bases de Datos y Publicaciones Estadísticas", 2016 [en línea] http://estadisticas.cepal.org/cepalstat/WEB_ CEPALSTAT/Portada.asp.

a Corresponde a la media de enero a junio de 2016.

Las tendencias alcistas en los precios de los productos básicos agrícolas deberían favorecer a los productores, pero los beneficios en general no se sostienen en el largo plazo y suelen ir a parar a los productores de agroexportación en detrimento de los más pequeños. Aunque se incrementen los precios al consumidor, con frecuencia no aumentan los precios de los productores. Esto tiene que ver con el poder de negociación de industriales e importadores, pero también con el papel de los intermediarios y su comportamiento oportunista en el manejo de información y concentración de capital productivo (Grandlgruber, García y Nazif, 2014). Por otra parte, los precios de los insumos agrícolas, como fertilizantes y petróleo, también inciden en la producción agropecuaria, ya que su alza eleva los costos de producción y los productores no siempre cuentan con poder de negociación para fijar un precio más alto para sus productos.

\section{Acceso a mercados y papel de los intermediarios}

Los productores y las empresas de menor tamaño en la subregión enfrentan más dificultades para colocar sus productos y servicios en mercados locales e internacionales. Las asimetrías de información se manifiestan en el desconocimiento de los actores rurales acerca de posibles nichos, canales de distribución y condiciones de oferta y demanda de los mercados. Los intermediarios suelen aprovechar estas asimetrías y asumen funciones de acopio y distribución de productos, pero también de provisión de transporte, financiamiento y venta de insumos. Asimismo, disponen de más información sobre los mercados y tienen mayor poder de negociación. El papel de los intermediarios es complejo: por una parte, cubren necesidades productivas para la movilización de los productos y, por otra, capturan un importante margen de ganancias en detrimento de las ganancias de los pequeños productores (IICA/RED SICTA, 2014). 
La diferencia en el precio pagado según el eslabón de la cadena de valor en que se ubiquen los actores pone de manifiesto el desafío de escalamiento de las unidades productivas. Para tener un mejor margen de ganancia, los productores necesitan apropiarse de segmentos de la cadena de mayor valor, incluida la etapa de comercialización. Sin embargo, enfrentan grandes retos debido a la carencia de activos, financiamiento, información, equipo de transporte e infraestructura para las tareas de transformación, almacenamiento, empaque y comercialización.

\section{Comercio extrarregional e intrarregional}

El comercio de bienes agroalimentarios de Centroamérica y la República Dominicana muestra un comportamiento heterogéneo. Los países que acumularon mayores ingresos derivados de sus exportaciones agroalimentarias en 2015 fueron: Guatemala (4.184 millones de dólares), Costa Rica (3.923 millones de dólares) y Nicaragua (2.029 millones de dólares) (véase el gráfico I.8). En Panamá (1.580 millones de dólares), El Salvador (1.648 millones de dólares) y la República Dominicana (2.347 millones de dólares) el valor de las importaciones de estos productos fue mayor que el de las exportaciones.

\section{Gráfico I.8}

Centroamérica y la República Dominicana: exportaciones e importaciones de productos agroalimentarios, 2015 o último año disponible ${ }^{a}$

(En millones de dólares)

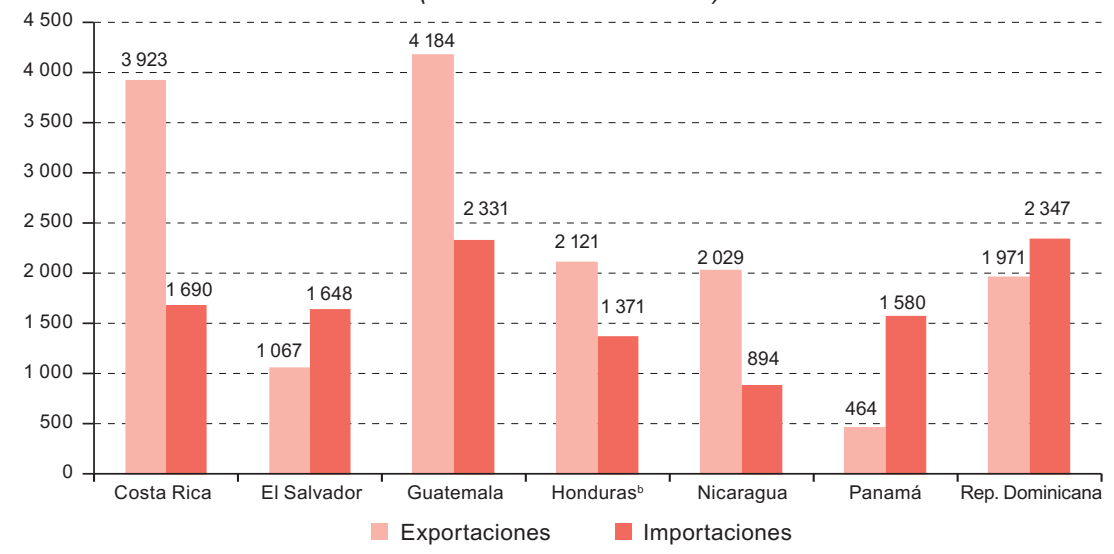

Fuente: Elaboración propia, sobre la base de información de la Base de Datos Estadísticos de las Naciones Unidas sobre el Comercio de Productos Básicos (COMTRADE), 2016 [en línea] http://comtrade.un.org/data/.

a Basado en la Clasificación Uniforme para el Comercio Internacional (Revisión 4). Incluye la sección 0 (productos alimenticios y animales vivos) y la sección 1 (bebidas y tabaco).

b El último año disponible es 2014.

Las exportaciones agroalimentarias de la subregión siguen teniendo un peso importante en el total de las exportaciones. En Honduras, Nicaragua y Costa Rica, el valor de las exportaciones agroalimentarias, mostradas en 
el gráfico I.8, representaron el $47 \%$, el $43 \%$ y el $41 \%$ del valor total de las exportaciones, mientras que en El Salvador y la República Dominicana este valor fue del 19\% y el $24 \%$, respectivamente (COMTRADE, 2016) ${ }^{15}$. Los principales productos agroalimentarios de exportación en Centroamérica son: café; bananas; azúcar de caña o remolacha y sacarosa químicamente pura; dátiles, higos, piñas, aguacates, guayabas, mangos y mangostanes (frescos o secos); aceite de palma y fracciones (sin modificaciones químicas); preparaciones alimenticias; crustáceos; carne bovina, productos de panadería, pastelería o galletería, jugos de frutas u hortalizas, y agua (incluida el agua mineral y con gas), nuez moscada, macis, amomos, cardomos y carne bovina (fresca o refrigerada) (SIECA, 2016). El azúcar, el café y los bananos siguen teniendo una participación importante en términos de volumen y valor en las exportaciones, y se ubican entre los diez productos principales de todos los países de Centroamérica y la República Dominicana (FAO, 2016a). Un desafío clave es extender las exportaciones agroalimentarias a mercados más dinámicos y de mayor valor agregado: no solo exportar los bienes agropecuarios tradicionales, sino agregar valor a partir de su transformación o forma de comercialización (CEPAL, 2016b).

De igual forma, se requiere fortalecer la diversificación de los socios comerciales de la subregión. Los Estados Unidos son el principal socio comercial de todos los países de Centroamérica y la República Dominicana. En 2015, el 45\% de los productos de exportación primarios de Costa Rica se dirigieron a este destino. Guatemala y El Salvador exportaron un 53\% y un 36\% hacia ese país (SIGCI, 2014). Los mercados de exportación en Centroamérica y la República Dominicana están enmarcados por los tratados de libre comercio vigentes. Uno de los más importantes para el comercio extrarregional es el Tratado de Libre Comercio entre República Dominicana, Centroamérica y los Estados Unidos (CAFTA-DR). También existen los tratados que cada país ha firmado de manera individual con otros países o regiones (como la Unión Europea, la Comunidad del Caribe (CARICOM), el Foro del Caribe del Grupo de Estados de África, del Caribe y del Pacífico (CARIFORUM)) (OEA, 2016). La aparición de otros socios comerciales, como China, otros países de América Latina $\mathrm{u}$ otras regiones o bloques comerciales, es un factor a considerar en la comercialización de bienes producidos en el espacio rural.

Las exportaciones intrarregionales constituyen el segundo destino principal de las exportaciones, después de las exportaciones a los Estados Unidos. En 2015, el valor total de las exportaciones en Centroamérica (sin incluir a la República Dominicana) se calculó en 27.999 millones de dólares. Las exportaciones intrarregionales se estimaron en un 32,7\% del total (SIECA, 2016). Se presenta también la oportunidad de incrementar el comercio intrarregional de productos agroalimentarios y aprovechar así las complementariedades que existen en materia de oferta y demanda entre los países de la subregión.

15 De acuerdo con la Clasificación Uniforme para el Comercio Internacional (Revisión 4). 


\section{E. Desafíos de productividad e innovación}

\section{Productividad}

Como se aprecia en el gráfico I.9, con excepción de Costa Rica, la productividad laboral agropecuaria ha mostrado un lento crecimiento en Centroamérica y la República Dominicana. De acuerdo con el estudio de Weller (2016), a partir de un procesamiento especial de las encuestas de hogares, en el período 1990-2002 la productividad laboral agrícola en general exhibió un crecimiento. Esto se asocia, entre otros factores, a los procesos de paz, modernización y fomento de las exportaciones en la subregión. La situación cambió en el período más reciente (2002-2012). Los países con una mayor tasa de crecimiento medio de la productividad laboral agropecuaria fueron Costa Rica $(4,7 \%)$ y la República Dominicana $(2,2 \%)$, mientras que El Salvador, Nicaragua y Panamá registraron tasas de crecimiento negativas, cercanas al -1\% (véase el gráfico I.9).

Gráfico I.9

Centroamérica y la República Dominicana: tasas de crecimiento medio de la productividad laboral media en el sector agropecuario, 1990-2002 y 2002-2012 ${ }^{\text {a }}$ (En porcentajes)

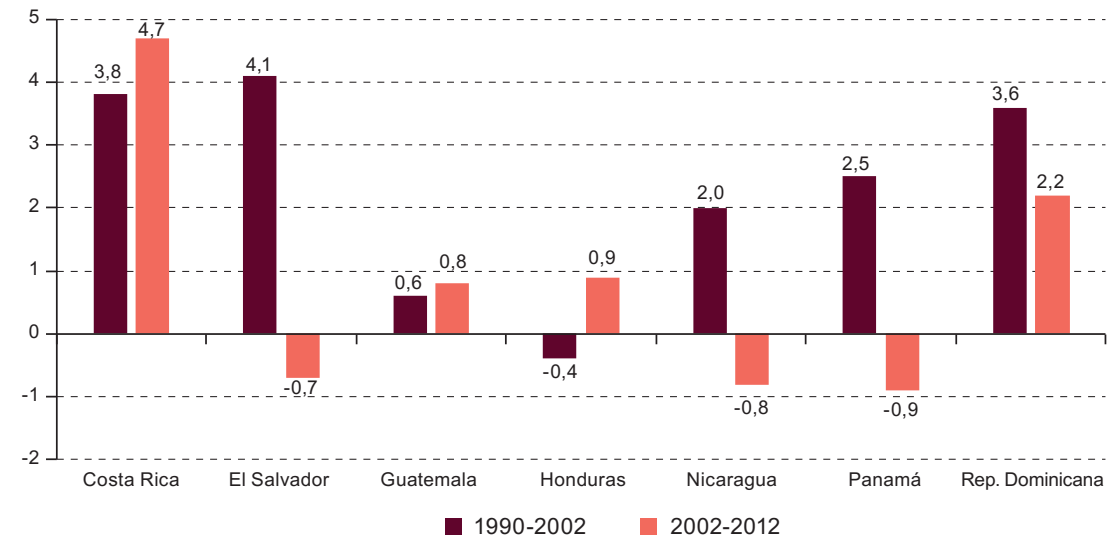

Fuente: J. Weller, "Transformaciones y rezagos: la evolución del empleo agropecuario en América Latina, 2002-2012", serie Macroeconomía del Desarrollo, N 174 (LC/L.4209), Santiago, Comisión Económica para América Latina y el Caribe (CEPAL), 2016, pág. 24.

Primer y último año disponible en cada período. Primer período: Costa Rica (1990-2002), Panamá y la República Dominicana (1991 y 2002), El Salvador (1992-2002), Guatemala (1989-2002) y Nicaragua (1990-2003). Segundo período: Costa Rica, El Salvador, Honduras, Panamá y República Dominicana (2002-2012), Nicaragua (2003-2010) y Guatemala (2002-2011).

El incremento moderado de las tasas de crecimiento de la productividad laboral agropecuaria en América Latina ha sido explicado más por la disminución del empleo en el sector agropecuario y el movimiento hacia otros sectores, que por cambios en los distintos sectores (Weller, 2016). En el centro y norte de la subregión, el peso del sector 
agropecuario es mayor y persisten brechas más grandes de productividad. En Costa Rica y, en menor medida, la República Dominicana, en tanto, se han registrado procesos de cambio estructural más profundos y las brechas de productividad son menores.

En la agricultura, otro indicador de la productividad es el rendimiento de los cultivos, que está influido por múltiples factores que van desde el tamaño de las unidades productivas, la tecnología empleada, las capacidades acumuladas y el manejo de los recursos, hasta cuestiones climáticas (incluidos los efectos del cambio climático). Como se muestra en el cuadro I.4, en las últimas tres décadas, los rendimientos de los granos básicos en la mayoría de los países de la subregión han crecido de forma moderada. En el caso del maíz, El Salvador ha tenido los mayores rendimientos y pasó de 1,9 toneladas por hectárea en el período 1980-1989 a 3,0 toneladas por hectárea en el período 2010-2013. En cambio, Nicaragua es el país con menor crecimiento de los rendimientos: de 1,2 toneladas por hectárea en el período 1980-1989 pasó a 1,4 toneladas por hectárea en el período 2010-2013. Si se comparan estas cifras con los rendimientos a nivel internacional, se constata que Centroamérica y la República Dominicana están lejos de la frontera productiva. Entre 2010 y 2013, el Brasil registró una media de los rendimientos para el cultivo de maíz de 4,7 toneladas por hectárea, mientras que en los Estados Unidos, el mayor productor de granos del mundo, la medida fue de 9,1 toneladas por hectárea. En México, el valor fue de 3,1 toneladas por hectárea (FAO, 2016a).

\section{Cuadro I.4 \\ Centroamérica y la República Dominicana: rendimiento medio de los granos básicos, 1980-2013}

(En toneladas por hectárea)

\begin{tabular}{lccccccc}
\hline & $\begin{array}{c}\text { Costa } \\
\text { Rica }\end{array}$ & El Salvador & Guatemala & Honduras & Nicaragua & Panamá & $\begin{array}{c}\text { República } \\
\text { Dominicana }\end{array}$ \\
\hline $1980-1989$ & 1,7 & 1,9 & 1,7 & 1,3 & 1,2 & 1,1 & 1,6 \\
\hline $1990-1999$ & 1,8 & 2,0 & 1,9 & 1,4 & 1,2 & 1,3 & 1,5 \\
\hline $2000-2009$ & 1,9 & 2,8 & 2,2 & 1,6 & 1,2 & 1,4 & 1,5 \\
\hline $2010-2013$ & 2,1 & 3,0 & 2,0 & 1,7 & 1,4 & 1,8 & 1,8 \\
\hline & & & Frijol & & & 1,8 \\
\hline $1980-1989$ & 0,5 & 0,7 & 0,8 & 0,5 & 0,6 & 0,4 & 0,0 \\
\hline $1990-1999$ & 0,5 & 0,8 & 0,8 & 0,8 & 0,6 & 0,4 & 0,8 \\
\hline $2000-2009$ & 0,6 & 0,9 & 0,9 & 0,7 & 0,8 & 0,3 & 1,0 \\
\hline $2010-2013$ & 0,6 & 0,8 & 0,9 & 0,8 & 0,8 & 0,4 & \\
\hline & & & Arroz & & & & \\
\hline $1980-1989$ & 3,0 & 3,8 & 2,6 & 3,0 & 3,4 & 1,9 & 4,7 \\
\hline $1990-1999$ & 4,2 & 4,7 & 3,0 & 3,5 & 3,3 & 4,6 & 5,2 \\
\hline $2000-2009$ & 3,9 & 6,8 & 2,9 & 3,0 & 3,5 & 5,8 & 5,1 \\
\hline $2010-2013$ & 3,5 & 6,3 & 2,9 & 4,7 & 4,3 & 5,9 & 5,5 \\
\hline
\end{tabular}

Fuente: Comisión Económica para América Latina y el Caribe (CEPAL), "CEPALSTAT. Bases de Datos y Publicaciones Estadísticas", 2016 [en línea] http://estadisticas.cepal.org/cepalstat/WEB_ CEPALSTAT/Portada.asp. 


\section{Tamaño y desempeño tecnológico}

El tamaño de las unidades productivas y la estructura de la tenencia de la tierra restringen las actividades agropecuarias del espacio rural en Centroamérica y la República Dominicana. Más de la mitad de los productores de la subregión se ubican en la categoría de unidades de producción más pequeñas: las microfincas o los productores de subsistencia. En esta categoría, los productores cuentan con un promedio de superficie de tierra menor de 5 hectáreas. El 50,5\%, el 74,6\% y el 62,1\% de los productores en Costa Rica, Panamá y Honduras, respectivamente, se ubica en este estrato. En Nicaragua, el 46,6\% cuenta con menos de 3,5 hectáreas, en El Salvador, el 68,6\% dispone de menos de 1 hectárea, y en Guatemala, el $67,5 \%$ de los productores de subsistencia tienen menos de 1,4 hectáreas (CEPAL, 2016c) ${ }^{16}$. Si bien no todos los pequeños productores tienen las mismas características y algunos cuentan con mayores capacidades, en general, en este segmento se dispone de menos activos y se obtienen menos rendimientos de los cultivos. La gran mayoría forma parte de la agricultura familiar, de subsistencia o de traspatio, con menos posibilidades de generar economías de escala y minimizar los costos de producción. Los productores más grandes, en cambio, cuentan con mejor equipamiento, personal calificado, más tecnología y capacidades para acceder a mercados internacionales o escalar en las cadenas de valor. Si bien en Centroamérica y la República Dominicana este tipo de productores representan una mínima cantidad, centralizan la mayor superficie de tierra. En Guatemala, por ejemplo, los productores que tienen más de 22,5 hectáreas representan apenas el 3,2\% del total y centralizan casi dos tercios de la superficie de la tierra (un 65,4\% del total) (CEPAL, 2016c).

Un componente de la tecnología agrícola es el acceso al riego. A pesar de que Centroamérica y la República Dominicana disponen de territorios con abundancia del recurso hídrico, la subregión enfrenta desafíos en materia de acceso, equipamiento y capacitación. Prevalece el sistema de riego por superficie (entre el $70 \%$ y el $90 \%$ de las tierras), al que le sigue el riego por aspersión y el riego localizado (FAO, 2016b).

También existen restricciones en cuanto a la adecuada implementación de buenas prácticas agropecuarias. La calidad de las semillas, las prácticas de nutrición vegetal y animal, el manejo de los suelos, las prácticas de inocuidad y la disminución de los servicios de extensión brindados por el Estado son factores limitantes del desempeño tecnológico en las actividades agropecuarias. Por otra parte, se ha identificado la resistencia al cambio de prácticas o técnicas por parte de los productores, muchas veces como consecuencia de asimetrías de información (Pomareda, 2016).

16 Sobre la base del último censo agropecuario disponible: Costa Rica (2014), El Salvador (20072008), Guatemala (2003), Honduras (1993), Nicaragua (2011) y Panamá (2000) (CEPAL, 2016c). 
La agroindustria tiene un peso significativo en la industria manufacturera de Centroamérica y la República Dominicana. En El Salvador, por ejemplo, alrededor del $69 \%$ de las unidades económicas de la manufactura estaban ubicadas en el rubro de alimentos y bebidas (MINEC, 2005). Este subsector suele estar compuesto por actividades de baja intensidad tecnológica y productividad. En Centroamérica y la República Dominicana se han identificado sistemas de producción agroindustriales de tipo artesanal o semiindustrial (micro y pequeña industria) y un número menor de empresas con procesos industriales modernos (Padilla, 2014). Se debe reconocer que las empresas agroindustriales modernas generalmente no se ubican en el espacio rural.

Las micro y pequeñas empresas no agrícolas - por ejemplo, las agroindustriales de tipo artesanal o semiindustrial, de comercio y servicios, como el turismo rural o transporte- están adquiriendo más peso en el espacio rural como respuesta a las necesidades de diversificación de los ingresos en los hogares. Estas empresas enfrentan desafíos como: acceso a insumos; falta de infraestructura adecuada para llevar a cabo su producción; problemas para crear economías de escala; escasa generación de valor agregado; problemas de inocuidad, calidad y trazabilidad que también condicionan las posibilidades de entrar a distintos mercados; debilidad en los encadenamientos productivos; insuficiente calificación de los recursos humanos, y exiguas o nulas actividades de innovación ${ }^{17}$. En el capítulo V se profundiza en este tema.

Por otra parte, más allá del tamaño y el desempeño tecnológico, el hecho de que las unidades productivas pequeñas actúen en forma aislada supone una limitación. Las empresas de menor tamaño que no generan procesos de asociatividad enfrentan más dificultades para acceder a mercados, conocimiento y financiamiento (Hernández, 2001).

En la subregión están aumentando las micro y pequeñas empresas de servicios rurales. En el comercio rural, muchos de los negocios de este tipo son informales. Por ejemplo, en Honduras se identificó que las empresas rurales de menor tamaño tienen un mayor grado de informalidad (el $51 \%$ de las empresas rurales no están constituidas legalmente) (Valenzuela, 2013). Las remesas son una fuente de ingreso que incentiva el establecimiento de este tipo de empresas. Las actividades de turismo rural son otro tipo de servicios que está emergiendo en la subregión. Entre las restricciones identificadas en estudios sobre cadenas de valor de turismo

Debido a la falta de estadísticas sobre los rasgos de las micro y pequeñas empresas rurales no agropecuarias, su caracterización se realiza a partir de estudios en los que se analiza a estas empresas en otros marcos que incluyen información más allá del nivel sectorial, como las cadenas de valor (Garry y Martínez, 2016; Odonne y Alarcón, 2016; Padilla y Cordero, 2016; Romero, Díaz y Aguirre, 2016; Odonne y Beltrán, 2014, Cordero, 2014; IICA/Red SICA, 2014; Bamber y Fernández-Stark, 2012; AGEXPORT, 2012 y 2014; Angulo y Mata, 2008). 
rural se encuentran: infraestructura insuficiente, escaso desarrollo de productos y destinos turísticos, falta de capacitación técnica y cultura turística, estrategias limitadas de comercialización y venta, y problemas de coordinación interinstitucional (véase el capítulo VI).

\section{Educación y capacitación}

La educación es una dimensión determinante en el aumento de productividad. La subregión presenta bajos niveles educativos de la población en general, que se agudizan en el espacio rural. En promedio, cerca del $40 \%$ de la población rural en edad de trabajar contaba con un nivel de instrucción básico (entre 0 y 5 años) en 2014. El mayor rezago se observa en Guatemala, donde el 63,7\% de la población económicamente activa (PEA) rural tiene entre 0 y 5 años de instrucción. En cambio, Costa Rica tiene el menor porcentaje de PEA rural solo con instrucción primaria $(18,7 \%)$ y el mayor porcentaje de PEA rural con 13 años o más de estudio $(12,9 \%)$ (véase el gráfico I.10).

\section{Gráfico I.10}

Centroamérica y la República Dominicana: distribución de la población económicamente activa (PEA) rural de 15 años y más, según años de instrucción, 2014 o último año disponible (En porcentajes)

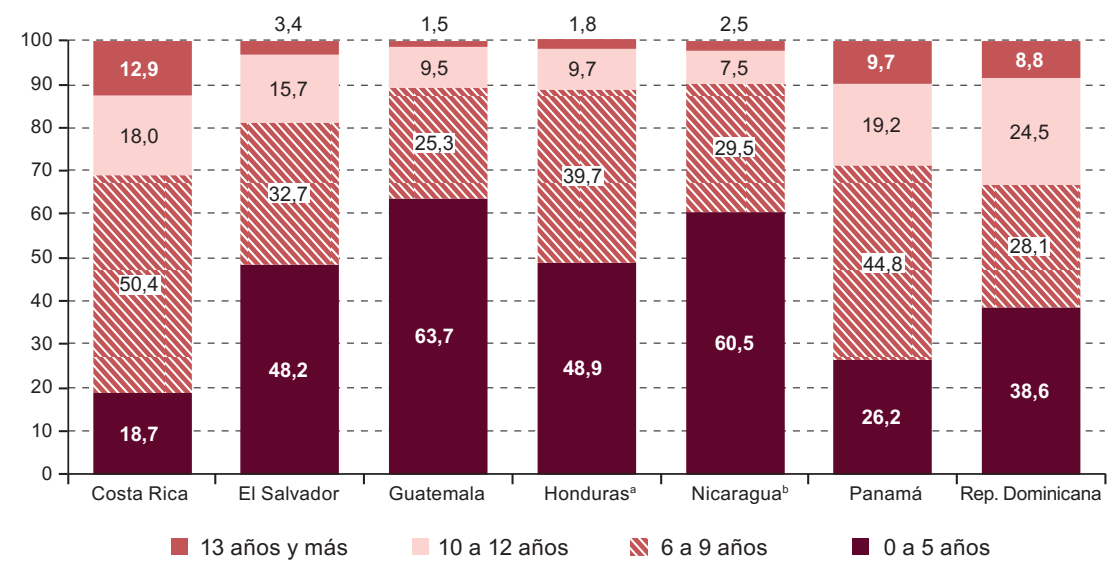

Fuente: Comisión Económica para América Latina y el Caribe (CEPAL), "CEPALSTAT. Bases de Datos y Publicaciones Estadísticas”, 2016 [en línea] http://estadisticas.cepal.org/cepalstat/WEB_ CEPALSTAT/Portada.asp.

a El último año disponible para Honduras es 2013.

b El último año disponible para Nicaragua es 2009.

La deserción en los niveles primario y secundario es otro de los desafíos de la educación en el espacio rural de la subregión. En el estudio de Adelman y Székely (2016) se identificó a los niveles de pobreza, 
ruralidad y pertenencia a un grupo indígena como factores relacionados con el nivel de deserción de las escuelas en Centroamérica. De igual forma, la demanda de fuerza de trabajo poco calificada (en actividades rurales menos dinámicas, como la agricultura, la maquila o el comercio informal) y los niveles de ingreso empujan la deserción de los jóvenes, que prefieren insertarse en el mercado laboral en el corto plazo antes que continuar con sus estudios.

En las actividades económicas del espacio rural, la calificación de la fuerza laboral es menor que en las áreas urbanas y la brecha de los ingresos varía con respecto al nivel de instrucción. En el sector agropecuario, los ocupados que cuentan con entre 0 y 5 años de educación y entre 6 y 9 años de educación ganaron solo un $17 \%$ y un $21,8 \%$ de los ingresos de los ocupados con 13 años o más de educación, respectivamente, frente al $23,9 \%$ y el 32,9\% de los ingresos de los ocupados con 13 años o más en las áreas urbanas (Weller, 2016).

Otros factores que inciden en la elección de los jóvenes de permanecer en el sistema escolar son los embarazos, el crimen y la violencia, así como el nivel de ingreso de los hogares. Las brechas en infraestructura educativa entre áreas rurales y urbanas también determinan los costos y beneficios de continuar con la instrucción educativa (Adelman y Székely, 2016).

Además de la educación formal, la capacitación en el medio laboral posibilita el desarrollo de competencias y habilidades no obtenidas en el sistema educativo. Si bien no sustituye a la educación formal, debido al avance acelerado de las tecnologías y los cambios en la estructura productiva, la capacitación laboral es un instrumento de igual importancia para invertir en el capital humano y con implicaciones en términos de un aumento de la productividad en las actividades económicas (Llisterri y otros, 2014; OIT, 2014; López Acevedo y Tan, 2010).

Un primer reto en Centroamérica y la República Dominicana es ampliar la cobertura rural de los institutos que ejecutan programas para la capacitación de recursos humanos. En un informe de la Organización Internacional del Trabajo (2014), se dio cuenta de que un gran número de las unidades de atención y la matrícula en ellas inscrita se encuentran ubicadas en las zonas urbanas, las ciudades principales y las capitales de los países de la subregión ${ }^{18}$. La heterogeneidad de

Por ejemplo, el Instituto Nacional de Aprendizaje (INA) de Costa Rica cuenta con 9 unidades regionales y 60 centros ejecutores, más de la mitad ubicados en el área central del país y con una concentración del 58,3\% de la matrícula atendida. El Instituto Nacional de Formación Profesional (INFOP) de Honduras cuenta con cuatro sedes regionales y ocho Centros Familiares Educativos para el Desarrollo de Honduras (CEFEDH) en la zona rural, pero el centro principal ubicado en Tegucigalpa concentra gran parte de la oferta formativa. El Instituto Nacional de Formación Profesional y Capacitación para el Desarrollo Humano (INADEH) de Panamá 
los mercados laborales, el proceso de diversificación de las economías rurales y las necesidades particulares inciden en las áreas o sectores en que se matriculan las personas, por lo que es necesario contar con programas de capacitación útiles en función de los cambios en la estructura productiva del espacio rural.

\section{Actividades de innovación}

Los países de Centroamérica y la República Dominicana en general tienen una baja actividad innovadora. De acuerdo con el Índice Mundial de Innovación 2016 de la Organización Mundial de la Propiedad Intelectual (OMPI), al analizar indicadores relacionados con la innovación en 7 componentes (instituciones, capital humano, sofisticación del mercado, sofisticación de los negocios, productos tecnológicos y de conocimiento, y productos creativos), de un total de 128 países examinados, se encontró que los países de Centroamérica (excepto Costa Rica) y la República Dominicana están entre los menos innovadores. Nicaragua tiene la actividad innovadora más baja (ocupa la posición 116), seguido por El Salvador (104), Honduras (101) y Guatemala (97). La República Dominicana (76), Panamá (68) y Costa Rica (45) fueron las economías mejor calificadas de la subregión.

En la subregión existe un vacío de información divulgada sobre las actividades de innovación a nivel rural. Solo Costa Rica, El Salvador, Panamá y la República Dominicana han realizado encuestas de innovación, pero estas se han orientado a la industria y los servicios. Entre los resultados que arrojan estas encuestas se pueden destacar algunos elementos comunes. Por ejemplo, solo entre el 30\% y el $50 \%$ de las empresas informaron haber realizado alguna innovación o consideran a la innovación como una estrategia de su organización. En todos los casos sobresale una mayor proporción de innovaciones en proceso, generalmente de tipo incremental, imitativo o no radical. Más del $90 \%$ de las empresas no tienen departamentos formales de investigación y desarrollo (I+D). Muchas de las empresas de la subregión que forman parte de la industria manufacturera operan en el sector agroindustrial. Las actividades de innovación recabadas por las encuestas pueden reflejar el comportamiento de este tipo de empresas, pero las empresas de este sector no necesariamente se ubican en áreas definidas como rurales.

En el cuadro I.5 se muestran algunos indicadores de ciencia y tecnología en el sector agropecuario. En la mayoría de los países de Centroamérica (excepto Costa Rica) y la República Dominicana, el

tiene 22 centros en diferentes zonas del país, pero la matrícula se concentra en el área central (Tocumen y Chorrera en Ciudad de Panamá concentran el 45,5\% de la matrícula) (OIT, 2014). 
presupuesto destinado a actividades de investigación y desarrollo agropecuario como porcentaje del PIB agropecuario es reducido en comparación con lo que ocurre en otros casos (como Chile o México). Si se considera a Centroamérica y la República Dominicana, se constata que el país que más gasto destina a investigación y desarrollo es Costa Rica (un 1,1\% del PIB agropecuario en 2012), mientras que el país con menor participación en este rubro es Guatemala (un 0,1\% del PIB agropecuario en 2012). Cabe destacar que el gasto en investigación y desarrollo agropecuario en relación con el PIB es superior al gasto en investigación y desarrollo total. Por ejemplo, en Costa Rica (2012), el gasto en investigación y desarrollo en relación con el PIB total fue del 0,57\%, en Guatemala ascendió al 0,04\%, y en El Salvador alcanzó el 0,03\% (RICYT, 2016).

\section{Cuadro I.5}

Centroamérica y la República Dominicana: indicadores de ciencia y tecnología en el sector agropecuario (En porcentajes y personas)

\begin{tabular}{|c|c|c|c|c|c|c|c|c|c|c|c|c|}
\hline \multirow[t]{2}{*}{ País } & \multicolumn{3}{|c|}{$\begin{array}{c}\text { Gasto en } \\
\text { investigación } \\
\text { y desarrollo } \\
\text { agropecuario } \\
\text { (en porcentajes del } \\
\text { PIB agropecuario) }\end{array}$} & \multicolumn{3}{|c|}{ Investigadores } & \multicolumn{3}{|c|}{$\begin{array}{l}\text { Investigadores } \\
\text { por millón de } \\
\text { habitantes }\end{array}$} & \multicolumn{3}{|c|}{$\begin{array}{c}\text { Investigadores } \\
\text { por cada } \\
100000 \text { productores }\end{array}$} \\
\hline & 2000 & 2006 & 2012 & 2000 & 2006 & 2012 & 2000 & 2006 & 2012 & 2000 & 2006 & 2012 \\
\hline Costa Rica & 0,8 & 0,8 & 1,1 & 248,2 & 252,6 & 241,5 & 63,2 & 57,5 & 50,3 & 75,9 & 77,0 & 75,9 \\
\hline El Salvador & 0,2 & 0,2 & $\ldots$ & 106,0 & 76,9 & $\ldots$ & 17,8 & 12,6 & $\ldots$ & 16,0 & 12,4 & $\ldots$ \\
\hline Guatemala & 0,1 & 0,1 & 0,1 & 111,1 & 119,8 & 141,8 & 9,9 & 9,2 & 9,4 & 7,5 & 6,2 & 6,6 \\
\hline Honduras & 0,3 & 0,2 & 0,2 & 76,4 & 68,9 & 87,6 & 12,3 & 9,8 & 11,0 & 10,4 & 10,1 & 13,2 \\
\hline Nicaragua & $\ldots$ & $\ldots$ & 0,4 & $\ldots$ & $\ldots$ & 131,5 & $\ldots$ & $\ldots$ & 21,9 & $\ldots$ & $\ldots$ & 38,1 \\
\hline Panamá & 0,6 & 0,5 & 0,7 & 117,6 & 149,0 & 133,0 & 38,5 & 43,4 & 35,0 & 43,9 & 56,0 & 51,9 \\
\hline $\begin{array}{l}\text { República } \\
\text { Dominicana }\end{array}$ & $\ldots$ & 0,5 & 0,3 & $\ldots$ & 131,3 & 199,6 & $\ldots$ & 13,8 & 19,4 & $\ldots$ & 26,2 & 45,1 \\
\hline Chile & 1,4 & 1,5 & 1,8 & 610,9 & 665,5 & 695,6 & 39,5 & 40,3 & 39,8 & 63,4 & 67,6 & 72,5 \\
\hline México & 1,0 & 1,1 & 1,0 & 3620,7 & 3723,8 & 3988,6 & 34,9 & 33,2 & 33,0 & 40,1 & 43,3 & 50,4 \\
\hline
\end{tabular}

Fuente: Indicadores de Ciencia y Tecnología Agropecuaria (ASTI), "Datos y análisis de libre acceso sobre inversión y capacidad de investigación agropecuaria en países de bajo y mediano ingreso", 2017 [en línea] http://asti.cgiar.org/es.

La disponibilidad de recursos humanos para ciencia y tecnología es variable. Costa Rica $(75,9)$, Panamá $(51,9)$ y la República Dominicana $(45,1)$ cuentan con un mayor número de estos recursos humanos por cada 100.000 productores, mientras que en Guatemala solo hay 6,6 investigadores por cada 100.000 productores (2012) (véase el cuadro I.5). La mayoría de los investigadores del sector agropecuario en la subregión cuenta con formación a nivel de licenciatura y en menor 
medida con estudios de posgrado. Un 33,9\% de los investigadores en el sector agropecuario de Costa Rica contaba con estudios de doctorado en 2012. En Guatemala, Nicaragua y Panamá esta cifra fue del 13,6\%, el 11,6\% y el 10\%, respectivamente. En Honduras, el 5\% de los investigadores relacionados con el sector agropecuario cuenta con esta formación (ASTI, 2017).

En materia de ciencia, tecnología e innovación, un desafío es fortalecer los sistemas de innovación agroproductivos (SIA) ${ }^{19}$. Estos sistemas derivan del marco de los sistemas nacionales de innovación, pero incluyen a actores específicos del sector e interacciones entre ellos para generar actividades de innovación y lanzamiento de nuevos productos agropecuarios y agroindustriales al mercado en un marco institucional común (Padilla, 2013).

Una de las fortalezas de la subregión es que cuenta con capacidades institucionales embrionarias en materia de ciencia, tecnología e innovación. Todos los países tienen un ministerio de agricultura y organismos nacionales de ciencia y tecnología. Entre estos dos actores se promueven las actividades en ciencia, tecnología e innovación en el sector. En los ministerios de agricultura de la mayoría de los países también se gestionan programas públicos de desarrollo rural. Otros actores de los sistemas de innovación agroproductivos son las universidades y los centros tecnológicos para la formación de recursos humanos especializados. Las instituciones puente $\mathrm{u}$ organizaciones intermediarias de innovación ayudan a reducir la incertidumbre al conectar a diferentes actores del sistema a fin de facilitar el intercambio y el flujo de conocimientos e información. La subregión tiene una importante presencia de organismos de cooperación internacional, asociaciones civiles y organizaciones no gubernamentales, y cuenta con centros de investigación y desarrollo públicos que apoyan al sector. Los siguientes son algunos de los desafíos que enfrentan las organizaciones de este tipo: capacidades insuficientes para realizar investigaciones complejas, poca interacción entre estos actores y el sector productivo, escasas interconexiones con las universidades y carencias para el financiamiento de las actividades (Padilla, Gaudín y Parra, 2013).

Las actividades de innovación son limitadas en el sector agropecuario de los países en desarrollo y en su lugar se tiende a adaptar e incorporar tecnología existente. El extensionismo tiene por

19 El término es utilizado por Padilla (2013). Otros conceptos similares son: sistemas nacionales de innovación del sector agropecuario (Vera-Cruz y Dutrénit, 2016) o sistemas nacionales de innovación agrícola (OCDE, 2013). La diferencia entre estos términos radica en las actividades que se incluyen, si únicamente corresponden al sector agropecuario o si abarcan las actividades de agroindustria y otros servicios relacionados. 
objeto transferir la tecnología y las mejores prácticas en las actividades económicas rurales (Swanson, 2010). De acuerdo con un informe sobre servicios de extensión en Centroamérica y la República Dominicana, se estima que la cobertura de estos servicios alcanza a entre el 15\% y el $40 \%$ de los productores. Los servicios de extensión se enfocan en la transferencia de tecnología hacia segmentos de la agricultura familiar mediante el trabajo con modelos como la promoción rural, las escuelas de campo de agricultores (ECA) y el modelo de visita y capacitación. En el mismo estudio se da cuenta de que otro de los desafíos del extensionismo es la conformación de equipos interdisciplinarios y la superación de la visión vertical de capacitación y visitas. Se ha sugerido fomentar la aplicación de metodologías con un enfoque participativo, tomando en cuenta las diferencias y necesidades de los distintos tipos de productores (FAO, 2014).

De acuerdo con el Índice Global de Emprendimiento 2017, la economía más emprendedora de la subregión es Costa Rica y la que presenta más desafíos es Nicaragua (GEDI, 2016). Panamá es la economía con más empresas nuevas registradas y el país donde los trámites para abrir una empresa son más rápidos y los costos son más bajos. En Costa Rica, a pesar de que los costos para abrir una empresa son más bajos (un 9,1\% del ingreso nacional bruto per cápita), la duración del trámite es mayor (22,5 días). En El Salvador (15,5 días), Guatemala (19,5 días), Honduras (13 días) y Nicaragua (13 días), si bien se necesitan menos días que en Costa Rica para abrir una empresa, los costos son más altos (un $40,7 \%, 24,1 \%$, 41,1\% y $68 \%$ del ingreso nacional bruto per cápita, respectivamente) (Banco Mundial, 2016) ${ }^{20}$. Esto se amplifica en el espacio rural debido a factores como la distancia a las cabeceras donde se concentran las dependencias que realizan los trámites jurídicos, los costos de transporte y transacción, el acceso a información, la ausencia de asesoría y capacitación, las opciones de financiamiento y el nivel de ingresos de la población.

\section{Financiamiento}

El crédito agropecuario como porcentaje del crédito total ha disminuido en las últimas dos décadas en casi todos los países de Centroamérica y la República Dominicana. En 2015, Nicaragua (12\%) y Honduras (7\%) fueron las economías con un mayor porcentaje del crédito agropecuario con respecto al crédito total en la subregión. En el resto de las economías de la subregión, este porcentaje se situó por debajo del 5\% (CEPAL, 2016a).

20 Último año disponible. 
El descenso de la participación de la banca de desarrollo es un factor que explica esta situación.

En Centroamérica y la República Dominicana, las entidades financieras de mayor tamaño y con más recursos para atender la demanda se encuentran ubicadas en áreas urbanas. En el espacio rural, en cambio, operan otras entidades de menor tamaño, que enfrentan mayores desafíos, como la falta de tecnología especializada, la menor calificación de los recursos humanos y la ausencia de instrumentos para mitigar riesgos, además de contar con marcos legales de regulación insuficientes (Valenzuela y Cruz, 2017; Vásquez y otros, 2016; Reyes, 2016; Argumedo, 2016).

El microcrédito ha sido un instrumento clave para financiar las actividades productivas en el espacio rural. Se destaca el trabajo de las microfinancieras en las zonas rurales de Centroamérica y la República Dominicana. La existencia de estas entidades se debe a que los esquemas de financiamiento de la banca comercial excluyen a las unidades productivas de menor tamaño establecidas en poblaciones más remotas, con pocas garantías y que, en general, representan un riesgo. De acuerdo con información de las asociaciones de microfinancieras, en Centroamérica y la República Dominicana, en 2014 el 46,8\% de su cartera era rural y el 50,3\% de sus clientes se ubicaron en estas áreas. La República Dominicana y Panamá son los países con un menor porcentaje de cartera y clientes rurales. Por el contrario, Nicaragua es el país con mayor participación de las microfinancieras en el espacio rural (véase el cuadro I.6).

Cuadro I.6

Centroamérica y la República Dominicana: participación del crédito rural en el crédito total de las organizaciones de microfinanzas, 2014 (En porcentajes del crédito total)

\begin{tabular}{lcccccccc}
\hline & $\begin{array}{c}\text { REDCAMIF } \\
\text { (total) }\end{array}$ & $\begin{array}{c}\text { REDCOM } \\
\text { (Costa } \\
\text { Rica) }\end{array}$ & $\begin{array}{c}\text { ASOMI } \\
\text { (El Salvador) }\end{array}$ & $\begin{array}{c}\text { REDIMIF } \\
\text { (Guatemala) }\end{array}$ & $\begin{array}{c}\text { REDMICROH } \\
\text { (Honduras) }\end{array}$ & $\begin{array}{c}\text { ASOMIF } \\
\text { (Nicaragua) }\end{array}$ & $\begin{array}{c}\text { REDPAMIF } \\
\text { (Panamá) }\end{array}$ & $\begin{array}{c}\text { REDOMIF } \\
\text { (República } \\
\text { Dominicana) }\end{array}$ \\
\hline $\begin{array}{l}\text { Cartera } \\
\text { rural }\end{array}$ & 46,8 & 74,9 & 56,9 & 73,3 & 49,7 & 54,9 & 5,0 & 13,2 \\
\hline $\begin{array}{l}\text { Clientes } \\
\text { rurales }\end{array}$ & 50,3 & 70,9 & 54,7 & 52,8 & 51,8 & 80,4 & 17,2 & 24,2 \\
\hline
\end{tabular}

Fuente: Red Centroamericana y del Caribe de Microfinanzas (REDCAMIF), Revista Microfinanzas de Centroamérica y del Caribe, $\mathrm{N}^{\circ}$ 22, pág. 7, 2014.

Se debe reconocer la existencia de otras iniciativas nacionales para la inclusión financiera rural en las cuales, además del microcrédito, también son importantes otros productos y servicios, como los seguros 
agropecuarios. En Centroamérica y la República Dominicana existen entidades públicas y privadas que ofrecen este tipo de servicios. Por ejemplo, en el Salvador, el Banco de Fomento Agropecuario (BFA) cuenta con una línea de crédito avío para incentivar el cultivo de granos básicos que incluye un seguro por pérdidas. La limitada participación de este tipo de entidades con una orientación de gestión integral de riesgos aún supone un desafío (CEPAL/CAC/SICA, 2013). En las estrategias nacionales de inclusión financiera que incorporen este tipo de instrumentos será clave la participación de múltiples actores, incluidos los ministerios de agricultura, las aseguradoras, las entidades financieras y las asociaciones de crédito, así como otras organizaciones nacionales e internacionales.

La subregión enfrenta el reto de fortalecer los esquemas de servicios financieros, tanto en la cobertura de clientes en el espacio rural, como en la diversificación de productos y servicios financieros rurales (créditos, microcréditos, seguros agropecuarios, depósitos, almacenaje, garantías, fianzas y seguros agropecuarios), para atender a segmentos excluidos por los esquemas tradicionales de la banca comercial.

\section{Cadenas de valor}

Una cadena de valor comprende las distintas actividades necesarias para que un bien o servicio llegue al consumidor final, desde la concepción, pasando por las etapas de procesamiento y comercialización (Kaplinsky y Morris, 2002). Todo productor, por pequeño que sea, pertenece a una cadena de valor, desde el momento que compra insumos y comercializa sus excedentes, aunque sea de manera informal.

El desafío en este campo es el fortalecimiento de las cadenas, lo que demanda un escalamiento económico de los eslabones y una mejor articulación entre ellos, así como entre los actores que los componen. En el capítulo III se presenta la metodología para el fortalecimiento de las cadenas y se ofrece un marco conceptual más detallado. En el cuadro I.7 se presentan ejemplos de las restricciones que enfrentan las cadenas de valor rurales de la subregión para su fortalecimiento. Cabe señalar que estas restricciones son más significativas en las unidades productivas de menor tamaño ${ }^{21}$.

21 Como se ha señalado en el estudio de Fernández-Stark y Bamber (2012), las unidades productivas de tamaño pequeño y mediano no son homogéneas, y, aunque la mayoría enfrenta mayores restricciones, también dependen de la formación, el nivel socioeconómico y la experiencia acumulada. 


\section{Cuadro I.7 \\ Centroamérica y la República Dominicana: ejemplos de restricciones por eslabón en cadenas de valor rurales}

\begin{tabular}{|c|c|}
\hline Eslabón & Restricción \\
\hline Provisión de insumos & $\begin{array}{l}\text { - Oferta limitada de proveedores de insumos } \\
\text { - Costos elevados de los insumos } \\
\text { - Ausencia de asistencia técnica en los insumos utilizados }\end{array}$ \\
\hline Producción & $\begin{array}{l}\text { - Falta de financiamiento } \\
\text { - Escaso o nulo acceso a capacitación y asistencia técnica } \\
\text { - Manejo inadecuado de recursos y control de calidad } \\
\text { - Falta de infraestructura, equipo y tecnología } \\
\text { - Bajos niveles de educación de los recursos humanos } \\
\text { - Dificultades para la asociatividad y articulación } \\
\text { - Problemas para generar economías de escala } \\
\text { - Escasa o nula innovación } \\
\text { - Poca vinculación con otros actores de la cadena } \\
\text { - Escasa alineación de los programas de producción con las } \\
\text { demandas de otros segmentos de la cadena }\end{array}$ \\
\hline Procesamiento & $\begin{array}{l}\text { - Falta de financiamiento } \\
\text { - Falta de infraestructura, equipo y tecnología } \\
\text { - Problemas en el cumplimiento de estándares de calidad, } \\
\text { trazabilidad y buenas prácticas } \\
\text { - Falta de capacitación } \\
\text { - Problemas para generar economías de escala } \\
\text { - Escasa innovación } \\
\text { - Bajos niveles de experiencia y formación de los recursos humanos }\end{array}$ \\
\hline Comercialización & $\begin{array}{l}\text { - Poco o nulo acceso a información de mercado (precios, canales } \\
\text { de distribución, condiciones de oferta y demanda) } \\
\text { - Debilidad en el poder de negociación y presencia de intermediarios } \\
\text { - Limitadas capacidades empresariales (gerenciales y comerciales) } \\
\text { - Elevados costos de transacción (por ejemplo, en la distribución) } \\
\text { - Falta de equipo de transporte en condiciones adecuadas } \\
\text { - Desconocimiento de estrategias de promoción y ventas } \\
\text { - Falta de vinculación con compradores }\end{array}$ \\
\hline
\end{tabular}

Fuente: Elaboración propia, sobre la base de S. Garry y R. Martínez, "Fortalecimiento de la cadena de turismo en el departamento de La Libertad, El Salvador", Documentos de Proyectos (LC/MEX/W.18), Ciudad de México, Sede Subregional de la CEPAL en México, 2016; N. Oddone y P. Alarcón, "Fortalecimiento de la cadena de turismo de Antigua Guatemala y de los municipios rurales del Departamento de Sacatepéquez", Documentos de Proyectos (LC/MEX/W.15), Ciudad de México, Sede Subregional de la CEPAL en México, 2016; R. Padilla y M. Cordero, "La creación de una cadena de valor: los chips fritos al vacío en Costa Rica", 2016, inédito; I. Romero, V. Díaz y A. Aguirre, "Fortalecimiento de la cadena de valor de los snacks nutritivos con base en fruta deshidratada en El Salvador", Documentos de Proyectos (LC/MEX/W.16), Ciudad de México, Sede Subregional de la CEPAL en México, 2016; N. Oddone y C.S. Beltrán, "La cadena del camarón de cultivo en El Salvador", Fortalecimiento de las cadenas de valor como instrumento de la política industrial. Metodología y experiencia de la CEPAL en Centroamérica, R. Padilla (ed.), Libros de la CEPAL, N 123 (LC/G.2606-P), Santiago, Comisión Económica para América Latina y el Caribe (CEPAL), 2014; M. Cordero, "Cadena de hortalizas de exportación no tradicionales en Guatemala", Fortalecimiento de las cadenas de valor como instrumento de la política industrial. Metodología y experiencia de la CEPAL en Centroamérica, R. Padilla (ed.), Libros de la CEPAL, N 123 (LC/G.2606-P), Santiago, Comisión Económica para América Latina y el Caribe (CEPAL), 2014; Instituto Interamericano de Cooperación para la Agricultura (IICA)/RED SICTA, Cadenas de valor de maíz blanco y frijol en Centroamérica. Actores, problemas y acciones para su competitividad, San José, 2014; P. Bamber y K. Fernández-Stark, Desarrollo de micro y pequeños productores apícolas rurales en Nicaragua y Honduras, Fondo Multilateral de Inversiones (FOMIN), 2012; Asociación Guatemalteca de Exportadores (AGEXPORT), Estudio de la cadena de valor de la cebolla en el Municipio de Sacapulas, Departamento de Quiché, Guatemala, Agencia de los Estados Unidos para el Desarrollo Internacional (USAID)/Asociación Guatemalteca de Exportadores (AGEXPORT), 2014. 
Además de las restricciones por eslabón, las cadenas pueden enfrentar desafíos sistémicos, es decir, los que tienen un impacto en su conjunto (por ejemplo, fallas en el marco institucional, bajos niveles de inversión pública y privada, o retos en materia macroeconómica).

Como se aborda en detalle en el capítulo III, de manera conceptual y metodológica, y en los capítulos V y VI, de manera empírica, el enfoque de cadenas permite realizar un análisis transversal que abarca diversas áreas que ya fueron identificadas en este capítulo: financiamiento, innovación, capacitación y comercialización y otras. Uno de los aportes centrales es el diseño de estrategias integrales y coordinadas que abordan los desafíos en las diversas etapas de la producción.

\section{F. Conclusiones}

El espacio rural de Centroamérica y la República Dominicana enfrenta diversos desafíos en materia de desarrollo productivo. A continuación se presenta un breve resumen.

En materia institucional, el sistema normativo que regula la estructura de la propiedad de la tierra y el desarrollo histórico de las estructuras económicas y sociales en el espacio rural han mantenido la concentración de la superficie de la tierra. Esta es una de las principales causas del escaso desarrollo productivo de las actividades agropecuarias y de las pocas posibilidades de encadenamiento con otras actividades económicas. El centralismo dificulta la atención pública que requiere el espacio rural de Centroamérica y la República Dominicana.

En materia de sostenibilidad ambiental, se necesitan medidas de adaptación a los efectos del cambio climático — como los eventos extremos (de origen hidrológico y meteorológico) y las afectaciones a los recursos hídricos (exceso y déficit) - que tengan un impacto en las actividades productivas rurales. En cuanto a la mitigación, son necesarias medidas y acciones para el desacoplamiento paulatino de las emisiones de carbono. Aunque las emisiones de gases de efecto invernadero de la subregión son menores en comparación con las de otras subregiones, este reto está ligado a la transformación productiva rural.

En materia de comercialización, los productores rurales son vulnerables al comportamiento variable de los precios internacionales de los productos agropecuarios. Otro desafío es el acceso a los mercados internacionales. Si bien hay una participación importante de las exportaciones agroalimentarias en las exportaciones totales, estas pueden escalarse hacia actividades más dinámicas e intensivas en conocimiento, y los socios comerciales pueden diversificarse. Se debe considerar al comercio intrarregional como una oportunidad para aprovechar las complementariedades entre los países de la subregión. Por otra parte, a 
nivel local persiste el reto de la debilidad en cuanto al poder de negociación de las unidades productivas de menor tamaño. El surgimiento de la figura de los intermediarios es consecuencia de esta debilidad.

En materia de productividad e innovación, uno de los principales desafíos es incrementar la productividad de las actividades económicas del espacio rural. Entre las dimensiones relacionadas con los niveles de productividad se identifica el desafío que supone el tamaño de las unidades productivas y el desempeño tecnológico. El bajo nivel de instrucción de la población rural es otra de las dimensiones recuperadas. La capacitación es un instrumento para invertir en la formación de los recursos humanos en el espacio rural. Es sugerente la falta de indicadores e información divulgada sobre ciencia, tecnología e innovación, sobre todo para actividades no agropecuarias. Si bien las actividades de innovación no son la generalidad, en ciertos sectores, como el agropecuario, se cuenta con un sistema de innovación agroproductivo incipiente. Un desafío del financiamiento rural consiste en ampliar los esquemas de servicios financieros en términos de cobertura de clientes y productos financieros a fin de atender a segmentos excluidos en el medio rural. Por último, las restricciones identificadas para el fortalecimiento de las cadenas de valor se complementan con los desafíos expuestos. El enfoque de cadenas de valor es transversal y es un instrumento muy útil para analizar los vínculos y complementariedades entre actores, sectores, regiones o naciones.

Aunque es difícil hacer generalizaciones dada la heterogeneidad de la subregión, se identifican dos comportamientos. Por una parte, Guatemala, Honduras y Nicaragua enfrentan los mayores desafíos en materia de desarrollo productivo, y, por la otra, Costa Rica, Panamá y la República Dominicana han tenido una mayor transformación rural. El Salvador es una economía con un comportamiento que oscila entre estos dos tipos de realidades. En cada país existen especificidades y tratar de entender la realidad rural en la subregión requiere de más de un diagnóstico. Una de las áreas de mejora identificadas es la necesidad de contar con más información a nivel rural. Si bien para analizar lo rural existen datos disponibles, sobre todo de las actividades del sector agropecuario, es necesario contar con información divulgada que apoye el análisis de otros sectores y actividades no agropecuarias en el espacio rural.

Se debe reconocer que el análisis aquí presentado se enfocó en identificar los principales desafíos en materia de desarrollo productivo, pero en el análisis de lo rural existen otras áreas (como el desarrollo social) que dan cuenta de los múltiples desafíos que enfrenta la subregión.

Por último, en Centroamérica y la República Dominicana es clave recuperar la atención de los Gobiernos y de los instrumentos de política pública para fortalecer la estructura productiva del espacio rural. Como se plantea en el capítulo II, las políticas agropecuarias y de desarrollo rural deben complementarse con una política industrial rural que reconozca los cambios recientes en el espacio rural y la importancia de la transformación productiva. 


\section{Bibliografía}

Adelman, M. y M. Székely (2016), "School dropout in Central America. An overview of trends, causes, consequences, and promising interventions", Policy Research Working Paper, N 7561, Washington, D.C., Banco Mundial.

AGEXPORT (Asociación Guatemalteca de Exportadores) (2014), Estudio de la cadena de valor de la cebolla en el Municipio de Sacapulas, Departamento de Quiché, Guatemala, Agencia de los Estados Unidos para el Desarrollo Internacional (USAID) / Asociación Guatemalteca de Exportadores (AGEXPORT).

(2012), Informe trimestral de avances. Proyecto cadenas de valor rurales, Guatemala, Agencia de los Estados Unidos para el Desarrollo Internacional (USAID)/ Asociación Guatemalteca de Exportadores (AGEXPORT).

Angulo, J. y A. Mata (2008), MIPYMES, agrocadenas y aprovechamiento del CAFTA en Centroamérica: análisis de los sectores lácteo, cerdo, pollo, maíz blanco y hortalizas bajo un enfoque de organización industrial, San José.

Argumedo, P. (2016), "Inclusión financiera de pequeños productores rurales. Estudio de caso en El Salvador", Documentos de Proyectos (LC/MEX/W.21), Ciudad de México, Sede Subregional de la CEPAL en México.

ASTI (Indicadores de Ciencia y Tecnología Agropecuaria) (2017), “Datos y análisis de libre acceso sobre inversión y capacidad de investigación agropecuaria en países de bajo y mediano ingreso" [en línea] http:/ / asti.cgiar.org/es.

Bamber, P. y K. Fernández-Stark (2012), Desarrollo de micro y pequeños productores apícolas rurales en Nicaragua y Honduras, Fondo Multilateral de Inversiones (FOMIN).

BancoMundial(2016), “DatosdelibreaccesodelBancoMundial”[enlínea]http:/ / datos. bancomundial.org/.

Barea, F. (1994), La reforma agraria en el Istmo centroamericano y República Dominicana durante el período 1986-1991, San José, Instituto Interamericano de Cooperación para la Agricultura (IICA).

Baumeister, A. (2013), Concentración de tierras y seguridad alimentaria en Centroamérica, Roma, Coalición Internacional para el Acceso a la Tierra (ILC)/Fondo de Desarrollo Noruego.

Berdegué, J. y otros (2013), Agricultura y desarrollo en América Latina: gobernanza y políticas públicas, Buenos Aires, Teseo.

Bonnal, P. y otros (2004), "Multifuncionalidad de la agricultura y la nueva ruralidad: ¿reestructuración de las políticas públicas a la hora de la globalización?", Desarrollo rural y nueva ruralidad en América Latina y la Unión Europea, E. Pérez y M. Farah, Bogotá, Pontificia Universidad Javeriana.

CBI (Centro para la Promoción de las Importaciones de Países en Desarrollo) (2012), "Cacao en Honduras. Análisis de la cadena de valor", Rotterdam, Ministerio de Relaciones Exteriores de los Países Bajos.

CELADE (Centro Latinoamericano y Caribeño de Demografía-División de Población de la CEPAL) (2016), "Estimaciones y proyecciones de población total, urbana y rural, y económicamente activa" [en línea] http:/ /www.cepal. org/es/estimaciones-proyecciones-poblacion-largo-plazo-1950-2100.

CEPAL(Comisión Económica para América Latina y el Caribe) (2016a), “CEPALSTAT. Bases de Datos y Publicaciones Estadísticas" [en línea] http://estadisticas. cepal.org/cepalstat/WEB_CEPALSTAT/Portada.asp.

(2016b), Horizontes 2030. La igualdad en el centro del desarrollo sostenible (LC/G.2660/Rev.1), Santiago, CEPAL. 
(2016c), Objetivos de Desarrollo Sostenible y retos del desarrollo rural en Centroamérica y la República Dominicana (LC/MEX/L.1205), Ciudad de México, Sede Subregional de la CEPAL en México.

(2015a), Observatorio Demográfico, 2015 (LC/G.2675-P), Santiago.

(2015b), Una mirada a los países del Proyecto Mesoamérica (LC/MEX/L.1183), Ciudad de México, Sede Subregional de la CEPAL en México.

(2011), La economía del cambio climático en Centroamérica. Reporte técnico 2011 (LC/MEX/L.1016), Ciudad de México, Sede Subregional de la CEPAL en México. (2010), La economía del cambio climático en Centroamérica. Sintesis 2010 (LC/MEX/L.978), Ciudad de México, Sede Subregional de la CEPAL en México. (2001), "La estructura agraria y el campesinado en el Salvador, Guatemala y Honduras" (LC/MEX/L.492), Ciudad de México, Sede Subregional de la CEPAL en México.

CEPAL/CAC/SICA (Comisión Económica para América Latina y el Caribe/ Consejo Agropecuario Centroamericano/Sistema de la Integración Centroamericana) (2013), Gestión integral de riesgos y seguros agropecuarios en Centroamérica y la República Dominicana: situación actual y líneas de acción potenciales (LC/MEX/L.1122), Ciudad de México, Sede Subregional de la CEPAL en México.

Chomitz, K., P. Buys y T. Thomas (2005), "Quantifying the rural-urban gradient in Latin America and the Caribbean", Policy Research Working Paper, $\mathrm{N}^{\circ} 3634$, Washington, D.C., Banco Mundial.

COMTRADE (Base de Datos Estadísticos de las Naciones Unidas sobre el Comercio de Productos Básicos) (2016) [en línea] http:/ / comtrade.un.org/data/.

Cordero, M. (2014), "Cadena de hortalizas de exportación no tradicionales en Guatemala", Fortalecimiento de las cadenas de valor como instrumento de la política industrial. Metodología y experiencia de la CEPAL en Centroamérica, R. Padilla (ed.), Libros de la CEPAL, No 123 (LC/G.2606-P), Santiago, Comisión Económica para América Latina y el Caribe (CEPAL).

CPDN (Contribuciones previstas determinadas a nivel nacional) (2017), "INDCSubmissions" [en línea] http://www4.unfccc.int/Submissions/INDC/ Submission\%20Pages/submissions.aspx.

Dirven, M. y otros (2011), "Hacia una nueva definición de "rural" con fines estadísticos en América Latina", Documentos de Proyectos (LC/W.397), Santiago, Comisión Económica para América Latina y el Caribe (CEPAL).

ECADERT (Estrategia Centroamericana de Desarrollo Rural Territorial) (2011), “Estrategia centroamericana de desarrollo rural territorial 2010-2030. Fondo Multiagencial para la ejecución de la ECADERT".

ECADERT/CAC/SICA (Estrategia Centroamericana de Desarrollo Rural Territorial/Consejo Agropecuario Centroamericano/Sistema de la Integración Centroamericana) (2010), Estrategia Centroamericana de Desarrollo Rural Territorial 2010-2030, San José, Instituto Interamericano de Cooperación para la Agricultura (IICA).

Echeverri, R. (2011), "Reflexiones sobre lo rural: economía rural, economía de territorios", Hacia una nueva definición de "rural" con fines estadísticos en América Latina, Documentos de Proyectos (LC/W.397), M. Dirven y otros, Santiago, Comisión Económica para América Latina y el Caribe (CEPAL).

Echeverri, R. y M. Ribero (2002), Nueva ruralidad visión del territorio en América Latina y el Caribe, Instituto Interamericano de Cooperación para la Agricultura (IICA). 
Edouard, F. (2010), Gobernanza en la tenencia de la tierra y recursos naturales en América Central, Roma, Organización de las Naciones Unidas para la Alimentación y la Agricultura.

EM-DAT (The International Disaster Database) (2016) [en línea] http:/ / www.emdat.be/. FAO (Organización de las Naciones Unidas para la Alimentación y la Agricultura) (2016a), "FAOSTAT" [en línea] http://www.fao.org/faostat/es/\#home. (2016b), AQUASTAT [en línea] http://www.fao.org/nr/water/aquastat/ data/query/results.html.

(2015), Evaluación de los recursos forestales mundiales 2015, Roma.

(2014), Estrategias de reformas institucionales en inversiones para los sistemas de extensión y transferencia de tecnología en Centroamérica y República Dominicana, Panamá.

(2012), Estudio de caracterización del Corredor Seco Centroamericano (Países CA-4), tomo I, Tegucigalpa.

(2010), "Aumento de precios en los mercados de alimentos", Informes de politica. Perspectivas económicas y sociales, Roma.

(2004), Política de desarrollo agrícola. Conceptos y principios, Roma.

Fernández-Stark, K., P. Bamber y G. Gereffi (2012), Inclusion of Small- and Mediumsized Producers in High-value Agro-food Value Chains, Center on Globalization, Governance and Competitiveness.

Fiallos, Á. (2007), "Las organizaciones de productores de Centroamérica y el diálogo sobre políticas públicas en el marco de los Tratados de Libre Comercio", Documento de Trabajo, $\mathrm{N}^{\circ}$ 24, San José, Proyecto RUTA.

FIDA (Fondo Internacional de Desarrollo Agrícola) (2011), Informe sobre la pobreza rural 2011, Roma.

Flores, M. y F. Rello (2002), Capital social rural. Experiencias de México y Centroamérica, Ciudad de México, Comisión Económica para América Latina y el Caribe (CEPAL)/Plaza y Valdes Editores.

Garry, S. y R. Martínez (2016), "Fortalecimiento de la cadena de turismo en el de partamento deLa Libertad,ElSalvador",Documentos deProyectos (LC/MEX/W.18), Ciudad de México, Sede Subregional de la CEPAL en México.

GEDI (Global Entrepreneurship and Development Institute) (2016), “Global entrepreneurship index" [en línea] https://thegedi.org/2016-globalentrepreneurship-index/.

Grandlgruber, B., H. García-Jiménez e I. Nazif (2014), Economía institucional: propuesta metodológica para el análisis de la formación de precios agrícolas (LC/MEX/L.1142), Ciudad de México, Sede Subregional de la CEPAL en México.

Hernández, R. (2001), “Elementos de competitividad sistémica de las pequeñas y medianas empresas (PYME) del Istmo Centroamericano", serie Estudios y Perspectivas, N 5 (LC/MEX/L.499), Ciudad de México, Sede Subregional de la CEPAL en México.

IICA (Instituto Interamericano de Cooperación para la Agricultura)/RED SICTA (2014), Cadenas de valor de maíz blanco y frijol en Centroamérica. Actores, problemas y acciones para su competitividad, San José.

Jansen, H. y J. Alwang (2006), “Concentración de la inversión pública en las zonas rurales de Centroamérica", Políticas públicas y desarrollo rural en América Latina y el Caribe: el papel del gasto público, F. Soto, J. Santos y J. Ortega, Santiago, Organización de las Naciones Unidas para la Alimentación y la Agricultura (FAO). 
Kaplinsky, R. y M. Morris (2002), A Handbook for Value Chain Research, Brighton, Institute of Development Studies.

Kay, C. (2009), "Estudios rurales en América Latina en el periodo de globalización neoliberal: ¿una nueva ruralidad?", Revista Mexicana de Sociología, vol. 71, N 4, Ciudad de México, Universidad Nacional Autónoma de México.

Kreft, S. y otros (2015), Global Climate Risk Index 2016. Who Suffers Most from Extreme Weather Events? Weather-related Loss Events in 2014 and 1995 to 2014, Berlín, GERMANWATCH.

Llisterri, J. y otros (2014), "Educación técnica y formación profesional en América Latina. El reto de la productividad", serie Políticas Públicas y Transformación Productiva, Banco de Desarrollo de América Latina.

López-Acevedo, G. y H. Tan (2010), Impact Evaluation of SME Programs in Latin America and Caribbean, Washington, D.C., Banco Mundial.

MAG (Ministerio de Agricultura y Ganadería) (2009), IV Censo Agropecuario 2007-2008. Resultados Nacionales [en línea] http://www.fao.org/fileadmin/ templates/ess/ess_test_folder/World_Census_Agriculture/Country_ info_2010/Reports/ESV_SPA_RES.REP_2008.pdf.

MAGA (Ministerio de Agricultura, Ganadería y Alimentación) (2015), Anuario estadístico de precios de productos e insumos agropecuarios, Guatemala.

MINEC (Ministerio de Economía) (2005), VII Censos Económicos 2005, tomo 1, San Salvador.

Naciones Unidas (2007), The Wye Group Handbook. Rural Households' Livelihood and Well Being. Statistics on Rural Development and Agriculture Household Income, Nueva York, Comisión Económica para Europa (CEPE)/Oficina Estadística de la Unión Europea (Eurostat)/ Organización de las Naciones Unidas para la Alimentación y la Agricultura (FAO)/Organización de Cooperación y Desarrollo Económicos (OCDE)/Banco Mundial.

OCDE (Organización de Cooperación y Desarrollo Económicos) (2013), Agricultural Innovation Systems. A Framework for Analysing the Role of the Government, París, OECD Publishing.

(2006), The New Rural Paradigm: Policies and Governance, París, OECD Publishing.

Oddone, N. y C.S. Beltrán (2014), "La cadena del camarón de cultivo en El Salvador", Fortalecimiento de las cadenas de valor como instrumento de la politica industrial. Metodología y experiencia de la CEPAL en Centroamérica, R. Padilla (ed.), Libros de la CEPAL, N 123 (LC/G.2606-P), Santiago, Comisión Económica para América Latina y el Caribe (CEPAL).

Oddone, N. y P. Alarcón (2016), “Fortalecimiento de la cadena de turismo de Antigua Guatemala y de los municipios rurales del Departamento de Sacatepéquez", Documentos de Proyectos (LC/MEX/W.15), Ciudad de México, Sede Subregional de la CEPAL en México.

Oddone, N. y otros (2016), "Fortalecimiento de la cadena de valor de tomate y chile verde dulce en El Salvador", Documentos de Proyectos, N 13 (LC/MEX/W.13), Ciudad de México, Sede Subregional de la CEPAL en México.

OEA (Organización de los Estados Americanos) (2016), "Sistema de Información sobre Comercio Exterior" [en línea] http:/ /www.sice.oas.org/Trade/CAFTA/ CAFTADR/CAFTADRin_s.asp. 
OIT (Organización Internacional del Trabajo) (2014), Situación de la formación profesional en Centroamérica y República Dominicana: 1998-2013, San José.

Padilla, R. (2014), Fortalecimiento de las cadenas de valor como instrumento de la politica industrial. Metodología y experiencia de la CEPAL en Centroamérica, R. Padilla (ed.), Libros de la CEPAL, No 123 (LC/G.2606-P), Santiago, Comisión Económica para América Latina y el Caribe (CEPAL).

(2013), "Sistemas de innovación en Centroamérica. Fortalecimiento a través de la integración regional", Libros de la CEPAL, $\mathrm{N}^{\circ} 118$ (LC/G.2559-P), Santiago, Comisión Económica para América Latina y el Caribe (CEPAL).

Padilla, R. y N. Odonne (2016), Manual para el fortalecimiento de cadenas de valor (LC/MEX/L.1218), Ciudad de México, Sede Subregional de la CEPAL en México.

Padilla, R. y M. Cordero (2016), “La creación de una cadena de valor: los chips fritos al vacío en Costa Rica", inédito.

Padilla, R., Y. Gaudin y R. Parra (2013), “Un enfoque sectorial: sistemas agroproductivos de innovación en Centroamérica", Sistemas de innovación en Centroamérica. Fortalecimiento a través de la integración regional, R. Padilla (ed.), Libros de la CEPAL, N ${ }^{\circ} 118$ (LC/G.2559-P), Santiago, Comisión Económica para América Latina y el Caribe (CEPAL).

Pérez, E. y M. Farah (2001), La nueva ruralidad en América Latina. Maestría en desarrollo rural 20 años, 2 vols., Bogotá, Pontificia Universidad Javeriana.

Pomareda, C. (2016), "Retos para el desarrollo productivo en el espacio rural en Centroamérica (Informe final)", San José.

Privado, M.A. (2016), “Una iniciativa urgente: Ley de Desarrollo Rural Integral” [en línea] http:/ / www.gt.undp.org/content/guatemala/es/home/ourperspective/ ourperspectivearticles / 2016/03/04/una-iniciativa-urgente-ley-de-desarrollorural-integral.html.

Programa Estado de la Nación (2016), Quinto Informe Estado de la Región en Desarrollo Humano Sostenible. Un informe desde Centroamérica y para Centroamérica, San José.

REDCAMIF (Red Centroamericana y del Caribe de Microfinanzas) (2014), Revista Microfinanzas de Centroamerica y del Caribe, $\mathrm{N}^{\circ} 22$.

(2005), "Servicios financieros rurales en Centroamérica. Con énfasis en actividades agropecuarias", Cuadernos de Microfinanzas, $\mathrm{N}^{\circ} 1$.

Reyes, R. (2016), “Inclusión financiera de pequeños productores rurales: estudio de caso en la República Dominicana", Documentos de Proyectos (LC/MEX/W.24), Ciudad de México, Comisión Económica para América Latina y el Caribe (CEPAL).

RICYT (Red de Indicadores de Ciencia y Tecnología) (2016) [en línea] http:/ / www.ricyt.org.

RIMISP (Centro Latinoamericano para el Desarrollo Rural) (2016), “Campañas de difusión - Grupos de Diálogo Rural” [en línea] http:/ / rimisp.org/contenido/ campana-de-difusion-grupos-de-dialogo-rural/.

Rodríguez, A. (2011), "Pertinencia y consecuencias de modificar los criterios para diferenciar lo urbano de lo rural", "Hacia una nueva definición de "rural" con fines estadísticos en América Latina", Documentos de Proyectos (LC/W.397), M. Dirven y otros, Santiago, Comisión Económica para América Latina y el Caribe (CEPAL).

Rodríguez, A., T. López y L. Meza (2015), "Innovaciones institucionales y en políticas sobre agricultura y cambio climático. Evidencia en América Latina y el Caribe", Documentos de Proyectos (LC/W.678), Santiago, Comisión Económica para América Latina y el Caribe (CEPAL). 
Romero, I., V. Díaz y A. Aguirre (2016), “Fortalecimiento de la cadena de valor de los snacks nutritivos con base en fruta deshidratada en El Salvador", Documentos de Proyectos (LC/MEX/W.16), Ciudad de México, Sede Subregional de la CEPAL en México.

RUTA-FAO (2006), “Las PYME agroindustriales en Centroamérica, perspectivas y retos.Mesa redondadeagroindustria",SanSalvador[enlínea] http:/ /www.food productenvision.com/index.php/docs/category/4-investigacion-y-desarrollo.

Swanson, B. (2010), Estudio mundial sobre buenas prácticas de los servicios de extensión y asesoramiento agropecuarios en el mundo, Roma, Organización de las Naciones Unidas para la Alimentación y la Agricultura (FAO).

Schejtman, A. y J. Berdegué (2004), Desarrollo territorial rural, Santiago, Centro Latinoamericano para el Desarrollo Rural (RIMISP).

SE-CMCA (Secretaría Ejecutiva del Consejo Monetario Centroamericano) (2016) [en línea] http:/ /www.secmca.org/simafir.html.

SIECA (Secretaría de Integración Económica Centroamericana) (2016), "Sistema de Estadísticas de Comercio de Centroamérica" [en línea] http:/ / estadisticas. sieca.int/.

SIGCI (Sistema Interactivo Gráfico de Datos de Comercio Internacional) (2014) [en línea] http:/ / www.cepal.org/comercio/ecdata2/.

Valenzuela, C. (2013), "Diagnóstico sectorial de las MIPYME no agrícola en Honduras" [en línea] http://www.mipyme.hn/images/leyes/diagnosticosectorial-de-la-MIPYME-no-agricola-en-honduras.pdf.

Valenzuela, C. y Cruz, D. (2017), "Estudio de caso sobre estrategias para promover la inclusión financiera en pequeños productores rurales en Honduras", Documentos de Proyectos (LC/MEX/W.22), Ciudad de México, Sede Subregional de la CEPAL en México.

Vásquez, J. y otros (2016), "Evolución reciente, situación actual y perspectivas de la inclusión financiera de pequeños productores rurales en Costa Rica", Documentos de Proyectos (LC/MEX/W.23), Ciudad de México, Sede Subregional de la CEPAL en México.

Vera-Cruz, A. y G. Dutrénit (2016), “Tendiendo puentes entre los actores del sistema de innovación del sector agropecuario: una introducción", Sistema de innovación del sector agropecuario en México. Tendiendo puentes entre los actores, A. Vera-Cruz y G. Dutrénit, Ciudad de México, Universidad Autónoma Metropolitana.

Weller, J. (2016), “Transformaciones y rezagos: la evolución del empleo agropecuario en América Latina, 2002-2012", serie Macroeconomía del Desarrollo, N 174 (LC/L.4209), Santiago, Comisión Económica para América Latina y el Caribe (CEPAL). 



\section{Capítulo II \\ Política industrial rural}

Ramón Padilla Pérez

Verónica Quiroz Estrada ${ }^{1}$

\section{Introducción}

El debate sobre la conveniencia y la necesidad de una política industrial se remonta, por lo menos, a los siglos XVII y XVIII y tiene sus orígenes en las discusiones entre mercantilistas y liberales. Los primeros pugnaban por la intervención del Estado mediante la regulación y el fomento del comercio internacional y el desarrollo productivo, mientras que los segundos abogaban por permitir que los mercados operaran libremente 2 . En América Latina, este debate tampoco es nuevo. La aceptación e implementación de la política industrial como un instrumento de desarrollo económico ha pasado por diversas etapas. En las últimas siete décadas, se transitó de la sustitución de importaciones (ISI), en la que el Estado desempeñó un papel central en la promoción del desarrollo productivo, a la apertura y liberalización, etapa en la que se abandonó e, incluso, demonizó la política industrial y, más recientemente a raíz de la crisis económico-financiera de 2008-2009, se experimentó un resurgimiento del rol del Estado.

\footnotetext{
1 Los autores agradecen los valiosos comentarios de Jorge Mario Martínez, Jennifer Alvarado y Lauren Phillips al primer borrador de este documento.

2 Pueden consultarse los principios mercantilistas, por ejemplo, en Von Hörnigk (1965), Misselden (1954) y List (1856), mientras que las ideas propugnadas por los liberales se encuentran en la obra clásica de Adam Smith, La riqueza de las naciones (2001).
} 
Diversas publicaciones recientes sobre el resurgimiento de la política industrial en América Latina coinciden en su papel central para un desarrollo económico de largo plazo, aunque pueden diferir en el alcance y los instrumentos. También se observa una coincidencia en reconocer que la nueva política industrial se da en un contexto internacional caracterizado por el libre comercio, la firma de acuerdos internacionales que restringen el uso de ciertos instrumentos y la presencia de un Estado articulador y promotor en lugar de un Estado omnipresente y dueño de los medios de producción (Ross-Schneider, 2015; Crespi, Fernández-Arias y Stein, 2014; Salazar-Xirinach, Nübler y Kozul-Wright, 2014; Padilla y Alvarado, 2014; Stiglitz y Lin, 2013; Devlin y Moguillansky, 2012; Bianchi y Labory, 2011; Peres y Primi, 2009; Cimoli, Dosi y Stiglitz, 2009). La Comisión Económica para América Latina y el Caribe (CEPAL) ha enfatizado que la política industrial es un instrumento clave para lograr un cambio estructural en un horizonte de igualdad (CEPAL, 2012 y 2016b).

El cambio estructural se define como la recomposición de la estructura del valor agregado y el empleo (Krüger, 2008). La transformación de economías predominantemente agrícolas en economías industriales, o la transición de estas últimas hacia los servicios, puede estar acompañada - o no- de un creciente desarrollo económico y social (Carmignani y Mandeville, 2014; Szirmai, 2011; Kaldor, 1961; Lewis, 1964). Para que esta transformación redunde en un crecimiento sostenido, inclusivo y ambientalmente sostenible - que la CEPAL describe como un cambio estructural progresivo-, se requiere un conjunto integral de políticas públicas (CEPAL, 2016).

En un sentido amplio, la política industrial incluye los servicios y las actividades primarias, aunque la manufactura ha sido el objeto central. En América Latina, durante el período de sustitución de importaciones (aproximadamente entre las décadas de 1930 y 1970), los esfuerzos de la política industrial se concentraron en generar los bienes de capital requeridos para el proceso de industrialización, mientras que el papel del sector agropecuario se concebía como de apoyo al desarrollo de la industria, limitado a la provisión de excedentes, por ejemplo, materias primas, alimentos, divisas y fuerza laboral (FAO, 2004). Luego, con el consenso de Washington (aproximadamente desde finales de la década de 1980 hasta la crisis internacional de 2008-2009), se promovió el enfoque de la "no política industrial". Esta visión tuvo un efecto negativo en las actividades agropecuarias, dado que se desmantelaron organizaciones de apoyo a la producción, se eliminaron subsidios y programas específicos, y se disminuyeron o suprimieron aranceles de importación.

En ambos períodos, la noción de política industrial rural parecía contener elementos conceptuales contrapuestos. A raíz del resurgimiento 
de la política industrial y los cambios en el paradigma rural, se ha diluido la contradicción aparente entre la política industrial y el espacio rural. Entre los cambios observados en el paradigma rural, se debe destacar la mayor interdependencia entre el sector agropecuario y otros sectores, como la manufactura, los servicios profesionales, los servicios ambientales, las tecnologías de la información y las comunicaciones (TIC) y el turismo rural; cambios en la estructura productiva que implican una reorganización de las etapas de producción en una cadena de valor; la disminución de la participación del empleo agropecuario en el empleo rural total; transiciones demográficas de la población radicada en zonas rurales, y la creciente importancia de los procesos de aprendizaje e innovación. Las brechas en materia social y económica entre el espacio rural y el urbano exigen nuevos enfoques para promover un desarrollo productivo incluyente. En 2014, el porcentaje de la población rural en situación de pobreza e indigencia en América Latina llegó al 46,2\% y al $27,6 \%$, respectivamente. En contraste, en el espacio urbano estas cifras fueron del 23,8\% y del 8\% (CEPAL, 2016a).

Aunque se define con mayor detalle en los siguientes apartados de este capítulo, la política industrial rural es entendida como la implementación por parte del Estado de instrumentos dirigidos al fortalecimiento de las actividades productivas del espacio rural con el propósito de lograr un cambio estructural mediante actividades de transformación (manufactura) y de servicios, así como la integración y complementariedad con actividades, mercados y sectores de mayor dinamismo e intensidad de conocimientos.

Esta política da respuesta a los cambios recientes en el espacio rural, que plantean la necesidad de contar con nuevos enfoques e instrumentos. Además, puede efectuar una contribución significativa al mejoramiento de las condiciones económicas y sociales en el espacio rural, así como al cumplimiento de los Objetivos del Desarrollo Sostenible (ODS) de la Agenda 2030.

El objetivo de este capítulo es definir el concepto y los instrumentos de la política industrial rural, así como reflexionar sobre su importancia para un cambio estructural progresivo. Las intervenciones en cadenas de valor rurales, que se abordan en los siguientes capítulos, se enmarcan en esta propuesta de conceptualización.

La estructura del capítulo es la siguiente: en primer lugar se realiza una breve revisión de lo que se entiende por espacio rural, su importancia y su complementariedad con otros sectores (sección A) y luego se ofrece una definición de la política industrial rural (sección B). A continuación, en la sección $C$ se proponen tres grupos de instrumentos que la política industrial rural tiene a su disposición, mientras que en la sección $\mathrm{D}$ se 
revisan experiencias de países que han aplicado instrumentos y acciones coincidentes con esta clase de política. Por último, en la sección E se presentan las conclusiones del capítulo.

\section{A. El espacio rural}

\section{Definición del espacio rural}

Antes de discutir qué se entiende por política industrial rural, es necesario definir el concepto de espacio rural, para lo que comúnmente se suelen adoptar tres criterios, sintetizados en el cuadro II.1, a saber: i) el económico o sectorial; ii) el demográfico, y iii) el territorial.

\section{Cuadro II.1}

Principales criterios para definir el espacio rural

\begin{tabular}{|c|c|c|}
\hline Económico o sectorial & Demográfico & Territorial \\
\hline $\begin{array}{l}\text { Toma en cuenta las } \\
\text { actividades económicas más } \\
\text { importantes del espacio rural, } \\
\text { en particular la agricultura, la } \\
\text { ganadería, la silvicultura, la } \\
\text { pesca y la acuicultura (sector } \\
\text { agropecuario). Con un enfoque } \\
\text { amplio, también incluye las } \\
\text { actividades agroindustriales, } \\
\text { los alimentos y bebidas, y los } \\
\text { servicios ubicados en el espacio } \\
\text { rural, por ejemplo, el turismo } \\
\text { rural y la elaboración } \\
\text { de artesanías. }\end{array}$ & $\begin{array}{l}\text { Toma en cuenta la división } \\
\text { de la población en rural } \\
\text { y urbana, usando como } \\
\text { referencia el tamaño y la } \\
\text { densidad de la población, } \\
\text { así como la intensidad de } \\
\text { los desplazamientos o la } \\
\text { lejanía (distancia) de los } \\
\text { centros urbanos. }\end{array}$ & $\begin{array}{l}\text { Se define lo rural como una } \\
\text { construcción social, donde se } \\
\text { manifiestan procesos económicos } \\
\text { y sociales localizados que } \\
\text { expresan una identidad y } \\
\text { propósitos compartidos. La base } \\
\text { económica de estos procesos } \\
\text { es multisectorial y se da en } \\
\text { un territorio, pero usualmente } \\
\text { articulada en torno a la oferta } \\
\text { ambiental o de recursos naturales, } \\
\text { donde convergen diversos } \\
\text { actores que determinan formas } \\
\text { de aprovechamiento y estructuras } \\
\text { productivas particulares. }\end{array}$ \\
\hline
\end{tabular}

Fuente: Elaboración propia, sobre la base de R. Echeverri, "Reflexiones sobre lo rural: economía rural, economía de territorios", Hacia una nueva definición de "rural" con fines estadísticos en América Latina, Documentos de Proyectos (LC/W.397), M. Dirven y otros, Santiago, Comisión Económica para América Latina y el Caribe (CEPAL), 2011; Organización de Cooperación y Desarrollo Económicos (OCDE), The New Rural Paradigm: Policies and Governance, París, OECD Publishing, 2006; Naciones Unidas, The Wye Group Handbook. Rural Households' Livelihood and Well Being. Statistics on Rural Development and Agriculture Household Income, Nueva York, Comisión Económica para Europa (CEPE)/Oficina Estadística de la Unión Europea (Eurostat)/ Organización de las Naciones Unidas para la Alimentación y la Agricultura (FAO)/Organización de Cooperación y Desarrollo Económicos (OCDE)/Banco Mundial, 2007.

El criterio económico o sectorial se refiere a la contribución de la principal actividad productiva en el espacio rural. La agricultura, la ganadería, la pesca, la acuicultura y la silvicultura son las actividades primordiales de las zonas rurales. Como se verá más adelante, la participación de estas actividades en el PIB y el empleo total ha disminuido en años recientes. No obstante, en muchas regiones de países en desarrollo aún son las principales actividades. Comúnmente se equipara lo rural con el sector agropecuario, pero, si se adopta un enfoque más incluyente, también abarca las actividades agroindustriales, así como 
otras manufacturas y servicios ubicados en el espacio rural, por ejemplo, el turismo rural y la elaboración de artesanías.

La definición de zonas rurales y urbanas, sobre la base de criterios demográficos, varía entre los países y en el tiempo. De acuerdo con algunas oficinas estadísticas de América Latina y el Caribe, la definición de áreas rurales es un residuo de lo urbano. En la Argentina, por ejemplo, la población urbana se define como aquella que habita en localidades de 2.000 o más habitantes; por lo tanto, la población rural será aquella con menos de 2.000 habitantes. En México, el umbral para definir la población urbana es de 2.500 habitantes. También se adopta como criterio el acceso a infraestructura o servicios básicos. No obstante, organismos internacionales coinciden en que medir lo rural como un residuo de lo urbano, sin considerar las características propias de lo rural, no es suficiente y puede arrojar resultados de comparación carentes de uniformidad (Naciones Unidas, 2007).

Debido a la variedad de criterios utilizados para delimitar el espacio de lo rural, la Organización de Cooperación y Desarrollo Económicos (OCDE) (1996) propuso una clasificación armonizada para los países miembros, utilizando la densidad demográfica a nivel de comunidades locales. Así, una población es rural cuando tiene 150 o menos habitantes por kilómetro cuadrado. A nivel de regiones, según el porcentaje de la población que vive en zonas rurales, se clasifican en tres categorías: i) predominantemente rurales (más del $50 \%$ de la población vive en comunidades rurales); ii) significativamente rurales (entre el $15 \%$ y el $50 \%$ vive en comunidades rurales), y iii) predominantemente urbanas (menos del 15\% vive en comunidades rurales).

Recientemente se ha puesto más atención en el tercer criterio: el territorial. La economía de lo rural puede entenderse desde una lógica de localización de los procesos económicos y sociales donde el eje articulador es el espacio geográfico. Abordar lo rural desde una lógica territorial apoya el análisis de la interrelación entre el espacio geográfico y la especialización territorial. Además, permite dar dirección a los proyectos de desarrollo a partir de la convergencia de intereses y voluntades, donde actores públicos y privados comparten un sentido de identidad y propósitos. El enfoque territorial destaca las oportunidades para construir de forma participativa nuevas propuestas de crecimiento, inversiones y sostenibilidad con un enfoque que respeta la cultura local (Dirven y otros, 2011).

El espacio rural es multifactorial y dinámico. El aspecto multifactorial se refiere a la variedad de consideraciones demográficas, económicas, sociales y medioambientales que abarca el conjunto de lo rural y lo reconoce como un espacio dinámico en tanto se observan transformaciones y ajustes tecnológicos, ecológicos, económicos y sociales en el mediano y largo plazo (Naciones Unidas, 2007). En la medida en que lo rural se reconoce como 
un espacio dinámico, los instrumentos de política para el desarrollo de las zonas rurales deben tomar en cuenta los cambios que en él emergen. En el cuadro II. 2 se resumen los cambios recientes en el paradigma rural.

\section{Cuadro II.2}

\section{Cambios recientes en el paradigma rural}

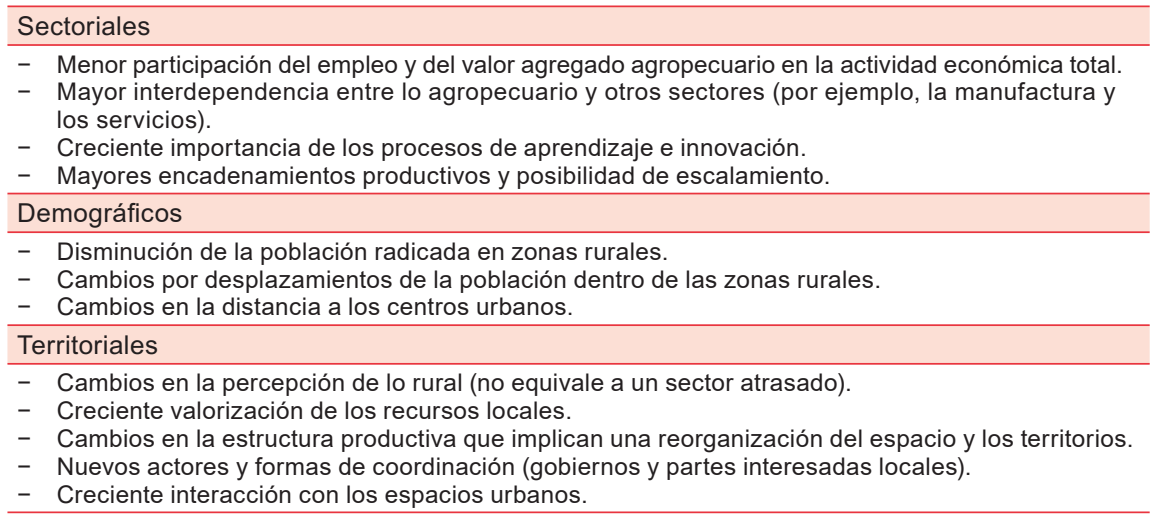

Fuente: Elaboración propia, sobre la base de Organización de Cooperación y Desarrollo Económicos (OCDE), The New Rural Paradigm: Policies and Governance, París, OECD Publishing, 2006.

La definición de espacio rural utilizada en este capítulo integra elementos de los tres criterios presentados e incorpora los cambios recientes ocurridos en dicho ámbito. Se entiende por espacio rural el espacio geográfico generalmente con una población de menor tamaño y densidad, según las delimitaciones usadas por cada país (criterio demográfico), donde ocurren procesos de interacción social y económica compartidos por múltiples actores y que aportan identidad al espacio (criterio territorial). Las actividades económicas rurales son multisectoriales: las principales son aquellas que corresponden al sector agropecuario, pero se reconoce la creciente importancia de actividades complementarias de manufactura y servicios, como la agroindustria, el turismo rural y las artesanías (criterio económico o sectorial).

En la presentación de estadísticas, al hacer referencia a lo rural, se utiliza la definición de áreas o zonas rurales adoptada por la oficina de estadísticas de cada país. En este capítulo, si la unidad de análisis se refiere a alguna actividad económica del espacio rural, la definición corresponderá a la fuente de información utilizada. El sector agropecuario o agrícola suele comprender las actividades de la primera gran división de la Clasificación Industrial Internacional Uniforme (CIIU) de Todas las Actividades Económicas: agricultura, ganadería, caza, silvicultura, pesca y acuicultura. Si se hace una referencia al sector primario, este se referirá a las actividades del sector agropecuario más la minería. 


\section{Importancia del espacio rural}

En esta sección se analiza el peso del espacio rural en América Latina y el Caribe y, en particular, en Centroamérica, México y la República Dominicana, donde se concentraron las tareas de fortalecimiento de cadenas de valor en el marco del proyecto CEPAL-Fondo Internacional de Desarrollo Agrícola (FIDA). Dado que no existe un criterio uniforme para definir el espacio rural y que las actividades económicas rurales son multisectoriales, en las estadísticas oficiales no se encuentra una identificación agregada de su contribución económica, por ejemplo, al producto interno bruto (PIB) o al valor agregado rural. Las estadísticas presentadas reflejan su participación significativa en materia demográfica y social; también se analiza su contribución en términos económicos.

Aunque en las últimas décadas se ha observado una caída del porcentaje de la población que vive en el espacio rural, se estima que en 2015 el 46\% de la población mundial vivía en zonas consideradas rurales. En América Latina y el Caribe, este porcentaje fue del 20,1\% en 2015, mientras que había alcanzado el 29,5\% en 1990. En Guatemala y Honduras, la población rural sigue teniendo una participación muy significativa: en 2015 llegó al 48,4\% y al 45,3\%, respectivamente, cifras superiores a la media de la región. En 2015, los países con el menor porcentaje de población rural de la subregión norte de América Latina fueron México (20,8\%), la República Dominicana (21\%) y Costa Rica (23,2\%) (véase el gráfico II.1).

Gráfico Il.1

Población rural como porcentaje de la población total, 1990 y 2015a

(En porcentajes)

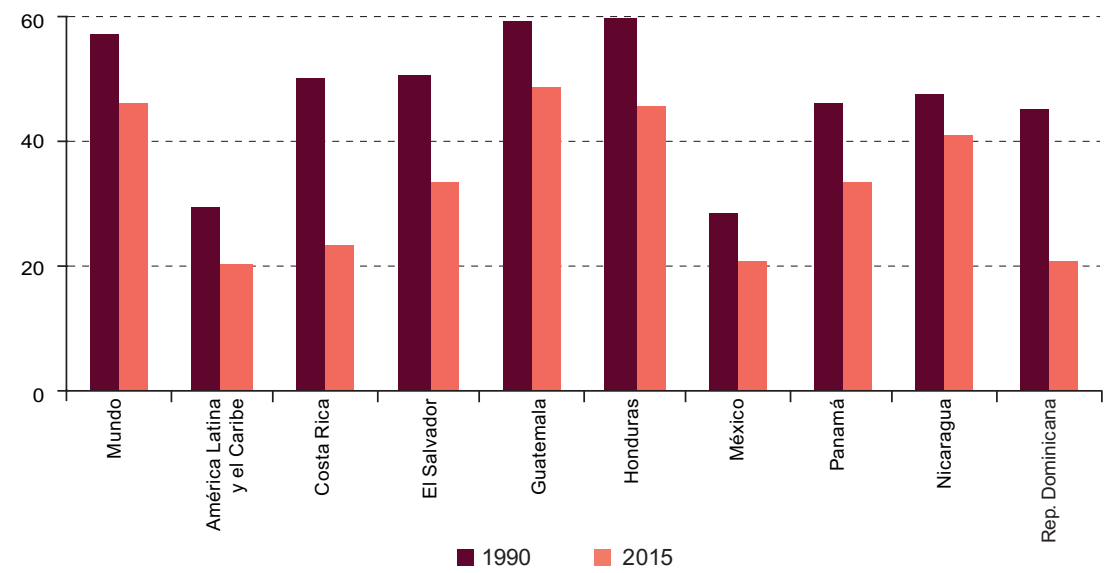

Fuente: Banco Mundial, 2016 [en línea] http://datos.bancomundial.org.

a La población rural se refiere a las personas que viven en zonas rurales según la definición de la oficina nacional de estadísticas de cada país y se calcula como la diferencia entre la población total y la urbana. 
El sector agropecuario suele perder participación en el PIB conforme las economías incrementan su nivel de ingreso. En 2014, la participación media de dicho sector en países de altos ingresos fue del 1,5\%, mientras que en los de ingresos bajos fue del 31,1\% (véase el gráfico II.2). En América Latina y el Caribe, la contribución del sector en 1990 llegó al 8,5\%, mientras que en 2014 fue del 5,5\%.

\section{Gráfico II.2}

Valor agregado agrícola como porcentaje del PIB total, 1990-2014 (En porcentajes)

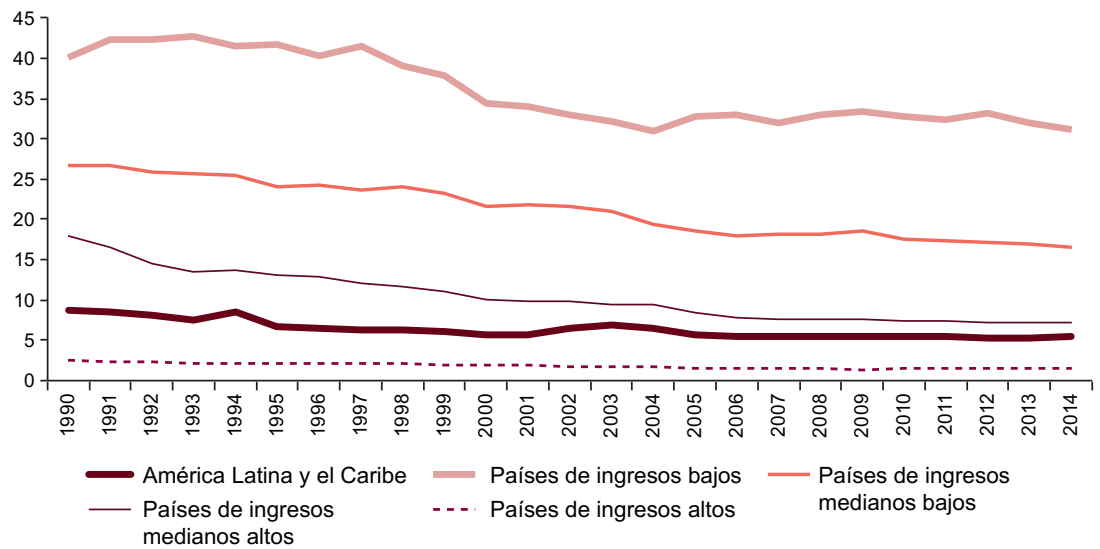

Fuente: Conferencia de las Naciones Unidas sobre Comercio y Desarrollo (UNCTAD), "UNCTAD STAT", 2016 [en línea] http://unctadstat.unctad.org/EN/; Banco Mundial, 2016 [en línea] http://datos. bancomundial.org.

a El valor agregado agrícola incluye las actividades 1 a 5 de la Clasificación Industrial Internacional Uniforme (CIIU) de Todas las Actividades Económicas, revisión 3: agricultura, ganadería, caza, silvicultura, pesca y acuicultura.

En los últimos 25 años, en Centroamérica, México y la República Dominicana ha disminuido la participación del PIB agropecuario. No obstante, en la mayoría de los países esta participación se ubica por encima del promedio de América Latina y el Caribe. Los países donde este sector tiene el mayor peso son Nicaragua, Honduras y Guatemala, mientras que el menor peso se observa en México, Panamá, Costa Rica y la República Dominicana (véase el cuadro II.3).

Los datos de empleo distinguen de manera más clara la gran contribución económica que tiene el espacio rural, a pesar del cambio estructural por el que ha pasado América Latina en décadas recientes. La proporción de la población económicamente activa (PEA) del espacio rural alcanzó en 2015 los niveles más altos en Honduras (42,6\%), Nicaragua $(39,2 \%)$ y Guatemala $(38,7 \%)$. En países que han tenido un 
cambio estructural más profundo en décadas recientes, como Costa Rica, México y la República Dominicana, la PEA rural representó el $21,6 \%$, el 20,2\% y el 20,1\% de la PEA total, respectivamente (véase el cuadro II.4).

\section{Cuadro II.3}

América Latina y el Caribe (8 países): PIB agropecuario como porcentaje del PIB total, a precios constantes, $1990-1995,2000-2005$ y 2010-2015

(En porcentajes)

\begin{tabular}{lccc}
\hline & $1990-1995$ & $2000-2005$ & $2010-2015$ \\
\hline Costa Rica & 8,1 & 7,1 & 6,0 \\
\hline El Salvador & 13,9 & 10,5 & 11,1 \\
\hline Guatemala & 13,0 & 11,8 & 11,3 \\
\hline Honduras & 14,0 & 12,9 & 12,4 \\
\hline México & 3,8 & 3,4 & 3,0 \\
\hline Nicaragua & 14,8 & 16,0 & 3,4 \\
\hline Panamá & 6,4 & 6,4 & 6,0 \\
\hline República Dominicana & 8,9 & 6,7 & 4,7 \\
\hline América Latina y el Caribe & 5,0 & 5,1 & 15,4 \\
\hline
\end{tabular}

Fuente: Comisión Económica para América Latina y el Caribe (CEPAL), "CEPALSTAT. Bases de Datos y Publicaciones Estadísticas", 2016 [en línea] http://estadisticas.cepal.org/cepalstat/WEB_ CEPALSTAT/Portada.asp.

a PIB a precios constantes de 2010.

Cuadro II.4

América Latina (8 países): población económicamente activa rural como porcentaje de la población económicamente activa total, 1990 y 2015

(En porcentajes)

\begin{tabular}{lcc}
\hline & 1990 & 2015 \\
\hline Costa Rica & 47,3 & 21,6 \\
\hline El Salvador & 44,9 & 27,7 \\
\hline Guatemala & 60,5 & 38,7 \\
\hline Honduras & 54,6 & 42,6 \\
\hline México & 25,5 & 20,2 \\
\hline Nicaragua & 43,9 & 39,2 \\
\hline Panamá & 41,8 & 30,0 \\
\hline República Dominicana & 42,1 & 20,1 \\
\hline América Latina & 27,4 & 18,8 \\
\hline
\end{tabular}

Fuente: Centro Latinoamericano y Caribeño de Demografía-División de Población de la CEPAL (CELADE), "Estimaciones y proyecciones de población total, urbana y rural, y económicamente activa", 2016 [en línea] http://www.cepal.org/es/estimaciones-proyecciones-poblacion-largoplazo-1950-2100.

En América Latina ha crecido la proporción de la PEA rural femenina ocupada: en 1997 era del 42,7\%, mientras que en 2014 ascendía al 45,7\%. Aun pese a este ligero incremento, en el espacio rural persiste una marcada concentración de mujeres en actividades de quehaceres domésticos (el 30,4\% 
de la PEA rural en 2014), mientras que el porcentaje de los hombres en estas actividades fue del 0,9\% en el mismo año (CEPAL, 2016a) ${ }^{3}$.

En América Latina, el sector agropecuario sigue siendo una actividad económica central del espacio rural. En promedio, el 52,8\% de la población ocupada rural se empleó en este sector en 2014, en comparación con el $62,4 \%$ registrado en 1997. No obstante, aumentó la participación del empleo rural en otros sectores, de manera que en el mismo año un 16\% se ocupó en la industria y un 31,1\%, en los servicios (véase el gráfico II.3).

\section{Gráfico II.3}

\section{América Latina (países seleccionados): población ocupada rural según actividad económica, 1997, 2005 y 2014}

(En porcentajes)

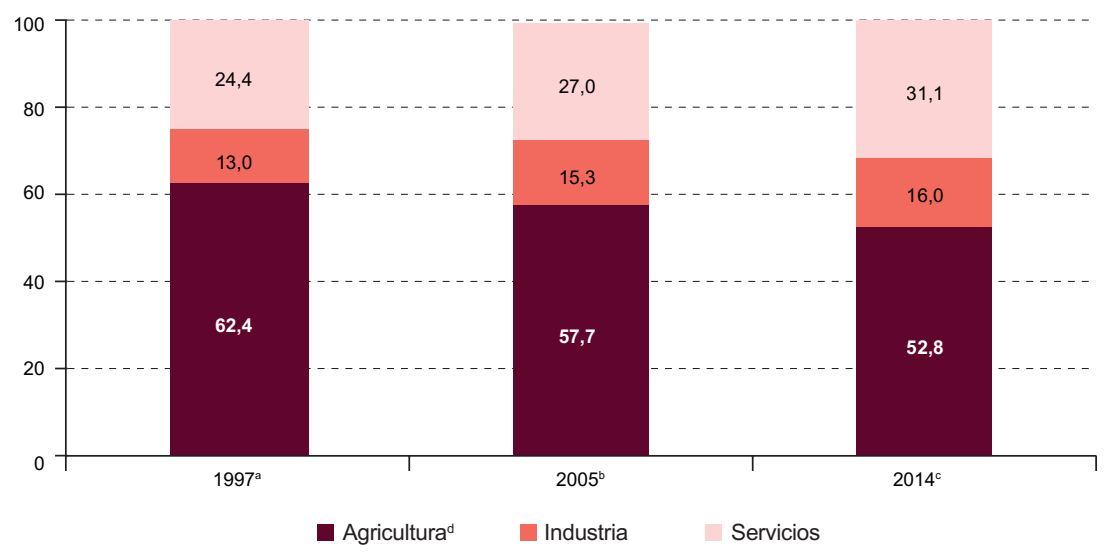

Fuente: Comisión Económica para América Latina y el Caribe (CEPAL), "CEPALSTAT. Bases de Datos y Publicaciones Estadísticas", 2016 [en línea] http://estadisticas.cepal.org/cepalstat/WEB_ CEPALSTAT/Portada.asp.

a Promedio ponderado de 12 países: Bolivia (Estado Plurinacional de) (1997), Brasil (1996), Chile (1996), Colombia (1997), Costa Rica (1997), El Salvador (1997), Guatemala (1989), Honduras (1997), México (1996), Nicaragua (1998), Perú (1997) y Venezuela (República Bolivariana de) (1997).

b Promedio ponderado de 15 países: Bolivia (Estado Plurinacional de) (2004), Brasil (2005), Chile (2003), Colombia (2005), Costa Rica (2005), Ecuador (2005), El Salvador (2004), Guatemala (2002), Honduras (2003), México (2004), Nicaragua (2005), Panamá (2005), Perú (2003), Paraguay (2005) y República Dominicana (2005).

c Promedio ponderado de 16 países: Bolivia (Estado Plurinacional de) (2013), Brasil (2014), Chile (2013), Colombia (2014), Costa Rica (2014), Ecuador (2014), El Salvador (2014), Guatemala (2014), Honduras (2013), México (2014), Nicaragua (2009), Panamá (2014), Paraguay (2014), Perú (2014), República Dominicana (2014) y Uruguay (2014).

d De acuerdo con la Clasificación Industrial Internacional Uniforme (CIIU) de Todas las Actividades Económicas, revisión 2 , se incluyen las actividades de la agricultura, ganadería, caza, silvicultura, pesca y acuicultura.

3 Para el dato de 2014, promedio ponderado de 16 países de América Latina: Bolivia (Estado Plurinacional de) (2013), Brasil (2014), Chile (2013), Colombia (2014), Costa Rica (2014), Ecuador (2014), El Salvador (2014), Guatemala (2014), Honduras (2013), México (2014), Nicaragua (2009), Panamá (2014), Paraguay (2014), Perú (2014), República Dominicana (2014) y Uruguay (2014). Para el dato de 1997, promedio ponderado de 12 países de América Latina (Bolivia (Estado Plurinacional de) 1997, Brasil 1996, Chile 1996, Colombia 1997, Costa Rica 1997, El Salvador 1997, Guatemala 1989, Honduras 1997, México 1996, Nicaragua 1998, Perú 1997 y Venezuela (República Bolivariana de) 1997). 
En el estudio de Rodríguez (2016) sobre empleo rural se señalan las siguientes tendencias en América Latina y el Caribe: i) aumento del empleo no agrícola (diversificación del empleo); ii) mayor participación del empleo femenino en zonas rurales, sobre todo en actividades no agrícolas; iii) incremento del empleo asalariado y reducción del empleo por cuenta propia, y iv) aumento de la residencia urbana de los empleados agrícolas.

Por otro lado, en el espacio rural de los países en desarrollo se concentra un alto porcentaje de la población en situación de pobreza. Según estimaciones de la CEPAL, en 2014 el 46,2\% del total de la población rural de América Latina se hallaba en situación de pobreza y el 27,6\%, en situación de indigencia. Como se puede observar en el gráfico II.4, el porcentaje de población en situación de pobreza e indigencia ha sido y es mayor en las zonas rurales que en las zonas urbanas.

\section{Gráfico II.4}

América Latina (19 países): población en situación de pobreza e indigencia, por zona geográfica, 1990 y $2014^{a}$

(En porcentajes)

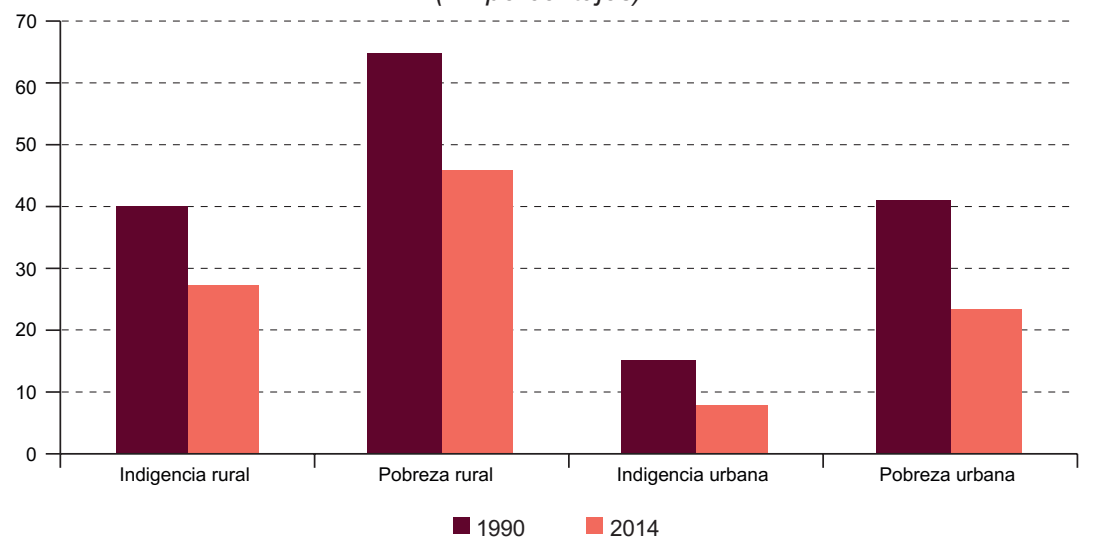

Fuente: Comisión Económica para América Latina y el Caribe (CEPAL), "CEPALSTAT. Bases de Datos y Publicaciones Estadísticas", 2016 [en línea] http://estadisticas.cepal.org/cepalstat/WEB_ CEPALSTAT/Portada.asp.

a Estimación basada en las cifras correspondientes a 19 países: Argentina, Bolivia (Estado Plurinacional de), Brasil, Chile, Colombia, Costa Rica, Ecuador, El Salvador, Guatemala, Haití, Honduras, México, Nicaragua, Panamá, Paraguay, Perú, República Dominicana, Uruguay y Venezuela (República Bolivariana de). Información revisada el 11 de abril de 2016.

\section{Interdependencia y complementariedad entre los sectores}

El debate sobre "industria primero" o "agricultura primero" es de larga data. Tradicionalmente, el término industrialización se ha entendido como la transición de la agricultura hacia las industrias manufactureras 
y se lo ha considerado sinónimo de progreso ${ }^{4}$. En épocas recientes, esta idea se ha trasladado a la transición hacia economías tercerizadas o basadas en servicios. Se encuentran ejemplos de este debate en análisis clásicos del desarrollo. Por ejemplo, Lewis (1954) y Kaldor (1961) sugieren una correlación positiva entre el incremento de la productividad de la economía y el crecimiento del sector industrial, mientras que la correlación sería negativa si se toma en cuenta al aumento del empleo en sectores no manufactureros. Por su parte, Hirschman (1961) argumentó que la agricultura tiene una capacidad limitada para inducir la formación de capital. Desde su perspectiva, la manufactura posee mayor capacidad de creación de encadenamientos intersectoriales hacia atrás y hacia delante, por lo que el proceso de desarrollo es una transformación integral hacia la economía industrial.

En años recientes, Szirmai (2011) argumentó que los factores que explican la centralidad de la manufactura como motor del crecimiento de los países en desarrollo se basan en diversos elementos, a saber:

- la correlación entre el crecimiento dinámico de la manufactura y el ingreso per cápita en el largo plazo;

- la mayor productividad del sector manufacturo en comparación con el sector agropecuario;

- mayores oportunidades de acumulación de capital y de economías de escala en la manufactura que en la agricultura, y

- una mayor concentración del progreso tecnológico en la manufactura.

La preponderancia del sector manufacturero y, más recientemente, de los servicios en las políticas industriales encontró impulso y sustento en el cambio estructural experimentado tanto por las economías desarrolladas como por los países en desarrollo. En el cuadro II.5 se muestra la evolución de la estructura sectorial promedio del PIB de América Latina y el Caribe, donde se observa un aumento de la participación del sector de los servicios y una disminución del peso de la agricultura y la manufactura.

No obstante, el auge de los servicios y el proceso de desindustrialización pueden tener implicaciones para los países en desarrollo. En estudios como el de McMillan y Rodrik (2011) y Rodrik (2015), se explica que en algunos países de América Latina y de África este proceso fue prematuro y ocurrió sin una industrialización basada en el aumento de las capacidades tecnológicas y sin estar acompañado

Este debate sobre la importancia de la estructura económica, en particular de la composición sectorial y de los cambios que atraviesa a través del tiempo, tiene sus primeras formulaciones en autores clásicos, como Smith (1958) y Ricardo (2001), aunque también en pioneros del cambio estructural, por ejemplo, Pasinetti (1973 y 1993), Sraffa (1960), Nurkse (1935) y Baumol (1967). 
del crecimiento esperado de la productividad y la generación de empleos de calidad o procesos de convergencia social. Además, la desindustrialización prematura podría eliminar el canal principal para lograr un crecimiento acelerado, como el que experimentaron en el pasado los países ahora desarrollados.

\section{Cuadro II.5}

América Latina y el Caribe: contribución del valor agregado al PIB por sector de actividad económica, años seleccionados (En porcentajes)

\begin{tabular}{lccccc}
\hline & 1965 & 1985 & 1995 & 2005 & 2015 \\
\hline Agricultura $^{a}$ & 16 & 11 & 7 & 6 & 5 \\
\hline Manufactura & 33 & 41 & 31 & 34 & 27 \\
\hline Servicios & 50 & 48 & 62 & 60 & 67 \\
\hline
\end{tabular}

Fuente: Banco Mundial, 2016 [en línea] http://datos.bancomundial.org.

a Incluye las actividades 1 a 5 de la Clasificación Industrial Internacional Uniforme (CIIU) de Todas las Actividades Económicas, revisión 3: agricultura, ganadería, caza, silvicultura, pesca y acuicultura.

De manera complementaria, también se ha postulado que estos análisis del cambio estructural se interpretaron sin tomar en cuenta una interdependencia compleja, acumulativa y circular entre las actividades agropecuarias y el resto los sectores. Así, la intervención para el cambio estructural se puede apoyar de forma creativa en las sinergias entre los sectores, lo que amplía sus complementariedades y mejora sus encadenamientos (Andreoni, 2011; Kay, 2009).

A medida que se observa un cambio estructural, las actividades primarias mantienen su importancia en la estrategia de desarrollo, dados sus fuertes encadenamientos con otros sectores. En un estudio elaborado por el Instituto Interamericano de Cooperación para la Agricultura (IICA) (2004) a partir de matrices de la contabilidad nacional de un grupo de países, se examinaron los encadenamientos existentes entre la agricultura ampliada - aquella que reconoce la interdependencia entre el sector agropecuario y la agroindustria- y el resto de la economía. El estudio abarcó 11 países de América -Argentina, Brasil, Canadá, Chile, Colombia, Costa Rica, Estados Unidos, México, Perú, Uruguay y Venezuela (República Bolivariana de) - y permitió concluir que las tres cuartas partes de la producción procedente de estas actividades se utilizan como insumo en otros sectores, en comparación con el $43 \%$ de la producción del resto de la economía que se convierte en insumos.

Desde otra perspectiva, se puede analizar la complementariedad de los sectores en términos del aprendizaje tecnológico y la acumulación de capacidades intra e intersectoriales. El cambio tecnológico en la agricultura, por ejemplo, involucra mejoras del proceso de transformación técnica y biológica para obtener cierto producto, por lo que es necesario 
construir y acumular capacidades tecnológicas en el campo, así como fomentar el aprendizaje intersectorial. El cambio estructural no solo implica un proceso de transición sectorial de la agricultura hacia la manufactura, sino también un proceso de interdependencia y de aumento de capacidades en el seno de los sectores. Los incrementos de la productividad del sector agropecuario son el resultado de la adopción, adaptación y aplicación de las innovaciones tecnológicas desarrolladas en forma intra e intersectorial (Andreoni, 2011). Esta interdependencia entre los sectores se puede constatar en la integración de industrias, como en el caso de las tecnologías de la información y las comunicaciones (TIC) y la agricultura, o la biotecnología aplicada al desarrollo agropecuario. En estas áreas se puede observar la integración de tecnologías y un proceso de convergencia y transformación productiva que desemboca en una mayor productividad.

El enfoque excesivo de la política industrial en la manufactura ha retardado el desarrollo agropecuario e, indirectamente, perjudicado el desarrollo industrial (Szirmai, 2011). Las experiencias de los procesos de industrialización de países como la República de Corea y la provincia china de Taiwán, que han logrado cerrar las brechas tecnológicas e incrementar significativamente la productividad, dan cuenta de que dichos procesos tuvieron como antesala del desarrollo de su sector manufacturero, el fortalecimiento del sector agropecuario (Chang, 2009)5. Es importante considerar las diferentes etapas de cambio estructural en que se encuentran los países y sus necesidades específicas. Existen países en desarrollo cuya transformación rural aún se halla en una fase temprana y que requieren poner énfasis en el incremento de la productividad del sector agropecuario. En niveles ulteriores de transformación, donde una mayor proporción de mano de obra se ha trasladado de la agricultura hacia otros sectores y han disminuido las brechas de productividad, se puede evaluar no solo el cambio intersectorial, sino también el cambio intrasectorial (FIDA, 2016; Weller, 2016; Rodrik, 2013). En cualquier caso, uno de los principales desafíos del espacio rural es la transformación productiva y el aumento de la productividad de sus actividades económicas centrales.

Dependiendo de la incorporación de tecnología en las actividades primarias, estas pueden ser altamente intensivas en capital y en conocimientos tecnológicos. El desarrollo de nuevas variedades de semillas o de semillas mejoradas, con características como la resistencia a las sequías, el calor, el frío o la sal; una mayor inmunidad a las plagas y enfermedades, y mejor contenido nutricional, así como las

Cabe señalar que el desarrollo de estos países de Asia también dependió de una política industrial específica y de procesos de redistribución de la tierra, entre otros factores (Wade, 1990). 
nuevas variedades genéticas de animales, son ejemplos de actividades intensivas en conocimientos que pueden elevar los rendimientos y mejorar la productividad del sector agropecuario. Estos desarrollos demandan inversiones significativas, así como esfuerzos en actividades de investigación y desarrollo (I+D) que permitan su aplicación de manera sostenible. La importancia del crecimiento de la productividad en el cambio estructural requiere tomar en cuenta no solo la reubicación de los recursos entre sectores, sino también las diferencias dentro de cada una de las industrias y los factores (Rodrik, 2013).

Un cambio estructural en el espacio rural, que se traduce en un mayor desarrollo económico y social, no se basa en trasladar recursos humanos de las actividades agropecuarias a la manufactura o de la manufactura a los servicios. Las transformaciones deben estar acompañadas de una mayor productividad y de un escalamiento económico dentro de las propias actividades agropecuarias. Es importante tener en cuenta que es posible que los recursos humanos se traspasen de la agricultura a la manufactura, pero a actividades poco productivas y tradicionalmente con salarios bajos, como el ensamble de componentes y bienes finales, o bien a empresas informales de baja productividad en un sector de servicios. Para que el cambio estructural tenga un carácter progresivo, es decir que redunde en un crecimiento sostenido, inclusivo y ambientalmente sostenible, es necesario un conjunto integral de políticas públicas (CEPAL, 2016). La política industrial rural, que se define a continuación, constituye un elemento central de dichas políticas.

\section{B. Definición y alcance de la política industrial rural}

\section{1. ¿Qué es la política industrial rural?}

La política industrial rural forma parte de la política industrial en un sentido amplio, pero dirigida a un espacio definido como rural. La política industrial es entendida como la intervención del Estado orientada a estimular actividades económicas específicas y a promover el cambio estructural. Representa un proceso dinámico en el que se aplican diversas acciones para perseguir o lograr ciertos objetivos basados en

\footnotetext{
El análisis del movimiento de la mano de obra del sector agropecuario (menos productivo) hacia un sector más productivo, como la industria, y la tendencia reciente hacia una mayor participación en los servicios, caracterizado por Baumol (1967) como un sector improductivo, se complementan con los análisis que descomponen la productividad a nivel de cada industria y que toman en cuenta la calidad y la importancia del tipo de los insumos o factores, como la inversión en TIC y la calificación del personal (Van Ark, O’Mahony y Timmer, 2008; O’Mahony y Timmer, 2009; Jorgenson, Ho y Samuels, 2015).
} 
las prioridades de desarrollo nacional (Padilla y Alvarado, 2014; Peres y Primi, 2009; Rodrik, 2008a)7.

La política industrial rural es entendida como la implementación por parte del Estado de instrumentos dirigidos al fortalecimiento de las actividades productivas del espacio rural, con el propósito de lograr un cambio estructural mediante actividades de transformación (manufactura) y de servicios, así como la integración y complementariedad con actividades, mercados y sectores de mayor dinamismo e intensidad de conocimientos. Es importante señalar que no significa renunciar a las vocaciones productivas de las localidades, sino escalarlas y complementarlas con actividades secundarias (por ejemplo, la agroindustria y las artesanías) y terciarias (como el turismo rural, los servicios ambientales y los servicios profesionales).

Para que la política industrial rural promueva un cambio estructural progresivo debe enfocarse, por lo menos, en tres procesos interrelacionados: i) el escalamiento económico y la incorporación del cambio tecnológico y procesos de innovación; ii) el escalamiento social, y iii) el escalamiento de la estructura productiva con un enfoque de sostenibilidad.

El escalamiento económico permite mejorar la posición competitiva de un país, sector productivo, empresa o productor. La inclusión de este concepto en la teoría del desarrollo implica que los actores económicos no son estáticos y pueden mejorar su posición actual para generar y capturar mayor valor por sus actividades. Se identifican cuatro tipos principales de escalamiento: i) producto; ii) proceso; iii) funcional, y iv) de cadena o intersectorial. En el cuadro II.6 se presentan definiciones y ejemplos de cada tipo de escalamiento económico en el espacio rural. Es importante aclarar que no todos los ejemplos que se dan para cada tipo de escalamiento entran en el campo de acción de la política industrial rural, pues no todos entrañan una transformación mediante la incorporación o integración con servicios y actividades de transformación. Por ejemplo, el apoyo a la investigación y el desarrollo orientado a mejorar la calidad de un producto agropecuario no forma parte de la política industrial rural, pero sí lo hace la asistencia para la introducción de nuevas tecnologías que permiten procesar productos primarios y venderlos empaquetados (agroindustria). No obstante, como se reconoce en los próximos párrafos, es vital lograr una estrecha coordinación entre la política de desarrollo rural, la agropecuaria y la industrial rural. En la siguiente sección se describen los instrumentos que la política industrial rural tiene a su alcance.

\footnotetext{
Una noción similar es el concepto de políticas de desarrollo productivo, definidas como aquellas intervenciones que procuran fortalecer la estructura productiva de una economía nacional en particular (Melo y Rodríguez-Clare, 2006), concepto que en ocasiones se usa de manera indistinta al de política industrial. Por cuestiones ideológicas (la crítica que se hizo y aún se hace a la política industrial) o conceptuales (el término desarrollo productivo parecería dar espacio a sectores más allá de la manufactura), hay autores que prefieren hablar de políticas de desarrollo productivo.
} 


\section{Cuadro II.6}

\section{Definición y ejemplos de escalamiento económico en el espacio rural}

\begin{abstract}
Tipo de escalamiento
Producto. Desarrollo de un producto nuevo o con mejores características. El producto final o el servicio ofrecido por la cadena presenta características tecnológicas, funcionales o estéticas que lo dotan de una mayor capacidad competitiva en mercados nacionales o internacionales.
\end{abstract}

Ejemplos

- Mejorar la calidad de un producto agropecuario gracias a la realización de actividades de investigación y desarrollo.

- Desarrollar productos o servicios con una certificación o etiquetados ambientales.

- Mejorar o renovar el diseño de productos (por ejemplo, juguetes artesanales de madera certificada).

Proceso. Es el resultado de la introducción de nuevas tecnologías que ofrecen técnicas de producción más eficientes o mejores formas de distribuir los productos o servicios. La compra de maquinaria y equipo, la adopción de técnicas avanzadas de producción o el uso de tecnologías de la información y las comunicaciones suelen conducir a un escalamiento de los procesos.

Funcional. Consiste en adquirir nuevas funciones de mayor valor agregado o complejidad tecnológica que involucran tareas de diseño, producción y comercialización cada vez más sofisticadas.

- Introducir una nueva técnica en los cultivos agrícolas (por ejemplo, agricultura de precisión, análisis de suelos, uso de fertilizantes ecológicos, nuevas prácticas silvícolas).

- Adoptar una nueva técnica para el procesamiento de productos agroindustriales, por ejemplo, nuevas técnicas de fritura o de deshidratación de frutas.

- Incorporar un nuevo equipo de transporte refrigerado que permita mantener la cadena de frío de los productos agropecuarios y agroindustriales.

- Participar en otros eslabones de la cadena. Por ejemplo, en la cadena de valor del café, se puede dejar de ser solo productores de café en bruto para comenzar a procesarlo y apropiarse de la etapa de comercialización y posicionamiento de marca en mercados locales o internacionales.

- Transitar del cultivo de un producto agropecuario a la elaboración de un producto agroindustrial (por ejemplo, la producción de snacks nutritivos elaborados con frutas deshidratadas).

Cadena o sectorial. La transición hacia nuevas actividades productivas o cadenas de valor basada en el aprovechamiento de conocimientos y habilidades adquiridos previamente.
- Utilizar la experiencia en el manejo comunitario de bosques para incursionar en el ecoturismo o en actividades agroindustriales, como la fabricación de muebles.

- Hacer uso de los conocimientos y la experiencia adquiridos en una cadena (por ejemplo, fruta deshidratada) para incursionar en nuevas cadenas (por ejemplo, nuevas tecnologías para freír frutas al vacío).

Fuente: Elaboración propia.

Estrechamente ligado al concepto de escalamiento económico, está el cambio tecnológico. En el espacio rural, así como en otros ámbitos, las capacidades productivas y tecnológicas son clave en los procesos de aprendizaje e innovación. Las capacidades productivas contemplan los factores usados para producir bienes y servicios a un nivel dado de eficiencia y con una determinada combinación de insumos. Las capacidades tecnológicas, por su parte, incorporan factores adicionales necesarios para producir y manejar el cambio tecnológico, incluyendo habilidades, conocimientos, experiencia, estructura institucional y enlaces (Bell y Pavitt, 1992). En las economías en desarrollo, por lo general se observa una introducción limitada de innovaciones radicales: en su lugar, se suelen adaptar, imitar y mejorar de forma incremental las tecnologías desarrolladas por países más avanzados tecnológicamente. 
El segundo elemento, el escalamiento social, está vinculado con el aumento del nivel de vida de los integrantes de la cadena y sus comunidades mediante condiciones de empleo decente caracterizadas por la protección social, la tutela de los derechos laborales, un ambiente de trabajo seguro y la equidad de género (Gereffi y Lee, 2015). El escalamiento social también es entendido como una mejor distribución en la captura de los beneficios generados en una cadena de valor por parte de las empresas y los productores que conforman el núcleo de la cadena, en particular por parte de los pequeños productores. Estos beneficios se pueden traducir en remuneraciones monetarias o utilidades más elevadas y en el mayor bienestar de los actores de la cadena (Salido y Bellhouse, 2016). Es importante señalar que no siempre se observa una relación directa entre escalamiento económico y social. Por ejemplo, una empresa procesadora de frutas puede mejorar la calidad de sus productos y sus canales de comercialización, lo que redunda en mayores ganancias. No obstante, estas ganancias podrían ser disfrutadas en su totalidad por el dueño, sin que beneficien de manera alguna a los obreros u otros segmentos de la cadena.

El tercer elemento es la sostenibilidad ambiental. Alcanzar un cambio estructural progresivo requiere que la transformación de la estructura productiva incorpore nuevas tecnologías de proceso y de producto que, por un lado, sean ambientalmente responsables y que, por otro, mitiguen el efecto que el cambio climático ejerce en las cadenas productivas rurales. Ejemplos de estas oportunidades son la bioeconomía, los productos y servicios con etiquetados ambientales, y la producción con tecnologías más limpias, como las energías renovables (CEPAL, 2016b) ${ }^{8}$.

Así, una política industrial rural con enfoque progresivo busca generar un crecimiento inclusivo que permita el escalamiento o la complementariedad con actividades que producen mayor valor agregado y que son más intensivas en conocimientos y tecnología, sin que se sacrifiquen las vocaciones productivas locales, se deterioren las condiciones económicas y sociales de los productores ni se intensifique el impacto ambiental. El grupo beneficiario de una política industrial rural está formado primordialmente por los productores individuales, los grupos de productores y las empresas del espacio rural, y por otros actores, como los proveedores especializados, los comercializadores, los empacadores o una región en su conjunto.

Aunque se reconoce que el sector agropecuario suele ser la actividad principal del espacio rural, la política industrial rural no es sinónimo de

La bioeconomía incluye diferentes conexiones entre sectores y cadenas de valor: actividades agropecuarias, forestales, pesqueras y acuícolas; las industrias de alimentos y bebidas, y de pulpa y papel; así como segmentos de las industrias química, farmacéutica, cosmética, textil y energética. La CEPAL (2016b) sugiere que la bioeconomía puede brindar opciones para el desarrollo rural y la creación de empleo, por ejemplo, mediante la agricultura para la producción de biomasa y el desarrollo de cadenas de valor a partir del uso de biomasa no alimentaria y desechos (bioinsumos para la agricultura). 
una política agrícola o agropecuaria. Esta última se concentra en mejorar el funcionamiento de los mercados de productos y factores en el sector agropecuario. Las políticas agropecuarias se pueden sintetizar en tres clases diferentes:

i) políticas de precio (la economía de mercado está determinada en mayor medida por las políticas macroeconómicas);

ii) políticas de recursos (que incluyen la política de tenencia de la tierra y las políticas de manejo de los recursos, como la tierra, el agua, los bosques y las pesquerías), y

iii) políticas de acceso (que incluyen el acceso a los insumos agropecuarios, los mercados de productos y la tecnología) (FAO, 2004).

La política industrial rural tampoco es exclusivamente una política de desarrollo rural. Hay coincidencias con el nuevo paradigma rural, que parte de un enfoque holístico que analiza la forma en que interactúan varios componentes de una economía local. En este enfoque de la política de desarrollo rural se enfatiza la importancia del territorio, la modernización económica y la inversión por encima de la provisión de subsidios, y el aporte de los servicios, en particular las $\mathrm{TIC}^{9}$. El enfoque de intervención de la política industrial rural no toma en cuenta todos los instrumentos de política aplicados en un área definida como rural, sino que se concentra en la transformación de la estructura productiva.

Finalmente, cabe señalar que el diseño e implementación de una política industrial rural no conlleva un menor apoyo a sectores de manufactura de media y alta tecnología, como la industria automotriz, la electrónica, los dispositivos médicos y la aeronáutica. Ambos enfoques - lo rural y lo no rural - son complementarios de una política industrial integral e inclusiva. El objetivo es rescatar el papel de las actividades económicas del espacio rural, que han sido poco atendidas por la política industrial, pero tienen un gran potencial en términos de un cambio estructural progresivo.

\section{Instrumentos de política industrial rural}

La política industrial rural es parte de la política industrial en su sentido amplio, como se mencionó anteriormente. Por ello, hay coincidencia en los instrumentos que tienen a su disposición, aunque el espacio y el

\footnotetext{
El nuevo paradigma rural es un enfoque que sirve como marco de orientación para los países miembros de la Organización de Cooperación y Desarrollo Económicos (OCDE) a fin de establecer sus estrategias individuales de desarrollo rural. Desde este nuevo enfoque, algunas áreas prioritarias de la política de desarrollo rural son: i) el transporte y el desarrollo de infraestructura de las TIC; ii) la provisión de servicios públicos; iii) la valorización de los servicios rurales (naturales y culturales), y iv) la promoción de empresas rurales (OCDE, 2006).
} 
enfoque de aplicación puedan ser distintos. La política industrial rural es predominantemente de tipo vertical, pues beneficia a un sector o espacio geográfico en particular, como es el caso del sector agropecuario o el espacio rural, pero también cuenta con instrumentos de corte horizontal ${ }^{10}$. Estos últimos no benefician solo al espacio rural, por ejemplo, mediante la provisión de infraestructura (telecomunicaciones o vías de transporte), una política macroeconómica que vela por la estabilidad de los principales indicadores o políticas comerciales neutras. Los instrumentos que a continuación se describen pueden ser considerados de corte vertical y clasificarse en tres categorías: i) políticas comerciales, de competitividad y de competencia; ii) políticas para el fomento productivo, y iii) políticas ambientales. Estos instrumentos se mencionan a título de ejemplo y se pueden aplicar de acuerdo con las especificidades del contexto económico, social, ambiental y productivo de cada país o región.

\section{Políticas comerciales, de competitividad y de competencia}

Las políticas comerciales, de competitividad y de competencia son en general de corte horizontal, pero, al estar dirigidas a ciertas actividades del espacio rural, se tornan verticales o selectivas. Se pueden agrupar en tres áreas principales: i) comerciales; ii) de competitividad, y iii) de competencia (véase el cuadro II.7).

\section{Cuadro II.7}

Políticas comerciales, de competitividad y de competencia

\begin{tabular}{ll}
\hline Área & Instrumentos \\
\hline Comerciales & - Promoción y fomento de las exportaciones rurales (agroindustria, \\
& - Servicios, artesanías) \\
& - Fomento de políticas de defensa comercial \\
\hline Competitividad & - Promoción de un marco macroeconómico estable \\
& - Velar por un tipo de cambio competitivo \\
& - Apoyo a la protección de inversiones y provisión de infraestructura \\
& - Promoción y fomento de la inversión extranjera directa (IED) en \\
& sectores y regiones rurales específicos \\
\hline Competencia & - Vigilancia de la competencia en los mercados agroalimentarios \\
& - Supervisión de la formación de precios en los mercados agroalimentarios
\end{tabular}

Fuente: Elaboración propia.

10 Véanse mayores detalles sobre la diferencia entre las políticas industriales horizontales y verticales en Padilla y Alvarado (2014). 
Las políticas comerciales buscan mejorar las condiciones de acceso de productores rurales (agroindustria, servicios, artesanías) a mercados internacionales. Incluyen la creación de organismos y programas especializados para promover las exportaciones, el acceso a nuevos mercados y medidas de defensa comercial.

La promoción de las exportaciones ayuda a la internacionalización de empresas y productores de bienes y servicios agropecuarios y agroindustriales; fomentan la participación en mercados de mayor dinamismo y exigencia. La internacionalización puede traer beneficios derivados del aprendizaje tecnológico y el aumento de las capacidades, aunque esto no sucede de forma automática (Crespi, Fernández-Arias y Stein, 2014). En el espacio rural es importante promocionar la participación en mercados internacionales de los pequeños productores y de micro y pequeñas empresas.

Por medio de la suscripción de acuerdos bilaterales y multilaterales, se tiene acceso a nuevos mercados. En décadas recientes, los países de América Latina y el Caribe han incrementado el número de tratados y acuerdos comerciales firmados con otros países y regiones. Los gobiernos pueden fomentar la ampliación y diversificación de los mercados para evitar la dependencia de un socio comercial en particular. Además de las negociaciones bilaterales, se pueden promover acuerdos multilaterales, tanto mundiales como regionales. Las políticas comerciales comúnmente establecen protecciones y condiciones preferenciales para productos rurales, como los agroalimentarios.

Cuando las importaciones causan un daño grave en algunas ramas de la producción nacional, se pueden incorporar medidas de defensa comercial, tales como excepciones temporales o salvaguardias, que protegen a ciertos sectores: los bienes agroalimentarios suelen verse favorecidos por estas medidas. También existen instrumentos de defensa comercial destinados a regular los precios de los productos importados en los mercados agropecuarios y agroindustriales, sobre todo en períodos de alta volatilidad, así como medidas para hacer frente a las distorsiones que causan los subsidios aplicados por otros países (Sotomayor, Rodríguez y Rodrigues, 2011).

Otro instrumento es el desarrollo de marcos eficientes para las inversiones y la provisión de infraestructura, cuyo objetivo es proteger las inversiones mediante un marco jurídico adecuado. El Estado puede intervenir proveyendo los bienes públicos a fin de que la estructura productiva rural resulte más competitiva. 
La promoción de la inversión extranjera directa (IED) en el espacio rural se encauza mediante beneficios particulares a los inversionistas o el apuntalamiento de actividades específicas en sectores y regiones rurales. Algunos mecanismos de atracción de la IED son los incentivos fiscales, los incentivos financieros y los subsidios directos para la puesta en marcha de la inversión. Asimismo, el sector público puede dar a conocer las ventajas del país, región o sector; proveer de información relevante a los inversionistas potenciales y facilitar el proceso de toma de decisiones e instalación (CEPAL, 2007). Es importante mencionar que la apertura a la inversión, por sí sola, no garantiza un mayor desarrollo del espacio rural. La atracción de empresas ancla debe estar complementada con la creación de condiciones propicias para producir efectos secundarios económicos y de conocimiento entre los actores que integran el área, así como entre estos y el resto de la economía local.

Las políticas de competencia buscan vigilar que en los mercados agroalimentarios no se observen comportamientos contrarios a la libre competencia entre los actores, por ejemplo, abusos de posición dominante o la formación de cárteles. La política pública también puede incidir sobre la formación de precios a través de acciones de política de competencia y apoyo a los productores frente a la alta volatilidad de los precios agroalimentarios; asimismo, es posible llegar a una serie de arreglos institucionales orientados a promover mercados menos distorsionados y de buen funcionamiento supervisando la formación de precios. En una cadena de valor agroalimentaria, los actores que participan tienen diferentes capacidades de negociación. Aquí emerge la figura del intermediario, que adquiere un papel destacado en la gobernanza de la cadena e influye en la formación de los precios. La política pública puede repercutir en la formación de los precios, tanto en el ámbito del comercio exterior como en relación al mercado interno y la regulación de las medidas de tributación, crédito, comercio, provisión de servicios de acopio y trazabilidad, entre otros factores (Gandlgruber, García y Nazif, 2014).

\section{Políticas para el fomento productivo}

Este grupo de políticas es el más amplio y ayuda a las empresas, cooperativas y productores individuales rurales a superar las barreras que enfrentan en materia de productividad, innovación y acceso a los mercados. Se pueden agrupar en seis áreas de intervención: i) productividad; ii) comercialización; iii) educación y capacitación; iv) acceso al financiamiento; v) ciencia, tecnología e innovación (CTI), y vi) articulación productiva (véase el cuadro II.8). 
Cuadro II.8

Políticas para el fomento productivo

\begin{tabular}{|c|c|}
\hline Área & Instrumentos \\
\hline Productividad & $\begin{array}{l}\text { - Apoyo para mejorar la productividad de las actividades productivas } \\
\text { rurales (transformación y servicios) } \\
\text { - Apoyo al acceso y al mejoramiento de los sistemas productivos y } \\
\text { los bienes públicos rurales } \\
\text { - Promoción y fomento de las buenas prácticas en el espacio rural } \\
\text { - Fomento de los emprendimientos rurales }\end{array}$ \\
\hline Comercialización & $\begin{array}{l}\text { - Apoyo a la recopilación y difusión de información sobre mercados } \\
\text { agroindustriales y de servicios } \\
\text { - Asistencia en la obtención de certificaciones para mejorar el } \\
\text { posicionamiento del producto o servicio } \\
\text { - Apoyo a la infraestructura (transporte y comercial) }\end{array}$ \\
\hline Educación y capacitación & $\begin{array}{l}\text { - Fomento de la formación de recursos humanos en el espacio rural } \\
\text { - Fomento y apoyo a la capacitación en TIC } \\
\text { - Fomento y apoyo a la capacitación en gestión de negocios }\end{array}$ \\
\hline Acceso al financiamiento & $\begin{array}{l}\text { - Promoción y fomento del crédito y el microcrédito rurales } \\
\text { - Fomento de los fondos de garantía para intermediarios financieros } \\
\text { - Promoción de capitales semilla y capitales de riesgo }\end{array}$ \\
\hline $\begin{array}{l}\text { Ciencia, tecnología e } \\
\text { innovación }\end{array}$ & $\begin{array}{l}\text { - Apoyo a la transferencia tecnológica y extensionismo } \\
\text { - Fomento y apoyo a los fondos tecnológicos y estímulos a la } \\
\text { innovación en el espacio rural (enfocados, por ejemplo, en la } \\
\text { agroindustria o los servicios turísticos rurales) } \\
\text { - Promoción y fomento de la inversión pública y privada en } \\
\text { investigación, desarrollo e innovación (I+D+I) } \\
\text { - Fortalecimiento de los sistemas de innovación agroalimentarios }\end{array}$ \\
\hline Articulación productiva & $\begin{array}{l}\text { - Promoción y fomento de las aglomeraciones en torno a productos } \\
\text { agroindustriales, servicios turísticos, y otras manufacturas y } \\
\text { servicios del espacio rural } \\
\text { - Promoción y fomento de la asociatividad rural } \\
\text { - Promoción y fomento del desarrollo de proveedores } \\
\text { - Fortalecimiento y fomento de cadenas de valor }\end{array}$ \\
\hline
\end{tabular}

Fuente: Elaboración propia.

En el primer grupo se encuentran los instrumentos y las acciones para enfrentar el reto de incrementar la productividad en el espacio rural, con énfasis en las unidades de producción de menor tamaño, como las microempresas y pequeñas empresas rurales, y los pequeños productores.

Las microempresas y pequeñas empresas rurales no agropecuarias están extendiéndose en el medio rural como respuesta, entre otros factores, a las necesidades de diversificar los ingresos de los hogares rurales. Entre los múltiples retos de las empresas no agropecuarias, se han identificado el tamaño, los volúmenes de producción, la baja productividad, la escasa generación de valor agregado, problemas de acceso a mercados, el cumplimiento de estándares de calidad y trazabilidad, brechas en el desempeño tecnológico y la informalidad (Angulo y Mata, 2008). La política de fomento de las microempresas y pequeñas empresas rurales puede operar, por ejemplo, mediante acciones para acceder a financiamiento; asistencia técnica; capacitación; incentivos para la asociatividad; acceso a insumos, maquinaria y equipo; el fortalecimiento de los vínculos con cadenas de valor; programas 
de modernización; inclusión de jóvenes y mujeres; empleo decente, e incorporación de TIC.

Una de las restricciones recurrentes mencionadas en estudios sobre cadenas de valor en el medio rural es la ausencia de buenas prácticas agrícolas y manufactureras (véanse los casos específicos de cadenas de valor rurales en Alvarado y otros, 2016; Romero, Díaz y Aguirre, 2016; Cordero, 2014; Oddone y Beltrán, 2014). El fomento de las buenas prácticas incluye apoyos y promoción para contar con certificaciones, sistemas de calidad y denominaciones de origen, además de asesorías puntuales para mejorar la calidad y los rendimientos de la producción agrícola y agroindustrial. También existen certificaciones de calidad para servicios de turismo, como el turismo sostenible.

Los gobiernos también pueden incentivar los emprendimientos rurales. El objetivo es la creación de nuevas oportunidades comerciales en el espacio rural. En el medio rural de América Latina y el Caribe, han aumentado las tasas de jefatura y el empleo rural femeninos. Entre 2000 y 2012, las tasas de jefatura femenina rural subieron en promedio más de seis puntos porcentuales. En el caso de los jóvenes, estos tienen un mayor nivel de instrucción. En el espacio rural latinoamericano, los jóvenes exhiben una menor participación en el empleo familiar no remunerado (informal) y una mayor participación en el empleo asalariado no agrícola (formal), aunque esta situación difiere en algunos países de Centroamérica ${ }^{11}$. Estos cambios demográficos dan cuenta de nuevas oportunidades y desafíos para incentivar los emprendimientos rurales entre estos grupos de la población.

Un segundo grupo de instrumentos está representado por aquellos que facilitan la colocación de los productos o servicios en mercados existentes o nuevos. Estas intervenciones se complementan con las políticas comerciales examinadas en el apartado anterior. Uno de los principales desafíos del medio rural es la asimetría en el acceso a información sobre mercados $\mathrm{y}$, en general, sobre los canales de comercialización de productos y servicios, las redes de distribución, y las condiciones de oferta y demanda. Esta asimetría se da entre los diferentes eslabones que componen una cadena de valor. La intervención incluye apoyos destinados a reunir y difundir información sobre los mercados potenciales, identificar los canales de comercialización, y determinar las condiciones de oferta y demanda. Otro tipo de instrumentos de este grupo son los apoyos para acceder a la infraestructura y el equipo de comercialización, por ejemplo, el transporte o los centros de acopio, o para mejorar estos componentes. Aquí también se incluye la asistencia técnica para la obtención de

11 Véase un análisis detallado en Srinivasan y Rodríguez (2016). 
certificaciones a fin de mejorar el posicionamiento de productos o servicios en diferentes nichos.

El tercer grupo corresponde a las actividades de educación y capacitación. Las intervenciones para apoyar la calificación de los recursos humanos procuran elevar el nivel y la calidad de la formación técnicoprofesional, así como la cantidad de recursos humanos y su permanencia en el sistema escolar. Una restricción frecuente observada en las cadenas de valor rurales es la falta de capacidades de los actores para gestionar los negocios. Además de la educación formal, los gobiernos pueden apoyar la capacitación para el desarrollo de habilidades en la gestión comercial. El objetivo de este instrumento es incrementar las capacidades empresariales de los productores o empresarios de menor tamaño a fin de mejorar su desempeño productivo.

Otra limitación de los actores rurales para acceder a las TIC, además de la oferta virtual y la infraestructura, son sus capacidades digitales, así como la percepción y el manejo de información en diferentes niveles tecnológicos (Nagel, 2012) ${ }^{12}$. La capacitación en TIC o alfabetización digital es un instrumento para enfrentar este desafío y crear condiciones para la integración de nuevas tecnologías en el espacio rural.

El cuarto grupo corresponde a las intervenciones para apoyar el financiamiento de las actividades productivas en el espacio rural. En América Latina y el Caribe, el acceso al crédito rural constituye un desafío clave. Una de las razones es que la banca comercial se enfoca en el crédito de corto plazo, muestra altos márgenes de intermediación y atiende la demanda de los segmentos de ingresos medios y altos, y así excluye a las unidades productivas de menor tamaño y, en general, a los sectores que presentan mayor riesgo (Titelman, 2003). En consecuencia, la banca de desarrollo y otras organizaciones de apoyo creadas con fondos públicos han brindado respaldo al crédito rural para actores excluidos del mercado formal o bien a instrumentos especiales y nuevas formas de intermediación.

Los fondos de garantía son otro instrumento de intervención gubernamental: complementan las garantías otorgadas por un acreditado en favor de un intermediario financiero como respaldo del crédito concedido. Mediante las garantías de una entidad pública, se respalda el crédito brindado a productores por intermediarios financieros. Otro tipo de instrumento del financiamiento rural es el microcrédito, que procura atender las necesidades financieras de unidades de menor tamaño. Un instrumento menos utilizado en las políticas de financiamiento rural

12 En la mayoría de las agendas digitales de la región se hace mención de la importancia de las TIC en el medio rural; sin embargo, hay escasez de propuestas para fomentar la adopción de las TIC en este ámbito (Nagel, 2012). 
es el apoyo a los fondos de capital de riesgo o capital semilla. El Estado puede proveer recursos que incentiven negocios innovadores en el espacio rural.

En el quinto grupo se encuentran las políticas de fomento de la CTI, que tienen incidencia directa sobre la mejora de la productividad de los actores del espacio rural. En el medio rural, la innovación es escasa; en los países en desarrollo, se suele adaptar y mejorar de manera incremental la tecnología agropecuaria y agroindustrial. Estas políticas facilitan la introducción exitosa en el mercado de nuevos productos, procesos y servicios a partir de apoyar la creación y difusión de conocimientos (Ekboir y otros, 2009). Estos instrumentos se relacionan con los procesos de escalamiento industrial y diversificación productiva. Los diferentes tipos de escalamiento económico de una cadena de valor - producto, proceso y funciones, por ejemplo- están ligados a una mejora o introducción novedosa de procesos, productos y formas de organización.

En el medio rural es muy importante el apoyo a la transferencia de tecnología y el extensionismo encauzado mediante paquetes tecnológicos, la promoción de ferias de intercambio tecnológico, giras tecnológicas y eventos demostrativos. Los fondos tecnológicos y los estímulos a la innovación en el espacio rural contribuyen a incrementar el valor de los productos y a mejorar los ingresos y las condiciones de vida de la población rural. Son estímulos que incluyen las actividades agropecuarias, la agroindustria y los servicios rurales. A diferencia del extensionismo, se busca la introducción en el mercado de nuevos productos, procesos o formas de organización y comercialización, y no solo la transferencia o adopción tecnológicas. También favorecen la vinculación entre varios actores, como las empresas, el sector gubernamental, las universidades y los centros de investigación y desarrollo (I+D).

La intervención gubernamental también puede darse por medio del fomento de la inversión pública y privada en I+D, alianzas públicoprivadas, proyectos de investigación y venta de insumos tecnológicos. El objetivo de este tipo de actividades es generar y difundir nuevos conocimientos que puedan aplicarse al desarrollo productivo. El componente institucional es sumamente importante para este grupo de políticas. En esta categoría se incluyen los instrumentos para fortalecer los sistemas de innovación agroalimentaria, que abarcan un amplio rango de actores que orientan, apoyan, crean, transfieren o adoptan innovaciones, además de quienes informan a los productores y al sector público sobre las innovaciones (OCDE, 2013; Padilla, 2013). 
El último grupo de esta batería de instrumentos es el fomento de la articulación productiva. Esta se basa en acuerdos de colaboración empresarial e interinstitucional con el objetivo de mejorar el desempeño productivo y competitivo de las unidades productivas, especialmente las de menor tamaño (Ferraro, 2010). En el espacio rural de América Latina y el Caribe las empresas manufactureras y de servicios de menor tamaño suelen tener poca capacidad para ofrecer los volúmenes de producción demandados por el mercado, brindan una calidad insuficiente y enfrentan limitaciones para escalar a segmentos de mayor valor agregado. Fomentar la asociatividad y las actividades de cooperación entre estas unidades de menor tamaño es una forma de afrontar estos retos.

El sector público también puede apoyar la conformación y el fortalecimiento de las aglomeraciones productivas en el espacio rural. Existen ventajas y externalidades asociadas a estas, así como una gran variedad de casos de éxito en términos de su eficiencia colectiva (Schmitz, 1999). Las aglomeraciones rurales ayudan a disminuir los costos, por ejemplo, de transporte y suministro; a atraer clientes, aumentar la especialización y la productividad; a diseminar conocimientos; y a crear sinergias con otros actores. Se debe tener en cuenta que el surgimiento de estas externalidades no sucede de manera automática y que estas iniciativas no reemplazan otras intervenciones, como la asistencia técnica, el financiamiento, una coordinación efectiva entre los diversos actores, la acumulación de capacidades, la introducción de innovaciones o la mejora de la posición que ocupan las unidades productivas (Crespi, FernándezArias y Stein, 2014).

Una de las restricciones observadas en los estudios sobre encadenamientos en el medio rural es la debilidad de los vínculos con clientes potenciales. Una forma de superar este desafío consiste en el desarrollo de proveedores. Estas intervenciones fomentan los programas que favorecen la integración de las unidades productivas en cadenas de suministro, fortalecen las capacidades productivas y tecnológicas, y proporcionan información sobre los mercados y canales de comercialización.

Finalmente, el fortalecimiento de cadenas de valor es otro instrumento de la política industrial rural. Se entiende como la transformación de la cadena mediante la superación de las restricciones que enfrenta, de manera que efectúe una mayor contribución al desarrollo económico y social del territorio donde opera (Padilla y Oddone, 2016). Las intervenciones están dirigidas a fortalecer los eslabones que conforman la cadena, así como las relaciones entre ellos. Para lograrlo, 
se hace uso de una amplia gama de herramientas, siempre con enfoque de cadena, como capacitación, fomento de la innovación, financiamiento y apoyo para acceso a mercados, entre otras. En el capítulo III de este libro se presenta la metodología de la CEPAL para el fortalecimiento de cadenas, mientras que en los capítulos V y VI se sintetiza la intervención en diversos tipos de cadenas.

\section{Políticas ambientales}

El cambio estructural progresivo no solo implica incrementar la productividad, sino también hacerlo de forma sostenible (CEPAL, 2016b). En el espacio rural, la política ambiental se ha vuelto un elemento indispensable de las políticas para el desarrollo productivo. En el cuadro II.9 se presentan algunos instrumentos de este tipo, y se integran y complementan con las medidas revisadas en las secciones precedentes.

\section{Cuadro II.9}

\section{Políticas ambientales}

\begin{tabular}{ll}
\hline Área & Instrumentos \\
\hline Mitigación del cambio & - Apoyo a la gestión de residuos y generación de energías alternativas \\
climático & en actividades de transformación y servicios en el espacio rural \\
& - Fomento de la provisión de servicios ambientales \\
& - Apoyo a la investigación y los servicios de extensión para la \\
& mitigación del cambio climático \\
\hline Adaptación al cambio & Apoyo a la gestión de riesgos en la provisión de servicios en el \\
climático & espacio rural (turismo) \\
& Fomento de la inversión privada en investigación, desarrollo e \\
& innovación $(I+D+I)$ para la adaptación al cambio climático \\
\hline
\end{tabular}

Fuente: Elaboración propia.

En el primer grupo se encuentran el fomento de la oferta de servicios ambientales que permitan mitigar el impacto de las actividades de transformación y los servicios en el medio ambiente rural. También se incluye la provisión de servicios para sistemas agroecológicos, que incentivan la producción sostenible en el ámbito de la silvicultura, la agricultura, la ganadería y la pesca. Estos sistemas utilizan los recursos locales y generan sinergias a nivel del ecosistema mediante prácticas de control biológico y nutrición sin el uso de productos sintéticos. La agricultura orgánica es un sistema agroecológico que incrementa el valor agregado de los productos agroindustriales. Este grupo comprende también el apoyo a la investigación y los servicios de extensión para la mitigación del cambio climático.

El segundo grupo de instrumentos se relaciona con los retos que supone la adaptación de las actividades rurales a los efectos del cambio climático. En América Latina y el Caribe, los impactos del cambio climático 
son una realidad y se ha alertado sobre su incidencia en el largo plazo. Se prevé que los efectos serán mayores en países de climas tropicales. Frente a este reto, un área de intervención es apoyar la adaptación de las unidades productivas a los efectos de dichos cambios. La política industrial rural puede encauzar este apoyo mediante el fomento de la oferta de servicios en materia de producción resiliente al cambio climático, los que se basan, por ejemplo, en el mejoramiento genético (creación de nuevas variedades de semillas resistentes, por ejemplo, a sequías, el calor o la sal), la gestión de los recursos hídricos, el control de la erosión y los nutrientes del suelo, el manejo integral de las unidades de producción, la vigilancia y el control de las plagas y enfermedades, la restauración de hábitats degradados, y los arreglos forestales y silvopastoriles (Rodríguez, López, Meza y Loboguerrero, 2015).

Una de las consecuencias del cambio climático es la exposición a fenómenos climáticos extremos. Los instrumentos de manejo de los riesgos climáticos en el sector productivo representan un componente fundamental de las políticas ambientales para la adaptación e incluyen servicios para el monitoreo del clima y la producción, utilización de pronósticos, sistemas de alerta temprana, incentivos a la diversificación productiva y fomento de esquemas financieros, como los seguros agropecuarios (CEPAL/CAC/SICA, 2013). En el turismo rural es de gran importancia contar con mecanismos de gestión de riesgos ante fenómenos climatológicos adversos, como se detalla en el capítulo VI. Se incluye también el apoyo a la investigación y los servicios de extensión para la adaptación de las actividades productivas del espacio rural al cambio climático.

Los diversos instrumentos para el desarrollo productivo no son excluyentes ni se dan de forma aislada. Por ejemplo, como se detalla en los siguientes capítulos, el fomento de cadenas de valor hace uso de una amplia gama de instrumentos complementarios en materia de educación, innovación y comercialización, entre otros.

\section{Experiencias en la aplicación de instrumentos coincidentes con la política industrial rural}

En materia de política industrial rural, al igual que con la política industrial en general, no hay estrategias ni instrumentos que funcionen de igual forma en todos los casos. Se pueden extraer lecciones valiosas, pero su diseño y su implementación no deben abandonar el pragmatismo ni la consideración de las especificidades económicas, institucionales, ambientales y sociales de cada país. 
A continuación, se presentan, a manera de ilustración, tres experiencias de países que han implementado instrumentos de política cuyos objetivos coinciden con la propuesta efectuada en este capítulo, aunque cabe señalar que estos instrumentos no han sido concebidos en forma explícita como parte de una política industrial rural. Se han elegido estas economías porque lograron fortalecer, con diferentes estrategias, la estructura productiva del espacio rural respectivo. Los países analizados tienen diferentes niveles de desarrollo. Chile es un país agroexportador de bienes primarios con experiencias valiosas en la aplicación de políticas en el espacio rural. Se incluye también un país desarrollado de ingresos altos: Nueva Zelandia. A pesar de que su estrategia apuntó a reducir la intervención del Estado, se han destinado enormes inversiones a rubros como la I+D+I, además de promover la transformación y el escalamiento de las actividades agropecuarias. Por último, se presenta la experiencia de Costa Rica, una economía en desarrollo de menor tamaño donde se han puesto en práctica instrumentos para fomentar los servicios de turismo sostenible y turismo rural. Una consideración final es que las políticas implementadas en estos tres casos aún deben someterse a una evaluación a fin de determinar el impacto que ejercieron.

\section{Chile}

El modelo económico chileno reciente ha tenido como uno de sus componentes centrales la promoción de las exportaciones de acuerdo con las vocaciones productivas locales: productos mineros, agroindustriales, frutícolas, vitivinícolas, forestales, pesqueros y acuícolas. El $11 \%$ de la población vive en zonas rurales, donde la agricultura y los productos manufacturados basados en recursos naturales son actividades clave. El valor agregado de la producción agrícola representa el $4 \%$ del PIB, cifra que supera el promedio de los países miembros de la OCDE (1,6\% en 2013). En 2015 los productos definidos como primarios y las manufacturas basadas en recursos naturales representaron alrededor del $92 \%$ de la canasta de exportaciones chilenas ${ }^{13}$.

Desde la década de 1970 se viene implementando un conjunto de instrumentos que dan gran impulso a los productos agrícolas y a los productos basados en recursos naturales (Moguillansky, Ramírez y Runaro, 2013). En el cuadro II.10 se sintetizan algunos de los instrumentos de política industrial rural utilizados desde los años previos a la apertura comercial.

13 Sobre la base de información del Banco Mundial (2016), la OCDE (2016) y SIGCI Plus (2016). 


\section{Cuadro II.10}

\section{Chile: ejemplos de instrumentos y acciones de política industrial rural}

\begin{tabular}{|c|c|}
\hline Período & Instrumentos y acciones \\
\hline $1930-1973$ & - Inversión estatal en el sector agroindustrial \\
\hline 1973-1989 & $\begin{array}{l}\text { - Impulso a Grupos de Transferencia Tecnológica (GTT) } \\
\text { - Se crea la institución puente Fundación Chile } \\
\text { - } \quad \text { Promoción de exportaciones; se crea PROCHILE }\end{array}$ \\
\hline 1990-1999 & 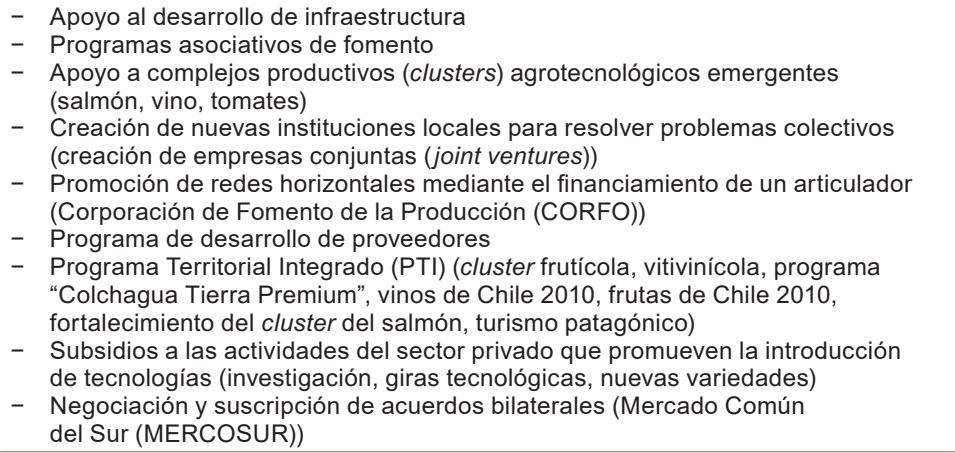 \\
\hline Desde 2000 & $\begin{array}{l}\text { - Programas para la disminución de asimetrías de información, el cierre de las } \\
\text { brechas entre pequeñas y medianas empresas (pymes) y grandes empresas } \\
\text { en el acceso al crédito, y la reducción de los costos de transacción } \\
\text { - Se implementa un programa de seguro agrícola (riesgos climáticos) } \\
\text { - Fomento de las buenas prácticas y sistemas de denominaciones de origen } \\
\text { para nuevos productos } \\
\text { - Planes de mejoramiento productivo: agendas de desarrollo de clusters } \\
\text { - Agencias Regionales de Desarrollo Productivo (ARDP) y la Corporación } \\
\text { de Fomento de la Producción (CORFO) } \\
\text { - Fomento de los encadenamientos de la agricultura familiar campesina } \\
\text { - Fomento de las alianzas productivas } \\
\text { - Fortalecimiento de cadenas de valor agroalimentarias } \\
\text { - Consorcios tecnológicos empresariales } \\
\text { - Papel clave de la CORFO en el fomento de la innovación, la intermediación } \\
\text { financiera, y el apoyo a capitales semilla, incubadoras, redes de inversionistas ángel, } \\
\text { empaquetamiento tecnológico, capacitación y formación de recursos humanos } \\
\text { - Focalización en programas estratégicos de especialización inteligente (turismo } \\
\text { sostenible, alimentos saludables, acuicultura y pesca sostenibles, productividad } \\
\text { - y construcción sostenible) } \\
\text { - Exfasis en programas de emprendimiento (start-ups) } \\
\text { - y elensión y apoyo a la agricultura familiar campesina para la innovación } \\
\text { - Apoyo a actividades conexas (por ejemplo, turismo rural) }\end{array}$ \\
\hline
\end{tabular}

Fuente: Elaboración propia, sobre la base de G. Moguillansky, E. Ramírez y A. Runaro, "Las políticas de desarrollo productivo en Chile 1990 y 2012", Documento de Trabajo, № 19, Santiago, Centro Latinoamericano para el Desarrollo Rural (RIMISP), 2013; Instituto de Desarrollo Agropecuario (INDAP), Lineamientos estratégicos 2014-2018. Por un Chile rural inclusivo, Santiago, Ministerio de Agricultura, 2014; A. Andreoni, "Structural and Industrial Policy: The Role of Intermediate Institutions in Manufacturing Agrarian Change", 2013 [en línea] https://www.economic-policyforum.org/wp-content/uploads/2013/10/Andreoni_Structural_Industrial_Policy_Brazil_Chile.pdf.

La revisión de organizaciones públicas de apoyo, como la Corporación de Fomento de la Producción (CORFO), ha sido clave. Creada hace 77 años, sus programas han beneficiado a varios sectores, incluidas las actividades del espacio rural, y tienen un fuerte acento en el desarrollo productivo y la colaboración público-privada. La Fundación Chile, por ejemplo, es una 
organización privada sin fines de lucro para la investigación científica y tecnológica, creada con la participación del Gobierno y el sector privado. En sus inicios, la fundación implementó una serie de proyectos de demostración enfocados en la transferencia de tecnologías y el cambio agromanufacturero (la adopción de las tecnologías industriales y las innovaciones basadas en la ciencia para la agricultura, la acuicultura y las unidades de producción agrícola). En algunos casos, estos proyectos demostrativos tuvieron como resultado la creación de nuevos laboratorios. Este organismo también fungió como entidad de certificación de calidad para frutas y verduras de exportación. La Fundación Chile puede considerarse una institución puente enfocada en facilitar las tecnologías transversales (TIC, biotecnologías, servicios de ingeniería, gestión de recursos humanos y tecnologías ambientales), que apoyan los procesos de escalamiento hacia actividades más innovadoras (Andreoni, 2013).

Una de las lecciones que deja la experiencia de Chile es que los instrumentos orientados a mejorar la competitividad, el desarrollo tecnológico y la innovación han tenido mejores resultados en aquellas regiones con cadenas de valor constituidas y donde las pymes se desarrollaron y pudieron exportar o estaban organizadas en aglomeraciones (Moguillansky, Ramírez y Furnaro, 2013).

No obstante, es importante reconocer las críticas al modelo chileno, que en años recientes ha mostrado un agotamiento producto de la sobreexplotación de los recursos naturales con limitada innovación, poca diversificación de la estructura productiva y escaso manejo sostenible. Ante esto, el Gobierno chileno se ha propuesto implementar políticas para desarrollar nuevos sectores productivos, potenciar la innovación e incrementar el desarrollo tecnológico a fin de incorporar mayor valor agregado a las actividades primarias. Las intervenciones públicas recientes rescatan la importancia de facilitar la coordinación entre diferentes sectores productivos, por ejemplo, para apoyar la transformación estructural del sector primario e integrarlo con nuevas industrias, como las TIC, la biotecnología y la generación de energías alternativas.

\section{Nueva Zelandia}

Nueva Zelandia representa una economía desarrollada de ingresos altos orientada al mercado externo. Es un país agroexportador neto y sus políticas han tenido un fuerte componente horizontal. A pesar de que en años recientes han disminuido los apoyos directos a los productores, destaca un aumento de la intervención pública en los servicios generales, como las áreas de investigación agrícola y la bioseguridad.

A raíz del cambio en la concepción del papel del Estado a finales de la década de 1980 y la disminución de los apoyos directos a los productores, 
el Gobierno de Nueva Zelandia impulsó otro tipo de estrategias, como la colaboración público-privada en investigación, el desarrollo y la innovación en la industria de los alimentos. Los consorcios de investigación son un ejemplo de este tipo de colaboraciones destinadas a vincular a la industria y al sector académico en proyectos conjuntos de investigación en áreas de desarrollo rural y en la creación de nuevas industrias, por ejemplo, la biotecnología y las TIC (Hartwich y Negro, 2010; Moguillansky, 2006).

En distintas iniciativas de política pública se ha reconocido la transformación productiva y la importancia de la industria de alimentos procesados, como el Grupo de Trabajo del Gobierno y la Industria de Alimentos y Bebidas (2005/2006) o la Agenda del Gobierno para el Crecimiento Económico (CORIOLIS, 2010). Un ejemplo de instrumentos de política pública que actualmente proporcionan apoyo a la transformación productiva es el programa Primary Growth Partnership, en el que se invierte en programas de innovación a largo plazo, en colaboración con la industria, para apoyar el escalamiento económico de productos del sector agropecuario (MPI, 2017). Otro instrumento es la red New Zealand Food Innovation Network (NZFIN), que brinda soporte al sector agroalimentario a través de los recursos científicos y tecnológicos, las facilidades y los conocimientos especializados necesarios para desarrollar nuevos productos y procesos. En particular, este programa ayuda a vincular la ciencia y la investigación con la manufactura de alimentos (NZFIN, 2014).

En Nueva Zelandia tuvo lugar un proceso de diversificación del uso de la tierra (huertos, viñedos, turismo de aventura, crianza de venados) y los productos basado en la ampliación de los vínculos con el sector agroindustrial. Por ejemplo, en el caso de los lácteos, se exporta mantequilla, crema, leche condensada, queso, yogur, albúminas y crema fresca (Polson, 2009). En la industria de alimentos procesados de Nueva Zelandia, además de los productos de sectores consolidados, como el lácteo, el cárnico, el pesquero, el acuícola y el hortícola, han aparecido nuevos productos derivados de la transformación de los productos primarios, por ejemplo, hortalizas y verduras empaquetadas, miel, salmón y mejillones procesados, carne procesada, helado, sopas, salsas de tomate, aperitivos, yogur, alimentos para mascotas, galletas, chocolate, fórmulas para lactantes, vitaminas y minerales, aceites, bebidas suaves, vino y papas fritas (MBIE, 2015).

Una lección importante es que los modelos de asociatividad de los productores, por ejemplo, las cooperativas, han sido clave para hacer frente a la desregulación y la competencia con grandes empresas, además de que Nueva Zelandia cuenta con una representación consolidada de cámaras y asociaciones profesionales de sus industrias principales. Si bien los agricultores neozelandeses demostraron gran flexibilidad frente a la política de apertura, la desregulación y la reducción de las intervenciones 
del Estado en el sector, dichos cambios tuvieron lugar en el contexto de una economía estable y dinámica, y con instituciones en buen funcionamiento. Además, las medidas se aplicaron en forma gradual y controlada (Cabral y otros, 2006; Lattimore, 1997).

\section{Costa Rica}

Costa Rica ha logrado un proceso de transformación productiva significativo en las últimas décadas. En el espacio rural no solo se han incentivado las actividades primarias, sino que también se han escalado y complementado con otras actividades, como los servicios de turismo. Actualmente Costa Rica es el principal destino turístico de Centroamérica. Las divisas por turismo representaron el 6,4\% del PIB en 2016 (ICT, 2017), con una amplia oferta de productos y servicios relacionados con los recursos naturales. El turismo rural es parte de la oferta de servicios del turismo sostenible del país y es ejemplo de las actividades productivas que han recibido el apoyo de la acción pública. En el cuadro II.11 se muestran ejemplos de instrumentos y acciones adoptados en Costa Rica en esta materia.

\section{Cuadro II.11}

\section{Costa Rica: ejemplos de instrumentos y acciones para fortalecer el turismo rural}

\begin{tabular}{|c|c|}
\hline Período & Instrumentos y acciones \\
\hline 1990-1999 & $\begin{array}{l}\text { - Se crea la Asociación Centroamericana para la Economía, la Salud y el Ambiente } \\
\text { (ACEPESA), que trabaja en aras del turismo sostenible y ha incidido sobre la } \\
\text { política turística nacional vinculada al turismo rural comunitario en Centroamérica } \\
\text { - Se crea el Consorcio Cooperativo Red Ecoturística Nacional (COOPRENA) } \\
\text { - Firma de un convenio de colaboración entre el Instituto de Desarrollo Agrario y el } \\
\text { Instituto Costarricense de Turismo (ICT) para promover el agroturismo como una } \\
\text { posible solución a los temas de pobreza rural } \\
\text { - Campaña del ICT Costa Rica, Sin Ingredientes Artificiales } \\
\text { - Se inicia el programa de Certificación para la Sostenibilidad Turística (CST) }\end{array}$ \\
\hline Desde 2000 & 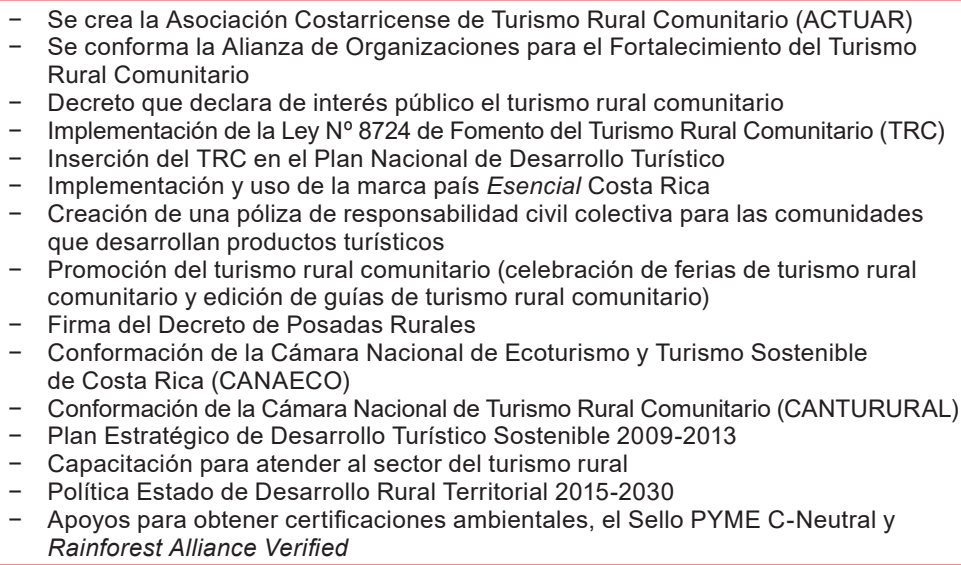 \\
\hline
\end{tabular}

Fuente: Elaboración propia, sobre la base de Instituto Interamericano de Cooperación para la Agricultura (IICA), Estudio sobre turismo rural en Costa Rica, San José, 2009; S. Salazar, Aportes del turismo rural comunitario en Costa Rica, San José, Instituto Nacional de Fomento Cooperativo, 2012. 
El turismo rural tiene sus orígenes en el auge del ecoturismo. En Costa Rica, la industria del ecoturismo emergió paralelamente a la consolidación del sistema de parques nacionales. Desde entonces, la política del Gobierno costarricense ha impulsado dos tipos de proyectos en los servicios turísticos: uno de tipo convencional (hoteles urbanos, resorts de playa y cruceros) y otro relacionado con el turismo sostenible (ecoturismo, turismo de aventura y turismo rural). En el segundo caso, el país es pionero en la implementación de distintos instrumentos. En la década de 1980 se fomentaron actividades relacionadas con la naturaleza y la aventura orientadas a un mercado incipiente de ecoturismo. La promoción de este sector llevó a que el país fuera nominado en 1992 por la Adventure Travel Society como el mejor destino ecoturístico del mundo (Honey, 2008).

A finales de la década de 1990, a partir de iniciativas de organizaciones locales, redes de organizaciones no gubernamentales, organismos internacionales y dependencias del gobierno, como el Instituto Costarricense de Turismo (ICT), el Ministerio de Agricultura y Ganadería (MAG) y el Instituto Nacional de Aprendizaje (INA), se impulsó formalmente en el país el turismo rural y el turismo rural comunitario. La Ley de Fomento del Turismo Rural Comunitario (TRC) entró en vigor en 2009 y tiene como objetivo "fomentar la actividad turística de tipo rural comunitario por medio del impulso de empresas de base familiar y comunitarias (...) con el fin de que las personas habitantes de las comunidades rurales procuren la gestión de su propio desarrollo, incluido el manejo de destinos turísticos locales y que además participen en la planificación y el aprovechamiento de los recursos naturales de su entorno de manera sostenible" (Asamblea Legislativa de la República de Costa Rica, 2009, pág. 1). Una de las razones por las que surge el TRC es que muchas de las actividades turísticas, aunque se denominaban sostenibles, no generaban beneficios para la población rural. El turismo rural tiene la ventaja de combinar las atracciones naturales y culturales, y las actividades productivas de la comunidad rural, por lo que constituye una opción para escalar y agregar valor a lo agropecuario (Fontana, 2012).

En Costa Rica, otra entidad pública relacionada con el apoyo al turismo sostenible y el turismo rural es el Ministerio de Ambiente y Energía y Telecomunicaciones (MINAET), que administra la protección y el control de los parques nacionales y posibilita opciones para la producción de bienes y servicios, como el pago por servicios ambientales y otros servicios para poblaciones cercanas a las áreas de conservación (IICA, 2009). Se cuenta también con el programa nacional de Certificación para la Sostenibilidad Turística (CST) desarrollado por el ICT y la Comisión Nacional de Acreditación (CST, 2016). Por otro lado, el sello diferenciador marca país "Esencial Costa Rica", que fomenta la Promotora del Comercio Exterior de Costa Rica (PROCOMER), pretende generar competitividad en 
Costa Rica y elevar los estándares de los productos y servicios ofrecidos por las empresas, incluidos los del turismo rural.

En diversos estudios se ha hecho notar los beneficios de escalar o complementar las actividades tradicionales agropecuarias con el turismo rural para diversificar los ingresos de la población rural (Salazar, 2012; IICA, 2009; Honey, 2008). Se debe reconocer que en Costa Rica han sido fundamentales las alianzas entre el sector público, las asociaciones de productores, las organizaciones no gubernamentales y las organizaciones privadas, así como los organismos cooperantes internacionales. Un desafío es que la oferta de este tipo de servicios está más consolidada en unidades productivas de mayor tamaño, mientras que las unidades más pequeñas enfrentan mayores restricciones.

\section{E. Conclusiones}

La política industrial implementada en América Latina y el Caribe en las últimas décadas - a lo largo del período de sustitución de importaciones, durante la apertura y liberalización económica, y más recientemente en el resurgimiento del interés por la política industrial - se ha concentrado en la industria manufacturera. En el caso particular de Centroamérica, México y la República Dominicana, los instrumentos se han focalizado en fomentar las manufacturas orientadas a la exportación. En años más recientes se ha reconocido el creciente peso del sector de los servicios y se dio impulso a sectores considerados clave, como el software y las llamadas industrias creativas. En este contexto, el espacio rural se ha mantenido al margen de la política industrial.

En este segundo capítulo se definió la política industrial rural y se enfatizó su importancia para un cambio estructural en el espacio rural. Se expusieron cinco ideas centrales. La primera: este espacio es definido de acuerdo con una integración de los criterios económicos o sectoriales, demográficos y territoriales. En este sentido, comprende las actividades rurales, como la agricultura, la ganadería, la pesca y la silvicultura, al igual que la agroindustria y los servicios que se producen y ofrecen en el espacio rural. La segunda idea plantea que la política industrial rural se define como la intervención del Estado orientada a fortalecer la estructura productiva del espacio rural a partir del escalamiento de las actividades rurales y de la transformación y complementariedad hacia actividades, mercados y sectores de mayor dinamismo e intensidad de conocimientos. Según la tercera, la política industrial rural reviste gran relevancia para los países de América Latina y el Caribe, donde las actividades rurales, como el sector agropecuario, aún tienen un peso significativo en la actividad económica total, y en las que se concentra la 
mayor parte de la población en situación de pobreza e indigencia. Según la cuarta, para que la política industrial rural promueva un cambio estructural progresivo, debe enfocarse por lo menos en tres procesos interrelacionados: i) el escalamiento económico y la incorporación del cambio tecnológico y los procesos de innovación; ii) el escalamiento social, y iii) el escalamiento de la estructura productiva con un enfoque de sostenibilidad. La quinta idea es que la política industrial rural, al estar dirigida a un sector o un territorio en particular, reviste predominantemente un corte vertical.

En la literatura y en la búsqueda de experiencias internacionales no se encontraron referencias previas a la política industrial rural. Países en desarrollo — como Chile y Costa Rica - y desarrollados — como Nueva Zelandia - han puesto en práctica estrategias alineadas, en mayor o menor medida, con lo que se propone en este capítulo. La experiencia de estos países muestra que, al igual que para la política industrial en sentido amplio, en materia de política industrial rural no existen soluciones únicas o una estrategia que pueda ser reproducida en otros países sin tomar en cuenta los factores económicos, sociales, culturales e históricos locales. Los instrumentos que persigan el cambio estructural rural, como los aquí propuestos, deben tener en cuenta el nivel de desarrollo de cada país y sus necesidades específicas. De igual forma, se deben tomar en consideración los niveles de intervención, la selección y la forma en que se llevan a cabo la ejecución y la evaluación de los instrumentos.

Este libro incluye dos capítulos donde se aborda el diseño de una política industrial rural aplicada a cadenas de valor. Se trata de intervenciones en cadenas de valor cuyos objetivos finales están alineados con los planes nacionales de desarrollo y planes sectoriales. En dichos capítulos se ilustran dos enfoques distintos: i) el fortalecimiento de las cadenas agropecuarias y agroindustriales existentes, con miras a incrementar su productividad y escalar hacia actividades de mayor valor agregado, y ii) el fortalecimiento de cadenas de valor de servicios, en particular las de turismo rural. 


\section{Bibliografía}

Alvarado, J. y otros (2016), "La cadena de valor de embutidos y otras conservas de carne de cerdo en México", Documentos de Proyectos (LC/MEX/W.17/Rev.1), Ciudad de México, Sede Subregional de la CEPAL en México.

Andreoni, A. (2013), "Structural and Industrial Policy: The Role of Intermediate Institutions in Manufacturing Agrarian Change" [en línea] https://www. economic-policy-forum.org/wp-content/uploads/2013/10/Andreoni_ Structural_Industrial_Policy_Brazil_Chile.pdf.

(2011), "Manufacturing agrarian change. Agricultural production, inter-sectoral learning and technological capabilities", Working Paper, $\mathrm{N}^{\circ}$ 11-13, DRUID Society.

Angulo, J. y A. Mata (2008), MIPYMES, agrocadenas y aprovechamiento del CAFTA en Centroamérica: análisis de los sectores lácteo, cerdo, pollo, maíz blanco y hortalizas bajo un enfoque de organización industrial, San José.

Arndt, C., A. McKay y F. Tarp (eds.) (2016), Growth and Poverty in Sub-Saharan Africa, Nueva York, Oxford University Press.

Asamblea Legislativa de la República de Costa Rica (2009), "Ley Fomento del Turismo Rural Comunitario. Ley No. 8724. Gaceta No. 191, 01 de octubre del 2009" [en línea] http://www.ict.go.cr/es/documentos-institucionales/ legislación-de-empresas / leyes-y-reglamentos / 630-ley-fomento-del-turismorural-comunitario/file.html.

Banco Mundial (2016) [en línea] http:/ / datos.bancomundial.org/.

Baumol, W. (1967), "Macroeconomics of unbalanced growth: the anatomy of urban crisis", American Economic Review, vol. 57, N³, Nashville, Tennessee, American Economic Association.

Bell, M. y K. Pavitt (1992), "Accumulating technological capability in developing countries", The World Bank Economic Review, vol. 6, N 1, Washington, D.C., Banco Mundial.

Bianchi, P. y S. Labory (2011), Industrial Policy after the Crisis: Seizing the Future, Cheltenham, Edward Elgar.

Cabral, L. y otros (2006), "Reforming agricultural policy: lessons from four countries", Working Paper, $\mathrm{N}^{\circ} 2$, Future Agricultures.

Carmignani, F. y T. Mandeville (2014), "Never been industrialized: A tale of African structural change", Structural Change and Economic Dynamics, vol. 31.

Castillo, M. y A. Martins (2016), "Premature deindustrialization in Latin America", serie Desarrollo Productivo, N 205 (LC/L.4183), Santiago, Comisión Económica para América Latina y el Caribe (CEPAL).

CELADE (Centro Latinoamericano y Caribeño de Demografía-División de Población de la CEPAL) (2016), "Estimaciones y proyecciones de población total, urbana y rural, y económicamente activa" [en línea] http:/ /www.cepal. org/es/estimaciones-proyecciones-poblacion-largo-plazo-1950-2100.

CEPAL (Comisión Económica para América Latina y el Caribe) (2016a), “CEPALSTAT. Bases de Datos y Publicaciones Estadísticas" [en línea] http:/ / estadisticas.cepal. org/cepalstat/WEB_CEPALSTAT/Portada.asp.

(2016b), Horizontes 2030. La igualdad en el centro del desarrollo sostenible (LC/G.2660/Rev.1), Santiago, CEPAL.

(2016c), Objetivos de Desarrollo Sostenible y retos del desarrollo rural en Centroamérica y la República Dominicana (LC/MEX/L.1205), Ciudad de México, Sede Subregional de la CEPAL en México. 
(2007), "Cinco piezas de política de desarrollo productivo", serie Desarrollo Productivo, N 176 (LC/L.2704-P), Santiago.

CEPAL/CAC/SICA (Comisión Económica para América Latina y el Caribe/ Consejo Agropecuario Centroamericano/Sistema de la Integración Centroamericana) (2013), Gestión integral de riesgos y seguros agropecuarios en Centroamérica y la República Dominicana: situación actual y líneas de acción potenciales (LC/MEX/L.1122), Ciudad de México, Sede Subregional de la CEPAL en México.

Chang, H.-J. (2012), "Debate: should industrial policy in developing countries conform to comparative advantage or defy it?", New Structural Economics, J. Lin, Washington, D.C., Banco Mundial.

(2009), Rethinking Public Policy in Agriculture. Lessons from Distant and Recent History, Roma, Organización de las Naciones Unidas para la Alimentación y la Agricultura.

Cimoli, M., G. Dosi y J. Stiglitz (2009), Industrial Policy and Development: The Political Economy of Capabilities Accumulation, Oxford, Oxford University Press.

Cordero, M. (2014), "Cadena de hortalizas de exportación no tradicionales en Guatemala", Fortalecimiento de las cadenas de valor como instrumento de la política industrial. Metodología y experiencia de la CEPAL en Centroamérica, R. Padilla (ed.), Libros de la CEPAL, No 123 (LC/G.2606-P), Santiago, Comisión Económica para América Latina y el Caribe (CEPAL).

Crespi, G., E. Fernández-Arias y E. Stein (eds.) (2014), ¿Cómo repensar el desarrollo productivo? Políticas e instituciones sólidas para la transformación económica, Washington, D.C., Banco Interamericano de Desarrollo.

CST (Certificación para la Sostenibilidad Turística) (2016), "Turismo Sostenible CST: Certificación para la Sostenibilidad Turística en Costa Rica" [en línea] http: / / www.turismo-sostenible.co.cr.

CORIOLIS (2010), Moving to the Centre: the future of the New Zealand food industry. Final Report to the Ministry of Economic Development, Aukland.

Devlin, R. y G. Moguillansky (2012), "What's new in the new industrial policy in Latin America?" Policy Research Working Paper, N 6191, Washington, D.C., Banco Mundial.

Dirven, M. y otros (2011), "Hacia una nueva definición de "rural" con fines estadísticos en América Latina", Documentos de Proyectos (LC/W.397), Santiago, Comisión Económica para América Latina y el Caribe (CEPAL).

Echeverri, R. (2011), "Reflexiones sobre lo rural: economía rural, economía de territorios", Hacia una nueva definición de "rural" con fines estadísticos en América Latina, Documentos de Proyectos (LC/W.397), M. Dirven y otros, Santiago, Comisión Económica para América Latina y el Caribe (CEPAL).

Ekboir, J. y otros (2009), Successful Organizational Learning in the Management of Agricultural Research and Innovation. The Mexican Produce Foundations, Washington, D.C., Instituto Internacional de Investigación sobre Políticas Alimentarias (IFPRI).

FAO (Organización de las Naciones Unidas para la Alimentación y la Agricultura) (2004), Política de desarrollo agrícola. Conceptos y principios, Roma.

Fernández-Stark, K., P. Bamber y G. Gereffi (2012), Inclusion of Small- and Mediumsized Producers in High-value Agro-food Value Chains, Center on Globalization, Governance and Competitiveness. 
Ferraro, C. (ed.) (2010), “Clusters y políticas de articulación productiva en América Latina", Documentos de Proyectos (LC/W.337), Santiago, Comisión Económica para América Latina y el Caribe (CEPAL).

FIA (Fundación para la Innovación Agraria) (2014), Memoria 2014, Santiago, Ministerio de Agricultura [en línea] http:/ / www.fia.cl/sobre-fia/memorias/.

FIDA (Fondo Internacional de Desarrollo Agrícola) (2016), Informe sobre el desarrollo rural 2016: fomentar la transformación rural inclusiva. Presentación general, Roma.

Fontana, Y. (2012), "Proceso de incidencia para la elaboración del proyecto de ley de fomento al turismo rural comunitario en Costa Rica, Ley 8724", tesis para optar al grado de magister, Facultad Latinoamericana de Ciencias Sociales (FLACSO)/Tecnológico de Costa Rica (TEC).

Gandlgruber, B., H. García-Jiménez e I. Nazif (2014), Economía institucional: propuesta metodológica para el análisis de la formación de precios agrícolas (LC/MEX/L.1142), Ciudad de México, Sede Subregional de la CEPAL en México.

Gereffi, G. (2014), "A global value chain perspective on industrial policy and development in emerging markets", Duke Journal of Comparative and International Law, vol. 24.

Gereffi, G. y J. Lee (2015), “Global value chains, rising power firms and economic and social upgrading", Critical Perspectives on International Business, vol. 11, $\mathrm{N}^{\circ}$ 3-4, Emerald.

Hartwich, F. y C. Negro (2010), "The role of collaborative partnerships in industry innovation: lessons learned from New Zealand`s dairy industry", Agribusiness, vol. $26, \mathrm{~N}^{\circ} 3$.

Hirschman, A. (1961), La estrategia del desarrollo económico, Ciudad de México, Fondo de Cultura Económica.

Honey, M. (2008), Ecotourism and Sustainable Development. Who Owns Paradise?, Washington, D.C., Island Press.

Humphrey, J. y H. Schmitz (2002), “Governance and upgrading: linking industrial cluster and global value chain research", IDS Working Paper, $\mathrm{N}^{\circ} 120$, Institute of Development Studies.

ICT (Instituto Costarricence de Turismo) (2017), “[en línea] http:/ /www.ict.go.cr/es/.

IICA (Instituto Interamericano de Cooperación para la Agricultura) (2009), Estudio sobre turismo rural en Costa Rica, San José.

(2004), Más que alimentos en la mesa: la real contribución de la agricultura a la economía, San José.

INDAP (Instituto de Desarrollo Agropecuario) (2014), Lineamientos estratégicos 2014-2018. Por un Chile rural inclusivo, Santiago, Ministerio de Agricultura.

Jorgenson, D., M. Ho y J. Samuels (2012), “A Prototype Industry-Level Production Account for the United States, 1947-2010", documento presentado en la World KLEMS Conference.

Kaldor, N. (1961), "Capital accumulation and economic growth", The Theory of Capital, F. Lutz y D. Hague, Londres, Macmillan.

Kay, C. (2009), “Development strategies and rural development: exploring synergies, eradicating poverty", The Journal of Peasant Studies, vol. 36, N 1, Taylor \& Francis.

Krüger, J. (2008), "Productivity and structural change: a review of the literature", Journal of Economic Surveys, vol. 22, No 2.

Lattimore, R. (1997), "The deregulation of New Zealand's food and fiber sector", Government and the Food Industry: Economic and Political Effects of Conflict and Co-Operation, T. Wallace y W. Schroder, Springer Science+Business Media, LLC. 
Lewis, A. (1954), "El desarrollo económico con oferta ilimitada de trabajo", La economía del subdesarrollo, A. Agarwala y S. Singh, Madrid, Tecnos.

Lin, J. (2012), New Structural Economics. A Framework for Rethinking Development and Policy, Washington, D.C., Banco Mundial.

List, F. (1856), The National System of Political Economy, J.B. Lippincott \& Co..

López-Acevedo, G. y H. Tan (2010), Impact Evaluation of SME Programs in Latin America and Caribbean, Washington, D.C., Banco Mundial.

Mazzucato, M. (2013), The Entrepreneurial State, Londres, Anthem Press.

McMillan, M.S.y D. Rodrik(2011), "Globalization, structural changeand productivity growth", NBER Working Paper, $N^{\circ} 17143$, Cambridge, Massachusetts, National Bureau of Economic Research.

Melo, A. y A. Rodríguez-Clare (2006), Productive Development Policies and Supporting Institutions in Latin America and The Caribbean, Washington, D.C., Banco Interamericano de Desarrollo.

MBIE (Ministerio de Empresas, Innovación y Empleo) (2015), The Investor's Guide to the New Zealand Food E Beverage Industry, Wellington.

MPI (Ministerio de Industrias Primarias) (2017), Primary Growth Partnership. Smart ideas, Smart Action, Smart Results. Ministry for Primary Industries, Wellington.

Misselden, E. (1954), "The circle of commerce", Source Readings in Economic Thought, P.C. Newman, A. Gayer y M. Spencer, Nueva York, Norton.

Moguillansky, G. (2006), "Australia y Nueva Zelandia: la innovación como eje de la competitividad", serie Comercio Internacional, N 72 (LC/L.2564-P), Santiago, Comisión Económica para América Latina y el Caribe (CEPAL).

Moguillansky, G., E. Ramírez y A. Runaro (2013), “Las políticas de desarrollo productivo en Chile 1990 y 2012", Documento de Trabajo, N 19, Santiago, Centro Latinoamericano para el Desarrollo Rural (RIMISP).

Naciones Unidas (2009), Clasificación Industrial Internacional Uniforme de Todas las Actividades Económicas (CIIU). Revisión 4 (ST/ESA/STAT/SER.M/4/Rev.4), Nueva York.

(2007), The Wye Group Handbook. Rural Households' Livelihood and Well Being. Statistics on Rural Development and Agriculture Household Income, Nueva York, Comisión Económica para Europa (CEPE)/Oficina Estadística de la Unión Europea (Eurostat) / Organización de las Naciones Unidas para la Alimentación y la Agricultura (FAO)/Organización de Cooperación y Desarrollo Económicos (OCDE)/Banco Mundial.

Nagel, J. (2012), "Principales barreras para la adopción de las TIC en la agricultura y en las áreas rurales", Documentos de Proyectos (LC/W.501), Santiago, Comisión Económica para América Latina y el Caribe (CEPAL).

Nurkse, R. (1935), "The schematic representation of the structure of production", Review of Economic Studies, vol. 2, N 3, Oxford University Press.

NZFIN (New Zealand Food Innovation Network) (2014) [en línea] http://food innovationnetwork.co.nz.

O'Mahony, M. y M. Timmer (2009), “Output, input and productivity measures at the industry level: The EU KLEMS database", The Economic Journal, vol. 119, $\mathrm{N}^{\circ} 538$, Wiley.

OCDE (Organización de Cooperación y Desarrollo Económicos) (2016), Agricultural Policy Monitoring and Evaluation 2016, París, OECD Publishing. (2013), Agricultural Innovation Systems. A Framework for Analysing the Role of the Government, París, OECD Publishing. 
(2006), The New Rural Paradigm: Policies and Governance, París, OECD Publishing. (1996), Better Policies for Rural Development, París, OECD Publications.

Oddone, N. y C.S. Beltrán (2014), "La cadena del camarón de cultivo en El Salvador", Fortalecimiento de las cadenas de valor como instrumento de la política industrial. Metodología y experiencia de la CEPAL en Centroamérica, R. Padilla (ed.), Libros de la CEPAL, N 123 (LC/G.2606-P), Santiago, Comisión Económica para América Latina y el Caribe (CEPAL).

Oddone, N., R. Padilla y B. Antunes (2014), “Metodología del proyecto CEPAL-GIZ para el diseño de estrategias de fortalecimiento de cadenas de valor", Fortalecimiento de las cadenas de valor como instrumento de la política industrial. Metodología y experiencia de la CEPAL en Centroamérica, R. Padilla (ed.), Libros de la CEPAL, N 123 (LC/G.2606-P), Santiago, Comisión Económica para América Latina y el Caribe (CEPAL).

Padilla, R. (2014), Fortalecimiento de las cadenas de valor como instrumento de la política industrial. Metodología y experiencia de la CEPAL en Centroamérica, R. Padilla (ed.), Libros de la CEPAL, N 123 (LC/G.2606-P), Santiago, Comisión Económica para América Latina y el Caribe (CEPAL).

(2013), "Sistemas de innovación en Centroamérica. Fortalecimiento a través de la integración regional", Libros de la CEPAL, N 118 (LC/G.2559-P), Santiago, Comisión Económica para América Latina y el Caribe (CEPAL).

Padilla, R. y J. Alvarado (2014), "El resurgimiento de la política industrial", Fortalecimiento de las cadenas de valor como instrumento de la política industrial. Metodología y experiencia de la CEPAL en Centroamérica, R. Padilla (ed.), Libros de la CEPAL, N 123 (LC/G.2606-P), Santiago, Comisión Económica para América Latina y el Caribe (CEPAL).

Padilla, R. y N. Oddone (2016), Manual para el fortalecimiento de cadenas de valor (LC/MEX/L.1218), Ciudad de México, Sede Subregional de la CEPAL en México.

Pasinetti, L. (1993), Structural Economic Dynamics. A Theory of the Economic Consequences of Human Learning, Cambridge, Cambridge University Press.

(1973), "The notion of vertical integration in economic analysis", Metroeconomica, vol. 25, $\mathrm{N}^{\circ}$ 1, Wiley.

Pavitt, K. y M. Bell (1992), "Acumulating technological capability in developing countries", The World Bank Economic Review, vol 6, No 1.

Peres, W. y A. Primi (2009), "Theory and practice of industrial policy. Evidence from the Latin American experience", serie Desarrollo Productivo, № 187 (LC/L.3013-P), Santiago, Comisión Económica para América Latina y el Caribe (CEPAL).

Polson, A. (2009), "Lecciones de las reformas realizadas en el sector agrícola de Nueva Zelanda" [en línea] http://2006-2012.sagarpa.gob.mx/agronegocios / Documents/PolsonS1P3.pdf.

Prebisch, R. (1949), El desarrollo económico de América Latina y algunos de sus principales problemas (E/CN.12/89), Santiago, Comisión Económica para América Latina y el Caribe.

Ricardo, D. (2001), On the Principles of Political Economy and Taxation, Batoche Books Kitchener. [Publicado originalmente en 1817].

Rodríguez, A. (2016), “Transformaciones rurales y agricultura familiar en América Latina. Una mirada a través de las encuestas de hogares", serie Desarrollo Productivo, N²04 (LC/L.4168), Santiago, Comisión Económica para América Latina y el Caribe (CEPAL). 
Rodríguez, A. y L. Meza (2016), “Agrobiodiversidad, agricultura familiar y cambio climático", serie Seminarios y Conferencias, N 85 (LC/L.4193), Santiago, Comisión Económica para América Latina y el Caribe (CEPAL).

Rodríguez, A., y otros (2015), "Innovaciones institucionales y en políticas sobre agricultura y cambio climático. Evidencia en América Latina y el Caribe", Documentos de Proyectos (LC/W.678), Santiago, Comisión Económica para América Latina y el Caribe (CEPAL).

Rodrik, D. (2015), "Premature Deindustrialisation in the Developing World" [en línea] http:/ / voxeu.org/article/premature-deindustrialiation-developing-world (2013), "Structural Change, Fundamentals, and Growth: An overview" [en línea] http:/ / drodrik.scholar.harvard.edu/files/dani-rodrik/files/structural-changefundamentals-and-growth-an-overview_revised.pdf.

(2008a), "Normalizing industrial policy", Working Paper, N 3, Washington, D.C., Banco Mundial.

(2008b), "The real exchange rate and economic growth", Brookings Papers on Economic Activity, $\mathrm{N}^{\circ} 2$, The Brookings Institution.

Romero, I., V. Díaz y A. Aguirre (2016), "Fortalecimiento de la cadena de valor de los snacks nutritivos con base en fruta deshidratada en El Salvador", Documentos de Proyectos (LC/MEX/W.16), Ciudad de México, Sede Subregional de la CEPAL en México.

Ross-Schneider, B. (2015), Designing Industrial Policy in Latin America, Nueva York, Palgrave Mcmillan.

Salazar, S. (2012), Aportes del turismo rural comunitario en Costa Rica, San José, Instituto Nacional de Fomento Cooperativo..

Salazar-Xirinachs, J., I. Nübler y R. Kozul-Wright (2014), "Industrial policy, productive transformation and jobs: theory, history and practice", Transforming Economies. Making Industrial Policy Work for Growth, Jobs and Development, J. Salazar-Xirinachs, I. Nübler y R. Kozul-Wright (eds.), Ginebra, Organización Internacional del Trabajo (OIT).

Salido, M. y T. Bellhouse (2016), Economic and Social Upgrading: Definitions, Connections and Exploring Means of Measurement (LC/MEX/L.1208), Santiago, Sede Subregional de la CEPAL en México.

Schmitz, H. (1999), "Global competition and local cooperation: success and failure in the Sinos Valley, Brazil", World Development, vol. 27, N 9, Amsterdam, Elsevier.

SI GCI (Sistema Interactivo Gráfico de Datos de Comercio Internacional) (2016) [en línea] http:/ / www.cepal.org/comercio/ecdata-2/.

Smith, A. (2001), La riqueza de las naciones, Madrid, Alianza Editorial. (1958), Investigación sobre la naturaleza y causas de la riqueza de las naciones, Ciudad de México, Fondo de Cultura Económica.

Sotomayor, O., A. Rodríguez y M. Rodrigues (2011), "Competitividad, sostenibilidad e inclusión social en la agricultura", Libros de la CEPAL, N 113 (LC/G.2503-P), Santiago, Comisión Económica para América Latina y el Caribe (CEPAL).

Sraffa, P. (1960), Production of Commodities by Means of Commodities: Prelude to a Critique of Economic Theory, Cambridge, Cambridge University Press.

Srinivasan, S. y A. Rodríguez (2016), "Pobreza y desigualdades rurales. Perspectivas de género, juventud y mercado de trabajo", serie Desarrollo Productivo, N 206 (LC/L.4206), Santiago, Comisión Económica para América Latina y el Caribe (CEPAL). 
Stiglitz, J.E. y J. Lin (eds.) (2013), The Industrial Policy Revolution I, Londres, Palgrave Macmillan.

Swanson, B. (2010), Estudio mundial sobre buenas prácticas de los servicios de extensión y asesoramiento agropecuarios en el mundo, Roma, Organización de las Naciones Unidas para la Alimentación y la Agricultura.

Szirmai, A. (2011), "Manufacturing and economic development", Working Paper, N²011/75, Instituto Mundial de Investigaciones de Economía del Desarrollo (UNU-WIDER).

Titelman, D. (2003), "La banca de desarrollo y el financiamiento productivo", serie Financiamiento del Desarrollo, N 137 (LC/L.1980-P), Santiago, Comisión Económica para América Latina y el Caribe (CEPAL).

UNCTAD (Conferencia de las Naciones Unidas sobre Comercio y Desarrollo) (2016), "UNCTAD STAT" [en línea] http:/ / unctadstat.unctad.org/EN/.

Van Ark, B., M. O'Mahony y M. Timmer (2008), "The productivity gap between Europe and the United States: trends and causes", Journal of Economic Perspectives, vol. 22, $\mathrm{N}^{\circ}$ 1, Nashville, Tennessee, American Economic Association.

Von Hörnigk, P.W. (1965), "Austria over all if she only will”, Early Economic Thought, A. Monroe (ed.), Cambridge, Massachusetts, Harvard University Press.

Wade, R. (1990), Governing the Market. Economic Theory and the Role of Government in East Asian Industrialization, Princeton University Press.

Weller, J. (2016), "Transformaciones y rezagos: la evolución del empleo agropecuario en América Latina, 2002-2012", serie Macroeconomía del Desarrollo, N 174(LC/L.4209), Santiago, Comisión Económica para América Latina y el Caribe (CEPAL). 


\section{Capítulo III \\ Metodología para el fortalecimiento de cadenas de valor}

Ramón Padilla Pérez

Nahuel Oddone

\section{Introducción}

En este capítulo se presenta la metodología para el fortalecimiento de cadenas de valor que se ha usado en diversos procesos de colaboración técnica con Gobiernos de Centroamérica, México y la República Dominicana. La metodología se basa en experiencias previas de la CEPAL en América del Sur (Stumpo y Rivas, 2013) y en Centroamérica (Padilla, 2014).

En este capítulo se sintetiza el Manual para el fortalecimiento de cadenas de valor (Padilla y Oddone, 2016), publicado recientemente por la CEPAL en colaboración con el Fondo Internacional de Desarrollo Agrícola (FIDA), que pueden consultar los lectores interesados en profundizar en estos temas y en contar con una guía y ejemplos prácticos asociados a los conceptos aquí expuestos ${ }^{1}$. En el Manual y en este capítulo se revisa y actualiza el material publicado en 2014 (Oddone, Padilla y Antunes, 2014), y se incorporan las lecciones recogidas en los nuevos procesos llevados a cabo hasta 2016.

La formulación de la metodología responde al interés creciente de los Gobiernos de América Latina y el Caribe por emprender acciones más

El Manual para el fortalecimiento de cadenas de valor se puede consultar en el sitio web de la CEPAL [en línea] http:/ / www.cepal.org/es. 
decididas en materia de política industrial. En algunos países, este interés se ha plasmado de manera explícita en la elaboración de planes nacionales de política industrial, como en El Salvador y Guatemala, mientras que en otros - Costa Rica y México - se han adoptado programas de apoyo a la competitividad o a cadenas de valor.

Los planes de política industrial son necesarios para incidir en los sectores productivos, fijar objetivos y prioridades, articular las acciones con otras políticas, y disponer los criterios de selección o determinar específicamente los sectores o cadenas que serán favorecidos en el período de vigencia del plan, entre otros factores. Después del diseño, se enfrenta el reto de ponerlos en práctica, operación que implica identificar espacios de intervención y beneficiarios potenciales. El enfoque de cadenas de valor posibilita el análisis de las restricciones existentes y el planteamiento de estrategias al nivel de los actores en cada eslabón de la cadena - enfoque microeconómico- con miras al aumento de la productividad y la agregación de mayor valor. La adopción de un enfoque microeconómico y sistémico conduce a la elaboración de estrategias específicas de intervención en diversos ámbitos, que a su vez lleva a la integración de los diversos instrumentos que tiene disponible la política industrial.

El capítulo está dividido en ocho secciones. En primer lugar, se ofrece una reflexión sobre el enfoque de cadenas de valor y su aporte al cambio estructural. En la segunda sección se postulan conceptos y definiciones clave de la metodología y en la tercera se presentan de manera general los nueve pasos de la metodología. La cuarta sección se concentra en el diagnóstico, mientras que la quinta y la sexta se enfocan en las mesas de diálogo y las buenas prácticas, respectivamente. En la séptima sección se abordan la elaboración de estrategias, el apoyo a la implementación y el lanzamiento. Por último, en la octava sección se presentan las conclusiones.

\section{A. Las cadenas de valor y el cambio estructural}

Desde la visión de la CEPAL, el desarrollo económico y social requiere de cambios profundos en la estructura productiva de los países de la región, que transformen la composición del producto, el empleo y el patrón de inserción internacional. Este cambio estructural progresivo, concebido como la transición hacia actividades y sectores con un mayor dinamismo productivo, que favorecen la protección del medio ambiente y más intensivos en conocimientos tecnológicos (CEPAL, 2016), demanda un innovador conjunto integral de políticas públicas cuyo horizonte sea la igualdad. Por sí solas, las fuerzas del mercado tienden a profundizar las estructuras prevalecientes. La política industrial constituye un elemento fundamental de este enfoque original y de la renovada ecuación Estadomercado-sociedad (CEPAL, 2012). 
El fortalecimiento de las cadenas de valor propicia la diversificación productiva y amplía la participación en aquella parte de la estructura productiva con mayor intensidad en conocimientos o cuya tasa de crecimiento de la demanda es más elevada, y así se contribuye a un cambio estructural. Luego, el fortalecimiento de la cadena va acompañado de un cambio estructural, en la medida que se incorporan nuevos y mejores productos, mayor productividad y actividades más intensivas en conocimientos. Al mismo tiempo, se tiende a aminorar la heterogeneidad estructural propia de las economías latinoamericanas, mediante el fortalecimiento de los actores que conforman la cadena y la incorporación de nuevos productores y prestadores de servicios. De esta manera, se persigue la reducción de brechas productivas que afectan a los países latinoamericanos; por ejemplo, entre empresas pequeñas y grandes, o entre productores enfocados a mercados locales y aquellos que compiten en mercados internacionales.

El fortalecimiento de una cadena de valor puede ser un instrumento efectivo para combatir la desigualdad, al favorecer mayores ingresos de los productores y una apropiación más equilibrada del valor agregado obtenido en la cadena. Es decir que el trabajo en materia de cadenas de valor no solo permite intervenir en las posibilidades de agregación de valor sino también en la distribución de los beneficios de ese valor entre los actores de la cadena. A las políticas públicas corresponde un papel central en estos procesos. En el cuadro III.1 se presentan las cadenas de valor que recibieron apoyo entre 2014 y 2016 en el marco del proyecto CEPAL-FIDA “Crecimiento inclusivo, política industrial rural y cadenas de valor participativas en América Latina y el Caribe".

\section{Cuadro III.1}

Cadenas de valor del proyecto CEPAL-FIDA "Crecimiento inclusivo, política industrial rural y cadenas de valor participativas en América Latina y el Caribe”, 2014-2016

\begin{tabular}{|c|c|c|}
\hline País & Cadena & Escala geográfica \\
\hline \multirow[t]{4}{*}{ El Salvador } & $\begin{array}{l}\text { Turismo en el departamento } \\
\text { de La Libertad }\end{array}$ & Departamento de La Libertad \\
\hline & $\begin{array}{l}\text { Snacks nutritivos basados en } \\
\text { fruta deshidratada }\end{array}$ & Nacional (todo el país) \\
\hline & Tomate y chile verde dulce & Nacional (todo el país) \\
\hline & $\begin{array}{l}\text { Turismo en Antigua Guatemala } \\
\text { y en los municipios rurales del } \\
\text { departamento de Sacatepéquez }\end{array}$ & Departamento de Sacatepéquez \\
\hline México & $\begin{array}{l}\text { Embutidos y otras conservas } \\
\text { de carne de cerdo }\end{array}$ & $\begin{array}{l}\text { Nacional (con especial atención a los estados de } \\
\text { Jalisco, Guanajuato, México, Michoacán, Nuevo } \\
\text { León, Puebla, Sonora y Yucatán) }\end{array}$ \\
\hline \multirow[t]{2}{*}{$\begin{array}{l}\text { República } \\
\text { Dominicana }\end{array}$} & $\begin{array}{l}\text { Lácteos para la producción } \\
\text { de quesos }\end{array}$ & $\begin{array}{l}\text { Nacional (con especial atención a las provincias } \\
\text { de Dajabón, Santiago Rodríguez, Puerto Plata, } \\
\text { Hato Mayor, Monte Plata e Higuey) }\end{array}$ \\
\hline & $\begin{array}{l}\text { Turismo en la provincia } \\
\text { de Pedernales }\end{array}$ & Provincia de Pedernales \\
\hline Costa Rica & Chips fritos al vacío & $\begin{array}{l}\text { Nacional (con exclusión de la zona capital } \\
\text { y metropolitana) }\end{array}$ \\
\hline
\end{tabular}

Fuente: Elaboración propia. 


\section{B. Definiciones y conceptos clave}

\section{Las cadenas de valor}

Una cadena de valor comprende la amplia variedad de actividades requeridas para que un producto o servicio transite a través de diferentes etapas, desde su concepción hasta su entrega a los consumidores y la disposición final después de su uso (Kaplinsky y Morris, 2002). A cada una de las etapas -concepción y diseño, producción del bien o servicio, tránsito de la mercancía, consumo y manejo, y reciclaje final — se las denomina eslabones. La cantidad de eslabones de una cadena de valor varía de manera sustancial según el tipo de industria. Las actividades de la cadena a veces son llevadas a cabo por una empresa y en otras ocasiones, por varias (Kaplinsky, 2000).

Sin que importe su tamaño, toda empresa o productor participa por lo menos en una cadena de valor local; así, un campesino de autoconsumo adquiere insumos (semillas, herramientas, fertilizantes y otros) y de este modo interactúa con otros eslabones de la cadena. Las empresas que exportan, directa o indirectamente, intervienen además en cadenas regionales o globales de valor.

Las cadenas globales de valor emergen como resultado de un nuevo patrón de producción basado en una deslocalización geográfica conectada con mercados finales dinámicos. El concepto de cadena global de valor se refiere a distintos eslabones en diversas empresas o plantas de una empresa situadas en diferentes espacios geográficos. Las cadenas globales de valor son sistemas internacionales organizados para optimizar la producción, la comercialización y la innovación, mediante la localización de productos y procesos en distintos países a fin de lograr beneficios por diferencias de costo, tecnología, comercialización y logística, entre otras variables (Lall, Albaladejo y Zhang, 2004)².

Cabe distinguir el alcance geográfico de la cadena y su participación en flujos de comercio internacional. A causa de la difusión del concepto de cadenas globales de valor, es común asociarlo con exclusividad a la escala global. No obstante, en América Latina es frecuente que su alcance sea nacional o regional cuando se trata tanto de productos primarios como de manufacturas y servicios. Por ende, son procesos de producción y de oferta de servicios que se inician y terminan en el territorio de un país o presentan interacción solo con uno o varios países vecinos. La metodología expuesta en este capítulo abarca el análisis de cadenas con diversos alcances geográficos.

En el diagrama III.1 se presenta la estructura general de una cadena de valor de bienes. El análisis de una cadena contiene, por lo menos, los siguientes cuatro elementos:

2 Véanse mayores detalles sobre las cadenas globales de valor en Gereffi y Fernández-Stark (2011). 
i) Los eslabones y los actores que los componen. Las diferentes etapas o pasos para la elaboración y entrega de un producto o servicio se conocen como eslabones. Cada eslabón está compuesto de un conjunto de empresas y productores, que pueden competir o cooperar en la provisión de dicho bien o servicio. En el diagrama III.1, el primer eslabón es la investigación y el desarrollo (I+D), dedicado a la creación de nuevos productos - actividad no siempre presente, dado que depende de la intensidad tecnológica de la cadena-. Así, las cadenas de bienes electrónicos y la farmacéutica desarrollan una intensa actividad de $\mathrm{I}+\mathrm{D}$, mientras que es menor en prendas de vestir y manufactura de plásticos. El segundo eslabón comprende las actividades de ingeniería, en las que se diseñan las propiedades funcionales y de forma de los bienes, así como los procesos por medio de los que se elaborará la manufactura. Este eslabón suele ubicarse en la misma localidad geográfica que la I+D o cerca de los centros de producción. El tercer eslabón - la manufactura - suele ser intensivo en bienes de capital para la fabricación de los bienes intermedios o componentes. El cuarto y el quinto eslabón - los ensambles, los subensambles y las pruebas finales - en general hacen un uso intensivo de mano de obra de menor calificación y con salarios relativamente más bajos, ya que suelen entrañar tareas rutinarias destinadas a armar y probar los bienes intermedios y componentes a fin de obtener el bien final. El sexto eslabón corresponde a las ventas, la comercialización de los bienes finales y los servicios posventa.

ii) Las relaciones (o vínculos) entre los eslabones y dentro de ellos. Si bien el enfoque permite desagregar las actividades y los actores que integran la cadena, las relaciones entre ellos son clave para un buen funcionamiento del todo. El análisis de la homogeneidad o heterogeneidad existente en el seno de cada eslabón, así como el análisis de los vínculos entre eslabones son elementos clave para la generación de políticas públicas focalizadas.

iii) La apropiación del valor agregado. En el diagrama III.1 se muestran diversos espacios para la apropiación del valor agregado en una cadena de valor: cuanto más arriba se encuentre el eslabón, mayor es el espacio que tiene. No todos los eslabones, ni los actores dentro de un eslabón, tienen la misma oportunidad de apropiarse del valor generado por toda la cadena. En una cadena de bienes manufacturados intensivos en tecnología, las actividades de investigación y desarrollo y de ventas y comercialización suelen dar los mayores espacios de captura de valor. Frecuentemente, cuanto mayor 
sea la complejidad tecnológica y la intensidad en el uso de conocimientos especializados, mayor será el poder para capturar valor agregado. Por lo tanto, en los estudios de cadenas de valor llevados a cabo por la CEPAL no solo importan los mecanismos de agregación de valor, sino también entender los beneficios que comporta la distribución de ese valor agregado.

Diagrama III.1

Estructura general de una cadena de valor de bienes

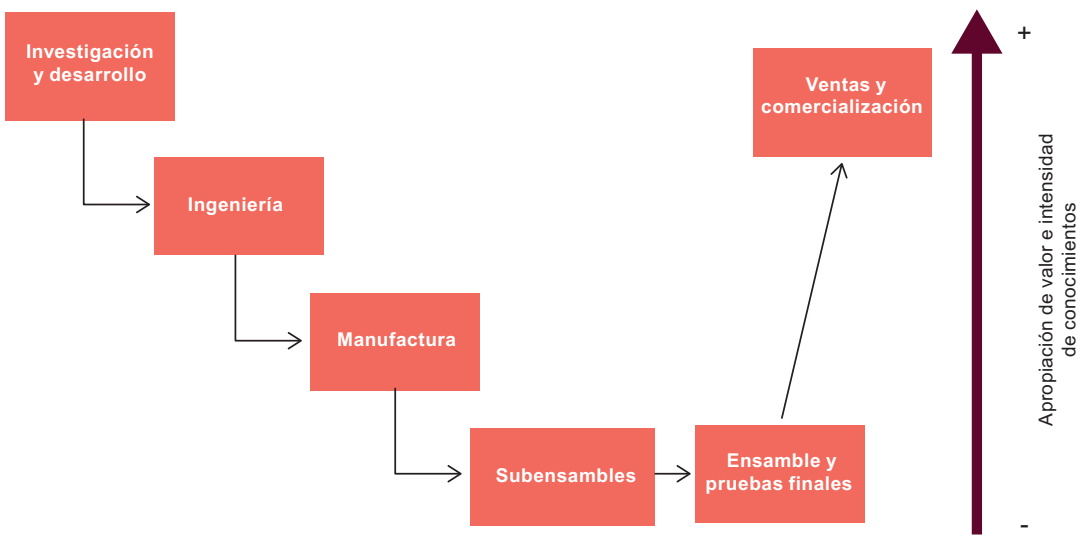

Fuente: R. Padilla y N. Oddone, Manual para el fortalecimiento de cadenas de valor (LC/MEX/l.1218), Ciudad de México, Comisión Económica para América Latina y el Caribe (CEPAL), 2016.

iv) La gobernanza de la cadena. Estudiar la gobernanza de las cadenas de valor es un paso necesario para analizar los mecanismos, los procesos y las reglas mediante los que las empresas y los productores se relacionan económicamente entre sí, y con el gobierno y otros actores. En este sentido, se busca conocer qué factores determinan la conducta de los agentes de la cadena, sobre la base de los tipos de vínculos y relaciones que se establecen entre estos, así como las reglas explícitas y tácitas en que se enmarcan sus conductas.

Cuando se analiza la gobernanza de una cadena de valor es conveniente formularse algunas interrogantes; por ejemplo, respecto de la estructura en la que se desempeñan los actores y quiénes son los miembros de mayor poder e influencia; cómo es el manejo de la información al interior de la cadena; cómo funciona el sistema de incentivos; qué regulaciones se ejercen sobre los miembros de la cadena; qué incidencia tienen las tradiciones sociales y culturales relacionadas con las formas y tipos de producción, y qué impacto ejercen en la generación y transferencia de nuevas tecnologías. Sin embargo, la gobernanza nunca es estática, se modifica en el curso del tiempo, y ello depende no solo de cambios en 
las estrategias de las empresas involucradas, sino también de factores institucionales, tecnológicos e innovaciones organizacionales, entre otros elementos (Gereffi, Humphrey y Sturgeon, 2005).

\section{Fortalecimiento y escalamiento}

El fortalecimiento se entiende como la transformación de la cadena a través de la superación de las restricciones que enfrenta, de manera que así aporte una mayor contribución al desarrollo económico y social del territorio en el que opera. Esta transformación se puede dar a través de una mejor articulación entre los actores de la cadena, la incorporación de nuevos actores productivos y de apoyo, y el escalamiento económico y social de los eslabones y de la cadena en su conjunto.

El escalamiento económico se entiende como la transición hacia actividades de mayor complejidad tecnológica, la mejora de los productos o servicios ofrecidos por la cadena, o la manufactura de bienes o provisión de servicios de manera más eficiente (Pietrobelli y Rabellotti, 2006). El escalamiento económico puede conducir a un escalamiento social en la cadena, que se traduce en un proceso de mejora de los derechos y prestaciones de los trabajadores y en una mayor calidad de su empleo, así como del entorno inmediato de la cadena (Barrientos, Gereffi y Rosi, 2013). El escalamiento social se halla vinculado con la cohesión social de un territorio, entendida como la capacidad de elevar el bienestar de todos los miembros de una sociedad a partir de la creación de un sentido de pertenencia por medio de derechos y la activa participación para promover la confianza mutua, ofrecer oportunidades y sostener una movilidad ascendente, además de enfrentar la desigualdad y la exclusión. Los mecanismos de inclusión abarcan el empleo, el sistema educativo, la creación de nuevos derechos y garantías para reforzar la igualdad, el bienestar y la protección social (CEPAL, 2007).

Existen cuatro formas diferentes de escalamiento económico (Humphrey y Schmitz, 2002; Gereffi, Humphrey y Sturgeon, 2005).

i) Escalamiento de productos, que corresponde al desarrollo y la comercialización de un producto con mejores características o un nuevo producto.

ii) Escalamiento de procesos, que es el resultado de la introducción de nuevas tecnologías que ofrecen técnicas de producción más eficientes o formas de distribución de los productos (o servicios) de la cadena.

iii) Escalamiento funcional, ocasionado por el desplazamiento de los actores de la cadena hacia eslabones de mayor valor agregado o complejidad tecnológica. Un ejemplo es la participación 
creciente y gradual de empresas encargadas del eslabón de manufactura en actividades de diseño.

iv) Escalamiento de cadena, que consiste en el movimiento hacia nuevas actividades productivas o cadenas de valor haciendo uso de conocimientos y habilidades previamente adquiridos. Así, el conocimiento y las habilidades obtenidas en el sector electrónico pueden emplearse para participar en el sector aeronáutico.

En cuanto al escalamiento social, se manifiesta en la forma de: a) acceso a condiciones de empleo más beneficiosas, protección social y derechos, y b) avances positivos en el entorno social y medioambiental de la cadena. El primer aspecto se vincula con el nivel de salarios, el tipo de empleo (formal o informal, tiempo completo o parcial), acceso a protección social, la jornada laboral y, en general, respeto a los derechos humanos. También guarda relación con el derecho de asociación laboral (Barrientos, Gereffi y Rosi, 2013). El segundo se traduce en el mejoramiento del entorno inmediato de la cadena, en términos de infraestructura, acceso a servicios básicos y educación de calidad, y el cuidado del medioambiente, entre otros. Por tanto, el escalamiento social ofrece la oportunidad de aminorar las brechas de bienestar entre individuos y entre grupos, así como perfeccionar los mecanismos de integración de individuos y grupos a la dinámica social, acentuando su sentido de adhesión y pertenencia a la sociedad; es decir, se logra una mayor cohesión social.

Es importante acotar que pese a existir una relación directa entre escalamiento económico y social, no siempre se plasma como tal. La mejora de productos y procesos, por ejemplo se refleja en mayor eficiencia y ganancias en la cadena. En cambio, su transferencia a todos los eslabones y a todos los integrantes de cada eslabón depende de diversos factores, como la gobernanza de la cadena, la estructura de empleo y el nivel de competencia, entre otros.

\section{La metodología para el fortalecimiento de cadenas de valor}

La metodología para el fortalecimiento de cadenas de valor consta de nueve pasos (véase el diagrama III.2) ${ }^{3}$. En el presente capítulo, cada paso se describe a grandes rasgos ${ }^{4}$.

Para profundizar en las etapas de la metodología, véanse Padilla y Oddone (2016).

4 La metodología publicada inicialmente por la CEPAL en 2014 (véanse Oddone, Padilla y Antunes, 2014) incluía seis pasos, dado que las mesas de diálogo se consideraban de manera horizontal y sin una posición predeterminada en el proceso. La experiencia práctica ha llevado a ubicar a las mesas específicamente después del diagnóstico y de la elaboración de estrategias. Por otro lado, la CEPAL ha avanzado hacia la asistencia técnica para la implementación, en la medida que sus recursos y su mandato lo han permitido. 
Diagrama III.2

Metodología para el fortalecimiento de cadenas de valor

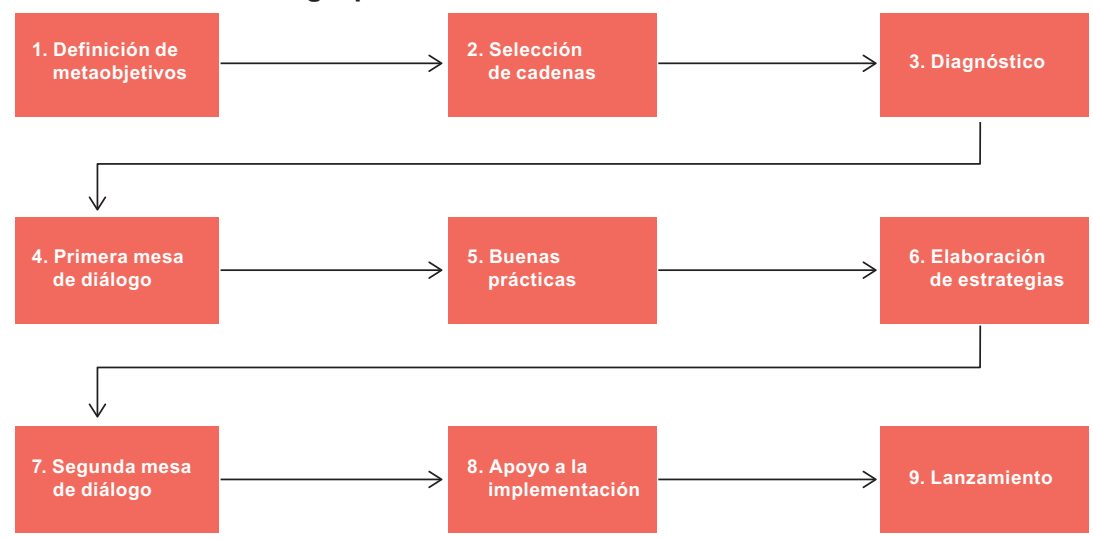

Fuente: R. Padilla y N. Oddone, Manual para el fortalecimiento de cadenas de valor (LC/MEX/I.1218), Ciudad de México, Comisión Económica para América Latina y el Caribe (CEPAL), 2016.

El primer paso es la definición de metaobjetivos. Estos se entienden como la finalidad última del proceso de fortalecimiento, en materia de desarrollo económico y social. Se espera que los metaobjetivos estén alineados con el plan nacional de desarrollo y las políticas públicas relevantes, como la industrial, la laboral, la ambiental y la de ciencia, tecnología e innovación. Algunos ejemplos de metaobjetivos son aumentar el empleo y los salarios reales, impulsar mayores exportaciones, provocar una creciente participación de las micro, pequeñas y medianas empresas (mipymes) y contribuir a incrementar la producción nacional.

El segundo paso es la selección de cadenas. En esta etapa se definen las cadenas que serán priorizadas para enfocar los esfuerzos de los sectores público y privado. Los criterios de selección deben ser congruentes con los metaobjetivos: el potencial de la cadena para contribuir al alivio de la pobreza, al crecimiento nacional o regional, a la generación de empleo, al crecimiento de las exportaciones, a la incorporación de tecnologías de punta y la inserción de mipymes, entre otros. También son susceptibles de inclusión otros criterios ligados a prioridades políticas estratégicas, como el desarrollo de regiones menos favorecidas y la reducción de asimetrías regionales.

El tercer paso es la elaboración del diagnóstico. En este ejercicio se identifican detalladamente restricciones y oportunidades en el interior de cada eslabón de la cadena, así como sus vínculos reales y potenciales. Se comienza por el mapeo de la cadena y la identificación y delimitación de los eslabones principales y sus funciones. A continuación se elabora un estudio de seis grandes áreas: contexto nacional e internacional de la cadena, desempeño económico (empleo, comercio, costos y márgenes, entre otros), análisis de mercado (competidores, clientes, estándares y 
certificaciones, entre otros), gobernanza de la cadena, instituciones de apoyo y medio ambiente. Por último, se identifican las restricciones por eslabón y a nivel de cadena (sistémicas).

La primera mesa de diálogo se organiza al finalizar el diagnóstico, con el objetivo de discutirlo y validarlo. Es un espacio para refrendar el interés en contar con la participación de los principales actores de la cadena y organizaciones de apoyo, que en su mayoría ya habían sido entrevistadas durante la elaboración del diagnóstico. Se espera que la mesa tenga una duración no mayor a tres horas, con el objetivo de garantizar la participación y permanencia de personas clave en la cadena. Después de una presentación breve del diagnóstico, se otorga la palabra a los participantes con el objetivo de enriquecer el análisis y garantizar que las restricciones y oportunidades identificadas sean relevantes y no se haya omitido alguna.

El quinto paso es el análisis de buenas prácticas internacionales. Estas proporcionan un referente para determinar la distancia que separa la cadena de valor estudiada de cadenas similares en otros países, así como lecciones para la elaboración de las estrategias.

El sexto paso es la elaboración de estrategias para superar las restricciones y aprovechar las oportunidades identificadas en el diagnóstico. Se trata de líneas estratégicas específicas en el nivel micro, que idealmente permiten reconocer responsables, tiempo y recursos.

La segunda mesa de diálogo tiene lugar con el objetivo de discutir las estrategias. Al igual que en la primera, se busca enriquecer el proceso y además se persigue celebrar un compromiso por parte de todos los actores respecto de las acciones que cada uno es responsable de llevar a cabo para el desarrollo de la cadena. Un elemento clave a desarrollar es un ejercicio de priorización de estrategias, en el que los integrantes de la mesa deciden de manera conjunta las acciones a ser ejecutadas de manera inmediata.

El octavo paso corresponde al apoyo para la implementación. La priorización de estrategias acordada en la segunda mesa de diálogo arroja una lista breve de acciones a ejecutar en el corto plazo. En función de los recursos disponibles y el mandato recibido como organización de asistencia técnica, se puede avanzar hacia la implementación a través de actividades puntuales como la capacitación de representantes de eslabones específicos de la cadena, la elaboración de análisis de mercado o la preparación de estudios de factibilidad. La puesta en práctica de todas las estrategias es una tarea de largo plazo que suele demandar recursos financieros significativos. En esta etapa se trata de capitalizar el buen ánimo de cooperación y trabajo que suele acompañar a la segunda mesa y dar un impulso inicial a la ejecución de actividades.

El último paso es el lanzamiento de la estrategia de fortalecimiento de la cadena. Es un evento participativo y mediático, en el que se 
convoca a representantes de los eslabones de la cadena y se anuncian los compromisos adquiridos. La difusión de este evento promueve el consenso entre los actores y sirve como demostración de efectividad a otras cadenas que quisieran iniciar un proceso similar.

En caso de no presentarse demoras significativas por falta de información, o un débil compromiso por parte de los sectores público o privado, los nueve pasos del proceso suelen desarrollarse en un período de ocho a nueve meses.

El enfoque de cadenas de valor no es nuevo. Su incorporación a la discusión sobre el desarrollo productivo se remonta a principios de la década de 1980. La metodología propuesta por la CEPAL tiene dos elementos distintivos: su carácter sistémico y participativo.

El análisis de los principales eslabones y sus relaciones se complementa con el estudio de los principales actores públicos y privados que apoyan, regulan e interactúan con la cadena; en eso consiste su carácter sistémico. En este sentido, se adoptan elementos del enfoque de sistemas de innovación (Freeman, 1987; Lundvall, 1992; Edquist, 1997), el cual contempla la importancia de las instituciones y las organizaciones en la operación de las empresas, en particular con respecto a la innovación. Los actores pueden ser clasificados en cinco categorías (véase el diagrama III.3):

i) Sector público que regula y apoya las actividades de la cadena. Pueden estar involucrados diversos organismos que regulan y certifican las actividades de la cadena (por ejemplo, en materia de salud, medio ambiente y comercio), así como aquellos que brindan apoyo (ministerios de economía, organismos públicos de apoyo a la ciencia, la tecnología y la innovación, y organismos de apoyo a pequeñas y medianas empresas).

ii) Universidades y colegios técnicos. Entre estas organizaciones cabe destacar a los departamentos, facultades o escuelas que tienen relación directa con la cadena, ya sea por intermedio de la formación de profesionales especializados o del extensionismo (asistencia técnica, cursos a la medida, renta de laboratorios, etcétera).

iii) Centros de investigación. Al igual que con las universidades y colegios técnicos, es necesario identificar el departamento directamente relacionado con la cadena. Estos centros también llevan a cabo labores de formación y extensionismo.

iv) Proveedores deservicios profesionales y especializados. Seobserva una creciente participación de estos servicios en las cadenas de bienes primarios y manufactura, ofrecidos principalmente por organismos privados. Cubren una amplia gama de temas, como logística, renta de equipo y maquinaria, certificaciones, pruebas y mercadotecnia, como se muestra en el diagrama III.3. 
v) Cámaras empresariales. Apoyan el desarrollo de cadenas de valor por conducto de representación política, facilitación de la asociatividad y prestación de servicios de asistencia técnica, entre otras gestiones.

\section{Diagrama III. 3}

\section{Enfoque sistémico de la cadena de valor}
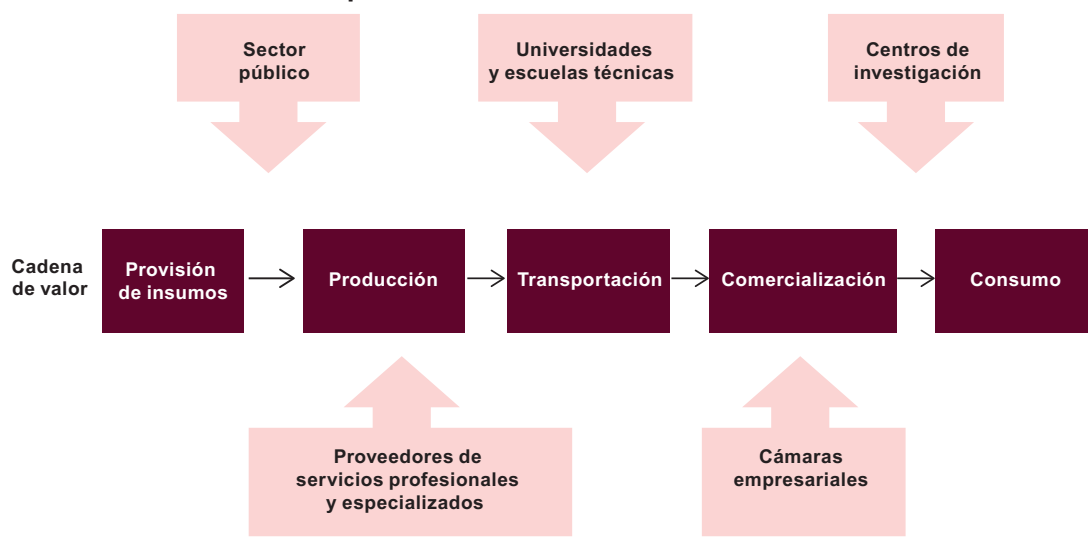

Fuente: R. Padilla y N. Oddone, Manual para el fortalecimiento de cadenas de valor (LC/MEX/l.1218), Ciudad de México, Comisión Económica para América Latina y el Caribe (CEPAL), 2016.

Un segundo elemento distintivo de la metodología de la CEPAL es su carácter participativo, que se manifiesta en dos dimensiones. Por un lado, los actores de la cadena (con un enfoque sistémico) son involucrados en la elaboración del diagnóstico (grupos focales, entrevistas), así como la validación de aquel y de las estrategias a través de las mesas de diálogo. Con esto se logra, principalmente, un mayor compromiso con el proceso de análisis, transparencia en la toma de decisiones y la conformación de acuerdos para el fortalecimiento de la cadena. Por otro lado, todo el proceso se desarrolla de manera conjunta con funcionarios públicos, en la búsqueda de su empoderamiento y apropiación de la metodología.

La metodología de cadenas de valor ofrece la oportunidad de incorporar el análisis y la generación de estrategias innovadoras en dos elementos fundamentales de la agenda de la cooperación internacional para el desarrollo: el empoderamiento femenino para la disminución de la desigualdad y el cuidado del medio ambiente. Es por ello que a lo largo de los estudios desarrollados con la metodología de la CEPAL, los equipos técnicos han puesto atención en aspectos de género y medio ambiente como variables de peso en el desarrollo de una política industrial moderna. En el Manual para el fortalecimiento de cadenas de valor se profundiza en estos dos temas transversales. 
Los principales resultados del proceso pueden resumirse en las siguientes tres grandes áreas:

i) Diseño de estrategias participativas para el fortalecimiento de las cadenas. El diseño de estrategias se basa en un diagnóstico de la situación de la cadena de valor (con enfoque en las restricciones) y en la identificación de buenas prácticas internacionales. Se elabora así un documento que consta de tres secciones principales: diagnóstico, buenas prácticas y estrategias. Estos componentes son validados por los organismos públicos que fungen como contraparte, así como por los integrantes de las cadenas a través de las mesas de diálogo y con observaciones directas a los documentos. Los gobiernos nacionales, con recursos propios o con el apoyo de otros organismos internacionales de carácter financiero, se encargan de poner en práctica e implementar las estrategias.

ii) Apropiación y replicabilidad metodológicas. La metodología diseñada por la CEPAL ha sido adoptada por organismos públicos en Centroamérica, México y la República Dominicana. Por ejemplo, el Ministerio de Economía de El Salvador incorporó oficialmente la metodología en su Plan Operativo de Transformación Productiva 2014-2019. La Mesa de Trabajo de Desarrollo de Cadenas Productivas, del Consejo Consultivo Empresarial para el Crecimiento Económico de México, hizo lo propio tras la experiencia desarrollada con la cadena de embutidos y otras conservas de carne de cerdo. La estrategia de acompañamiento de la CEPAL incluye la transferencia de conocimientos y la creación de capacidades en funcionarios públicos.

iii) Mejora del diálogo público-público, privado-privado y públicoprivado. La metodología se enfoca a enriquecer el diálogo público-privado como elemento clave en el desarrollo de una política industrial. Mediante esta colaboración, los sectores público y privado pueden definir y poner en marcha una agenda de desarrollo productivo, en la que los actores del sector privado participen como asesores en el diseño, la ejecución, el seguimiento y la evaluación de políticas y programas públicos, legislación, reglamentos y especificaciones técnicas. La metodología también fomenta el diálogo entre los organismos públicos que regulan y apoyan la cadena. Por conducto de las mesas de diálogo se conocen en detalle las actividades que realiza cada organismo, así como los retos que enfrentan. Como resultado de los procesos podría promoverse la creación de comisiones públicas específicas para atender restricciones de la cadena. Por último, también se fomenta la colaboración entre los diversos eslabones de la cadena y en el interior de ellos. 
Los dos primeros pasos de la metodología - la identificación de metaobjetivos y la sección de cadenas- se analizan con detalle en el capítulo IV de este libro, mientras que en las siguientes secciones de este capítulo se abordan los pasos restantes.

\section{El diagnóstico}

El ejercicio de diagnóstico se aboca a identificar las restricciones enfrentadas por la cadena de valor, que impiden su fortalecimiento. Las restricciones, también conocidas como cuellos de botella, son los obstáculos o problemas que enfrentan los eslabones de la cadena o la cadena en su conjunto (restricciones sistémicas), que impiden su buen funcionamiento o articulación y, por consiguiente, el escalamiento económico y social. El proceso de resolución de dichos obstáculos es entendido como fortalecimiento de una cadena de valor.

En el diagrama III.4 se resumen los componentes del diagnóstico: se parte de un mapeo de la cadena y de la identificación de sus eslabones y actores principales. Luego se analiza el contexto internacional y nacional de la cadena, las características económicas, de mercado, de gobernanza, de las instituciones de apoyo y de medio ambiente. En cada paso conviene tener en mente que el objetivo final es la identificación de restricciones. En el Manual se ofrecen más detalles sobre el proceso de mapeo de la cadena y la identificación de las organizaciones de apoyo.

\begin{tabular}{|c|c|c|}
\hline \multicolumn{3}{|c|}{$\begin{array}{c}\text { Diagrama III.4 } \\
\text { Diagnóstico de la cadena }\end{array}$} \\
\hline \multicolumn{3}{|c|}{ MAPEO DE LA CADENA E IDENTIFICACIÓN DE LOS ESLABONES PRINCIPALES } \\
\hline \multicolumn{3}{|c|}{ IDENTIFICACIÓN Y CARACTERIZACIÓN DE LOS ACTORE PRINCIPALES DE LA CADENAS } \\
\hline \multicolumn{2}{|c|}{ Actores por eslabón } & Organizaciones de apoyo \\
\hline \multicolumn{3}{|c|}{ Niveles de análisis } \\
\hline Contexto & Económico & $\begin{array}{l}\text { Mercado y conocimientos } \\
\text { tecnológicos }\end{array}$ \\
\hline $\begin{array}{l}\text { - Tendencias y regulaciones globales, } \\
\text { cambios tecnológicos y dinámicas } \\
\text { de crecimiento } \\
\text { - Factores político-sociales nacionales }\end{array}$ & $\begin{array}{l}\text { - Producción, distribución territorial, } \\
\text { empleo, comercio internacional, } \\
\text { inversión } \\
\text { - Competitividad, costos y márgenes } \\
\text { de ganancia por eslabón }\end{array}$ & $\begin{array}{l}\text { - Demanda, producto(s) y precios } \\
\text { - Oferta, competidores, clientes } \\
\text { - Estándares y certificaciones } \\
\text { - Generación y fuentes } \\
\text { de conocimientos }\end{array}$ \\
\hline $\begin{array}{l}\text { Gobernanza } \\
\text { - Relaciones de poder y vínculos entre } \\
\text { los eslabones } \\
\text { - Circulación de la información } \\
\text { - Apropiación del valor agregado }\end{array}$ & $\begin{array}{l}\text { Organizaciones de apoyo } \\
\text { - En sus dimensiones normativa, jurídica, } \\
\text { política, social, económico- financiera } \\
\text { y científico-tecnológica }\end{array}$ & $\begin{array}{l}\text { Medio ambiente } \\
\text { - Impacto ambiental } \\
\text { - Sostenibilidad y adaptaciones } \\
\text { frente al cambio climático }\end{array}$ \\
\hline Sistémicas & Restricciones & Por eslabón \\
\hline
\end{tabular}

Fuente: R. Padilla y N. Oddone, Manual para el fortalecimiento de cadenas de valor (LC/MEX/I.1218), Ciudad de México, Comisión Económica para América Latina y el Caribe (CEPAL), 2016. 
Siguiendo el diagrama III.4, donde se muestran los contenidos y los niveles de análisis del diagnóstico de una cadena, se ha elaborado el listado de preguntas (véase el recuadro III.1) que responde a sus diferentes segmentos, con el objetivo de aplicarlo a los actores centrales de cada eslabón y a la red de organizaciones de apoyo. Los temas y preguntas que enseguida se presentan constituyen una guía metodológica, que debe adaptarse para cada cadena, de acuerdo con su contexto y sus características, así como su relación con los metaobjetivos del ejercicio.

\section{Recuadro III.1}

\section{Preguntas base para la elaboración del diagnóstico}

\section{Mapeo de la cadena}

A través del mapeo se reconocen los actores y las relaciones objeto de estudio en el interior de los eslabones; y se determina qué información se necesita reunir y dónde se llevará a cabo el trabajo de campo.

Batería de preguntas

- ¿Cuál es el núcleo de la cadena de valor (proceso de transformación clave de la cadena)?

- ¿Cuáles son los principales insumos demandados por el núcleo de la cadena (materia prima, componentes, bienes intermedios)?

- ¿Cuáles son los requerimientos de maquinaria y equipo del núcleo de la cadena?

- ¿Cuáles son los canales de comercialización y distribución del principal producto o servicio de la cadena?

- ¿Quiénes son los consumidores del producto o servicio central de la cadena?

- ¿Cuáles son las características principales de los productos o servicios de cada eslabón, en particular los factores de producción utilizados y el ciclo de vida?

\section{Análisis de contexto}

Consideraciones generales de la cadena en cuanto al contexto sectorial, nacional, regional e internacional:

- ¿Cuáles son las tendencias nacionales que caracterizan el sector en el que se inserta la cadena (producción, empleo, comercio exterior, principales empresas, grado de concentración)?

- ¿Cuáles son las tendencias internacionales del sector al que pertenece la cadena de valor (producción, empleo, comercio, principales empresas, grado de concentración)?

- ¿Cuál es la dinámica tecnológica del principal bien o servicio de la cadena (nuevas tecnologías de producto o proceso que podría influir en el comportamiento de la cadena)?

\section{Análisis económico}

En cuanto a producción, inversión y distribución territorial:

- ¿Cómo ha evolucionado la estructura de la cadena en los últimos cinco años? En especial, ¿han surgido o desaparecido nuevos actores?

- ¿Cuál es el origen del capital en cada uno de los eslabones (dominio de empresas nacionales o extranjeras)? 
Recuadro III.1 (continuación)

- ¿Cuál es el tipo de empresa (grande, media, pequeña, micro) más frecuente en cada uno de los eslabones de la cadena?

- ¿Cuál es la dinámica de generación/desaparición de empresas en cada uno de los eslabones de la cadena?

- ¿Cuál es el nivel de producción (valor de ventas, valor agregado) de la cadena?

- ¿Cómo ha evolucionado la producción de la cadena en los últimos cinco años?

- ¿Se han hecho inversiones significativas en los últimos cinco años en los eslabones de la cadena de valor (compra de activos, inversión en infraestructura, etcétera)?

- ¿Cuál es la distribución territorial de los actores y eslabones de la cadena de valor en el país o la región?

- ¿Qué características tienen los vínculos comerciales en la cadena? Por ejemplo, ¿el productor también se encarga de la comercialización?

- ¿Qué características tienen los vínculos logísticos? Es decir ¿qué costos acarrean y quién los cubre? Por ejemplo, ¿el productor también se encarga del transporte?

- ¿Qué forma de transporte se utiliza para la comercialización de los productos y servicios de la cadena?

- ¿Qué características tiene el proceso de producción (describir los pasos)?

- ¿Cuáles son las principales tecnologías usadas (maquinaria y equipo, conocimientos especializados, etcétera)?

Con relación al empleo:

- ¿Cuál es el empleo (número de empleados permanentes y temporales) generado por cada uno de los eslabones de la cadena y cuál es su distribución por empresa en el interior de cada eslabón?

- ¿Qué tipo de empleo se crea en la cadena, distinguiendo entre calificado y no calificado, género y nivel de educación?

- ¿Cuál ha sido la evolución del empleo en cada eslabón de la cadena en los últimos cinco años?

- ¿Cuál es el salario promedio pagado en cada eslabón?

- ¿Cuál ha sido la evolución de los salarios promedio ofrecidos en los últimos cinco años?

- ¿Cuál es la participación femenina en la cadena?

- ¿Qué ventajas comparativas tiene el trabajo femenino en la cadena?

- ¿Qué diferencias de género existen en materia de salarios y apropiación del valor generado?

Por lo que respecta al comercio exterior:

- ¿Cuál ha sido el nivel de las exportaciones del producto final de la cadena en los últimos tres años? En caso de que más de un eslabón exporte un bien final o intermedio, considerar las exportaciones de cada uno.

- ¿Cuál es la participación de la cadena (producto final) en los principales mercados de destino (competitividad exportadora)?

- ¿Cómo ha evolucionado la demanda externa por el producto final de la cadena? Es decir, ¿se ha incrementado o reducido en los últimos cinco años la demanda por el producto final de la cadena?

- ¿Cuál ha sido la evolución de las importaciones, y su origen, para aquellos eslabones de la cadena que así lo requieran en los últimos cinco años? 
Recuadro III.1 (continuación)

- ¿Se importan productos similares o sustitutos a los producidos por la cadena? En caso afirmativo, ¿de qué países provienen?

- ¿Existen barreras para la comercialización y distribución (costos, disponibilidad, infraestructura, etcétera)?

En materia de competitividad, costos y márgenes de ganancias:

- ¿Cuáles son los factores centrales de competitividad de los eslabones de la cadena? En otras palabras, ¿con base en qué estrategia o ventaja comparativa compiten (conocimientos tecnológicos o de mercado, bajos costos laborales, localización geográfica, participación en redes, acceso a recursos naturales, etcétera?

- ¿Qué factores endógenos (recursos humanos, capacidades tecnológicas y productivas, capital) y exógenos (regulaciones, barreras a la entrada, falta de oferta de financiamiento) limitan la competitividad de cada eslabón de la cadena?

- ¿Cuáles son los costos de producción promedio en cada eslabón de la cadena?

- ¿Cuáles son los márgenes de utilidad promedio en cada eslabón de la cadena?

- ¿Qué barreras se afrontan para la obtención de financiamiento en los eslabones de la cadena (falta de garantías, altas tasas de interés, ausencia de instrumentos financieros adecuados, escasez de fondos en el sector financiero formal)?

- ¿Cuáles son los costos por entrar en la cadena (por ejemplo, costos de inversión y de operaciones para comenzar el negocio)?

\section{Análisis de mercado y conocimientos tecnológicos}

En lo que respecta al análisis de mercado:

- ¿Quiénes son los consumidores principales de la cadena, nacionales o internacionales?

- ¿Cuáles son las características principales de los clientes en términos de poder de compra, localización geográfica, hábitos y costumbres, y elementos sociodemográficos?

- ¿Cuáles son las tendencias actuales y proyectadas del consumo de los productos de la cadena en los mercados principales de destino?

- ¿Quiénes son los principales competidores de la cadena, nacionales o internacionales?

- ¿Cuáles son las características de los competidores en términos de origen del capital, capacidades tecnológicas y productivas, y participación de mercado, entre otros?

- ¿Cuáles han sido las estrategias desarrolladas por los competidores para el acceso a nuevos mercados?

- ¿La cadena resulta favorecida por acuerdos comerciales internacionales (aranceles, cuotas, etcétera)?

- ¿Cuáles son las condiciones arancelarias aplicables a los principales productos de la cadena?

En cuanto a los requerimientos y estándares de mercado:

- ¿Cuáles son los estándares de calidad que deben cumplir los productos de la cadena?

- ¿Qué normas y parámetros nacionales y/o internacionales rigen la producción y la comercialización de los principales productos de la cadena?

- ¿Existe conciencia entre los actores de la cadena sobre el cumplimiento de reglas, normas y estándares? 
Recuadro III.1 (continuación)

Con respecto a conocimientos tecnológicos:

- ¿En los eslabones de la cadena se realizan actividades formales e informales de investigación, desarrollo e innovación $(I+D+l)$ ? ¿Cuántas de ellas cuentan con apoyo público?

- ¿Cuáles son las principales fuentes de conocimiento de cada uno de los eslabones de la cadena (universidades, centros de investigación, consultoría, reclutamiento de recursos humanos especializados, etcétera)?

- ¿Cuáles son los mecanismos para la transferencia de conocimientos y tecnologías a los eslabones de la cadena?

- ¿Existe una oferta de enseñanza técnica y/o superior enfocada en la cadena?

\section{Análisis de gobernanza}

- ¿Qué estructura presenta la cadena (dominada por compradores, proveedores, intermediarios, etcétera)?

- ¿Quiénes son los eslabones o actores dominantes en la cadena?

- ¿Qué tipo de relaciones de poder ejercen los eslabones dominantes (proveeduría, compra, conocimientos, acceso a redes, fijación de precios estándares, financiamiento)?

- ¿Cuál es la naturaleza de las relaciones (formales e informales) entre los distintos eslabones (vertical y horizontal)? ¿Con qué frecuencia y calidad ocurren estas interacciones?

- ¿Cuál es la participación de cada uno de los eslabones en el valor agregado total de la cadena? ¿Se observan esquemas formales o informales de asociación en la cadena (cooperativas, asociaciones gremiales, cámaras)?

- En caso de que la cadena se halle internacionalizada, ¿está integrada en redes globales?

- ¿Cómo están organizadas las redes globales en las que participa la cadena de valor?

- ¿Se observa una integración vertical u horizontal a lo largo de la cadena? ¿Operan agrupaciones y redes de aglomeración industrial y de especialización en la cadena?

- ¿Cuáles son las prácticas comunes de comunicación e intercambio de información en la cadena?

- ¿Qué grado de confianza existe entre los actores dentro de cada eslabón y a lo largo de la cadena?

\section{Análisis de las organizaciones de apoyo}

- ¿Cuáles son las principales organizaciones públicas que participan o apoyan la cadena de valor?

- ¿Qué tipo de incentivos y apoyos, incluyendo los fiscales, existen para la cadena de valor?

- En particular, ¿hay incentivos para la investigación, los programas de cooperación, el diseño de productos o la incorporación de nuevas tecnologías?

- ¿Existe apoyo público para tener acceso a más y mejores condiciones de financiamiento?

- ¿Se han establecido acuerdos con universidades y/o escuelas técnicas en materia de educación y capacitación? 
Recuadro III.1 (conclusión)

- ¿Se sostienen vínculos con universidades y/o centros de investigación en materia de investigación, desarrollo e innovación?

- ¿Existen cámaras o asociaciones que agrupen y representen a los actores del eslabón central de la cadena? En caso afirmativo, ¿cuáles son sus funciones?

- ¿Se dispone de una oferta de servicios especializados de apoyo a la cadena (certificaciones, asistencia técnica o mercadotécnica)?

\section{Análisis del medio ambiente}

Las preguntas más comunes en el análisis de cuestiones ambientales en el desarrollo de cadenas de valor se relacionan con los siguientes aspectos.

- ¿De las actividades de producción y procesamiento de la cadena se desprenden impactos ambientales negativos?

- ¿Cuáles son las fuentes de energía que se emplean y cuál es la eficiencia del uso de energía en los diferentes eslabones de la cadena?

- ¿Cuál es la gestión del recurso agua utilizada en los diferentes eslabones de la cadena?

- ¿Qué tipo y cantidad de productos químicos se aplican en los diferentes procesos de la cadena?

- ¿Qué residuos se arrojan al medio ambiente y cómo es su gestión en los diferentes eslabones?

- ¿Se originan gases de efecto invernadero u otras emisiones contaminantes en los procesos de producción de los eslabones?

- ¿Qué otra fuente potencial de contaminación se reconoce como, por ejemplo, acidificación y eutrofización?

- ¿Las empresas están desarrollando medidas de mitigación o adaptación al cambio climático?

- ¿El cambio climático está afectando las actividades de la cadena?

- ¿Se están tomando medidas para mitigar el impacto del cambio climático en las actividades de la cadena?

Fuente: R. Padilla y N. Oddone, Manual para el fortalecimiento de cadenas de valor (LC/MEX/I.1218), Ciudad de México, Comisión Económica para América Latina y el Caribe (CEPAL), 2016.

La guía parte del supuesto de que existe amplio acceso a la información sobre la cadena de estudio. No obstante, se pueden enfrentar limitaciones en cuanto a la disponibilidad de información, que exigirán una adaptación de la guía. Se recomienda hacer un esfuerzo por cubrir la totalidad de los elementos, dado que resultan necesarios para preservar el enfoque sistémico del estudio y asegurar que se hayan examinado todas las áreas posibles de restricciones y oportunidades en el funcionamiento de la cadena.

Es de gran importancia contar con un consultor experto local que apoye en la elaboración del diagnóstico y la organización de las mesas de diálogo. El entendimiento de las fortalezas y restricciones de cada cadena demanda conocimientos especializados que se adquieren a través del trabajo directo con los actores. Este contacto permite también identificar a los actores clave que deben ser entrevistados e invitados a las mesas. 


\section{E. Mesas de diálogo}

Un elemento distintivo de la metodología para el fortalecimiento de cadenas de valor es la construcción de espacios de diálogo entre los actores de la cadena, y entre estos y las organizaciones de apoyo. En esta sección se ofrece una breve caracterización de estos espacios (véanse mayores detalles en Rayo (2014)). Las llamadas mesas de diálogo representan un proceso de comunicación y cooperación entre diferentes actores relevantes en un tema, quienes colaboran para el desarrollo mutuo y del propio sistema relacional al que pertenecen (identificación de soluciones y su aplicación).

Un espacio de diálogo ofrece la oportunidad de conversar en torno a un objetivo bien definido para identificar y poner en vigor soluciones que rebasan la decisión individual. Los espacios de diálogo aportan una plataforma de colaboración para el intercambio de ideas y la aplicación fluida de cursos de acción. Además, se pueden llegar a considerar como un espacio de consulta o sugerencias de políticas públicas.

La metodología para el fortalecimiento de cadenas propone la organización de mesas de diálogo en dos puntos particulares del proceso: la validación y el enriquecimiento del diagnóstico y de las estrategias. Los sectores público y privado organizados suelen ser los convocantes de las mesas, y en ellas participan representantes de los eslabones de la cadena de valor y las organizaciones de apoyo. El diálogo facilita un avance en el análisis de los resultados preliminares obtenidos en el diagnóstico y en la formulación de las estrategias propuestas, al tiempo que favorece la transparencia y el compromiso de los actores con el proceso.

Los espacios de diálogo entre actores clave son cada vez más importantes y necesarios para desarrollar iniciativas integrales y sostenibles. La creación de mesas de diálogo contribuye al establecimiento de alianzas y el surgimiento de proyectos conjuntos públicos y privados, tanto a través del acercamiento de los actores, como por intermedio de la construcción colectiva de soluciones. Pese a estos beneficios, el diálogo no es una práctica común en el interior de las cadenas de valor.

Existen espacios de diálogo de carácter consultivo (corto plazo) y cooperativo (mediano y largo plazo, o permanentes). El primer tipo de espacio constituye un puente valioso para la consulta, validación y generación de aportes con miras a la formulación de políticas. El segundo, gracias a su carácter de mayor permanencia, brinda la ocasión de avanzar hasta la etapa de aplicación de acciones. En el marco de la metodología de la CEPAL se acudió al primer tipo a lo largo del proceso de acompañamiento (mesas de diálogo de diagnóstico y estrategias), aunque se ha observado una evolución del espacio hacia uno de carácter cooperativo, con una agenda de trabajo de largo plazo (véase el cuadro III.2). 
Cuadro III.2

Espacios de diálogo: tipos y características

\begin{tabular}{|c|c|}
\hline Diálogos de carácter consultivo & Diálogos de carácter cooperativo \\
\hline \multicolumn{2}{|c|}{ Características } \\
\hline $\begin{array}{l}\text { Los actores aportan sus conocimientos, } \\
\text { puntos de vista y experiencias. En general, la } \\
\text { aplicación posterior de las recomendaciones y } \\
\text { conclusiones del diálogo es responsabilidad de } \\
\text { los iniciadores. }\end{array}$ & $\begin{array}{l}\text { Los actores comparten la responsabilidad y } \\
\text { colaboran activamente para poner en práctica } \\
\text { soluciones o acciones. Cuanto mayor sea el } \\
\text { énfasis de la implementación, mayor será la } \\
\text { disposición a cooperar y asumir la responsabilidad } \\
\text { de alcanzar logros. }\end{array}$ \\
\hline \multicolumn{2}{|r|}{ Subcategorías } \\
\hline $\begin{array}{ll} & \text { Consulta singular/grupal. } \\
\text { - } & \text { Consulta institucionalizada. } \\
\text { - } & \text { Plataforma de múltiples actores } \\
& \text { para el intercambio. }\end{array}$ & $\begin{array}{ll}\text { - } & \text { Iniciativa de múltiples actores. } \\
\text { - } & \text { Plataforma de múltiples actores } \\
\text { para la implementación. } \\
\text { - } \quad \text { Asociación de actores clave. }\end{array}$ \\
\hline
\end{tabular}

Fuente: R. Padilla y N. Oddone, Manual para el fortalecimiento de cadenas de valor (LC/MEX/l.1218), Ciudad de México, Comisión Económica para América Latina y el Caribe (CEPAL), 2016.

Tres factores son determinantes en la selección de los actores que participarán en un espacio de diálogo: el objetivo que se pretende alcanzar, el nivel donde se trabajará (internacional, regional, nacional o local) y el carácter del diálogo (consultivo o cooperativo). Los actores participantes deben estar directamente vinculados a cada cadena. Se los identifica y selecciona con base en su representación en la cadena, a partir de las entrevistas realizadas para el diagnóstico. Asimismo, se toma en cuenta su representación territorial y de escala empresarial, como los consejos o asociaciones conformados por el sector privado articulado. En cuanto a las organizaciones del sector público vinculadas a la cadena, vale la pena esforzarse por involucrar a todas aquellas que en mayor o menor medida conforman el entramado en el cual se desenvuelven los actores de la cadena.

Los siguientes elementos son esenciales para el éxito de las mesas de diálogo de las cadenas de valor:

- Compromiso y amplia coordinación con el sector público

- Agendas claras y concisas

- Conocimiento detallado de las características de cada actor

- Manejo de los principios de diálogo y gestión de conflictos

- Resultados rápidos y socialización de resultados

- Fortalecimiento de relaciones humanas y de los procesos de asociatividad entre los actores que conforman los diferentes eslabones de la cadena.

Las mesas de diálogo suelen despertar muchas expectativas $\mathrm{y}$, a veces, se podrían suscitar conflictos. No es muy común que sus integrantes (funcionarios públicos, productores, intermediarios, 
proveedores de insumos, agentes de comercialización y distribuidores) participen en reuniones conjuntas. Por ello, es conveniente disponer de una metodología de trabajo participativo a fin de que, si los participantes así lo acuerdan, se transite de un espacio consultivo (corto plazo) a un espacio cooperativo (largo plazo). Se recomienda describir con claridad los objetivos de las mesas de diálogo y limitar rigurosamente las intervenciones, para que las reuniones no se extiendan demasiado ni se utilicen como tribuna de intereses particulares ni para presentar solicitudes poco realistas. La organización de solo dos mesas - una para validar el diagnóstico y otra para acordar las estrategias-, ha demostrado ser una buena práctica. En cambio, si se organizan más reuniones suele decaer el interés o bien surgen confusiones respecto de la duración y los pasos necesarios para completar el proceso. También es recomendable evitar que el diagnóstico y el diseño de estrategias se politicen o que, incluso si esto no ocurriera, los actores involucrados se sintieran participando en un proceso político para el cual no fueron convocados. La credibilidad es esencial para la participación del sector privado y la implementación posterior de las estrategias.

\section{F. Las buenas prácticas}

El diagnóstico provee información fundamental para conocer la situación presente en una determinada cadena de valor, en particular las restricciones que enfrenta y las oportunidades que se le abren. El diagnóstico es un primer paso en la definición de estrategias que conduzcan a la superación o minimización de las restricciones, así como al aprovechamiento de las oportunidades, con miras a alcanzar los metaobjetivos definidos para el desarrollo de la cadena de valor. Aun así, la identificación de restricciones y oportunidades, necesaria para la definición de acciones y políticas, es insuficiente. En este sentido, resulta útil examinar otras realidades comparables, con lo que se identificarán experiencias y se extraerán lecciones sobre la forma en que problemas similares se han resuelto en contextos diferentes.

La investigación de buenas prácticas se basa en la observación selectiva de un conjunto de experiencias en diferentes contextos, con objeto de derivar principios más generalizables (Overman y Boyd, 1994) ${ }^{5}$. Se trata de un proceso estructurado que se aleja de ejercicios informales de

\footnotetext{
Es relevante aclarar que en esta metodología se utiliza la palabra "buenas" aplicada a las prácticas. No obstante, se debe reconocer que en otros estudios es común usar el término "mejores prácticas". El análisis de un conjunto de prácticas no garantiza que no pudiera haber prácticas mejores fuera del conjunto analizado y, por lo tanto, no se tiene la absoluta certeza de que la práctica que se quiere aprovechar es realmente la "mejor". Por la falta de universalidad, en este manual se utiliza el término "buenas prácticas". En otros estudios es común el uso del término "prácticas inteligentes".
} 
búsqueda y descripción de prácticas exitosas. Desde esta perspectiva, es necesario observar qué cuestiones han funcionado para resolver problemas similares en otras cadenas, cuáles son los factores que determinaron su éxito -que generalmente son de "contexto", como aspectos legales y normativos, o acuerdos interinstitucionales-y qué posibilidades certeras hay de recrear esos elementos de "contexto" para replicar la práctica.

El proceso de indagación sobre buenas prácticas y, en especial, la explicación del éxito de las prácticas observadas, puede efectuarse de manera informal o a través de esquemas estructurados. En el marco de la metodología para el fortalecimiento de cadenas de valor, la utilización de un proceso formal de análisis crítico de las prácticas observadas facilita la adaptación a la situación que se quiere transformar. Se parte del conocimiento de la restricción o problema de la cadena de valor que se desea resolver con la aplicación de la buena práctica (véase el diagrama III.5). Como primer paso, es conveniente hacer un listado de restricciones y compararlas con las prácticas observadas en otras situaciones a partir de una descripción general, los resultados obtenidos y los elementos de contexto. En cuanto a este último punto, con los datos obtenidos se establece, por ejemplo, hasta qué punto la práctica es utilizable independientemente del contexto (aplicación) o si existe alguna condición del escenario que sea necesario recrear para que la práctica tenga el éxito esperado (adaptación). En caso de que sea imposible la aplicación y la adaptación de la buena práctica, es necesario recomenzar el proceso de búsqueda en otros contextos.

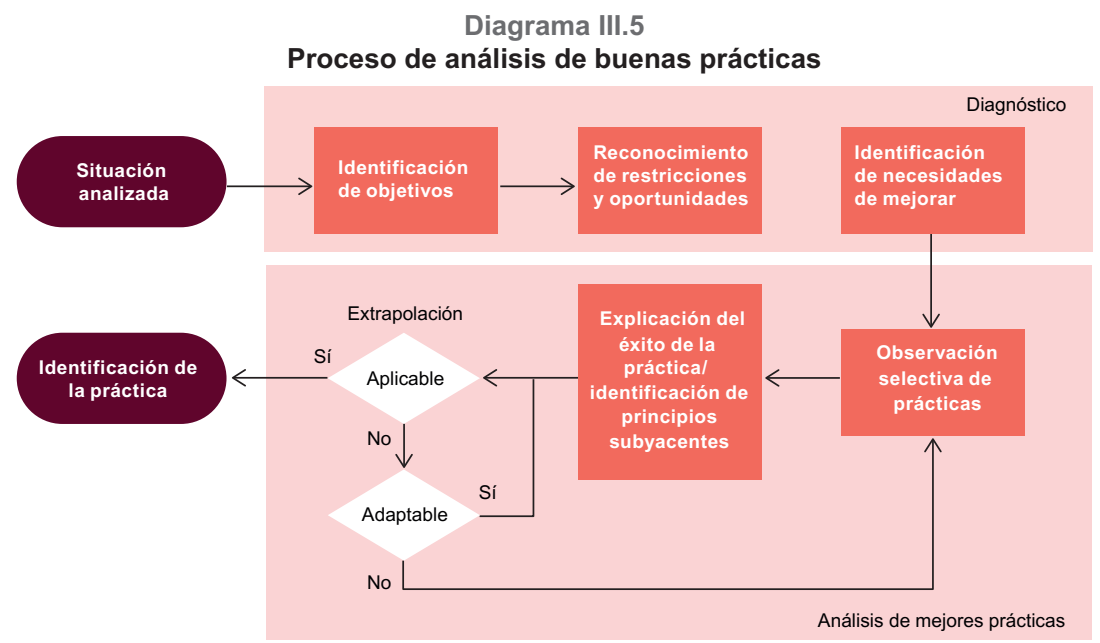

Fuente: N. Oddone, R. Padilla y B. Antunes, "Metodología del Proyecto CEPAL-GIZ para el diseño de estrategias de fortalecimiento de cadenas de valor", Fortalecimiento de las cadenas de valor como instrumento de la política industrial. Metodología y experiencia de la CEPAL en Centroamérica, Libros de la CEPAL, № 123 (LC/G.2606-P), Santiago, Comisión Económica para América Latina y el Caribe (CEPAL), 2014. 
Es válido utilizar un enfoque cualitativo para identificar las buenas prácticas, bajo el criterio de priorizar los esfuerzos de búsqueda en aquellas que tengan potencial de subsanar las deficiencias detectadas en la situación analizada y que al mismo tiempo sean efectivas y sustentables. Se condice así con la definición de que una buena práctica tiene la capacidad de provocar cambios reales en la dirección deseada, si se cuenta con un enfoque innovador, replicable y sostenible (Rhi-Sausi, Conato y Lamela, 2011). También se puede seguir un enfoque cuantitativo en la identificación de posibles buenas prácticas a partir de técnicas estadísticas para el análisis e identificación de los resultados de las diferentes prácticas, basadas en el cumplimiento de condiciones como su universalidad y la posibilidad de su mutua comparación. Estos procedimientos de búsqueda de buenas prácticas suelen ser conocidos como procedimientos de análisis comparado o benchmarking.

Al traslado o la incorporación de la práctica identificada a otro contexto se le denomina extrapolación y es susceptible de varias interpretaciones. Si en la extrapolación se utiliza un proceso formal de análisis crítico de las prácticas observadas, se facilita la adaptación a la situación que se desea hacer prosperar. Por otro lado, es preciso que haya receptividad de las contrapartes involucradas en dicha situación, a raíz de los cambios que se producirían a partir de la extrapolación de la experiencia. En el análisis de contexto se debe poner especial atención al nivel de desarrollo del país donde la práctica fue observada, puesto que es un factor clave para que sea posible o exitoso el traslado de esta a la nueva situación (Veselý, 2011). Para que una medida aplicada en una cadena mucho más avanzada e inserta en un contexto más favorable sea extrapolada a otra menos desarrollada, se requiere prestar atención al análisis del contexto a fin de identificar los factores de éxito subyacentes y determinar las necesidades de adaptación. Es esencial evaluar la puesta en marcha y los resultados de las acciones que se pueden transponer en el seguimiento de un análisis de buenas prácticas. Esta determinación permite identificar si es válido aplicar medidas adicionales de adaptación para contribuir efectivamente a los objetivos definidos con antelación, como los metaobjetivos, así como para enriquecer el proceso de análisis y extrapolación de buenas prácticas.

Si bien la búsqueda de buenas prácticas puede arrojar resultados valiosos, también existen riesgos empíricos capaces de impactar en su interpretación. En primer lugar, y como ha sucedido en la mayoría de los casos estudiados, es probable que la información relativa a las prácticas no esté fácilmente disponible. En particular, las prácticas centradas en elevar el desempeño de agentes económicos del sector privado podrían juzgarse como información confidencial o privilegiada. Además, aunque la información no sea definida con estos criterios restrictivos, el hecho de que no sea registrada o que no se desee su divulgación crea barreras a su utilización en procesos de análisis de medidas exitosas. Pero incluso en este escenario, todavía existen muchas oportunidades de hacer avanzar la gestión del conocimiento relativo a la investigación de buenas prácticas. 


\section{G. Las estrategias, el apoyo a la implementación y el lanzamiento}

En esta sección se describen los tres pasos finales de la metodología: la elaboración de estrategias, el apoyo a la implementación y el lanzamiento.

\section{La elaboración de estrategias}

Las estrategias constituyen la forma principal de resolver cada una de las restricciones observadas en una cadena. Suelen basarse en las buenas prácticas investigadas y en otras fuentes de conocimiento, análisis y reflexión, como entrevistas a especialistas o expertos destacados.

Las estrategias se organizan por programas, que son los grandes asuntos en los que está planificada y sistematizada la intervención para el fortalecimiento de la cadena. Se conforman en torno a una serie de líneas de acción cuyo objetivo es la promoción y consecución de dicho fortalecimiento, y se dirigen a todos los actores de la cadena, no solo al sector público (véase el diagrama III.6). De esta forma, se detallan las acciones que cada actor debe emprender para fortalecer la cadena, además de que se apoyan en la creación de los consensos y acuerdos promovidos en las mesas de diálogo.

Diagrama III.6

Proceso de elaboración de estrategias

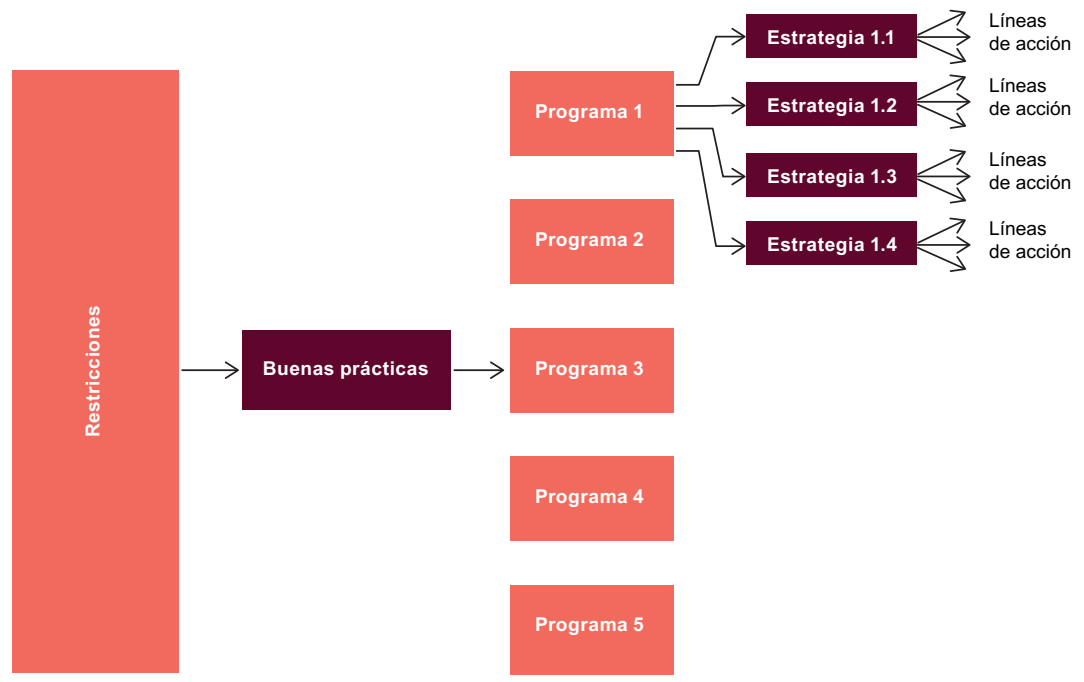

Fuente: N. Oddone, R. Padilla y B. Antunes, "Metodología del Proyecto CEPAL-GIZ para el diseño de estrategias de fortalecimiento de cadenas de valor", Fortalecimiento de las cadenas de valor como instrumento de la política industrial. Metodología y experiencia de la CEPAL en Centroamérica, Libros de la CEPAL, N 123 (LC/G.2606-P), Santiago, Comisión Económica para América Latina y el Caribe (CEPAL), 2014. 
No existe un número máximo ni mínimo de estrategias por cada programa o de líneas de acción por cada estrategia. Las necesidades y capacidades existentes en la cadena son la base para definir la amplitud y profundidad de las acciones requeridas a nivel sistémico y por eslabón.

Como el enunciado de los programas indica el área de intervención, es deseable que su redacción se formule en términos generales, por ejemplo: "fortalecimiento de las capacidades de innovación de los productores de la cadena". Las estrategias identifican con mayor detalle las acciones enmarcadas en el programa, por ejemplo: "incrementar los recursos disponibles para la contratación de personal cualificado" o "estrechar los vínculos de las empresas con centros de investigación especializados". Las líneas de acción materializan y puntualizan las actividades que deben llevarse a cabo para el cumplimiento de las estrategias. Un ejemplo de redacción es: "crear un programa de intercambio de investigadores de universidades y empresas en temas previamente seleccionados y de importancia central para el desarrollo de la cadena".

La matriz de comparación de estrategias ayuda a los hacedores de política pública y actores privados a priorizar la ejecución de las estrategias diseñadas, de acuerdo con el costo, plazo de implementación e impacto relativos (véase el diagrama III.7). Se trata de una herramienta destinada a facilitar el proceso de decisión, de acuerdo con la voluntad política, los recursos financieros y los tiempos disponibles para su ejecución. En el eje Y se representa el plazo de implementación, que se extiende de corto a largo; y en el eje $\mathrm{X}$ se define el impacto de las estrategias, que se extienden de bajo a alto. El tamaño del círculo indica el costo relativo de cada una de las estrategias.

Diagrama III.7

Matriz de comparación de costos, plazo de implementación e impactos relativos de las estrategias

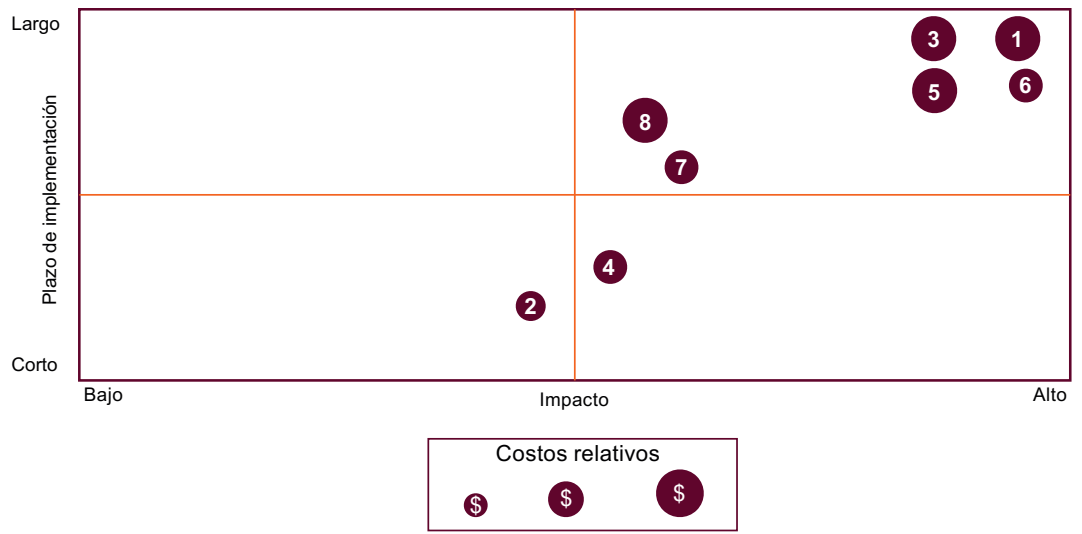

Fuente: N. Oddone, R. Padilla y B. Antunes, "Metodología del Proyecto CEPAL-GIZ para el diseño de estrategias de fortalecimiento de cadenas de valor", Fortalecimiento de las cadenas de valor como instrumento de la política industrial. Metodología y experiencia de la CEPAL en Centroamérica, Libros de la CEPAL, № 123 (LC/G.2606-P), Santiago, Comisión Económica para América Latina y el Caribe (CEPAL), 2014. 
Es un ejercicio de carácter orientativo, por lo que para su construcción se usan los conocimientos y la experiencia desarrollada por los responsables del proceso de fortalecimiento de la cadena. Un ejercicio más preciso de definición de costos, tiempos e impactos requeriría un esfuerzo adicional considerable, por lo que se plantea para una etapa posterior.

Un componente importante en la elaboración de estrategias de intervención es el esfuerzo para evaluar y monitorear el progreso en su puesta en vigor. Al implementar un sistema de evaluación es primordial diseñar e incorporar un sistema de medición, por intermedio de indicadores cuantitativos o cualitativos que indiquen el progreso alcanzado. Con ese propósito se construye una batería de indicadores por programa que estén ligados a los metaobjetivos acordados y las estrategias de fortalecimiento diseñadas para cada cadena. Estos indicadores ayudan al seguimiento de las estrategias en su etapa de implementación, al monitoreo de los acuerdos alcanzados y a la consecución de los metaobjetivos previamente establecidos. Antes de iniciar la implementación de los programas y las estrategias, es necesario establecer una línea base y el valor meta que se quiere alcanzar en cada uno de los indicadores.

\section{El apoyo a la implementación}

Las estrategias y las líneas de acción son específicas y focalizadas, condiciones básicas para iniciar con rapidez la ejecución de actividades que fortalezcan las cadenas. El principal reto identificado por la CEPAL en los países de la región es la falta de recursos financieros públicos para poner en práctica las estrategias. La CEPAL ha dado asistencia técnica puntual con el fin de impulsar el proceso público-privado de fortalecimiento de la cadena y aprovechar el compromiso de los actores, que suele estar presente al término de la segunda mesa de diálogo.

El apoyo a la implementación ha seguido tres mecanismos:

i) La asistencia para la gestión de recursos públicos internos, que se puede efectuar, a su vez, por medio de tres mecanismos. Primero, identificar estrategias que no demanden recursos financieros adicionales significativos, como la creación y revisión de leyes o reglamentos, y la modificación de procedimientos administrativos. En general, estas acciones repercuten de forma significativa en el funcionamiento de la cadena y su costo de implementación es bajo. Segundo, prestar asesoría al organismo público socio a fin de que gestione recursos específicos para el apoyo de una cadena; por ejemplo, que el Ministerio de Economía tramite recursos adicionales con la Presidencia o el Ministerio de Finanzas, sobre la base de los documentos de diagnóstico 
y estrategias, y las mesas de diálogo. Tercero, promover que programas existentes sean reorientados de manera que incluyan espacios específicos para el fortalecimiento de la cadena; por ejemplo, dentro de un programa de financiamiento rural, abrir una línea especial de crédito para pequeños productores de la cadena seleccionada.

ii) El apoyo para la gestión de recursos de la cooperación internacional. El diagnóstico, las estrategias y las mesas de diálogo son susceptibles de emplearse como base para la negociación de financiamiento por parte de la cooperación y la banca internacional. Por ejemplo, en Guatemala el Ministerio de Economía (MINECO) ejecutó recursos provenientes de un préstamo del Banco Mundial en apoyo a las estrategias diseñadas, con asistencia técnica de la CEPAL, para la cadena de valor de hortalizas de exportación. De manera similar, GIZ en Guatemala abrió una línea especial, dentro de uno de sus programas de cooperación en Centroamérica, para el apoyo de cadenas de valor seleccionadas.

iii) La asistencia puntual para la ejecución de líneas de acción relacionadas con la capacitación o la formulación de planes específicos que se derivan de las estrategias. En el conjunto de estrategias propuestas para el fortalecimiento de las cadenas comúnmente se incluyen necesidades de capacitación en temas específicos orientados a elevar las capacidades de los actores, así como la realización de estudios de factibilidad y formulación de planes específicos de ejecución. Por ejemplo, a raíz del proceso de fortalecimiento en la cadena de turismo de La Libertad (El Salvador), el Ministerio de Turismo solicitó a la CEPAL la impartición de un curso de entrenamiento de herramientas de mercadotecnia en línea a los proveedores de servicios turísticos locales.

La puesta en práctica de las estrategias también se facilita si se impulsa una institucionalización de las mesas de diálogo como mecanismo para el trabajo conjunto. Como ya se expuso, en un inicio las mesas de diálogo tienen un carácter consultivo y son convocadas para tareas puntuales: discusión del diagnóstico y de las estrategias. Si los actores se organizan y transforman las mesas en un espacio cooperativo, se da un impulso relevante a las acciones de fortalecimiento. La conformación de espacios cooperativos ayuda a la toma de decisiones conjuntas, empodera a los actores de la cadena, promueve la rendición de cuentas, y fomenta la acción y el compromiso del sector público. 


\section{El lanzamiento}

El lanzamiento es el último paso de la metodología. Es un evento participativo y mediático, en el que se convoca a los actores privados y públicos de la cadena, se presentan los principales resultados —en términos de restricciones identificadas, estrategias y apoyo a la implementación-y se anuncian los compromisos adquiridos. Se apunta a dos objetivos principales:

i) fortalecer el compromiso entre los actores de la cadena y socializar los acuerdos alcanzados, y

ii) difundir los resultados de manera que sirva como demostración y despierte el interés en otras cadenas que quisieran iniciar un proceso similar.

En la experiencia de la CEPAL, el evento es convocado por el sector público, en asociación con el sector privado. Algunos elementos centrales para que el lanzamiento cumpla sus principales objetivos son:

i) asegurar una amplia participación de los actores de la cadena, así como de las organizaciones públicas y privadas de apoyo;

ii) contar con la presencia de representantes de alto nivel públicos y privados, por ejemplo, ministros y viceministros, directores de cámaras y líderes de cooperativas, entre otros, y

iii) anunciar compromisos públicos y privados, y recursos financieros comprometidos para la implementación de las estrategias.

\section{H. Reflexiones finales}

El diseño de intervenciones públicas en las cadenas de valor es una estrategia de gran utilidad que facilita la implementación de políticas industriales, pues permite focalizar las inversiones estratégicas destinadas a superar las restricciones que afectan a cada eslabón, organizar las intervenciones públicas por orden de prioridad de común acuerdo con actores del sector privado y sistematizarlas, y agiliza la coordinación de las medidas de las entidades públicas que prestan apoyo a la cadena. En el largo plazo, en la medida en que se implementan las estrategias, se avanza hacia un cambio estructural progresivo, gracias al escalamiento económico y social de las cadenas.

La metodología se centra en la identificación de las restricciones que dificultan el escalamiento de los diversos eslabones de la cadena de valor, con atención tanto a cada eslabón como al conjunto. Asimismo, conduce a identificar estrategias público-privadas para superar los obstáculos 
existentes, entre otras cosas mediante la innovación de productos y procesos, procedimientos destinados a realzar la calidad, fortalecer las capacidades empresariales, difundir información sobre mercados y promover las exportaciones. El análisis de las restricciones y el diseño de estrategias se llevan a cabo en estrecha colaboración con los integrantes de cada eslabón de la cadena, tanto productores como otros actores del sector privado (por ejemplo, proveedores de bienes y servicios, intermediarios y distribuidores), las instituciones públicas involucradas y el sector académico.

La metodología descrita se distingue por cuatro fortalezas. En primer lugar, se realizan análisis microeconómicos a fondo, tanto en el examen de la cadena de valor en el marco del diagnóstico como a la hora de proponer estrategias. Este enfoque microeconómico posibilita la identificación de las restricciones existentes en determinados eslabones, así como la falta de ciertos eslabones y las debilidades que presentan los vínculos entre ellos. Debido al nivel de agregación que suponen, los diagnósticos sectoriales difícilmente ofrecen esta información de fundamental importancia para el diseño de estrategias focalizadas. Además, este enfoque facilita el diseño de programas para la incorporación de pequeños productores al proceso productivo y toma en cuenta factores como género y medio ambiente.

En segundo lugar, la metodología se apoya en que todo el proceso sea participativo. Uno de los elementos centrales es la organización de mesas de diálogo para analizar y validar el diagnóstico y las estrategias propuestas. En esas mesas de diálogo participan diferentes integrantes de las cadenas (productores, intermediarios, proveedores de insumos y servicios, comerciantes mayoristas y minoristas, y otros), representantes de los organismos públicos relevantes (ministerios de economía, medio ambiente, educación, ciencia y tecnología, agricultura y salud, entre otros), organizaciones no gubernamentales, universidades y empresas certificadoras de la aplicación de las normas de protección del medio ambiente, entre otros. Las mesas ofrecen un mecanismo transparente para el análisis y la toma de decisiones, que favorece la adopción de acuerdos entre los sectores público y privado.

Vale la pena mencionar que, tras el diagnóstico y la proposición de estrategias de la CEPAL, se han establecido diferentes mecanismos de diálogo público-privado en cada cadena de valor. A modo de ejemplo, se menciona la creación de la Asociación de Deshidratadores de Fruta de El Salvador (ADEFRUDELSAL) o la reactivación de la Mesa Nacional de Hortalizas en ese mismo país. El diálogo público-privado, por lo general, debe estar basado en una distribución equilibrada de responsabilidades, costos, riesgos y beneficios entre los actores involucrados. El sector público y el sector privado tienen responsabilidades complementarias pero no sustituibles. En consecuencia, las acciones del sector privado 
deben ser consideradas como un complemento a los esfuerzos del sector público y no como un reemplazo de sus responsabilidades (Oddone y Rodríguez, 2015).

En tercer lugar, se apunta al desarrollo de capacidades locales. En todas las etapas del proceso participan activamente funcionarios públicos y, en algunos casos, también representantes de organizaciones privadas como las cámaras empresariales. Estos actores contribuyen con información para elaborar los diagnósticos, acompañan al equipo de trabajo encargado de elaborar el estudio de campo, apoyan la organización de las mesas de diálogo y proporcionan insumos para la formulación de las estrategias. Además, la asistencia técnica suele ir acompañada de talleres para capacitar a funcionarios públicos, con miras a que puedan aplicar la metodología en futuras actividades. Asimismo, la metodología para el fortalecimiento de cadenas de valor de la CEPAL ha sido presentada en espacios académicos de América Latina y el Caribe que han permitido enriquecerla a partir del debate y la discusión.

En cuarto lugar, se basa en un enfoque sistémico de la política industrial. El respaldo a las cadenas no se centra exclusivamente en el eslabón principal conformado por los productores de bienes o servicios finales, sino que se extiende a los proveedores de insumos y equipos, a los servicios (control de calidad, difusión de nuevas tecnologías y transporte, entre otros) y a la comercialización. El fortalecimiento de la cadena exige el refuerzo de cada de uno de los eslabones, la consolidación de las relaciones entre ellos y el perfeccionamiento de las capacidades de las instituciones que les prestan apoyo (universidades, centros de investigación, cámaras empresariales y organismos de certificación, entre otras).

Aunque los casos presentados en este libro pertenecen al espacio rural, la metodología no está orientada con exclusividad a cadenas de valor pertenecientes a un sector específico. Ha sido aplicada a cadenas de productos primarios, manufacturas y servicios. De igual manera, la estructura general de nueve pasos y el contenido de cada uno de ellos está pensado para la intervención en cadenas que actualmente se hallan en operación. Pero puede ser ajustada para cadenas en construcción o que se quiere desarrollar. Por ejemplo, sería necesaria la introducción de estudios de mercado y de factibilidad, en lugar de diagnósticos (véanse mayores detalles sobre el caso de los chips fritos al vacío en Costa Rica en Cordero y Padilla (2016)).

A los lectores interesados en la aplicación de esta metodología, se les invita a consultar las publicaciones completas de cada cadena de valor, que sintetizan el diagnóstico, las buenas prácticas y la elaboración de estrategias. 


\section{Bibliografía}

AGRIPROFOCUS (2014), Género en cadenas de valor [en línea] http://agripro focus.com/upload/GenderToolkitSPANISH1426607706.pdf.

Amaya, P. y O. Cabrera (2013), La transformación estructural: una solución a la trampa de bajo crecimiento económico en El Salvador, San Salvador, Banco Central de Reserva de El Salvador.

Alvarado, J., L. Gil y N. Oddone (2016), "Fortalecimiento de la cadena de valor del turismo en Pedernales, República Dominicana. Versión Preliminar", Documentos de Proyectos, Ciudad de México, Comisión Económica para América Latina y el Caribe (CEPAL)/Fondo Internacional de Desarrollo Agrícola (FIDA).

Alvarado, J. y otros (2016), "La cadena de valor de embutidos y otras conservas de carne de cerdo en México", Documentos de Proyectos (LC/MEX/W.17), Ciudad de México, Comisión Económica para América Latina y el Caribe (CEPAL).

Antunes, B. y C. Monge (2014), “Las cadenas de fibras sintéticas-ropa deportiva en El Salvador", Fortalecimiento de las cadenas de valor como instrumento de la política industrial. Metodología y experiencia de la CEPAL en Centroamérica, Libros de la CEPAL, No 123 (LC/G.2606-P), Santiago, Comisión Económica para América Latina y el Caribe (CEPAL).

(2013), "Diagnóstico de la cadena de fibras sintéticas-ropa deportiva en El Salvador", Documentos de Proyectos (LC/MEX/L.1119), Ciudad de México, Comisión Económica para América Latina y el Caribe (CEPAL).

Bardach, E. (2000), A Practical Guide for Policy Analysis. The Eightfold Path to More Effective Problem Solving, Washington, D.C., Chatham House Publishers.

Barrientos, S., G. Gereffi y A. Rosi (2013), "Economic and social upgrading in global production networks: developing a framework for analysis, capturing the gains", Working Paper, No 3, The University of Manchester.

CEPAL (Comisión Económica para América Latina y el Caribe) (2016), Horizontes 2030. La igualdad en el centro del desarrollo sostenible (LC/G.2660/Rev.1), Santiago. (2014a) América Latina y el Caribe en la agenda para el desarrollo después de 2015: Reflexiones preliminares basadas en la trilogía de la igualdad (LC/L.3843) [en línea] http://repositorio.cepal.org/bitstream/handle/11362/36804/ S1420169_es.pdf?sequence $=1$.

(2014b), Pactos para la igualdad: hacia un futuro sostenible (LC/G.2586 (SES.35/3)), Santiago.

(2013), "Lineamientos estratégicos para el desarrollo industrial en Argentina. Documento de base", Buenos Aires, inédito.

(2012), Cambio estructural para la igualdad: una visión integrada del desarrollo (LC/G.2524), Santiago.

(2010), La hora de la igualdad: brechas por cerrar, caminos por abrir (LC/G.2432 (SES.33/3)), Santiago.

(2008), La transformación productiva 20 años después. Viejos problemas, nuevas oportunidades (LC/G.2367(SES.32/3)), Santiago.

(2007), Cohesión social. Inclusión ysentido depertenenciaen América Latinayel Caribe (LC/G.2335/Rev.1), Santiago.

Chaminade, C. y R. Padilla (2016), "The challenge of alignment and barriers for the design and implementation of science, technology and innovation policies for innovation systems in developing countries", Papers in Innovation Studies Paper, No 2014/26 [en línea] http://wp.circle.lu.se/upload/CIRCLE/ workingpapers/201426_Chaminade_Padilla-Perez.pdf. 
Cimoli, M. (ed.) (2005), "Heterogeneidad estructural, asimetrías tecnológicas y crecimiento en América Latina", Documentos de Proyectos (LC/W.35), Santiago, Comisión Económica para América Latina y el Caribe (CEPAL).

CLI (Collective Leadership Institute) (2011), “Working with Stakeholder Dialogues: Key Concepts and Competencies for Achieving Common Goals" [en línea] http:/ / collectiveleadership.com.

Cordero, M. (2014), "Cadena de hortalizas de exportación no tradicionales en Guatemala", Fortalecimiento de las cadenas de valor como instrumento de la politica industrial. Metodología y experiencia de la CEPAL en Centroamérica, Libros de la CEPAL, No 123 (LC/G.2606-P), Santiago, Comisión Económica para América Latina y el Caribe (CEPAL).

Cordero, M. y R. Padilla (2017), “Creación de una cadena de valor: chips fritos al vacío en Costa Rica", Fortalecimiento de cadenas de valor rurales, Documentos de Proyectos (LC/TS.2017/24), Ciudad de México, Comisión Económica para América Latina y el Caribe (CEPAL).

Devlin, R. y G. Moguillansky (2010), Alianzas público-privadas para una nueva visión estratégica del desarrollo, Libros de la CEPAL, N 108 (LC/G.2426-P), Santiago, Comisión Económica para América Latina y el Caribe (CEPAL).

Durán Lima, J. y D. Zaclicever (2013), “América Latina y el Caribe en las cadenas internacionales de valor", serie Comercio Internacional, $\mathrm{N}^{\circ} 124$ (LC/L.3767), Santiago, Comisión Económica para América Latina y el Caribe (CEPAL).

Edquist, Ch. (ed.) (1997), Systems of Innovation: Technologies, Institutions and Organizations, Londres, Pinter.

FAO (Organización de las Naciones Unidas para la Alimentación y la Agricultura) (2011), FAO at Work, 2010-2011. Women - key to food security, Roma.

FIDA (Fondo Internacional del Desarrollo Agrícola) (2012), Gestión del medio ambiente y los recursos naturales, Roma [en línea] https://www.ifad.org/ documents/10180/19e012c8-b414-4f95-a87b-f2ddb03e8e6b.

Freeman, Ch. (1987), Technology Policy and Economic Performance: Lessons from Japan, Londres, Pinter.

Garry, S. y R. Martínez (2016), "Fortalecimiento de la cadena de turismo en el Departamento de La Libertad, El Salvador", Documentos de Proyectos (LC/MEX/ W.18), Ciudad de México, Comisión Económica para América Latina y el Caribe (CEPAL).

Gereffi, G. (1994), "The organisation of buyer-driven global commodity chains: how U.S. retailers shape overseas production networks", Commodity Chains and Global Capitalism, G. Gereffi y M. Korzeniewicz (eds.), Westport, Praeger.

Gereffi, G. y K. Fernández-Stark (2011), Global Value Chains: A Primer, Centro sobre Globalización, Gobernanza y Competitividad, Universidad de Duke.

Gereffi, G., J. Humphrey y T. Sturgeon (2005), "The governance of global value chains", Review of International Political Economy, vol. 12, N 1 , Londres, Routledge.

GIZ (Agencia Alemana de Cooperación Internacional) 2011, Stakeholders Dialogues. Manual, Echborn, noviembre.

Gomes, C. y N. Oddone (2016), "Fortalecimiento de la cadena de los lácteos en la República Dominicana. Versión preliminar", Documentos de Proyectos, Ciudad de México, Comisión Económica para América Latina y el Caribe (CEPAL).

Haussmann, R., D. Rodrik y A. Velasco (2005), "Growth diagnostics”, The Washington Consensus Reconsidered:Towards a New Global Governance,J.Stiglitzy N.Serra (eds.), Nueva York, Oxford University Press.

Humphrey, J. y H. Schmitz (2002), "How does insertion in global value chains affect upgrading in industrial clusters?", Regional Studies, vol. 36, N 9, Taylor \& Francis. 
Kabeer, N. (1999), “Resources, Agency, achievements: reflections on the measurement of women's empowerment", Development and Change, vol. 30, $\mathrm{N}^{\mathrm{o}} 3$.

Kaplinsky, R. (2000), "Globalisation and unequalisation: what can be learned from value chain analysis?", Journal of Development Studies, vol. 37, N², Taylor \& Francis.

Kaplinsky, R. y M. Morris (2002), A Handbook for Value Chain Research, Brighton, Instituto de Estudios de Desarrollo.

Kosacoff, B. y A. López (2008), “América Latina y las cadenas globales de valor: debilidades y potencialidades", Revista Globalización, Competitividad y Gobernabilidad, vol. 2, N 1, Washington, D.C., Georgetown University.

Lall, S., M. Albaladejo y J. Zhang (2004), "Mapping fragmentation: electronics and automobiles in East Asia and Latin America", Oxford Development Studies, vol. $32, \mathrm{~N}^{\circ} 3$.

López, A., D. Ramos e I. Torre (2009), “Las exportaciones de servicios de América Latina y su integración en las cadenas globales de valor", Documentos de Proyecto (LC/W.240), Santiago, Comisión Económica para América Latina y el Caribe (CEPAL).

Lundvall, B. (ed.) (1992), National Systems of Innovation: Towards a Theory of Innovation and Interactive Learning, Londres, Pinter.

Morrison, A., C. Pietrobelli y R. Rabelloti (2008), "Global value chains and technological capabilities: a framework to study learning and innovation in Developing Countries", Oxford Development Studies, vol. 36, $\mathrm{N}^{\circ} 1$.

Naciones Unidas (s/f), Pacto Mundial de las Naciones Unidas [en línea] https:// www.unglobalcompact.org/.

Ocampo, J.A. (2014), “Latin American structuralism and production development strategies", Transforming Economies: Making Industrial Policy Work for Growth, Jobs and Development, J.M. Salazar-Xirinachs, I. Nübler y R. Kozul-Wright, Ginebra, Organización Internacional del Trabajo (OIT).

OCDE (Organización de Cooperación y Desarrollo Económicos) (2013), Interconnected Economies: Benefiting from Global Value Chains, París.

OCDE/CEPAL (Organización de Cooperación y Desarrollo Económicos/Comisión Económica para América Latina y el Caribe), Perspectivas económicas de América Latina 2013: políticas de pymes para el cambio estructural (LC/G.2545), Santiago.

Oddone, N. y P. Alarcón (2016), “Fortalecimiento de la cadena de turismo de Antigua Guatemala y de los municipios rurales del Departamento de Sacatepéquez", Documentos de Proyectos (LC/MEX/W.15), Ciudad de México, Comisión Económica para América Latina y el Caribe (CEPAL).

Oddone, N. y R. Padilla (2016), "Economic and social upgrading through professional and supporting services: Lessons from the shrimp value chain in El Salvador", Regions E Cohesion, vol. 6, No 1, Luxemburgo, Berghahn Journals and Laboratoire de Sciences Politiques, Université du Luxembourg.

Oddone, N. y otros (2016), "Fortalecimiento de la cadena de valor de tomate y chile verde dulce en El Salvador", Documentos de Proyectos (LC/MEX/W.13), Ciudad de México, Comisión Económica para América Latina y el Caribe (CEPAL).

Oddone, N. y H. Rodríguez (2015), “Alianzas público-privadas como motor de la innovación local transfronteriza", Gobernanza y políticas públicas, K. Ramírez y otros (coords.), Mexicali, Baja California, Universidad Autónoma de Baja California.

Oddone, N. y C. Beltrán (2014), “Diagnóstico de la cadena de camarón de cultivo en El Salvador", Documentos de Proyectos (LC/MEX/L.1137), Ciudad de México, Comisión Económica para América Latina y el Caribe (CEPAL). 
Oddone, N., R. Padilla y B. Antunes (2014), "Metodología del Proyecto CEPAL-GIZ para el diseño de estrategias de fortalecimiento de cadenas de valor", Fortalecimiento de las cadenas de valor como instrumento de la política industrial. Metodología y experiencia de la CEPAL en Centroamérica, Libros de la CEPAL, No 123 (LC/G.2606-P), Santiago, Comisión Económica para América Latina y el Caribe (CEPAL).

Ongaro, E. (2009), "A protocol for the extrapolation of "Best Practices": how to draw lessons from one experience to improve public management in another situation" [en línea] http://epsa2009.eu/files/Symposium/An\%20 approach $\% 20$ to $\% 20$ the $\% 20$ extrapolation $\% 20$ of $\% 20$ practices_EOngaro.pdf.

ONUDI (Organización de las Naciones Unidas para el Desarrollo Industrial) (2009a), "Value chain diagnostics for industrial development. Building blocks for a holistic and rapid analytical tool", UNIDO Working Paper, Viena. (2009b), Developing a Value Chain Diagnostics Tool for Common Practice at UNIDO. Expert Group Meeting Report, Viena [en línea] http://www.unido. org/fileadmin/user_media/Services/IFI/Event/EGM_VC/UNIDO_Value_ Chain_EGM_Report.pdf.

Overman, S. y K. Boyd (1994), "Best practice research and post bureaucratic Reform", The Journal of Public Administration Research and Theory.

Padilla, R. (ed.) (2014), Fortalecimiento de las cadenas de valor como instrumento de la política industrial. Metodología y experiencia de la CEPAL en Centroamérica, Libros de la CEPAL, N 123 (LC/G.2606-P), Santiago, Comisión Económica para América Latina y el Caribe (CEPAL).

Padilla, R. y N. Oddone (2016), Manual para el fortalecimiento de cadenas de valor (LC/MEX/1.1218), Ciudad de México, Comisión Económica para América Latina y el Caribe (CEPAL).

Padilla, R. y J. Alvarado (2014), "El resurgimiento de la política industrial", Fortalecimiento de las cadenas de valor como instrumento de la politica industrial. Metodología y experiencia de la CEPAL en Centroamérica, Libros de la CEPAL, N 123 (LC/G.2606-P), Santiago, Comisión Económica para América Latina y el Caribe (CEPAL).

Pietrobelli, C. y R. Rabellotti (eds.) (2006), Upgrading to compete: Global Value Chains, Clusters and SMEs in Latin America, Washington, D.C., Banco Interamericano de Desarrollo (BID).

Quirola Suárez, D. (2010), “Análisis del concepto de Buen Vivir aplicado a la planificación del turismo sostenible", documento presentado en la Primera Cumbre de Turismo Sostenible, Galápagos, Secretaría Nacional de Planificación y Desarrollo (SENPLADES).

Ramírez, F., y otros (2012), "El empoderamiento de las mujeres en las cadenas de valor: un reto para las políticas de desarrollo rural", Síntesis para decisores. Policy Brief, Turrialba, Programa Agroambiental Mesoamericano, CATIE/Real Embajada de Noruega.

Rayo, A. (2014), "Espacios de diálogo para construir estrategias de desarrollo conjunto público y privado", Fortalecimiento de las cadenas de valor como instrumento de la politica industrial. Metodología y experiencia de la CEPAL en Centroamérica, Libros de la CEPAL, No 123 (LC/G.2606-P), Santiago, Comisión Económica para América Latina y el Caribe (CEPAL).

Rentzhog, M. (2010), At Your Service: The Importance of Services for Manufacturing Companies and possible Trade Policy Implications, Junta Nacional de Comercio de Suecia. 
Rhi-Sausi, J Luis, D. Conato y M. Lamela (2011), Capitalización de buenas prácticas para la cohesión social, Rosario, Programa URBAL III.

Romero, I., V. Díaz y A. Aguirre (2016), "Fortalecimiento de la cadena de valor de los snacks nutritivos con base en fruta deshidratada en El Salvador", Documentos de Proyectos (LC/MEX/W.16), Ciudad de México, Comisión Económica para América Latina y el Caribe (CEPAL).

Ruben, R. (2001), "Políticas y tecnologías para el uso sostenible de recursos naturales: la experiencia centroamericana", Nueva ruralidad y politica agraria. Una alternativa neoinstitucional para Centroamérica, H. Clemens, y R. Ruben (eds.), Centro de Estudios para el Desarrollo Rural, Universidad de Amsterdam/ Editorial Nueva Sociedad.

Sen, A. (2000), "Work and rights", International Labour Review, vol. 139, № 2.

Stumpo, G. y D. Rivas (comps.) (2013), La industria argentina frente a los nuevos desafios y oportunidades del siglo XXI (LC/L.3637), Santiago, Comisión Económica para América Latina y el Caribe (CEPAL).

Taglioni, D. y D. Winkler (2014), Making Global Value Chains work for Development, Washington, D.C., Banco Mundial.

Vallina, J. (2008), “Los hoteles y el medio ambiente: ecoeficiencia y buenas prácticas ambientales", Hoteles en verde: ecoeficiencia y gestión ambiental en el sector hotelero, Oviedo, Formastur/Unión Hotelera del Principado de Asturias.

Veselý, A. (2011), "Theory and methodology of best practice research: a critical review of the current state", Central European Journal of Public Policy, vol. 5, N². 
Capítulo IV

\section{La selección de cadenas de valor en el contexto de una política industrial}

Caroline Gomes Nogueira

Ramón Padilla Pérez

Francisco G. Villarreal

\section{Introducción}

La intervención pública para el fortalecimiento de cadenas de valor demanda un proceso de selección. Ante recursos humanos y financieros limitados, y el enorme número de cadenas que conforman el aparato productivo de un país o una región, es necesario escoger aquellas donde se concentrarán los esfuerzos de política pública en el corto plazo.

Entre los encargados del diseño e implementación de las políticas públicas en América Latina y el Caribe, es común encontrar cierta resistencia a la selección. Por un lado, la selección de ganadores (picking winners) y el apoyo a campeones industriales han recibido críticas por las distorsiones de mercado que pueden causar, la incapacidad de los gobiernos para identificar efectivamente las industrias y sectores estratégicos, y la posibilidad de quedar sujeto a presiones del sector privado en la búsqueda de rentas, entre otras (Pack y Saggi, 2006; Pack, 2000; Krueger, 1990; Schultze, 1983). Ante ello, es de vital importancia diseñar un proceso de selección transparente y objetivo. 
La selección no implica que el sector público imponga barreras a otras cadenas o que las excluya de los apoyos. Las cadenas seleccionadas recibirán un apoyo temporal, basado en un plan estratégico claramente definido y con indicadores de seguimiento. Como se observa en casos exitosos de Asia Oriental, el apoyo a sectores estratégicos estuvo sujeto a revisiones periódicas, que llevaron a escoger nuevas industrias emergentes sobre la base de las capacidades productivas y tecnológicas nacionales desarrolladas, y a retirar los beneficios públicos a aquellas que habían logrado consolidarse (Hobday, 1995; Amsden, 1989; Enos y Park, 1988).

La legitimidad, fortaleza y objetividad de la selección dependen en gran parte de que el proceso se realice con criterios económicos y estratégicos, es decir, en sintonía con planes sectoriales y de desarrollo formulados por los gobiernos, y sobre la base del potencial que cada cadena tiene para contribuir al desarrollo económico y social. En esta línea, la CEPAL desarrolló una metodología para la selección de cadenas de valor, que se presenta en este capítulo.

Este capítulo está dividido en cinco secciones, además de esta introducción. En la primera (sección A) se efectúa una revisión conceptual y se examinan distintos enfoques que abordan la conveniencia y la necesidad de seleccionar sectores o cadenas. En la segunda (sección B) se examinan casos recientes en los que Gobiernos de la región, con apoyo de organismos internacionales y empresas de consultoría, han seleccionado sectores como parte de sus estrategias de desarrollo. En la tercera sección (C) se presenta una propuesta metodológica para seleccionar las cadenas, mientras que en la cuarta (sección D) se discute la construcción de indicadores a partir de los metaobjetivos propuestos y se valora la importancia de incorporar tanto variables prospectivas como criterios cualitativos en el proceso de selección. Por último, en la sección E se exponen las conclusiones y reflexiones finales en torno a las fortalezas, las limitaciones y los desafíos para la selección de cadenas.

\section{A. ¿Por qué seleccionar cadenas?}

En la literatura económica se encuentran diversas posturas que justifican la importancia de seleccionar los sectores que recibirán el apoyo en el marco del diseño e implementación de una política industrial. En esta sección, se destacan cinco enfoques, que presentan visiones complementarias. 


\section{1. ¿Existen realmente las políticas industriales horizontales?}

La decisión de focalizar o no las medidas de política industrial en determinados productores, empresas, industrias o regiones - lo que se conoce como la selección de ganadores - ha sido una de las cuestiones más controvertidas en los debates de política industrial de los últimos años (Salazar-Xirinachs, Nübler y Kozul-Wright, 2014). Autores como Chang (2010) y Stiglitz, Lin y Monga (2013) señalan que la distinción entre las medidas horizontales - que son neutras en todos los sectoresy las medidas verticales - de apoyo a industrias, empresas o regiones específicas- es, en realidad, una opción falsa, ya que incluso la mayoría de las medidas generales de política industrial favorecen a un determinando grupo sobre otros.

Las políticas que tradicionalmente son consideradas de corte horizontal —como el fomento de la exportación, la formación de recursos humanos, el apoyo a la investigación y el desarrollo (I+D), y la construcción de infraestructura pública - en general terminan favoreciendo a un sector determinado sobre otros. Por un lado, la selección se da por el enfoque mismo de las políticas, por ejemplo al diseñar medidas para apoyar a las empresas exportadoras sin importar de qué sector sean estas, se favorece a aquellas orientadas hacia el mercado exterior y no a las que venden exclusivamente en el mercado nacional. Por otro lado, ante la heterogeneidad en términos de las capacidades de las empresas, las más grandes o con mayores recursos suelen tener ventajas para beneficiarse de políticas horizontales. Por ejemplo, el acceso a subvenciones compartidas para actividades de I+D, en las que la empresa contribuye con fondos equivalentes a los proporcionados por el gobierno, suele ser más sencillo para las empresas grandes que para las pequeñas, mientras que los fondos concursables de I+D son otorgados en su mayoría a firmas que ya cuentan con ciertas capacidades.

Ocampo (2014), por su parte, señala que los defensores de las medidas horizontales pasan por alto el hecho de que, ante recursos fiscales escasos, es necesario especificar dónde se deben utilizar dichos recursos, lo que implica necesariamente un proceso de selección. Por lo tanto, este tipo de decisiones se deben tomar en el marco de una estrategia de desarrollo $y$, en aras de la transparencia, conviene que estas opciones sean explícitas en lugar de implícitas. En síntesis, en la práctica es muy difícil diseñar medidas horizontales, por lo que, tal como han argumentado Hausmann y Rodrik (2006), los gobiernos están condenados a elegir. 


\section{La existencia de fallas de mercado}

Un segundo enfoque justifica la selección de cadenas en la existencia de fallas de mercado, que surgen ante la ausencia de mercados competitivos o la presencia de mercados incompletos, por ejemplo, en situaciones de asimetrías de información o externalidades (Crespi, Fernández-Arias y Stein, 2014; Lin, 2012; Hausmann y Rodrik, 2006). De acuerdo con este enfoque, los mercados también fallan cuando las decisiones de inversión son interdependientes y requieren coordinación.

Crespi, Fernández-Arias y Stein (2014) justifican la selección basándose en la presencia de lo que llaman dilema del pionero. La identificación de nuevas actividades suele ser un proceso de autodescubrimiento que exige esfuerzos e inversiones de parte de algún pionero, pero la posible falta de apropiación de este descubrimiento reduce el incentivo económico para hacer las inversiones necesarias. Estos autores subrayan que la selección puede verse afectada por la posible presencia de fallas de gobierno, es decir que, si la intervención gubernamental no logra una asignación socialmente eficiente de los recursos, creará ineficiencias y conducirá a una mala asignación de los recursos escasos. Por ejemplo, el gobierno puede conceder subvenciones a empresas o sectores seleccionados, pero esto puede proteger a empresas ineficientes de la competencia y crear barreras a la entrada de nuevos jugadores. Además, los subsidios y otros tipos de apoyos directos pueden dar lugar al problema de riesgo moral. En este sentido, los autores argumentan que es necesario diseñar políticas basadas en parámetros de eficiencia, costo, riesgo y simplicidad.

Lin (2012), por su parte, propone un marco metodológico práctico para identificar los sectores clave, en línea con la ventaja comparativa existente en el país y una guía sobre cómo eliminar los obstáculos al crecimiento en estos sectores al abordar las fallas de coordinación y de mercado. La selección se fundamenta en la existencia de fallas de mercado, en particular las externalidades positivas generadas por las empresas pioneras, la falta de infraestructura demandada por sectores emergentes específicos y los costos de transacción.

\section{El desafío de las ventajas comparativas y la creación de ganadores}

Un tercer enfoque destaca la importancia de desafiar las ventajas comparativas existentes en un país o región, y apoyar la creación de nuevos sectores. A la inversa de lo postulado por el enfoque de la nueva economía estructural (Lin, 2012), los pioneros del pensamiento desarrollista latinoamericano (por ejemplo, Prebisch, 1949; Sunkel y Paz, 1970) y más recientemente Chang (2010), se oponen a la idea de que las ventajas 
comparativas inherentes a la estructura, así como la dotación de factores de un país, sean determinantes de su desarrollo económico. En su lugar, es necesario implementar políticas que apunten a desarrollar nuevos sectores y modificar la ventaja comparativa actual mediante la intervención directa del sector público.

De manera similar, Ocampo (2014) señala que con frecuencia no resulta evidente cuál actividad innovadora debe promoverse. En tales casos, el fomento de la innovación puede ser indistinguible de la promoción del desarrollo de un determinado sector. En esta situación, criticar la promoción de un sector determinado porque implica elegir ganadores equivale a ignorar las características intrínsecas de las estrategias de desarrollo productivo. El primer punto que se pasa por alto es determinar qué sectores deben promoverse - lo que exige un proceso de aprendizaje desde el punto de vista de la formulación de políticas públicas- y, aún más importante, cómo debe llevarse adelante este proceso. Desde esta perspectiva, las decisiones que deben tomarse no son muy diferentes a las que enfrentan las empresas privadas cuando deciden expandirse hacia nuevas líneas de productos y hacer una apuesta estratégica basada en las capacidades acumuladas a través del tiempo. El segundo punto que a menudo se pasa por alto es que las políticas selectivas suelen estar diseñadas para crear las condiciones propicias para el éxito de la iniciativa, por lo que, en lugar de escoger ganadores, en realidad están dirigidas a crearlos.

\section{El aprovechamiento de ventanas de oportunidad}

El cuarto enfoque señala la importancia de aprovechar las ventanas de oportunidad que se abren durante los períodos de cambio de paradigma para invertir en sectores innovadores y de rápido crecimiento, como la nanotecnología, la biotecnología y la inteligencia artificial. Pérez (2002) destaca que los cambios tecnológicos dan lugar a períodos ventajosos tanto para las empresas nuevas como para las ya consolidadas. La autora señala que la aparición de un nuevo paradigma técnico-económico afecta los comportamientos relacionados con la innovación y la inversión, abre un nuevo potencial de creación de riqueza, y origina nuevas prácticas y comportamientos. La acción de estos agentes pioneros define gradualmente la nueva frontera de las buenas prácticas y su éxito se convierte en una poderosa señal de la dirección de las prácticas más rentables.

Desde esta perspectiva, Mazzucato y Pérez (2015) señalan que el papel del Estado es fundamental para asegurar el aprovechamiento de estas ventanas de oportunidad, lo que implica apoyar empresas o sectores específicos. La inversión pública directa es sumamente importante para promover la creación de bienes públicos y la toma de riesgos vinculados a la investigación y la innovación en los sectores público y privado. 


\section{El cambio estructural}

El quinto enfoque está relacionado con la necesidad de adoptar políticas públicas activas y selectivas para transformar la estructura productiva y llevar a cabo un cambio estructural. La CEPAL ha puesto sobre la mesa la importancia del cambio estructural para el desarrollo económico y social a largo plazo. Para ello, las estructuras productivas y exportadoras de los países en desarrollo deben reorientarse hacia sectores más dinámicos, de mayor productividad o de alto contenido tecnológico (Cimoli, 2005; Kosacoff y López, 2008). En este enfoque se enfatiza la necesidad de ir más allá de las fallas de mercado y de reconocer que el gobierno tiene un papel importante en la creación y el fortalecimiento de los sectores productivos y las capacidades orientados a lograr un cambio estructural (CEPAL, 2012).

El cambio estructural demanda el apoyo de los sectores existentes y la creación de nuevos sectores. Ante recursos humanos y financieros limitados, el gobierno debe concentrar los esfuerzos en un grupo de sectores, lo que requiere de un proceso de selección.

\section{B. La selección de sectores en la práctica: herramientas y estrategias}

En la presente sección se resumen tres casos en los que Gobiernos de la región, en ocasiones con apoyo de organismos internacionales y empresas de consultoría, han seleccionado sectores para impulsarlos como parte de sus estrategias de desarrollo.

\section{Identificación de conglomerados (clusters) de alto potencial en Centroamérica: Instituto Centroamericano de Administración de Empresas (INCAE) e Instituto de Desarrollo Internacional de Harvard}

A finales de la década de 1990, el Instituto Centroamericano de Administración de Empresas (INCAE), conjuntamente con el Instituto de Desarrollo Internacional de Harvard, con una fuerte inspiración metodológica en el trabajo de Michael Porter (1990), identificaron en Centroamérica un grupo de sectores o actividades calificados como clusters de alto potencial. En el cuadro IV.1 se presentan los cuatro clusters seleccionados y las condiciones favorables que llevaron a dicha selección, que se basó en estudios sobre las actividades económicas centroamericanas con mayores opciones de insertarse ventajosamente en el mercado internacional (INCAE/HIID, 1999). 


\section{Cuadro IV.1}

\section{Centroamérica: clusters de alto potencial}

\begin{tabular}{|c|c|}
\hline Cluster & Condiciones favorables \\
\hline Turismo & $\begin{array}{l}\text { - La subregión ofrece grandes categorías de productos turísticos que } \\
\text { la diferencian de otras regiones: biodiversidad, arqueología, ciudades } \\
\text { coloniales, deportes de aventura y acuáticos, y culturas vivas. }\end{array}$ \\
\hline Agronegocios & $\begin{array}{l}\text { - Este cluster ha sido el eje tradicional de la economía de la subregión } \\
\text { y su potencial se basa en las excepcionales condiciones climáticas } \\
\text { del Istmo Centroamericano. Sin embargo, aún no se ha explotado } \\
\text { totalmente su verdadero potencial. } \\
\text { - Las tendencias de los mercados mundiales y la experiencia ya } \\
\text { acumulada guardan oportunidades al alcance de la región. }\end{array}$ \\
\hline Textiles & $\begin{array}{l}\text { - La subregión tiene un acceso favorable al mercado por sus bajos } \\
\text { costos de mano de obra y su ubicación geográfica. } \\
\text { - } \quad \text { La proximidad al mercado estadounidense ayuda a reducir los tiempos } \\
\text { de respuesta de la cadena de abastecimiento, lo que hace de la } \\
\text { subregión un centro natural de abastecimiento para un mercado que } \\
\text { exige plazos de entrega más breves y flexibles. } \\
\text { - } \quad \text { Además, se cuenta con experiencias de desarrollo de paquete } \\
\text { completo que pueden replicarse en la subregión. }\end{array}$ \\
\hline $\begin{array}{l}\text { Servicios electrónicos } \\
\text { y de software }\end{array}$ & $\begin{array}{l}\text { - Exitosa atracción de inversión extranjera directa (IED) en el sector. } \\
\text { - Políticas explícitas y agresivas de capacitación de personal para el } \\
\text { desarrollo de la industria del software. } \\
\text { - Existencia de varias empresas de maquila electrónica y desarrollo } \\
\text { de software. }\end{array}$ \\
\hline
\end{tabular}

Fuente: Instituto Centroamericano de Administración de Empresas (INCAE)/Instituto de Desarrollo Internacional de Harvard, Centroamérica en el siglo XXI: una agenda para la competitividad y el desarrollo sostenible. Bases para la discusión sobre el futuro de la región, Alajuela, 1999.

\section{Selección de sectores prioritarios en México en términos de productividad y potencial de crecimiento}

El Comité Nacional de Productividad (CNP), órgano consultivo del Poder Ejecutivo federal, integrado por miembros de los sectores público y privado, el ámbito académico y trabajadores, fue creado en 2013 para auxiliar en la formulación de políticas en materia de productividad y empleo. Este comité definió, además de acciones de carácter transversal, instrumentos con un enfoque sectorial, para lo que identificó sectores prioritarios en términos de productividad y potencial de crecimiento.

El enfoque sectorial adoptado por los subcomités del CNP tiene el objetivo de elevar la productividad y se centra en tres estrategias: i) incrementar la productividad en sectores de alto empleo; ii) promover la expansión de sectores de alta productividad mediante mayor empleo e inversión, y iii) aprovechar las oportunidades de crecimiento en sectores de alta productividad surgidas de las reformas aprobadas por el gobierno federal (véase el cuadro IV.2) ${ }^{1}$.

Al inicio de su mandato (2012-2018), el Presidente Enrique Peña Nieto se embarcó en un conjunto ambicioso de reformas estructurales en materia de telecomunicaciones, educación y energía, entre otros temas. Véase mayor información en [en línea] http://reformas.gob.mx/. 


\section{Cuadro IV.2}

Enfoque sectorial

\begin{tabular}{lll}
\hline $\begin{array}{c}\text { Estrategia 1 } \\
\begin{array}{c}\text { Sectores de alto empleo } \\
\text { y baja productividad }\end{array}\end{array}$ & $\begin{array}{c}\text { Sectores de alta productividad } \\
\text { que pueden crecer }\end{array}$ & $\begin{array}{c}\text { Estrategia 2 } \\
\text { Oportunidad de crecimiento } \\
\text { gracias a las reformas }\end{array}$ \\
\hline 1. Comercio al por menor & $\begin{array}{l}\text { 1. Autopartes } \\
\text { 2. Turismo }\end{array}$ & $\begin{array}{l}\text { 1. Energético } \\
\text { 3. Gastronomía }\end{array}$ \\
$\begin{array}{ll}\text { 3. Proindustria } \\
\text { 4. Eléctrico y electrónico }\end{array}$ & \\
\hline
\end{tabular}

Fuente: Comité Nacional de Productividad de México, 2015 [en línea] http://www.gob.mx/ productividad/articulos/comite-nacional-de-productividad-cnp.

Para identificar los sectores altamente productivos y con un elevado potencial de crecimiento, el CNP recurrió a la metodología de Hausmann y otros (2011), conocida como "Atlas de complejidad económica", una técnica para elaborar medidas de la sofisticación de los productos y de los países a partir de los datos económicos disponibles. Los autores elaboraron un mapa del espacio del producto en el mundo, sobre la base de datos relativos al comercio de 774 códigos de productos, desde verduras a equipamientos electrónicos sofisticados. Con esta técnica se busca estimar el conocimiento productivo que posee cada país, mediante la visualización de las canastas de productos. Estos instrumentos fueron diseñados para estudiar no solo la riqueza económica, sino también la estructura económica y la sofisticación de las economías. En este sentido, para los autores el desarrollo económico y productivo es el resultado de la acumulación de capacidades y habilidades que permiten a un país producir bienes cada vez más complejos.

\section{Focalización de esfuerzos en Chile}

En 2006, el Ministerio de Hacienda de Chile aprobó la creación del Consejo Nacional de Innovación para la Competitividad (CNIC), con la meta de delinear los objetivos futuros de la estrategia de innovación y competitividad del país. Tras su creación, el CNIC estableció la necesidad de priorizar y focalizar los esfuerzos de desarrollo productivo, inversión e innovación, habida cuenta de que hasta entonces había prevalecido el criterio que propugnaba las políticas industriales horizontales.

Se contrató a la firma de consultoría internacional Boston Consulting Group (BCG) para elaborar un estudio que permitiera seleccionar clusters exportadores (CNIC, 2007 y 2008). En primer lugar, el CNIC elaboró un mapa de los sectores con mayor potencial de desarrollo de la economía chilena por medio de un análisis del nivel de apertura al comercio internacional, la competitividad sustentada en la innovación y el capital humano, y el aprovechamiento de las ventajas que otorgan los recursos naturales potenciados con una fuerte inyección de conocimientos (CNIC, 2007). 
En un paso siguiente, se organizó un taller de análisis de escenarios y se reunió información bibliográfica sobre los sectores con mayor potencial de desarrollo del país, datos económicos del Banco Central de Chile sobre cada actividad productiva y datos de la evolución de las exportaciones nacionales en los últimos años. Esta información fue complementada con entrevistas a miembros del CNIC y otros expertos nacionales, según los sectores productivos.

Toda esta información permitió conformar una lista inicial de casi 70 sectores potenciales, que posteriormente se acotó a 31 mediante la aplicación de cuatro criterios básicos: i) las posibilidades de consolidación de distintas oportunidades (por ejemplo, un nuevo tipo de variedad de frutas de exportación); ii) el tamaño actual y el tamaño esperado del sector; iii) su compatibilidad con las ventajas competitivas actuales o factibles de ser desarrolladas en la economía chilena, y iv) la posibilidad de que el sector fuera considerado una plataforma transversal que pudiera brindar apoyo a otros sectores (por ejemplo, recursos humanos o energía).

A los 31 sectores priorizados, se aplicó un análisis más detallado basado en cuatro variables:

i) la participación de cada sector en el producto interno bruto (PIB);

ii) el potencial de crecimiento en términos de aportes al PIB en los próximos diez años;

iii) la competitividad en términos de la ubicación geográfica en relación con los principales mercados consumidores; la existencia de recursos naturales; el capital humano (existente y capacidad de atracción); la capacidad de atraer inversiones (internas y extranjeras); el acceso a tecnología, infraestructura y logística; la asociación y conexión entre los distintos agentes de un sector y los sectores relacionados; la sostenibilidad ambiental; la sostenibilidad de las ventajas; y el marco regulatorio, y

iv) el grado de intervención necesaria del Estado para capturar el potencial del sector.

Los 11 clusters seleccionados fueron acuicultura, servicios de deslocalización, turismo, porcicultura-avicultura, fruticultura, minería del cobre, alimentos procesados, servicios financieros, logística y transporte, comunicaciones y construcción (CNIC, 2007). La selección se complementó con la elaboración de un mapa de creación de valor del sector, un análisis de situación actual del sector en Chile, un análisis del sector en países de referencia, la identificación de cuellos de botella y oportunidades, la definición de visión a largo plazo y la confección de una hoja de ruta específica. 


\section{La metodología de selección de cadenas ${ }^{2}$}

En el capítulo III de este libro se presentan los nueve pasos para el fortalecimiento de cadenas de valor que integran la metodología propuesta por la CEPAL. En esta sección, se abordan con mayor detalle los dos primeros pasos: la identificación de metaobjetivos y la selección de las cadenas.

Para seleccionar una cadena, es necesario establecer en primer lugar los metaobjetivos del proceso de fortalecimiento, definidos como el fin que se persigue en última instancia en materia de desarrollo económico y social. El prefijo "meta" los distingue de los objetivos particulares que surgen en el trabajo con las cadenas.

Entre diversos metaobjetivos, cabe citar aumentar el empleo y los salarios, dinamizar la productividad, incrementar las exportaciones, fortalecer la participación de los pequeños productores e incrementar la producción nacional. De manera complementaria a los indicadores económicos, se pueden seguir criterios de carácter cualitativo: consideraciones geográficas (por ejemplo, brindar apoyo a cadenas de regiones menos favorecidas), sociales (como atender a grupos vulnerables) y ambientales, entre otros.

La definición de metaobjetivos suele efectuarse en una reunión de trabajo con funcionarios públicos de alto nivel, que determinan cuál es el resultado esperado del fortalecimiento de la cadena. También puede optarse por un proceso participativo, donde la definición de los metaobjetivos se realice en conjunto con representantes del sector privado y la sociedad civil. Los metaobjetivos ofrecen una guía para las acciones que se llevarán a cabo en el resto de las etapas del proceso de fortalecimiento. En particular, las cadenas seleccionadas deben poseer un alto potencial de contribuir a su consecución. Las preguntas que guían la definición de los metaobjetivos son:

- ¿Cuáles son los principales retos que se enfrentan en materia de desarrollo productivo?

- ¿Cuáles son los principales objetivos en materia de desarrollo productivo del plan nacional de desarrollo?

- ¿Cuáles son los principales objetivos planteados en el plan sectorial que es responsabilidad del organismo público que lidera el proceso de fortalecimiento de la cadena?

- ¿De qué manera puede contribuir el fortalecimiento de cadenas de valor al desarrollo productivo?

Esta sección está basada en Padilla y Oddone (2016). 
En la definición de los metaobjetivos es muy importante asegurar que estén alineados horizontal y verticalmente ${ }^{3}$.

- Alineación horizontal: los metaobjetivos se alinean con los planes de desarrollo y los planes sectoriales. Así, en caso de que un objetivo de desarrollo nacional sea el apoyo a las regiones menos favorecidas, el fortalecimiento de las cadenas se orientará al desarrollo productivo de dichas zonas. En consonancia con este criterio, si un objetivo central del ministerio de agricultura es incrementar el abasto nacional de productos primarios, el metaobjetivo de una cadena en este sector será elevar la producción y la productividad nacionales.

- Alineación vertical: los metaobjetivos deben alinearse también con los instrumentos específicos, es decir que el diseño de estrategias para el fortalecimiento de cadenas de valor debe corresponderse con los metaobjetivos planteados. El análisis microeconómico y los procesos participativos son de gran utilidad para focalizar los instrumentos, de forma que se vigile que están efectivamente orientados al cumplimiento de los objetivos (véase el diagrama IV.1).

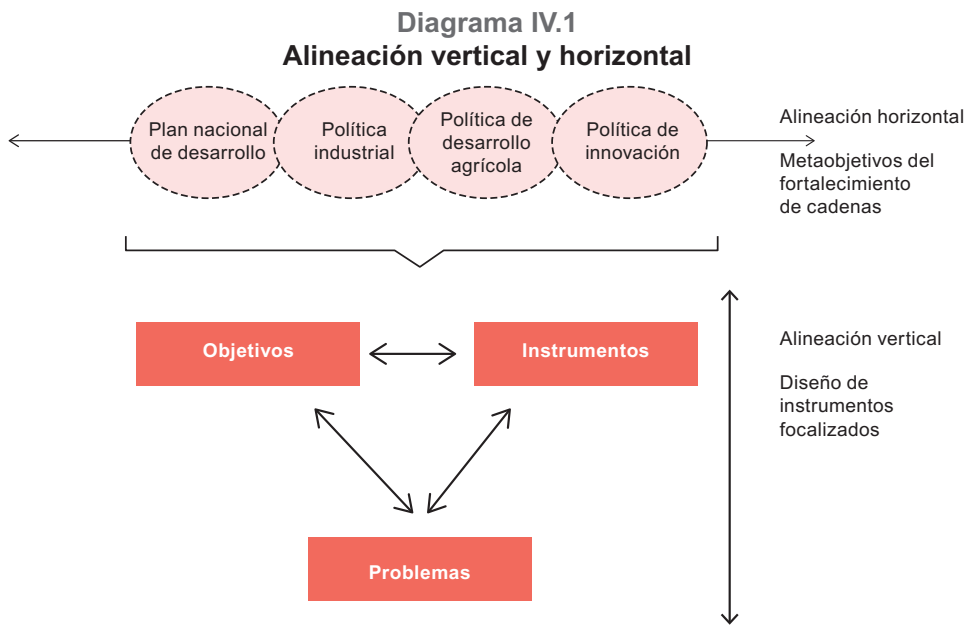

Fuente: Elaboración propia, sobre la base de C. Chaminade y R. Padilla, "The challenge of alignment and barriers for the design and implementation of science, technology and innovation policies for innovation systems in developing countries", Research Handbook on Innovation Governance for Emerging Economies: towards better models, S. Kulhman y G. Ordoñez-Matamoros (eds.), Cheltenham, Edward Elgar Publishing, enero de 2016.

3 Véanse más detalles sobre la alineación vertical y horizontal de objetivos y políticas públicas en Chaminade y Padilla (2017). 
El proceso de selección de cadenas está conformado por seis pasos, que se ilustran en el diagrama IV.2. Los criterios para la selección de cadenas concuerdan con los metaobjetivos, es decir, con el potencial de la cadena para contribuir a su cumplimiento. En los procesos de asistencia técnica brindados por la CEPAL, se ha percibido un firme interés de parte de los gobiernos por contar con un proceso objetivo y transparente para seleccionar las cadenas. La selección de una o varias cadenas implica que en el corto o mediano plazo recibirán un apoyo gubernamental especial, lo que podría ser objeto de presiones por parte de grupos particulares. Los pasos que se exponen a continuación han sido una herramienta útil para otorgar objetividad al proceso.

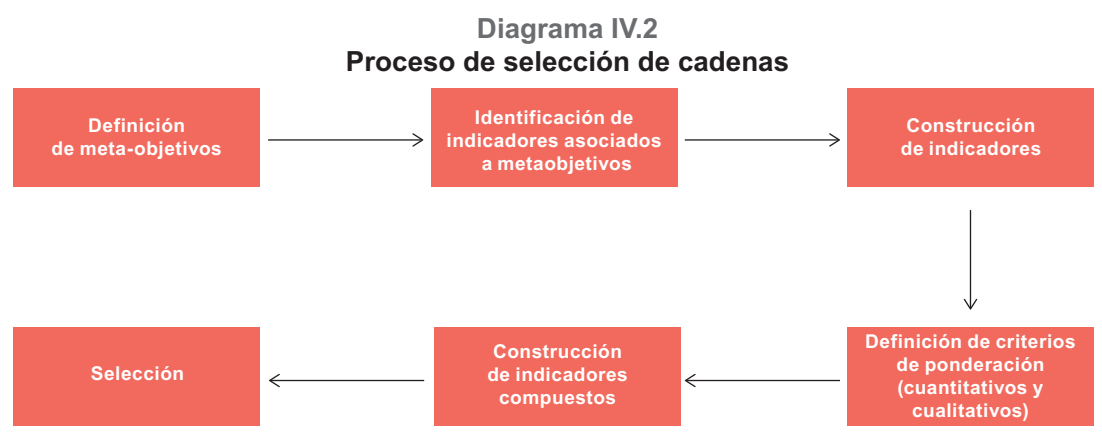

Fuente: R. Padilla y N. Oddone, Manual para el fortalecimiento de cadenas de valor (LC/MEX/L.1218), Ciudad de México, Comisión Económica para América Latina y el Caribe (CEPAL), 2016.

Tras la definición de los metaobjetivos, el siguiente paso es identificar uno o varios indicadores que permitan estimar el aporte potencial de la cadena al cumplimiento de cada metaobjetivo. Idealmente, los indicadores seleccionados deben aportar información complementaria respecto del logro de los metaobjetivos. Por ejemplo, si uno de los metaobjetivos es la incorporación de pequeñas y medianas empresas (pymes), se pueden seleccionar indicadores relacionados con las dimensiones relevantes de la determinación del tamaño de las empresas, como es el caso del volumen de ventas y la creación de empleo.

El tercer paso corresponde a la construcción de los indicadores, y en él se acude a las siguientes fuentes principales de información:

- datos de las cuentas nacionales, en particular los referentes a producción y empleo;

- matrices de insumo-producto para estimar principalmentelos encadenamientos productivos y la capacidad dinamizadora de la cadena en materia de empleo, comercio y valor agregado nacional; 
- datos relativos al comercio internacional de bienes y servicios: exportaciones, importaciones e inversión extranjera directa;

- uso de microdatos de censos, encuestas e impuestos internos, y

- registros administrativos.

Estas fuentes se utilizan para construir indicadores cuantitativos. La selección de cadenas también puede incorporar indicadores cualitativos, por ejemplo, el que una cadena esté concentrada en una región específica (fuera del área metropolitana o en la franja costera) o conformada sobre todo por grupos vulnerables. En la siguiente sección se profundiza en la construcción de indicadores.

El cuarto paso es la definición de los criterios para ponderar los indicadores. Se puede optar por dar un mismo peso a cada metaobjetivo o por otorgar una ponderación mayor a los considerados prioritarios. También es posible incluir criterios de exclusión: si una cadena no cumple con un valor mínimo o máximo, se la excluye sin importar los valores alcanzados en los otros indicadores (por ejemplo, si se define que la cadena debe estar ubicada en regiones de menor desarrollo relativo para lograr el metaobjetivo de apoyar el desarrollo de las zonas menos favorecidas, toda cadena que incumpla con este requisito quedará excluida del proceso). En este paso también se decide si se hará una suma de los indicadores después de haberlos normalizado o si se seguirá otro proceso de agregación. Es de suma importancia definir claramente los criterios de forma previa a la selección para garantizar la objetividad y la transparencia del proceso.

El quinto paso consiste en el desarrollo del indicador compuesto para cada cadena, mientras que en el sexto y último paso se pasa a la selección de la cadena. El proceso descrito en esta sección permite identificar las cadenas que tendrían la mayor contribución a los metaobjetivos.

\section{El desarrollo de indicadores a partir de los metaobjetivos propuestos}

El uso de información estadística del dominio público dota de objetividad al mecanismo de selección. Por ello, en primera instancia se busca construir indicadores cuantitativos que permitan resumir la información disponible para poder obtener una clasificación de las cadenas de valor que se someten al análisis.

Las fuentes de información relevantes dependen de la disponibilidad de datos en cada país, así como de los metaobjetivos seleccionados. En términos generales, las principales fuentes de información incluyen el Sistema de Cuentas Nacionales, la balanza de pagos, y las encuestas de 
hogares y establecimientos, además de los sistemas de información especializada, los registros administrativos y la información reunida por las asociaciones de productores.

El Sistema de Cuentas Nacionales provee información con respecto a la composición y evolución de la actividad económica, la generación de valor agregado, su distribución funcional y los encadenamientos existentes entre las diferentes actividades productivas a partir de los datos contenidos en los cuadros de oferta y utilización, y las matrices de insumo-producto.

La balanza de pagos aporta información relativa a los flujos de comercio de bienes y servicios, de remesas y de financiamiento desde y hacia las diferentes actividades productivas del país.

Si bien la información proveniente de las cuentas nacionales y la balanza de pagos es muy útil, en la mayoría de los países el nivel de desagregación existente no permite identificar cadenas de valor individuales. Por ello, es necesario complementar la información con datos obtenidos de las encuestas de hogares y establecimientos. Entre ellas destacan los censos económicos, las encuestas agropecuarias e industriales, y las diversas encuestas de hogares orientadas a indagar la situación del empleo, y los patrones de ingreso y gasto. Entre los indicadores que pueden obtenerse, están el número de establecimientos, las horas trabajadas, las remuneraciones, los patrones de ingreso y gastos, así como los niveles de productividad.

Finalmente, dependiendo de la disponibilidad y la pertinencia de la información, se puede recurrir a los datos provenientes de sistemas de información especializados (por ejemplo, bases de datos temáticas con información a nivel muy desagregado), registros administrativos (como impuestos y permisos públicos), asociaciones de productores (cámaras y cooperativas) y estudios previos (elaborados por académicos, el sector privado o el ámbito gubernamental).

\section{E. La aplicación de la metodología: la selección de cadenas en México}

Una vez identificadas las fuentes de información disponibles, el siguiente paso es construir indicadores que den cuenta del aporte a la consecución de los metaobjetivos. Dado que en general cada metaobjetivo tiene más de una dimensión relevante, por ejemplo encadenamientos hacia atrás y hacia adelante en el caso del fortalecimiento de la integración de una cadena de valor, conviene contar por lo menos con dos indicadores complementarios asociados a cada metaobjetivo. 
En el recuadro IV.1 se detallan los indicadores utilizados en el caso de la cadena de valor de embutidos y otras conservas de cerdo en México (Alvarado y otros, 2017), que incluyen información proveniente de las cuentas nacionales, la encuesta de la industria manufacturera, matrices de insumo-producto y datos procedentes de un estudio sobre productividad realizado por la Secretaría de Hacienda y Crédito Público (véase la sección B) sobre la base de la metodología de Hausmann y otros (2011).

\section{Recuadro IV.1 \\ México: metaobjetivos e indicadores para la cadena de valor de embutidos y otras conservas de cerdo}

\section{Metaobjetivo 1: fortalecer el abasto nacional}

1.1. Ventas nacionales como proporción de las ventas nacionales de manufactura. El valor utilizado es la proporción promedio del período 20092012 según datos de la Encuesta Anual de la Industria Manufacturera (EAIM) por clase de actividad (seis dígitos del Sistema de Clasificación Industrial de América del Norte (SCIAN) (INEGI, 2013)). Una magnitud mayor de este indicador denota una mayor importancia relativa de las ventas realizadas por la clase de actividad en el mercado nacional.

1.2. Cociente entre el multiplicador de demanda final (hacia adelante) de la producción nacional con respecto al multiplicador de importaciones. El cociente se calcula con la siguiente fórmula: $\sum_{i=1}^{n} b_{i, j}^{d} / \sum_{i=1}^{n} b_{i, j}^{m}$, donde los superíndices $d$ y $m$ denotan los coeficientes de las matrices de requerimientos (directos e indirectos) nacionales e importados, respectivamente. Dichas matrices se calculan sobra la base de los datos de la matriz de insumo-producto actualizada a 2012 por rama de actividad (cuatro dígitos del código SCIAN). Los multiplicadores hacia adelante indican los niveles de sensibilidad de la producción y las importaciones de la clase de actividad a las fluctuaciones de la demanda agregada. Por lo tanto, mayores valores del cociente entre multiplicadores indicarán que, ante un incremento de la demanda agregada, la producción nacional crecerá relativamente más que las importaciones.

\section{Metaobjetivo 2: promover la inserción de pymes a la cadena}

2.1. Número de empleados por establecimiento. El valor utilizado es el cociente promedio del período 2009-2012 según la Encuesta Anual de la Industria Manufacturera (EAIM) por clase de actividad (6 dígitos del código SCIAN). Si el indicador arroja valores pequeños, denota la existencia de un mayor número de pymes en la clase de actividad.

2.2. Cociente entre la proporción de ventas (indicador 1.1) y el número de establecimientos. El valor utilizado es la proporción promedio del período 2009-2012 según datos de la Encuesta Anual de la Industria Manufacturera por clase de actividad (6 dígitos del código SCIAN). $\mathrm{Si}$ se obtienen valores altos, el indicador denota mayores niveles de concentración en la clase de actividad. 
Recuadro IV.1 (continuación)

\section{Metaobjetivo 3: incrementar el valor agregado nacional (industrialización, tecnología)}

3.1. Valor agregado como proporción de la manufactura total. El valor utilizado es la proporción promedio del período 2009-2012 según datos de la Encuesta Anual de la Industria Manufacturera por clase de actividad (6 dígitos del código SCIAN). Un nivel alto de este indicador es evidencia de una mayor importancia relativa del valor agregado por cada clase de actividad.

3.2. Multiplicador de valor agregado. Los multiplicadores de valor agregado para cada rama de actividad $j$ se calculan con la siguiente fórmula: $\sum_{\mathrm{i}=1}^{\mathrm{n}} \frac{\mathrm{v}_{\mathrm{i}}}{\mathrm{v}_{\mathrm{j}}} \mathrm{b}_{\mathrm{i}}$, donde $\mathrm{v}_{\mathrm{i}}=\frac{\mathrm{vab}_{\mathrm{i}}}{\mathrm{x}_{\mathrm{i}}}$ representa el cociente entre el valor agregado bruto y el valor bruto de la producción de la rama de actividad $i$, mientras que $b_{i, j}$ es el coeficiente de requerimientos directos e indirectos desde la clase de actividad $i$ hasta la clase de actividad $j$, es decir, es el elemento $(i, j)$ de la matriz inversa de Leontief. Esta se calcula con los datos de la matriz de insumo-producto actualizada a 2012 por rama de actividad (4 dígitos del código SCIAN). Los multiplicadores indican el nivel de crecimiento del valor agregado como consecuencia del incremento de la demanda de productos de las diferentes clases de actividad.

\section{Metaobjetivo 4: fortalecer la integración de la cadena}

4.1. Encadenamientos. En este caso se clasifica cada rama de actividad (4 dígitos del código SCIAN) según la tipología propuesta por Chenery y Watanabe (1958) sobre la base de los valores relativos de los encadenamientos directos hacia adelante y hacia atrás:

\begin{tabular}{lll}
\hline & \multicolumn{1}{c}{$\mathrm{DBL}_{\mathrm{j}}<\overline{\mathrm{DBL}_{\mathrm{J}}}$} & \multicolumn{1}{c}{$\mathrm{DBL}_{\mathrm{j}} \geq \overline{\mathrm{DBL}}_{\mathrm{J}}$} \\
\hline $\mathrm{DFL}_{\mathrm{i}}<\overline{\mathrm{DFL}_{\mathrm{I}}}$ & Producción primaria/final & Producción secundaria/final \\
\hline $\mathrm{DFL}_{\mathrm{i}} \geq \overline{\mathrm{DFL}_{\mathrm{I}}}$ & $\begin{array}{l}\text { Producción primaria/ } \\
\text { intermedia }\end{array}$ & $\begin{array}{l}\text { Producción secundaria/ } \\
\text { intermedia }\end{array}$ \\
\hline
\end{tabular}

Aquí $\mathrm{DBL}_{\mathrm{j}}=\sum_{\mathrm{i}=1}^{\mathrm{n}} \mathrm{a}_{\mathrm{i}, \mathrm{j}}$ y $\mathrm{DFL}_{\mathrm{i}}=\sum_{\mathrm{j}=1}^{\mathrm{n}} \mathrm{a}_{\mathrm{i}, \mathrm{j}}$ denotan el valor de los encadenamientos directos hacia atrás y hacia adelante, respectivamente, los que se calculan a partir de los coeficientes de la matriz de coeficientes técnicos $a_{i, j}$ de la matriz de insumo-producto actualizados a 2012. Los valores $\overline{\mathrm{DBL}}_{\mathrm{j}} \mathrm{y} \overline{\mathrm{DFL}}_{\mathrm{i}}$ son los valores de los encadenamientos promedio de toda la economía. La tipología permite identificar las fases del proceso productivo correspondientes a las diversas clases de actividad. Si se obtienen niveles bajos de encadenamientos hacia atrás, significa que la clase de actividad se concentra en la explotación de recursos (producción primaria). En cambio, los niveles altos de encadenamientos hacia atrás denotan mayores niveles de transformación (producción secundaria). Los niveles bajos de encadenamientos hacia adelante indican que la clase de actividad se concentra en la elaboración de productos para consumo final, mientras que los niveles altos significan que la clase de actividad se especializa en la manufactura de insumos intermedios. Al tomar en cuenta el objetivo de fortalecer la integración de la cadena, se privilegian las clases de actividad especializadas en la producción secundaria de insumos intermedios, ya que los incrementos de sus niveles de actividad tienen mayor impacto en el resto de las actividades. 
Recuadro IV.1 (conclusión)

4.2. Índice de complejidad-factibilidad. Este índice fue originalmente calculado por la Secretaría de Hacienda a nivel de producto según la nomenclatura del Sistema Armonizado de la Organización Mundial de Aduanas (OMA). Se utilizaron las tablas de equivalencia de Pierce y Schott (2012) para identificar su correspondencia con el clasificador industrial SCIAN. Para cada clase de actividad (6 dígitos del código SCIAN) se calculó el promedio del índice de complejidad-factibilidad de todos los productos incluidos en la clasificación. El indicador tiene carácter prospectivo y permite identificar las clases de actividad con mayor potencial para dinamizar la actividad económica de los sectores relacionados.

\begin{abstract}
Fuente: Elaboración propia, sobre la base de J. Alvarado y otros, "La cadena de valor de embutidos y otras conservas de carne de cerdo en México", Documentos de Proyectos (LC/MEX/W.17/Rev.1), Ciudad de México, Comisión Económica para América Latina y el Caribe (CEPAL), 2017; Instituto Nacional de Estadística y Geografía (INEGI), "Sistema de Clasificación Industrial de América del Norte, México: SCIAN 2013”, Ciudad de México, 2013; J. R. Pierce y P. K. Schott, "A concordance between ten-digit U.S. Harmonized System Codes and SIC/NAICS product classes and industries", Journal of Economic and Social Measurement, vol. 37, N ${ }^{\circ} 1-2,2012$; H. Chenery y T. Watanabe, "International comparison of the structure of production", Econometrica, vol. 26, N 4, 1958.
\end{abstract}

Con la finalidad de privilegiar la selección de cadenas de valor donde las perspectivas de logro de los metaobjetivos sean mayores, es necesario definir criterios de exclusión que permitan discriminar entre las actividades de manera objetiva. En el caso de los indicadores cuantitativos, el criterio puede definirse como algún punto de la distribución de valores, por ejemplo, la mediana del indicador. En el caso de los indicadores cualitativos, en cambio, es necesario explicitar las razones para excluir ciertas categorías.

En el caso de la cadena de valor de embutidos en México, uno de los indicadores seleccionados para el metaobjetivo de fortalecimiento de la integración de la cadena de valor fue un indicador elaborado sobre la base de los valores relativos de los encadenamientos hacia atrás y hacia adelante (indicador 4.1 del recuadro IV.1), que permitió clasificar las actividades según el grado de transformación logrado y el tipo de productos elaborados. En este caso, se decidió excluir las actividades clasificadas como producción primaria orientada principalmente al consumo final, lo que refleja los débiles encadenamientos que caracterizan a dichas actividades.

Una vez aplicados los criterios de exclusión, se obtiene una clasificación actualizada de las actividades en función de los diferentes indicadores. Si bien algunas actividades pueden ubicarse en los primeros lugares de clasificación respecto de algún indicador, es posible que queden excluidas en función de otros. En este caso, es recomendable adoptar algún criterio destinado a mantener el equilibrio entre los distintos metaobjetivos. Por ejemplo, si se optó por dos indicadores asociados a cada metaobjetivo, una posibilidad es tomar en cuenta solo aquellas actividades que tengan por lo menos un indicador vigente después de aplicar los criterios de exclusión. 
El último paso necesario para preseleccionar las actividades candidatas para ser intervenidas por la política pública es ponderar los diferentes indicadores a fin de elaborar un indicador compuesto. Aunque en principio se dispone de diversas metodologías, en la práctica la más transparente ha consistido en asignar un peso equivalente a cada indicador ${ }^{4}$. Ya que las magnitudes y las unidades de medida de los diferentes indicadores no necesariamente son comparables entre sí, es preferible utilizar la clasificación obtenida a fin de garantizar el tratamiento homogéneo de los indicadores para la ponderación. Debido a que el objetivo es identificar una cadena de valor en particular, se pueden asignar 3 puntos a la actividad que haya logrado el primer puesto en la clasificación de cada indicador, 2 puntos al segundo lugar, 1 punto al tercero y 0 punto al resto. Posteriormente, la clasificación general se obtiene a partir del promedio de puntos obtenidos por cada actividad, es decir, la suma de los puntos de todos los indicadores entre el número total de indicadores.

Si bien el resultado del método recién descrito ofrece una clasificación de las actividades basada en indicadores cuantitativos, que permite preseleccionar los primeros candidatos, la selección final de la cadena de valor que se intervendrá debe tomar en cuenta criterios de naturaleza cualitativa, como la factibilidad de ejecución, la atención a grupos o regiones prioritarios, y la alineación con los planes sectoriales o de desarrollo.

En el caso de México, mediante la aplicación de este procedimiento se identificaron como candidatas las siguientes actividades:

- elaboración de alimentos para animales;

- preparación de embutidos y otras conservas de carne de ganado, aves y otros animales comestibles, y

- elaboración de tortillas de maíz y molienda de nixtamal.

De entre ellas, se seleccionó la preparación de embutidos por ser una actividad más cercana al mandato de la Secretaría de Economía, que, en última instancia, sería la entidad responsable de implementar las recomendaciones surgidas del análisis.

\section{F. Reflexiones finales: fortalezas y desafíos de la selección de cadenas}

La selección de sectores o regiones es una acción necesaria e ineludible en el diseño de una política industrial. La disponibilidad limitada de recursos humanos y financieros, y la consecuente necesidad de focalizar los recursos, así como la importancia de promover los

$4 \quad$ Véase un análisis detallado de las alternativas de ponderación en el trabajo de Schuschny y Soto (2009). 
sectores nacientes y aprovechar las ventanas de oportunidad, son algunas de las justificaciones para perseguir este objetivo. El contar con una metodología objetiva para la selección dota de transparencia y legitimidad al proceso.

En este capítulo se detalló la propuesta de la CEPAL para la selección de cadenas de valor. Se parte de la identificación de metaobjetivos, que dan un marco al análisis de las cadenas con el mayor potencial de contribuir a su cumplimiento. Frecuentemente se recurre a una combinación de indicadores cuantitativos y cualitativos, que ofrecen información sistematizada para la selección.

La selección basada en criterios cuantitativos enfrenta como limitación central la falta de disponibilidad de datos. Las cadenas representan actividades muy desagregadas del total de la economía, por lo que a menudo no se dispone de información a nivel de cadena. Ello exige hacer inferencias y elaborar indicadores complementarios que aporten información desde distintos ángulos.

Otra limitación es que, al basarse principalmente en indicadores ya existentes, la selección se fundamenta sobre todo en la situación de la cadena previa al proceso de fortalecimiento. Los ejercicios de prospectiva con una mayor profundidad que los índices de complementariedad económica aportan información de gran utilidad sobre la contribución potencial que podría efectuar la cadena si se superan las restricciones que la constriñen en la actualidad. Estos ejercicios de prospectiva demandan tiempo y recursos económicos.

Los pasos que se exponen en este capítulo pueden adaptarse a circunstancias particulares. No obstante, hay requisitos que siempre deberían estar presentes, como establecer claramente desde un inicio los mecanismos y los criterios que se tomarán en cuenta para la selección, incluidas las fórmulas de ponderación y de elaboración de indicadores compuestos, para asegurar así la objetividad del proceso. Por otro lado, la selección debe partir de la identificación de objetivos claros y llevarse adelante de manera transparente. 


\section{Bibliografía}

Alvarado, J. y otros (2017), "La cadena de valor de embutidos y otras conservas de carne de cerdo en México", Documentos de Proyectos (LC/MEX/W.17/Rev.1), Ciudad de México, Comisión Económica para América Latina y el Caribe (CEPAL).

Amsden, A. (1989), Asia's Next Giant, Nueva York, Oxford University Press.

Boston Consulting Group (2010), “Estrategia para promover la inversión y transferencia de operaciones a México" [en línea] http://amiti.org.mx/wp-content/ uploads/2011/10/2010_Estudio_BCG_SE.pdf.

CEPAL (Comisión Económica para América Latina y el Caribe) (2012), Cambio estructural para la igualdad: una visión integrada del desarrollo. Sintesis (LC/G.2524 (SES.34/4)), Santiago.

Chaminade, C. y R. Padilla (2017), "The challenge of alignment and barriers for the design and implementation of science, technology and innovation policies for innovation systems in developing countries", Research Handbook on Innovation Governance for Emerging Economies: Towards Better Models, S. Kulhman y G. Ordoñez-Matamoros (eds.), Cheltenham, Edward Elgar Publishing, enero.

Chang, H. (2010), "Industrial policy: can we go beyond an unproductive confrontation?", Working Papers, No 2010/1, Turkish Economic Association.

Chenery, H. B. y T. Watanabe (1958), "International comparison of the structure of production", Econometrica, vol. 26, $\mathrm{N}^{\circ} 4$.

Cimoli, M. (ed.) (2005), Heterogeneidad estructural, asimetrías tecnológicas y crecimiento en América Latina (LC/W.35), Santiago, Comisión Económica para América Latina y el Caribe (CEPAL)/Banco Interamericano de Desarrollo (BID).

CNIC (Consejo Nacional de Innovación para la Competitividad) (2007), "Hacia una estrategia nacional de innovación para la competitividad", vol. I [en línea] http:/ /www.economia.gob.cl/cnidweb/wp-content/uploads/sites/35/2007/05/ Hacia-una-estrategia-nacional-de-innovaci\%C3\%B3n-vol-I.2007.pdf. (2008), "Hacia una estrategia nacional de innovación para la competitividad", vol. II [en línea] http://www.cnid.cl/wp-content/uploads/2008/05/Haciauna-estrategia-nacional-de-innovaci\%C3\%B3n-vol-II.2008.pdf.

CNP (Comité Nacional de Productividad de México) (2015), [en línea] http: / / www.gob.mx/productividad/articulos / comite-nacional-de productividad-cnp, [fecha de consulta: marzo de 2017].

Crespi, G., E. Fernández-Arias y E. Stein (eds.) (2014), ¿Cómo repensar el desarrollo productivo? Políticas e instituciones sólidas para la transformación económica, Washington D.C., Banco Interamericano de Desarrollo (BID).

Enos, J. y W. Park (1988), The Adoption and Diffusion of Imported Technology: The Case of Korea, Londres, Croom Helm.

Hausmann, R. y D. Rodrik (2006), “Doomed to choose: industrial policy as predicament", documento preparado para el primer seminario Blue Sky, organizado por el Center for International Development, 9 de septiembre.

Hausmann, R., D. Rodrik y A. Velasco (2005), "Growth Diagnostics", John F. Kennedy School of Government, Cambridge, Harvard University [en línea] http: / / citeseerx.ist.psu.edu/viewdoc/download?doi=10.1.1.446.2212\&rep=re p1\&type $=$ pdf.

Hausmann, R. y otros (2011), The Atlas of Economic Complexity: Mapping Paths to Prosperity, Massachusetts Institute of Technology/Center for International Development of Harvard University/MIT Media Lab. 
Hobday, M. (1995), Innovation in East Asia: The Challenge to Japan, Cheltenham, Edward Elgar Publishing.

INCAE/HIID (Instituto Centroamericano de Administración de Empresas/ Harvard Institute for International Development) (1999), Centroamérica en el siglo XXI: una agenda para la competitividad y el desarrollo sostenible. Bases para la discusión sobre el futuro de la región, Alajuela.

INEGI (Instituto Nacional de Estadística y Geografía) (2013), Sistema de Clasificación Industrial de América del Norte, México: SCIAN 2013, Ciudad de México.

Kosacoff, B. y A. López. (2008), "América Latina y las cadenas globales de valor: debilidades y potencialidades", Revista Globalización, Competitividad y Gobernabilidad, vol. 2, N 1, Washington, D.C., Georgetown University.

Krueger, A. O. (1990), "Government failures in development", Journal of Economic Perspectives, vol. 4, No 3, págs. 9-23.

Lin, J. Y. (2012), New Structural Economics: a framework for rethinking development and policy, Washington D.C., Banco Mundial.

Mazzucato, M. y C. Pérez (2015), "Innovation as growth policy: the challenge for Europe", The Triple Challenge: economic development, climate change, and governance, J. Fagerberg, S. Laestadius y B. Martin (eds.), Oxford University Press, diciembre.

Ocampo, J. A. (2014), "Latin American structuralism and production development strategies", Transforming Economies: making industrial policy work for growth, jobs and development, J.M. Salazar-Xirinachs, I. Nübler, y R. Kozul-Wright (eds.), Ginebra, Organización Internacional del Trabajo (OIT).

Pack, H. (2000), "Industrial Policy: Growth Elixir or Poison?", World Bank Research Observer, vol. 15, No 1.

Pack, H. y K. Saggi (2006), "Is there a case for industrial policy? A critical survey", World Bank Research Observer, vol. 21, No 2, septiembre.

Padilla, R. y N. Oddone (2016), Manual para el fortalecimiento de cadenas de valor (LC/MEX/L.1218), Ciudad de México, Comisión Económica para América Latina y el Caribe (CEPAL).

Pérez, C. (2002), Technological Revolutions and Financial Capital: The Dynamics of Bubbles and Golden Ages, Edward Elgar Publishing, enero.

Pierce, J.R. y P.K. Schott (2012), "A concordance between ten-digit U.S. harmonized system codes and SIC/NAICS product classes and industries", Journal of Economic and Social Measurement, vol. 37, $\mathrm{N}^{\circ} 1-2$.

Porter, M. (1990), The Competitive Advantage of Nations, Harvard University Press.

Prebisch, R. (1949), El desarrollo económico de la América Latina y sus principales problemas (E/CN.12/89), Nueva York.

Salazar-Xirinachs, J.M., I. Nübler y R. Kozul-Wright (2014), Transforming Economies: Making Industrial Policy Work for Growth, Jobs and Development, Ginebra, Organización Internacional del Trabajo (OIT).

Schultze, Ch. (1983), "Industrial policy: a dissent", The Brookings Review, octubre.

Schuschny, A. y H. Soto (2009), "Guía metodológica: diseño de indicadores compuestos de desarrollo sostenible", Documentos de Proyectos (LC/W.255), Santiago, Comisión Económica para América Latina y el Caribe (CEPAL), mayo.

Stiglitz, J. E., J. Y. Lin y C. Monga (2013), "The rejuvenation of industrial policy", World Bank Policy Research Working Paper, No 6628, Washington, D.C., Banco Mundial, septiembre.

Sunkel, O. y P. Paz (1970), El subdesarrollo latinoamericano y la teoría del desarrollo, Ciudad de México, Siglo XXI. 



\section{Capítulo V \\ El fortalecimiento de cadenas de valor de productos primarios y agroindustriales}

Ramón Padilla Pérez

\section{Introducción}

Las actividades productivas en el espacio rural de América Latina y el Caribe enfrentan diversos desafíos relacionados con la institucionalidad, la comercialización, la productividad y la innovación, tal como se analizó en el capítulo I. En lo que respecta a la producción de bienes primarios y agroindustriales, existe una marcada heterogeneidad entre los grandes y los pequeños productores en términos de las capacidades productivas y tecnológicas, el acceso a los mercados y la captura de valor agregado, entre otros factores. En la región, las cadenas de valor de estos bienes suelen estar integradas por una mayoría significativa de pequeños productores que afrontan diversas barreras para incrementar su productividad y competitividad en mercados locales, nacionales e internacionales.

El fortalecimiento de una cadena se logra mediante una mejor articulación de los eslabones, la incorporación de nuevos actores, y un escalamiento económico y social. El escalamiento económico resulta de la transformación productiva de los eslabones de la cadena - y de la cadena en su conjunto- hacia mejores productos y servicios, y procesos de producción más complejos o actividades de mayor valor agregado y un uso más intensivo de los conocimientos. Por su parte, el escalamiento social es producto de un mayor nivel de vida de los integrantes de la 
cadena y sus comunidades, logrado gracias a condiciones de empleo decente, protección social, derechos laborales y un ambiente de trabajo seguro (Padilla y Oddone, 2016).

En este primer capítulo empírico, se hace un análisis transversal del diagnóstico y el diseño de estrategias para cuatro cadenas de valor de productos primarios y agroindustriales: tomate y chile verde (El Salvador), lácteos (República Dominicana), embutidos y otras conservas de carne de cerdo (México) y snacks basados en frutas deshidratadas (El Salvador). El apoyo a las cadenas se dio en el marco del proyecto conjunto de la CEPAL y el Fondo Internacional de Desarrollo Agrícola (FIDA) “Crecimiento inclusivo, política industrial rural y cadenas de valor participativas en América Latina y el Caribe" y el material presentado en este capítulo se basa en Oddone y otros (2016); Alvarado y otros (2016); Gomes y Oddone (2017); Romero, Díaz y Aguirre (2016). El objetivo es identificar retos en común y el papel que la política pública puede jugar en su superación.

Las estrategias diseñadas para el fortalecimiento de cada cadena incluyen instrumentos que son parte de una política industrial rural, es decir que buscan el escalamiento hacia actividades de manufactura y servicios y su integración con ellas. Pero también abarcan diversos instrumentos complementarios que pertenecen al campo de las políticas de desarrollo agropecuario o de desarrollo rural. Así, se reconoce la importancia de contar con ambos grupos de instrumentos de manera integrada.

Este capítulo está dividido en cinco secciones, además de esta introducción. En sintonía con la metodología para el fortalecimiento de cadenas de valor presentada en el capítulo III, en la primera sección se exponen los metaobjetivos perseguidos en cada una de las cuatro cadenas. En la segunda sección se describen los principales eslabones de cada cadena, su gobernanza, las instituciones y organizaciones que regulan y apoyan las cadenas, y se proporciona un análisis breve de los márgenes y la captura de valor agregado. En la tercera sección se examinan de manera transversal las restricciones que enfrentan las cuatro cadenas de valor, mientras que en la cuarta se presentan las estrategias para superarlas. En la quinta sección se ofrecen las conclusiones.

\section{A. La definición de metaobjetivos}

Como se expuso en el capítulo III, el primer paso de la metodología es la definición de los metaobjetivos, entendidos como el fin último que se persigue en materia de desarrollo económico y social con el fortalecimiento de la cadena. Los metaobjetivos definidos en las cuatro cadenas de estudio ilustran los distintos propósitos que tienen los países de la región cuando se embarcan en procesos de fortalecimiento de cadenas. 
En el caso de la cadena de embutidos en México, se fijaron las siguientes metas:

- satisfacer la demanda del producto en el ámbito nacional, es decir, incrementar la producción nacional de manera que la demanda interna fuera atendida principalmente con producción nacional y no con importaciones;

- promover la inserción de pequeñas y medianas empresas (pymes) y pequeños productores en la cadena;

- incrementar el valor agregado nacional mediante una mayor compra de bienes y servicios a proveedores locales, y

- fortalecer la integración de la cadena por medio de vínculos más estrechos entre los eslabones que la componen.

El proceso de colaboración técnica en la cadena de tomate y chile verde en El Salvador tuvo como principal metaobjetivo incrementar la producción nacional de manera que la demanda interna de estos productos se viera satisfecha cada vez más por productores locales y no por importaciones. Para ello se concentró en aumentar la productividad de los pequeños productores rurales, con especial atención en aquellos que buscan consolidar modelos de negocio sostenibles.

El fortalecimiento de la cadena de valor de los lácteos en la República Dominicana planteó como metaobjetivos principales satisfacer la demanda nacional de lácteos, potenciar la incorporación de micro, pequeñas y medianas empresas, y mejorar la calidad de la producción nacional de leche.

La cadena de snacks nutritivos basados en frutas deshidratadas está en proceso de consolidación. Existe un pequeño grupo de actores que transforman los productos primarios, principalmente frutas, en bienes agroindustriales para el mercado nacional e, incluso, para la exportación. Los metaobjetivos apuntaron a desarrollar capacidades para incursionar en actividades complementarias de mayor valor agregado sobre la base de la transformación, a incrementar la productividad y a fortalecer la participación de las micro y pequeñas empresas.

Se observan objetivos compartidos en los cuatro procesos. El primero es incrementar la producción nacional para satisfacer la demanda del producto, con la meta implícita de reducir o sustituir las importaciones. Se espera que esta sustitución ocurra como resultado de una mayor productividad de los productores nacionales y no gracias a la introducción de medidas proteccionistas. El segundo es incorporar pequeñas empresas y pequeños productores, lo que reconoce las menores capacidades productivas y tecnológicas con respecto a los grandes productores (en particular en las cadenas de embutidos y de lácteos), pero también el impacto que ejerce su fortalecimiento en materia de inclusión social. El tercero consiste en desarrollar capacidades para incursionar en nuevas actividades productivas que permitan generar y capturar mayor valor agregado. 


\section{B. Las cadenas de valor}

En esta sección se resumen las principales características productivas y económicas de las cadenas de valor. En los documentos completos se presenta el diagnóstico en seis áreas: contexto nacional e internacional de la cadena, análisis económico, análisis de mercado y conocimientos tecnológicos, gobernanza, organizaciones de apoyo y restricciones. La información presentada a continuación se reunió entre mediados de 2014 y mediados de 2016, período en el que se llevaron a cabo los procesos de fortalecimiento de las cadenas ${ }^{1}$.

\section{Los eslabones de las cadenas de valor}

\section{a) La cadena de tomate y chile verde en El Salvador}

En El Salvador, el tomate y el chile verde forman parte de la misma cadena, pues en su mayoría son cultivados por el mismo grupo de productores y comparten eslabones comunes hacia atrás y adelante. Estos productos tienen una alta demanda, dado que son componentes significativos de la dieta alimentaria salvadoreña, que no es satisfecha con la producción nacional. En 2013, la producción de tomates alcanzó las 18.500 toneladas, mientras que el restante $80 \%$ del consumo nacional fue atendido por importaciones (véase el gráfico V.1).

\section{Gráfico V.1}

El Salvador: producción nacional e importaciones de tomate, 2000-2013 (En toneladas)

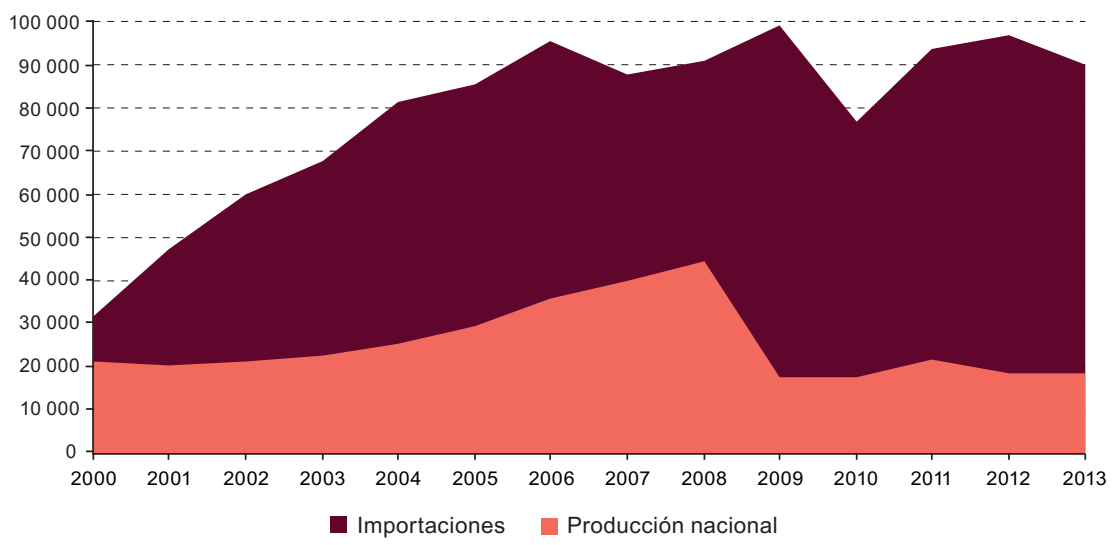

Fuente: N. Oddone y otros, "Fortalecimiento de la cadena de valor de tomate y chile verde dulce en El Salvador", Documentos de Proyectos, N 13 (LC/MEX/W.13), Ciudad de México, Sede Subregional de la CEPAL en México, 2016, pág. 14.

Los pasos de la metodología descrita en el capítulo III abarcan en promedio ocho meses. En este período de dos años se trabajó con las cuatro cadenas de manera escalonada. 
De manera resumida, la cadena tiene cuatro eslabones (véase el diagrama V.1), que se describen a continuación.

Diagrama V.1

EI Salvador: cadena de valor de tomate y chile verde dulce

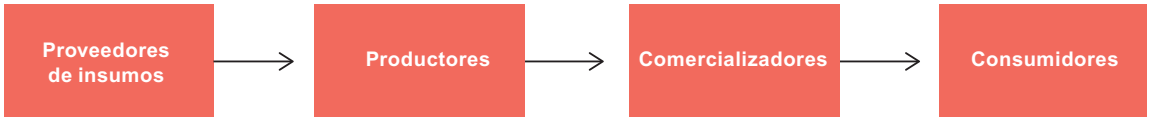

Fuente: N. Oddone y otros, "Fortalecimiento de la cadena de valor de tomate y chile verde dulce en El Salvador", Documentos de Proyectos, N 13 (LC/MEX/W.13), Ciudad de México, Sede Subregional de la CEPAL en México, 2016, pág. 14.

i) Los principales insumos para el cultivo de tomate y chile verde dulce son las semillas, los fertilizantes, los fungicidas y los herbicidas. Para los productores que cultivan en condiciones protegidas, también son necesarios los materiales para la construcción y el mantenimiento de la infraestructura del invernadero, casa malla o túnel. El Salvador es un importador neto de estos insumos.

ii) El eslabón de producción está atomizado y tiene una clara orientación hacia las explotaciones de carácter comercial. Se estima que hasta el $90 \%$ de los productores de hortalizas comercializan sus cultivos (Ministerio de Agricultura y Ganadería, 2014) ${ }^{2}$. El total de productores de hortalizas registrados en 2014 fue de 28.928, entre los que se incluyen los productores comerciales (25.975) y de subsistencia (2.954). La gran mayoría de los productores salvadoreños de hortalizas $(96,6 \%)$ trabajan a cielo abierto, lo que limita su capacidad para obtener rendimientos estables en términos de volumen y calidad. El cultivo de hortalizas se concentra en 7 de los 14 departamentos del país, y se observa una gran heterogeneidad entre los productores en función del área de superficie cosechada, las capacidades y la productividad.

iii) Se distinguen tres canales principales de comercialización: mayoristas formales (supermercados y restaurantes), mayoristas informales (la central de abastos, conocida como La Tiendona) y los minoristas. En años recientes se observó una concentración de la distribución a raíz del auge de las cadenas de hipermercados, supermercados y centros comerciales. La exportación de tomate es inexistente y la de chile verde dulce se da en bajas cantidades.

La Encuesta Nacional Agropecuaria de Propósitos Múltiples (ENAPM) no contiene datos desagregados para tomate y chile verde, por lo que se abordan para el conjunto de las hortalizas. 
iv) Existen tres tipos principales de consumidores: los hogares, la restauración y el consumo institucional. Los que mayor peso tienen son los primeros dos, mientras que el consumo institucional tiene carácter residual.

Cabe mencionar que la cadena de tomate y chile verde dulce de El Salvador no cuenta con un eslabón de procesamiento consolidado que transforme las hortalizas cultivadas en el ámbito nacional en salsas, conservas $\mathrm{u}$ otros productos de mayor valor agregado. Si bien existen empresas que procesan tomate, en su mayoría recurren a tomate fresco o deshidratado importado de Guatemala.

\section{b) La cadena de embutidos y otras conservas de cerdo en México}

Esta cadena incluye la producción de diversos productos agroindustriales, como jamones, salchichas y chorizos. En 2013 la industria cárnica empleaba a 252.611 personas en México, un tercio de las cuales se dedicaba a la matanza de ganado y aves; un sexto, al corte y empacado de carne fresca; y el resto, a la preparación de conservas y embutidos. Si bien más del $90 \%$ de los productos cárnicos procesados que se consumen en México son de origen nacional, en 2013 se importaron más de 750.000 toneladas del insumo principal (la carne de cerdo). La cadena está integrada por seis eslabones (véase el diagrama V.2).

\section{Diagrama V.2}

México: cadena de valor de los embutidos y otras conservas de carne de cerdo

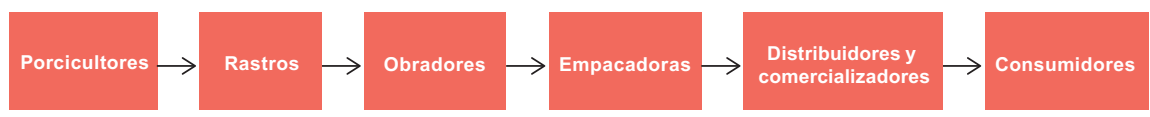

Fuente: J. Alvarado y otros, "La cadena de valor de embutidos y otras conservas de carne de cerdo en México", Documentos de Proyectos (LC/MEX/W.17/Rev.1), Ciudad de México, Sede Subregional de la CEPAL en México, 2016.

i) El punto de partida es el sistema productivo porcino primario, que comprende el cuidado de los animales reproductores, la crianza de la descendencia y el engorde de los lechones. En términos de las capacidades productivas y tecnológicas, existe una marcada heterogeneidad entre los porcicultores, los que pueden clasificarse en tres grupos: i) con instalaciones tecnificadas y un gran número de cerdos, tecnología de punta, certificaciones y alta productividad; ii) con instalaciones tradicionales o semitecnificadas, productividad media y uso de tecnologías tradicionales, y iii) de traspatio, sistema rural o autoabastecimiento, que son de tamaño pequeño, con un uso 
básico de tecnología y baja productividad. De 2000 a 2013, el número de cabezas sacrificadas de ganado porcino aumentó un $25,1 \%$ : de 13.444 .829 a 16.818 .454 . Esto se tradujo en un incremento de la producción de carne de cerdo en un porcentaje similar $(24,6 \%)$, pues pasó de 1.029 .955 a 1.283 .672 toneladas.

ii) La cadena de transformación primaria de los porcinos criados en México inicia con la matanza, que está a cargo de los rastros. Existen tres tipos de rastros: municipales, privados y establecimientos Tipo Inspección Federal (TIF). El rastro municipal, como su nombre lo indica, es administrado o concesionado por el municipio. El rastro privado es un servicio público concesionado a particulares, mientras que el TIF cumple con normativas estrictas en materia de sanidad, calidad y trato animal. Estos últimos suelen tener el mayor tamaño y las mayores capacidades tecnológicas. En 2013 el 80\% de los rastros contaba con menos de diez empleados.

iii) El siguiente eslabón está a cargo de los obradores, que llevan a cabo el despiece de la canal de cerdo en cortes primarios y secundarios. Una característica de este eslabón es la utilización intensiva de mano de obra, ya que el despiece se realiza en forma manual con herramientas punzocortantes.

iv) La transformación secundaria da inicio en el cuarto eslabón: las empacadoras. Los productos cárnicos procesados son aquellos en los que las propiedades de la carne fresca han sido modificadas mediante uno o más procedimientos, como molienda, adición de especias, alteración del color y tratamiento de calor. Existen empacadoras grandes con procesos integrados, alta rentabilidad y alta tecnificación, pero más del $80 \%$ son microempresas con menos de diez trabajadores y sujetas a restricciones importantes que merman su productividad y competitividad (véase el gráfico V.2).

v) El siguiente eslabón corresponde a la distribución y la comercialización, que son las actividades dedicadas a la provisión de productos o servicios al consumidor. Por un lado, hay una estructura tecnificada asociada a supermercados y al mercado de exportación, que utiliza la cadena de frío para mantener la seguridad y calidad del producto $y$, por el otro, prevalece una estructura tradicional que no utiliza refrigeración, lo que causa pérdidas económicas y repercute en la salud de los consumidores. En cuanto a la comercialización, alrededor de un tercio de estos productos se adquiere en tiendas de abarrotes; una cuarta parte, en supermercados; una 
quinta parte, en carnicerías y loncherías; y más del 10\%, en mercados populares.

vi) El último eslabón está conformado por los consumidores, que, al igual que la comercialización, están segmentados por los puntos de venta: supermercados, tiendas locales, mercados, restaurantes y hoteles, entre otros.

\section{Gráfico V.2}

México: proporción de unidades económicas dedicadas a la preparación de embutidos y otras conservas de ganado, aves y otros animales comestibles, por tamaño, 2004, 2009 y 2013

(En porcentajes)

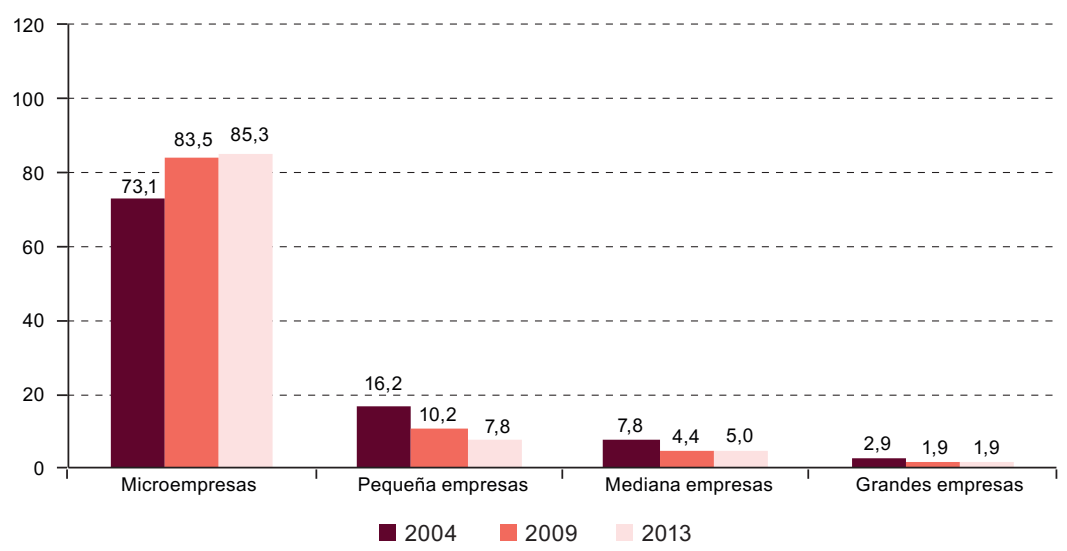

Fuente: J. Alvarado y otros, "La cadena de valor de embutidos y otras conservas de carne de cerdo en México", Documentos de Proyectos (LC/MEX/W.17/Rev.1), Ciudad de México, Sede Subregional de la CEPAL en México, 2016.

\section{c) La cadena de lácteos en la República Dominicana}

Esta cadena tiene una amplia presencia en el territorio nacional. En 2014 la producción nacional de leche fue de 1.600.000 litros diarios. El $54,1 \%$ de esta producción se utiliza en la fabricación artesanal de quesos, el $16 \%$ se destina a las grandes procesadoras industriales, y el $20 \%$ es para autoconsumo en fincas, mientras que el $5,5 \%$ se encauza hacia el consumo fresco (mediante venta en bidones) y el $4,4 \%$ es utilizado por las fábricas de yogur y dulces. En el gráfico V.3 se presenta la producción estimada de productos lácteos del período 1980-2014, según información de FAOSTAT. La República Dominicana requiere importaciones para cubrir el déficit productivo y satisfacer la demanda de la industria procesadora y del mercado local. La proporción de leche de producción nacional considerada procesable por la gran industria es relativamente baja (alrededor del 20\%), por lo que se importa leche en polvo o líquida para su procesamiento. La cadena está integrada por seis eslabones (véase el diagrama V.3). 
Gráfico V.3

República Dominicana: producción estimada de lácteos, 1980-2014 (En millones de litros)

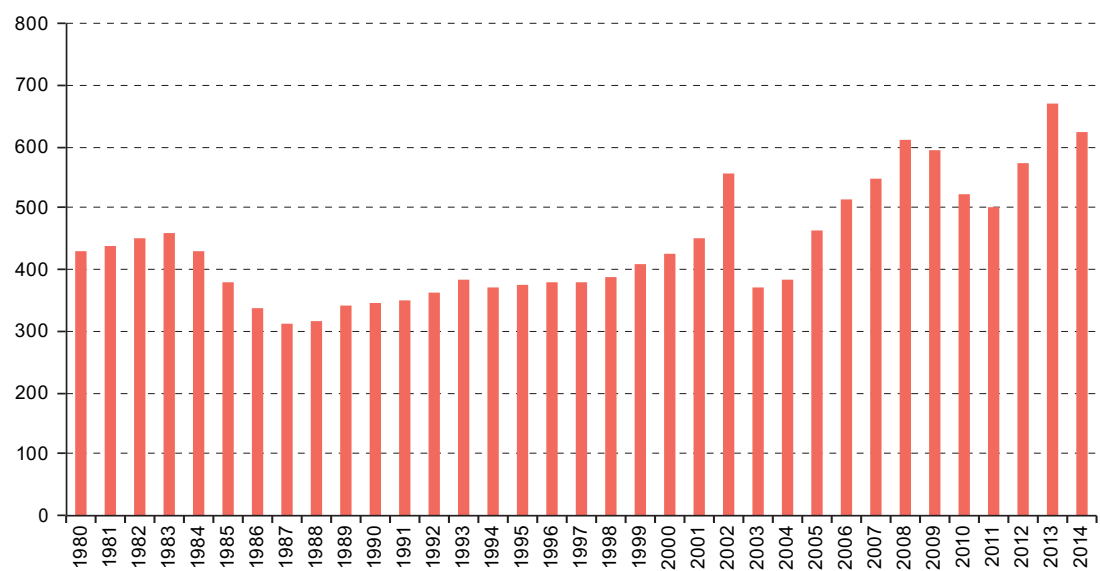

Fuente: C. Gomes y N. Oddone, "Fortalecimiento de la cadena de valor de los lácteos en la República Dominicana", Documentos de Proyectos, Ciudad de México, Sede Subregional de la CEPAL en México, 2017.

República Dominicana: cadena de valor de los lácteos

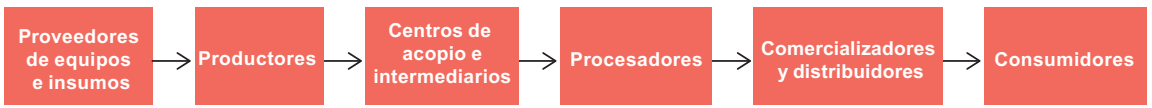

Fuente: C. Gomes y N. Oddone, "Fortalecimiento de la cadena de valor de los lácteos en la República Dominicana", Documentos de Proyectos, Ciudad de México, Sede Subregional de la CEPAL en México, 2017.

i) La cadena de lácteos está vinculada a una extensa red de proveedores de insumos con diferentes tipos de actores, la mayoría de ellos comercializadores de insumos importados. En el análisis se priorizó el estudio de los proveedores de insumos para la producción de leche, el procesamiento de leche pasteurizada a temperatura ultra alta (UHT) y la elaboración de quesos. Se incluyen los proveedores de equipo, alimentos y medicamentos para animales, empaques para leche (Tetra Pack) y productos para la elaboración de quesos, entre otros.

ii) Eleslabón dela producción está conformadopor los ganaderos. La mayor parte de la producción láctea de la República Dominicana se sustenta en la ganadería familiar $(90 \%)$, constituida por pequeños productores con menos de 50 cabezas de ganado. Se observan grandes diferencias entre los ganaderos en cuanto a su acceso a tecnología, infraestructura y financiamiento. Por lo general, los pequeños cuentan con tecnología muy elemental en 
sus fincas y la mayoría realiza el ordeño bajo árboles o techos de zinc y sobre suelos de tierra.

iii) En el país existen alrededor de 90 centros de acopio y enfriamiento de leche, la mayoría de los cuales son sociedades. El concepto de centro de acopio comprende una realidad heterogénea en cuanto a infraestructura, equipamiento, capacidad de concentración, administración y entrega de la leche. El centro de acopio cumple una función fundamental, pues contribuye a la comercialización de la leche a partir de su concentración, análisis y mantenimiento en condiciones aptas para la industria. Los productores entregan la leche al centro en diferentes medios de transporte: caballo, motocicleta ocamioneta, dependiendo de la distancia y de la capacidad económica del ganadero. La intermediación ocurre principalmente en la región este, donde los centros de acopio son escasos.

iv) $\mathrm{Al}$ igual que los otros eslabones de la cadena, el procesamiento también es altamente heterogéneo. Alrededor del $54 \%$ de la producción nacional de leche es consumido por una gran cantidad de micro y pequeñas queserías artesanales, muchas de ellas familiares o con hasta tres empleados $(57 \%)$, y con grandes diferencias técnicas y de rendimiento. El precenso del Viceministerio de Comercio Interno del Ministerio de Industria, Comercio y mipymes arrojó una estimación superior a las 400 queserías. El $64 \%$ de ellas se ubica en zonas rurales y el $20 \%$, en zonas semirrurales, por lo general en los patios de las casas o en instalaciones sin condiciones para el manejo de alimentos, ya que son galpones con techos de tinglado y en algunas ocasiones tienen piso de tierra. Los procesadores grandes y medianos consumen menos del $25 \%$ de la leche producida en el mercado nacional, que es comprada principalmente por las cuatro empresas más grandes del país - Pasteurizadora Rica, Nestlé, Induveca y Sigma Alimentos (ex Sosúa) — y otras más pequeñas, como Lácteos Dominicanos (Ladom), Leche Fresca y Pasteurizadora María.

v) El eslabón de distribución y comercialización presenta un esquema de varios niveles según la calidad de la leche y las características del procesamiento. Las pequeñas queserías artesanales y familiares que usan leche de grados B, C o D comercian en colmados y colmadones o tiendas de abasto cotidiano, las que forman parte de la tradición comercial nacional y cuyos estándares de calidad son inferiores a los de los supermercados. Los colmados, que constituyen puntos de venta 
básicos en el país, son un tipo de almacén que se encuentra en toda la geografía nacional y ofrecen amplios horarios de atención. La venta de la producción artesanal, sobre todo de quesos, puede ser directa o intermediada.

vi) Según datos de la FAO (2011), el consumo anual per cápita de leche en la República Dominicana —entre 103,3 y 104,5 litroses inferior al promedio mundial -234,3 litros-, aunque la oferta de leche y quesos nacionales y extranjeros es vasta. Los productos importados expendidos en supermercados compiten fuertemente en precio y calidad con los productos nacionales. En general, el consumidor dominicano decide sus compras por el precio del producto y los sabores tradicionales, por lo que este predominio del precio puede tener como consecuencia que se pasen por alto algunos estándares de calidad.

\section{d) La cadena de valor de snacks basados en frutas deshidratadas en EI Salvador}

Esta cadena está en proceso de desarrollo, con un número reducido de productores (el estudio de campo permitió identificar ocho deshidratadores de frutas), pues no existe una cultura extendida del consumo de este producto en el mercado nacional. De acuerdo con información sobre las tendencias mundiales de los mercados, la creciente adopción de hábitos de alimentación más saludable impulsará la demanda mundial de este tipo de productos. En El Salvador la cadena está conformada por los siguientes cuatro eslabones (véase el diagrama V.4).

\section{Diagrama V.4 \\ El Salvador: cadena de valor de snacks nutritivos basados en frutas deshidratadas}

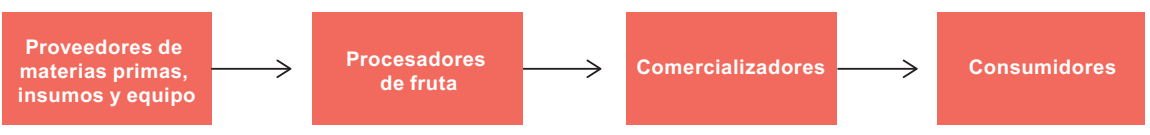

Fuente: I. Romero, V. Díaz y A. Aguirre, "Fortalecimiento de la cadena de valor de los snacks nutritivos con base en fruta deshidratada en El Salvador", Documentos de Proyectos (LC/MEX/W.16), Ciudad de México, Sede Subregional de la CEPAL en México, 2016.

i) El primer eslabón está integrado por los proveedores de fruta, que es la materia prima principal para la elaboración de los snacks. El Salvador cuenta con una oferta de frutas, como el coco, el mango, el plátano y el guineo de seda, pero predominan los productores de pequeña escala. En el caso de otras variedades frutales, como el mango, la papaya y la piña, se recae significativamente en importaciones provenientes sobre todo de Costa Rica y Guatemala. La oferta de aditivos (antioxidantes y conservadores), 
y de maquinaria y equipos para el corte, la deshidratación y el empaque de las frutas está dominada por los bienes importados. De igual manera, los empaques para la venta del producto final son en su mayoría importados.

ii) En el segundo eslabón - los procesadores de frutas- se identificaron tres tipos de productores: a) artesanales con bajos volúmenes de producción, acceso limitado a tecnologías, y retos significativos en materia de calidad y productividad; b) procesadores semiindustriales que utilizan equipos de producción en lote (no continuos) y cuyos productos cuentan con registros sanitarios, y c) procesadores industriales con certificaciones incluso a nivel internacional, uso extensivo de tecnologías en los procesos productivos y control de calidad.

iii) En el tercer eslabón se encuentran los comercializadores y distribuidores de los snacks. En el mercado nacional, los procesadores artesanales venden sus productos directamente al consumidor final, aunque en poco volumen. Para colocar sus productos en volúmenes mayores, acuden a un intermediario. Los procesadores de mayor escala comercian sus productos sobre todo por medio de cadenas de supermercados o en tiendas minoristas por conducto de distribuidores. Los procesadores semiindustriales e industriales mantienen con los intermediarios una relación de tipo transaccional: los intermediarios cobran una comisión preestablecida y los rangos de negociación son limitados.

iv) En El Salvador, el mercado de snacks nutritivos basados en frutas deshidratadas abarca dos segmentos de consumo: a) la industria alimentaria, que compra el producto a granel y lo comercializa, ya sea con marca propia o como ingrediente de otros productos, y b) productos de marca comercializados, en su mayoría, a través de supermercados y establecimientos de servicios alimentarios. Además, se cuenta con canales de exportación.

\section{La gobernanza de las cadenas de valor}

En las cadenas de productos primarios, la gobernanza puede adoptar diversas formas, como se observa en las cuatro cadenas de valor aquí estudiadas. En algunas cadenas, un actor o grupo de actores, por ejemplo los intermediarios, ejercen un fuerte control sobre los productores, mientras que en otras se dan relaciones horizontales o de mercado.

En la cadena de lácteos, los intermediarios y los distribuidores tienen un control amplio de los eslabones de producción. Por ejemplo, en 
la región este de la República Dominicana los transportistas controlan la mayoría del flujo de leche hacia las queserías de la región. Son ellos quienes comúnmente imponen el precio y las formas de pago a los productores.

Por su parte, en la cadena de embutidos la segmentación regulatoria del mercado, el impacto de las importaciones en el abasto y la importancia del mercado de carne en fresco implican que, pese a que en cada eslabón pueden identificarse uno o dos actores dominantes - sea mediante los volúmenes de producción ofrecidos, los precios de compra y venta, o su influencia en la normativa vigente-, está acotada su relevancia en toda la cadena. Por ello, la gobernanza es de mercado, donde el principal vínculo entre los eslabones consiste en la relación comercial, caracterizada por transacciones informales de baja complejidad. Esta situación da origen a una estructura donde el grado de coordinación y, por lo tanto, el de jerarquía, son acotados. De manera similar, la cadena de tomate y chile verde dulce tiene predominantemente una gobernanza de mercado, es decir que no hay un control significativo por parte de un actor o grupo de actores debido a la fragmentación de la producción, su bajo nivel de sofisticación y su esquema de distribución.

En la cadena de snacks, la gobernanza también puede considerarse de mercado, con relaciones informales intra e intereslabones donde ningún actor ejerce un control significativo sobre la cadena. Dado el volumen de producción, los procesadores no tienen un poder excesivo en la fijación de precios y las condiciones de la materia prima. De igual manera, debido a lo atomizado de las ventas de frutas deshidratadas, tampoco se observa un control significativo por parte de los comercializadores o intermediarios.

\section{Estimación de costos y márgenes}

En el cuadro V.1 se presenta la estimación de costos y márgenes a lo largo de las cuatro cadenas analizadas. El primer elemento que cabe resaltar es la significativa captura de valor que se da en los últimos eslabones (venta al consumidor y distribución), en contraste con lo recibido por los productores. Por ejemplo, en el caso de la cadena de embutidos, los porcicultores reciben 25 pesos mexicanos por cada 100 pesos de embutidos comercializados en un supermercado. El segundo elemento, que se ilustra en la cadena de tomate y chile verde, es que la distribución del valor agregado varía dependiendo de las condiciones de producción y de comercialización. Los productores que operan en condiciones protegidas tienen un margen promedio de 17 centavos de dólar por kilogramo, que se reduce significativamente entre los que cultivan a cielo abierto y gozan de menores rendimientos. En la misma línea, el precio que los productores reciben al comercializar sus productos mediante canales formales es mayor que cuando lo hacen de manera informal. 


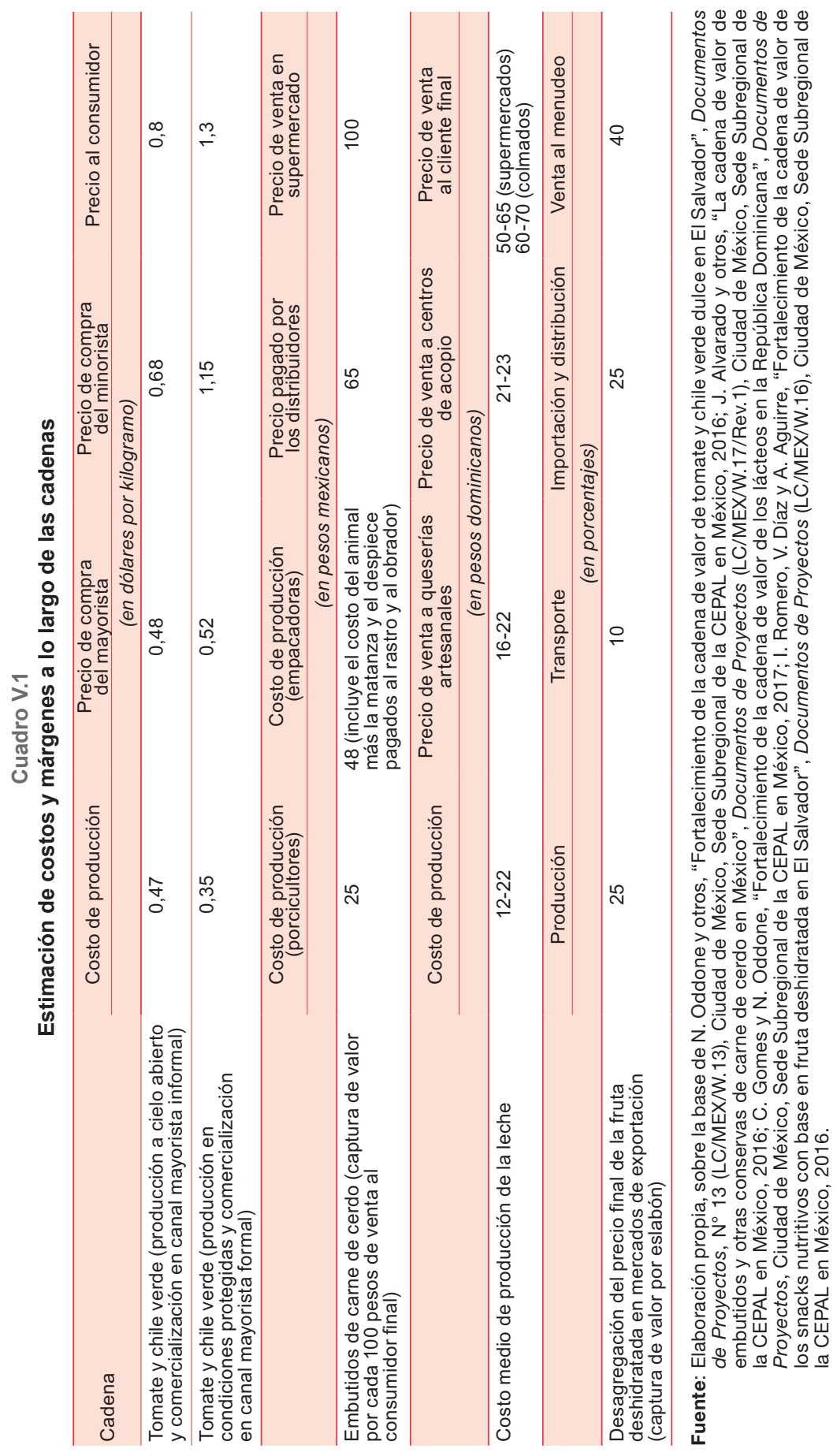




\section{Instituciones y organizaciones que apoyan y regulan las cadenas}

La metodología de cadenas sigue un enfoque sistémico. Además de analizar los eslabones y los vínculos entre ellos, estudia las instituciones y las organizaciones que regulan y apoyan la cadena: universidades, centros de investigación, cámaras empresariales y organismos públicos, entre otras. En general se identificaron diversos organismos de apoyo en cada caso, pero con baja coordinación entre ellos e insuficientes recursos humanos y financieros para la supervisión y el apoyo de las actividades. Los diagnósticos de cadena hacen un recuento detallado de su papel. A continuación se presenta una breve síntesis.

En la cadena de lácteos, los actores reciben apoyo de diversas entidades privadas y gremiales, como la Asociación Dominicana de Productores de Leche (APROLECHE), las federaciones de ganaderos, las cooperativas y las asociaciones para actividades específicas de la cadena (Asociación Dominicana de Procesadores de Lácteos y Derivados y Asociación Dominicana de Industrias Lácteas, entre otras). En el ámbito público, destacan dos organismos de fomento y regulación: la Dirección General de Ganadería del Ministerio de Agricultura y el Consejo Nacional para la Reglamentación y Fomento de la Industria Lechera (CONALECHE). Otros organismos públicos de apoyo son el Instituto Dominicano de Calidad (INDOCAL) y el Instituto Dominicano de Investigaciones Agropecuarias y Forestales (IDIAF).

Entre las instituciones que forman parte de la red pública de apoyo a los productores de tomate y chile verde en El Salvador están el Ministerio de Agricultura y Ganadería (MAG), a través de diversas direcciones, la Escuela Nacional de Agricultura (ENA), el Centro Nacional de Tecnología Agropecuaria y Forestal de El Salvador (CENTA) y el Banco de Fomento Agropecuario (BFA). En la parte privada, se observa un bajo nivel de asociación entre los productores.

Las actividades de la cadena de embutidos en México están sujetas a la normativa sobre salud animal, responsabilidad de la Secretaría de Agricultura, Ganadería y Desarrollo Rural, Pesca y Alimentación (SAGARPA), por conducto del Servicio Nacional de Sanidad, Inocuidad y Calidad Agroalimentaria (SENASICA), y sobre salud humana, responsabilidad de la Secretaría de Salud a través de la Comisión Federal para la Protección contra Riesgos Sanitarios (COFEPRIS). Estos mismos organismos públicos, junto con la Secretaría de Economía, el Fideicomiso de Riesgo Compartido (FIRCO) y la Agencia de Servicios a la Comercialización y Desarrollo de Mercados Agropecuarios (ASERCA), entre otros, ofrecen diversos apoyos a la cadena. En el sector privado, la cadena cuenta con diversos organismos de apoyo, entre los que figuran 
la Organización de Porcicultores del País (OPORPA), la Confederación de Porcicultores Mexicanos (CPM), la Cámara Nacional de la Industria de Transformación (CANACINTRA), el Consejo Nacional Agropecuario (CNA) y el Consejo Mexicano de la Carne (COMECARNE).

Por último, la cadena de snacks basados en frutas deshidratadas encuentra apoyo en el Ministerio de Economía (MINEC) y el Ministerio de Agricultura y Ganadería (MAG). En materia de asistencia técnica y nuevos conocimientos, se apoya en el Centro Nacional de Tecnología Agropecuaria y Forestal (CENTA) y universidades, como la Universidad de El Salvador y la Universidad Católica de El Salvador. Asimismo, cuenta con una amplia oferta de laboratorios de ensayo que realizan análisis fisicoquímicos y microbiológicos; en sentido contrario, la oferta de empresas certificadoras es limitada. En materia de servicios financieros, los actores de la cadena pueden acudir al BFA y a cajas de crédito.

\section{Las restricciones}

En esta sección se presentan las principales restricciones que enfrentan las cadenas de valor analizadas para lograr su escalamiento y efectuar una mayor contribución al cumplimiento de los metaobjetivos. Si bien aquí se pone el foco en los retos, es importante reconocer que los diagnósticos también permitieron identificar fortalezas, que se resumen en el documento completo correspondiente a cada cadena.

- La primera restricción presente en las cuatro cadenas es una heterogeneidad significativa en términos de capacidades productivas y tecnológicas. En los eslabones de producción primaria y de transformación, se observan grandes brechas en materia de productividad y rentabilidad entre los actores que conforman la cadena, en particular entre los pequeños y los grandes productores. El tamaño pequeño afecta la capacidad de alcanzar economías de escala, acceder al financiamiento, comprar equipos y maquinaria, negociar precios de materias primas y tener acceso a fuentes de conocimientos tecnológicos $y$ de mercado. Estas diferencias fueron observadas entre porcicultores, productores de tomates y chiles, y ganaderos grandes y pequeños, pero también entre fabricantes de embutidos, deshidratadores de frutas y productores de quesos. Como se muestra en el cuadro V.1, el costo de producción entre los productores de tomate que tienen acceso a tecnologías de cultivo en condiciones protegidas y aquellos que trabajan a cielo abierto es de 35 y 47 centavos de dólar por kilogramo, respectivamente. 
- Se observa una alta fragmentación y débil organización dentro delos eslabones y entre ellos. Los productores de tomate y de frutas deshidratadas en El Salvador mostraban una baja asociatividad, mientras que los porcicultores de México estaban organizados en torno a dos asociaciones que compitían entre sí. La falta de confianza y la elevada informalidad de las relaciones constituyen elementos centrales que permiten justificar esta situación. Esta restricción es particularmente fuerte en las interacciones entre los productores y los comercializadores, en las que suelen darse tensiones y un incumplimiento de los acuerdos.

- Las cuatro cadenas enfrentan una fuerte competencia por parte de las importaciones. El volumen de producción, los precios o la calidad son factores que juegan en contra de los productores nacionales. En El Salvador se observa una dependencia significativa de las importaciones de tomate y de frutas procedentes, sobre todo, de otros países centroamericanos, con frecuencia a menor precio y de mayor calidad que en el mercado local. Esta competencia se da tanto por canales formales como a través del contrabando. En el caso de los embutidos, existe una amplia oferta de cerdos de importación, principalmente de los Estados Unidos, cuyo precio en general es inferior al del producto nacional, con términos de entrega estandarizados y regidos por contratos con plazos de varios meses. En la cadena de lácteos, solo una cuarta parte de la leche producida en el país tiene la calidad para ser industrializada, por lo que las grandes y medianas empresas suplen la necesidad de buenos insumos recurriendo a la importación.

- La dependencia de las importaciones también ocurre en materia de insumos agropecuarios (por ejemplo, fertilizantes, medicamentos y material genético), insumos especializados (como material de empaque y químicos para el procesamiento de alimentos) y de maquinaria y equipos para las actividades primarias y de transformación. Esta constituye una restricción, pues los precios son mayores y la disponibilidad es menor, y los servicios especializados comúnmente asociados a la venta de insumos, maquinarias y equipos no siempre son de fácil acceso.

- Seidentificó una calidad e inocuidad insuficiente de los productos primarios y procesados, factor que, como se mencionó, afecta en particular a los pequeños productores. Ello guarda un vínculo estrecho con las siguientes tres restricciones adicionales.

- Se observa una debilidad en la aplicación de buenas prácticas agrícolas (BPA), buenas prácticas ganaderas (BPG) y buenas 
prácticas de manufactura (BPM). Por ejemplo, en la producción de frutas en El Salvador se detectó que los productores enfrentan dificultades para rastrear problemas sanitarios de origen y evitar la contaminación de parcelas. De igual forma, los productores de tomate y de leche se mostraban interesados en la aplicación de BPA que brindaran una mayor bioseguridad $\mathrm{y}$ trazabilidad a sus productos.

- Los productores enfrentan una falta de acceso a recursos humanos especializados, conocimientos tecnológicos y de gestión de negocios. Por ejemplo, los pequeños y medianos productores de la cadena de embutidos se topaban con el reto de capacitar a su personal en BPM. En las cadenas, en general se identificaron necesidades de fortalecer las capacidades empresariales, tanto de los agricultores como de los transformadores, en diversos temas, como planificación de la producción, mercadotecnia, logística, habilidades de negociación, contabilidad y finanzas.

- Una baja inversión en actividades de investigación, desarrollo e innovación $(\mathrm{I}+\mathrm{D}+\mathrm{I})$. Por un lado, los productores no suelen contar con los recursos humanos y financieros necesarios para llevar a cabo estas actividades. Por otro lado, cuando en el medio nacional existen centros tecnológicos y de investigación que pueden proveer servicios especializados a la cadena, la vinculación es débil o inexistente.

Las restricciones anteriores redundan en mayores costos de producción y una menor productividad, lo que atenta contra la competitividad de los productores. Como se documenta en los informes de las cadenas de lácteos y tomates, la productividad es acotada, incluso si se la compara con la de otros países de la región.

- Existe una falta de capacidades de los productores primarios para incursionar en actividades de procesamiento (manufactura). En la cadena de tomate y chile verde no hay procesadores nacionales que transformen la producción primaria local en salsas, conservas $\mathrm{u}$ otros productos agroindustriales. En la misma línea, los procesadores de productos primarios, en especial los de menor tamaño, enfrentan retos en términos de calidad, precio e innovación, como lo muestra el caso de los deshidratadores de frutas.

- El acceso a mercados nacionales e internacionales es un reto que afrontan las cadenas. Para los productores pequeños es difícil participar en mercados formales que demandan acreditaciones sanitarias, etiquetados, tablas nutricionales, códigos de barras y certificaciones. La calidad y las buenas 
prácticas son centrales para obtener certificaciones que les den acceso a canales de comercialización. Los alimentos, en su forma primaria y procesada, exigen un creciente número de certificaciones en materia de comercio justo, producción orgánica y no utilización de sustancias químicas, como glutamato monosódico, entre otras.

- La falta de conocimientos acerca del mercado, y de acceso a equipos de transporte y medios de financiamiento son factores que obligan a los productores a acudir a servicios de intermediación para comercializar sus productos. Como se muestra en el cuadro V.1, a menudo se da una gran captura de valor en las actividades de comercialización y venta final de los productos, en detrimento del margen de ganancia de los productores. Además, se observan casos en los que los intermediarios dañan la calidad de los productos por no contar con el equipo adecuado de transporte, por ejemplo, camiones refrigerados para transportar la leche.

- La falta de acceso al financiamiento es una restricción que guarda un vínculo directo con las anteriores. Las actividades primarias en general son consideradas de alto riesgo para el sector financiero, mientras que los pequeños emprendedores en el área de los productos agroindustriales no encuentran fácilmente opciones de crédito en los canales formales, debido a la dificultad de satisfacer los requerimientos que solicita el banco, ya sea por garantías o documentación, o porque las tasas de interés no son atractivas. Como se documentó para la cadena de tomate y chile verde, las inversiones tecnológicas para el cultivo de hortalizas y la curva de aprendizaje que enfrentan los productores exigen tiempos que no coinciden con los calendarios de pagos de los préstamos. En los países donde se encuentran las cadenas analizadas existen bancos de desarrollo, pero los actores de la cadena, en particular los más pequeños, se topan con dificultades para cumplir con los requisitos debido a la falta de estados financieros, planes de negocio sólidos y formalización de sus actividades (pago de impuestos y contribuciones sociales).

- El consumidor recibe información incompleta sobre la calidad y las ventajas de los productos. Por ejemplo, en la cadena de embutidos se detectó que los consumidores tienen pocos elementos - además del precio- para evaluar la calidad de los productos que compran, lo que tal vez genere desincentivos para elaborar embutidos de mejor calidad, que no puede ser distinguida fácilmente por el comprador. Se observa una situación similar 
entre las variedades de tomate y chile verde. Otro elemento relacionado con el consumo es la baja expansión de la demanda local de los productos en el caso de mercados maduros como el de los embutidos, así como en nuevos nichos, como el de las frutas deshidratadas. En ambas situaciones, el acotado incremento de la demanda es una restricción para el crecimiento de la cadena.

- Existe, en general, poca información estadística acerca de la cadena. Por un lado, una cadena representa una parte pequeña de la actividad económica, por lo que no es posible tener información detallada proveniente de las cuentas nacionales. Los censos industriales y agropecuarios son fuentes más precisas para tener indicadores cuantitativos a nivel de las cadenas, pero no siempre están disponibles ni se llevan a cabo de manera periódica. Por ejemplo, el censo agropecuario más reciente de la República Dominicana data de 1998. Por otro lado, cuando la información estadística sí existe, frecuentemente se encuentra dispersa en varios sistemas y no siempre hay uniformidad entre ellos. Esta representa otra restricción para la formulación y evaluación de las políticas públicas.

- Como se expuso en la sección anterior, las actividades de las cadenas son reguladas y apoyadas por diversos organismos públicos. Esta restricción se asocia con la falta de coordinación de los apoyos públicos a la cadena, la insuficiencia de fondos y la discontinuidad de los programas. La falta de coordinación entre las instancias no permite alcanzar sinergias ni una utilización más racional de los recursos. No se cuenta con planes plurianuales que permitan dar seguimiento y continuidad a las acciones. Los recursos comprometidos han sido insuficientes para atender las necesidades de las cadenas.

- La última restricción es la falta de atención al impacto que la cadena tiene en el medio ambiente, pero también el abordaje de los efectos del cambio climático en la cadena. Por ejemplo, en las actividades agrícolas se observa una falta de conocimiento acerca del manejo de envases de plástico que contienen agroquímicos nocivos para el medio ambiente, que se tiran al campo y a fuentes de abastecimiento de agua. También se observa un desconocimiento de los beneficios económicos que puede traer aparejada la implementación de tecnologías limpias y medidas de cuidado ambiental. No se identificaron estrategias que permitieran adaptar las actividades productivas ante nuevas condiciones climáticas o fenómenos climatológicos adversos para los rendimientos. 
En el cuadro V.2 se agrupan estas restricciones en tres categorías: producción; distribución, comercialización y consumo; e institucionales.

\section{Cuadro V.2}

Restricciones que enfrentan las cadenas de valor analizadas de productos primarios y agroindustriales

\begin{tabular}{|c|c|c|}
\hline Producción & $\begin{array}{l}\text { Distribución, } \\
\text { comercialización } \\
\text { y consumo }\end{array}$ & Institucionales \\
\hline $\begin{array}{l}\text { Heterogeneidad en capacidades } \\
\text { productivas y tecnológicas }\end{array}$ & \multirow{6}{*}{$\begin{array}{l}\text { Insuficientes capacidades } \\
\text { para acceder a } \\
\text { mercados nacionales e } \\
\text { internacionales formales } \\
\text { Carencia de conocimientos } \\
\text { de mercado } \\
\text { Falta de información entre } \\
\text { los consumidores sobre la } \\
\text { calidad y las ventajas de } \\
\text { los productos }\end{array}$} & \multirow{3}{*}{$\begin{array}{l}\text { Alta fragmentación y débil } \\
\text { organización dentro de los } \\
\text { eslabones y entre ellos, así } \\
\text { como elevada informalidad } \\
\text { en las relaciones y falta de } \\
\text { confianza entre los actores }\end{array}$} \\
\hline \multirow{2}{*}{$\begin{array}{l}\text { Fuerte competencia de productos } \\
\text { importados que se venden } \\
\text { a menores precios }\end{array}$} & & \\
\hline & & \\
\hline $\begin{array}{l}\text { Dependencia de importaciones de } \\
\text { insumos, maquinaria y equipos }\end{array}$ & & \multirow{3}{*}{$\begin{array}{l}\text { Débil coordinación, } \\
\text { discontinuidad, e } \\
\text { insuficiencia de los recursos } \\
\text { de los programas públicos } \\
\text { de apoyo }\end{array}$} \\
\hline $\begin{array}{l}\text { Calidad e inocuidad insuficiente de } \\
\text { los productos primarios y procesados }\end{array}$ & & \\
\hline \multirow{2}{*}{$\begin{array}{l}\text { Debilidad en la aplicación de BPA, } \\
\text { BPG y BPM }\end{array}$} & & \\
\hline & & \multirow{2}{*}{$\begin{array}{l}\text { Falta de información } \\
\text { estadística sobre la cadena }\end{array}$} \\
\hline \multirow{2}{*}{$\begin{array}{l}\text { Falta de acceso a recursos humanos } \\
\text { especializados }\end{array}$} & & \\
\hline & & \multirow{4}{*}{$\begin{array}{l}\text { Insuficiente acceso } \\
\text { al financiamiento }\end{array}$} \\
\hline Baja inversión en I+D+I & & \\
\hline \multicolumn{2}{|l|}{$\begin{array}{l}\text { Capacidades limitadas para incursionar } \\
\text { en actividades de procesamiento }\end{array}$} & \\
\hline $\begin{array}{l}\text { Ausencia de una estrategia ambiental } \\
\text { y de mitigación de los efectos del } \\
\text { cambio climático }\end{array}$ & & \\
\hline
\end{tabular}

Fuente: Elaboración propia, sobre la base de N. Oddone y otros, "Fortalecimiento de la cadena de valor de tomate y chile verde dulce en El Salvador", Documentos de Proyectos, N 13 (LC/MEX/W.13), Ciudad de México, Sede Subregional de la CEPAL en México, 2016; J. Alvarado y otros, "La cadena de valor de embutidos y otras conservas de carne de cerdo en México", Documentos de Proyectos (LC/MEX/W.17/Rev.1), Ciudad de México, Sede Subregional de la CEPAL en México, 2016; C. Gomes y N. Oddone, "Fortalecimiento de la cadena de valor de los lácteos en la República Dominicana", Documentos de Proyectos, Ciudad de México, Sede Subregional de la CEPAL en México, 2017; I. Romero, V. Díaz y A. Aguirre, "Fortalecimiento de la cadena de valor de los snacks nutritivos con base en fruta deshidratada en El Salvador", Documentos de Proyectos (LC/MEX/W.16), Ciudad de México, Sede Subregional de la CEPAL en México, 2016.

\section{Las estrategias para el fortalecimiento de cadenas de valor rurales}

El fortalecimiento de cadenas de valor rurales requiere de un amplio conjunto de políticas. El análisis comparado de las cadenas permite identificar tres grupos: fortalecimiento institucional, política de desarrollo agropecuario y política industrial rural. Si bien se presentan a continuación por separado, los tres grupos son complementarios y es necesaria su articulación. De hecho, se observa una marcada coincidencia en el tipo de instrumentos dirigidos a las actividades primarias y los orientados a la transformación. Las diferencias se dan en las actividades de apoyo, su enfoque y los actores a los que están orientados. 


\section{Fortalecimiento institucional}

El fortalecimiento institucional crea un marco sólido para las actividades primarias y de transformación de las cadenas rurales, así como para una mayor articulación entre ellas. El trabajo con las cuatro cadenas de valor permite identificar las siguientes cinco estrategias comunes:

i) Coordinar las acciones públicas para la regulación y el fomento de la cadena. Se recomienda designar a un organismo público como coordinador de las diversas acciones públicas relacionadas con la cadena. Este organismo será el encargado de vigilar su integración y alineamiento.

ii) Fortalecer las capacidades del sector público para la formulación y evaluación de políticas, así como para la inspección y supervisión de las actividades de la cadena. Es central aumentar los recursos financieros comprometidos, pero también crear capacidades entre los funcionarios públicos. La supervisión de las disposiciones en materia de bienestar animal, inocuidad de los productos (primarios y agroindustriales) y verificación del cumplimiento del reglamento de BPA y BPM, entre otros objetivos, es clave para garantizar la calidad de los productos y la competencia justa entre los actores.

iii) Actualizar el marco regulatorio para facilitar la operación de la cadena y reducir la incertidumbre relacionada con vacíos o indefiniciones. Entre las acciones, se encuentra la definición del ámbito de competencia operativa específico de las dependencias oficiales a fin de evitar duplicidades, traslapes y omisiones en la implementación de políticas públicas; la publicación de normas oficiales técnicas sobre las especificaciones y características de los productos; y cambios en las regulaciones sobre la propiedad de la tierra que den certidumbre a los productores.

iv) Diseñar estrategias públicas plurianuales y focalizadas que superen los mandatos de los gobiernos. La metodología de cadenas permite el diseño de estrategias focalizadas al nivel de los actores que componen cada eslabón.

v) Fortalecer la elaboración y difusión de estadísticas que permitan un mejor análisis, formulación y evaluación de las políticas públicas. El análisis a nivel de cadena requiere, además de la información disponible en las cuentas nacionales, de encuestas y censos que proporcionen datos a nivel de los actores que componen los eslabones. 


\section{Política de desarrollo agropecuario para el fortalecimiento de cadenas}

Los instrumentos que se enumeran a continuación no representan una lista exhaustiva de aquellos de los que dispone la política de desarrollo agropecuario, sino una síntesis de las estrategias orientadas a fortalecer las cuatro cadenas estudiadas.

- Fomentar una cultura de calidad e inocuidad de los productos agropecuarios mediante cursos de capacitación y de difusión de buenas prácticas orientados a los diversos eslabones de la cadena. Asimismo, fortalecer la provisión de servicios dirigidos a mejorar la calidad, como los laboratorios de control de calidad, metrología y normalización.

- Formular programas de bioseguridad y trazabilidad para las cadenas agropecuarias. Además, apoyar la implementación de BPA y BPG por medio de capacitación, asistencia técnica y acceso al financiamiento, y facilitar la formación de alianzas entre productores para el cumplimiento de los reglamentos de BPA y BPG.

- Mejorar las capacidades productivas y gerenciales de los productores agropecuarios mediante programas de capacitación continua, para lo que es clave formular programas de extensionismo con universidades y escuelas técnicas que cuenten con planes de enseñanza y áreas de investigación afines a la cadena.

- Promover actividades de $\mathrm{I}+\mathrm{D}+\mathrm{I}$ que permitan mejorar la calidad de los productos agropecuarios y sus rendimientos; incrementar las actividades de investigación llevadas a cabo en el país en ámbitos relacionados con las cadenas (por ejemplo, mejoramiento genético y prácticas especializadas); fortalecer la colaboración entre productores y escuelas técnicas, laboratorios, universidades y centros de investigación; y establecer una colaboración con centros de investigación internacionales.

- Facilitar el acceso al financiamiento por medio de la adaptación de instrumentos existentes en la banca comercial y la banca de desarrollo en términos de garantías, evaluación de antecedentes crediticios y riesgos, procesos de obtención de créditos y cálculo de costos, entre otros.

- Diseñar e implementar un programa de seguros agropecuarios para los actores de la cadena, con instrumentos adaptados a 
las necesidades y capacidades de los pequeños productores rurales, y que tome en cuenta la construcción de un sistema de identificación de riesgos ambientales.

- Promover la instrumentación de medidas que mitiguen los efectos de las actividades de la cadena en el medio ambiente. En materia ganadera, por ejemplo, pueden introducirse sistemas silvopastoriles, programas para evitar la sobreexplotación de pastizales, la utilización de cercos vivos, planes de uso de desechos para compost y la utilización de desechos de la industria (como el bagazo de la industria cervecera y la melaza de la producción azucarera) para alimentar el ganado. También se recomienda adoptar fuentes alternativas de energía en fincas, centros de acopio y puntos de venta a fin de reducir los costos y el impacto ambiental.

- Mejorar los sistemas de riego y aumentar la productividad del agua mediante la implementación de tecnología, la concientización en su uso, la protección ante contaminación y la restauración de suelos. Entre las acciones, pueden mencionarse, por ejemplo, promover la agricultura de conservación y de precisión, y hacer un uso más eficiente y ecológico de insumos como los fertilizantes.

- Fomentar la asociatividad intra e intereslabón de los actores de la cadena, de modo que les permita alcanzar economías de escala, la compra conjunta de maquinaria y equipo, y una comercialización a mayor escala, entre otros beneficios. Entre los instrumentos, pueden mencionarse el facilitar los espacios de diálogo, asistencia para la conformación legal de las asociaciones e incentivos condicionados a la realización de proyectos conjuntos. Asimismo, se recomienda fortalecer las capacidades de las asociaciones privadas mediante asistencia técnica, capacitación y financiamiento.

- Facilitar la comercialización y distribución de los productos agropecuarios, para lo que se requieren diversas acciones: forjar o reforzar los vínculos entre los productores y los canales de comercialización (centrales de abasto, supermercados, restaurantes, entre otros); promover el diseño de una estrategia de inteligencia de mercado que proporcione información sobre tendencias en el mercado nacional e internacional; y apoyar la inversión en equipos de transporte que permitan distribuir los productos en condiciones adecuadas, por ejemplo.

- Promover el consumo de los productos finales de la cadena mediante el diseño de campañas públicas de difusión 
que brinden información sobre las ventajas nutricionales, orientaciones para distinguir adecuadamente la calidad de los productos e incentivar el consumo de la producción nacional.

- Utilizar el poder de las compras públicas para impulsar la cadena. Un ejemplo es el uso de los programas de comedores escolares, que demandan un gran volumen de productos agropecuarios, para incrementar la demanda que tienen los productores nacionales, en especial los más pequeños. Este instrumento debe ir acompañado de asistencia técnica para garantizar la calidad de los productos y su competitividad en materia de precios.

- Supervisar la competencia justa en los mercados donde se comercializan los productos agropecuarios, lo que exige, por ejemplo, eliminar la competencia desleal por contrabando y supervisar que no existan controles excesivos en la fijación de precios ni en las condiciones de compra.

\section{Política industrial rural para el fortalecimiento de cadenas}

Al igual que en la sección anterior, a continuación se presentan los instrumentos propuestos para fortalecer las cuatro cadenas analizadas, aunque no constituyen una lista exhaustiva de aquellos que están al alcance de la política industrial rural.

- Diseñar e implementar políticas comerciales y de competitividad que apoyen a los productores rurales de bienes agroindustriales. Como se menciona en el capítulo II, estas políticas no suelen estar dirigidas a un grupo en particular. Consisten en negociaciones para facilitar el acceso a mercados internacionales, obras de infraestructura que propicien la comercialización y políticas macroeconómicas que brinden certidumbre a los productores, entre otras.

- Asegurar que exista una competencia justa en los mercados donde se comercializan los productos agroindustriales. Al igual que para los productos primarios, se requiere combatir la competencia desleal por contrabando, verificar que no existan controles excesivos en la fijación de precios ni en las condiciones de compra, y garantizar que no se impongan barreras significativas a la entrada de nuevos competidores, entre otras acciones.

- Crear cursos especializados sobre aspectos técnicos y gestión empresarial dirigidos a los actores de la cadena. Por ejemplo, en la cadena de snacks se recomendó diseñar un diplomado en diversos temas de interés expresados por los deshidratadores: 
técnicas de deshidratación, aseguramiento de la calidad, procesos de certificación, normas de etiquetado y finanzas. Para ello es conveniente buscar el apoyo de escuelas técnicas y universidades.

- Promover la implementación de programas de bioseguridad y trazabilidad y, en general, de BPM. Por tratarse de productos agroindustriales, estos programas deben estar vinculados con la implementación de BPA y BPG.

- Facilitar el acceso de pequeños productores agroindustriales al financiamiento, lo que incluye adecuar el diseño de los productos financieros y reconocer las necesidades y capacidades de estos productores. En este sentido, se recomienda diseñar metodologías alternativas de calificación crediticia, ampliar el alcance de los servicios de garantía, y vincular los apoyos a la inversión en maquinaria y equipos con esquemas de asistencia técnica. También se sugiere elaborar mecanismos de aseguramiento ante riesgos sanitarios y de mercado.

- Fomentar una cultura de calidad entre los productores agroindustriales y en todos los eslabones que integran la cadena, para lo que es necesario impartir talleres regulares de capacitación a los actores de la cadena con el objetivo de concientizarlos sobre la importancia de conservar la calidad e inocuidad en todo el proceso; apoyar la formación y el fortalecimiento de empresas que prestan servicios especializados para la mejora de la calidad; e incrementar la oferta de laboratorios de metrología y normalización. Las acciones se extienden a otros eslabones, por ejemplo, los distribuidores y comercializadores, que son también responsables de que el producto llegue en óptimas condiciones al consumidor.

- Fortalecer las capacidades de comercialización de los diferentes actores que conforman la cadena. Por un lado, se requiere asistir a los productores para que desarrollen una estrategia de inteligencia comercial que les permita identificar los segmentos que demandan sus productos, las características deseadas y sus competidores. Se debe incluir también asistencia para el desarrollo o el fortalecimiento de una marca, el empaquetado y etiquetado, y la obtención de certificaciones. Por otro lado, se propone apoyar a los pequeños productores agroindustriales en las negociaciones con los principales canales de venta -que suelen ser los supermercados, las tiendas locales y los restaurantes- a fin de obtener mejores condiciones de acceso.

- Fomentar la transformación de productos primarios y el escalamiento hacia actividades de mayor valor agregado. Proveer asistencia técnica y apoyos financieros a productores 
agropecuarios que quieran complementar sus ingresos con actividades de transformación. También se incluye apoyar la creación de nuevas empresas (incubación) orientadas a desarrollar productos agroindustriales con una base rural.

- Promover actividades de I+D+I que permitan mejorar la calidad de los productos, reducir costos y crear nuevos productos agroindustriales. El apoyo puede proporcionarse a productores y emprendedores, pero también a universidades, escuelas técnicas y centros de investigación vinculados con el sector productivo. El apoyo para la transferencia y adaptación de tecnologías es clave.

- Fomentar una mayor asociatividad entre los integrantes de cada eslabón (horizontal), así como mejores relaciones entre los eslabones (vertical). Al igual que en las políticas de desarrollo agropecuario, entre los instrumentos se encuentran facilitar los espacios de diálogo, la asistencia para la conformación legal de las asociaciones e incentivos financieros condicionados a la implementación conjunta.

- Proporcionar asistencia a los productores para la creación de marcas colectivas, para lo cual es necesario idear logos y eslóganes, diseñar campañas de comunicación y establecer criterios comunes de calidad entre los integrantes de la marca.

- Promover un mayor consumo de los productos agroindustriales. Se pueden seguir diversos enfoques, como incrementar el consumo de productos con una demanda madura (por ejemplo, embutidos y quesos) haciendo hincapié en sus ventajas, comprar productos con características nuevas (por ejemplo, snacks nutritivos basados en frutas deshidratadas), y promocionar, cuando sea posible, el consumo de productos de origen nacional.

- Incentivar la introducción de medidas que mitiguen el impacto que la cadena ejerce en el medio ambiente, al tiempo que se ofrecen mayores ganancias a los productores. Una estrategia es fomentar la implementación de proyectos de energías renovables y eficiencia energética para la transformación de productos primarios. Otra consiste en la compra de productos primarios que sigan prácticas ambientales adecuadas para el manejo de plaguicidas y fertilizantes. También puede fomentarse el uso de empaques inocuos para el medio ambiente, así como campañas para su adecuada eliminación después del consumo.

En el cuadro V.3 se resumen las estrategias para el fortalecimiento de las cadenas de valor rurales analizadas. 


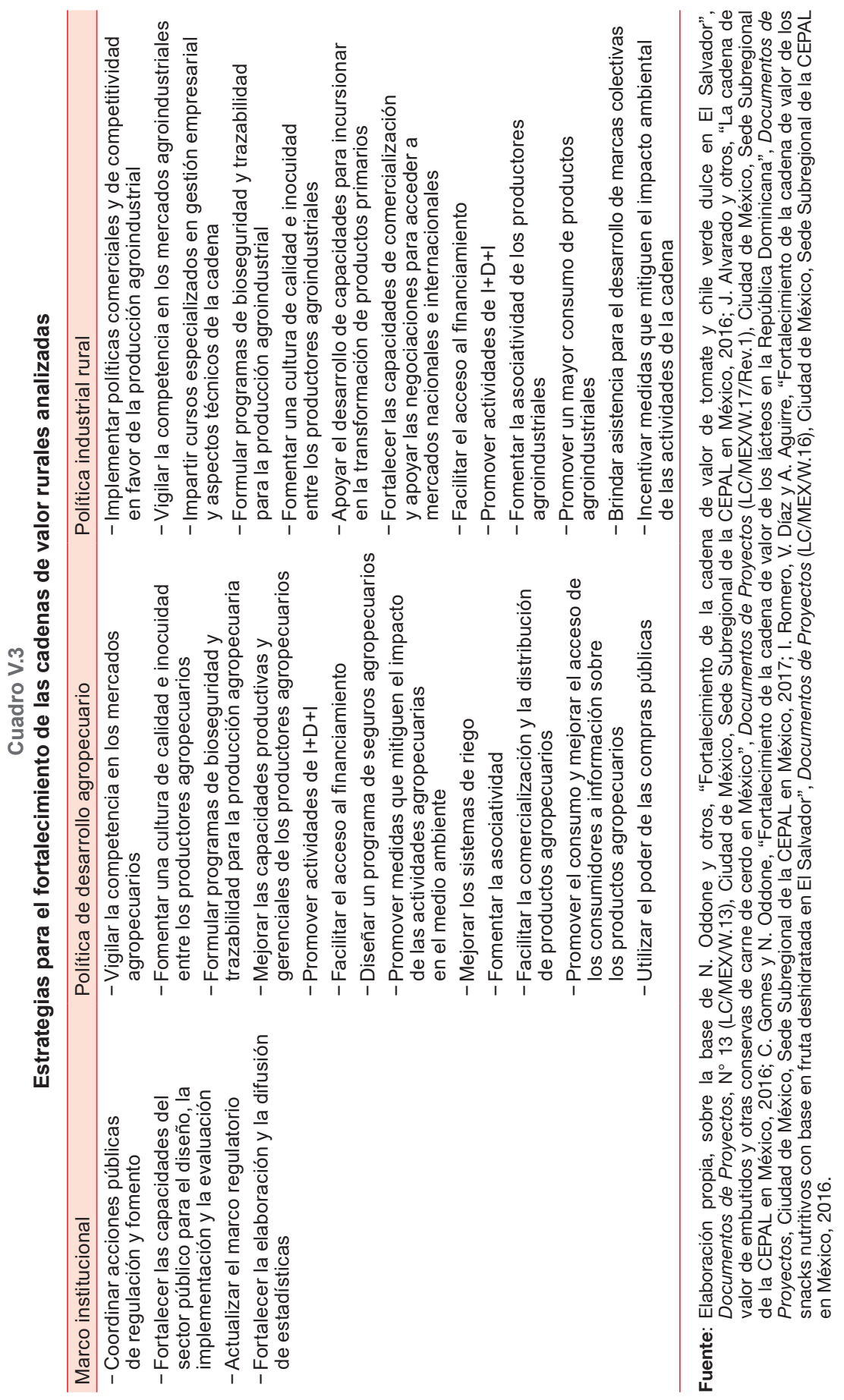




\section{E. Conclusiones}

El análisis transversal de las cadenas de productos primarios muestra que, a pesar de operar en contextos nacionales distintos, de estar conformadas en torno a productos diferentes y de tener diversos grados de desarrollo, enfrentan restricciones en común, en particular los pequeños productores, en lo que atañe a las capacidades productivas y tecnológicas, el acceso al financiamiento, los conocimientos tecnológicos y de mercado, y el acceso a los consumidores finales. En contraste, las grandes empresas, algunas de ellas transnacionales, y los grandes productores gozan de capacidades significativamente superiores, lo que define un contexto de marcada heterogeneidad productiva.

En este capítulo se ilustran los instrumentos que la política industrial rural tiene a su alcance para alcanzar un objetivo en particular: el fortalecimiento de las cadenas de valor. Sobresale la gran variedad de instrumentos en materia de desarrollo productivo en diversas áreas, como capacitación, innovación, comercialización y buenas prácticas. Como puede observarse con mayor detalle en los estudios completos de cada caso (Oddone y otros, 2016; Alvarado y otros, 2016; Gomes y Oddone, 2017; Romero y otros, 2016), el enfoque de cadenas permite formular estrategias focalizadas para cada eslabón y toda la cadena en su conjunto. Cada estrategia define los actores que serán beneficiados y los responsables de brindar el apoyo, así como los temas específicos de cada intervención.

La política industrial rural es distinta a la de desarrollo agropecuario, dado que la primera se enfoca en actividades de transformación llevadas a cabo en espacios rurales, comúnmente agroindustria y artesanías, o en la prestación de servicios como el turismo rural, que se aborda en el siguiente capítulo. No obstante, ambas políticas deben estar articuladas, sobre todo, cuando se busca fortalecer cadenas de valor con eslabones pertenecientes a diversos sectores: primario, secundario y terciario. Como se ilustra en este capítulo, hay una coincidencia cercana en el tipo de instrumentos usados por los dos tipos de políticas, aunque difieren en los enfoques, los actores destinatarios y las actividades que apoyan. La política industrial rural no se concentra solo en las actividades agroindustriales, sino que abarca los servicios y otras manufacturas que se prestan o elaboran en el espacio rural. En el siguiente capítulo se aborda otro campo de acción: el fomento del turismo rural.

El enfoque de cadena permite alcanzar mayores niveles de competitividad y eficiencia en la producción de bienes y la provisión de servicios. Si las estrategias de fortalecimiento se concentran en las actividades de transformación, pero sin atender las actividades primarias, se corre el riesgo de contar con materia prima de baja calidad y de afrontar 
problemas potenciales de inocuidad y altos precios, lo que perjudica la competitividad de los productores agroindustriales y los lleva a buscar una mejor oferta en mercados de importación. El enfoque de cadena también aborda los retos que se enfrentan en materia de distribución y comercialización.

Una característica central de la metodología de cadenas de valor (véase el capítulo III) es su carácter participativo. Las restricciones de las cadenas, resumidas en la tercera sección de este capítulo, fueron validadas con los actores de las cadenas mediante entrevistas directas y mesas de diálogo. De igual forma, las estrategias fueron validadas y priorizadas por medio de espacios de diálogo. Esto responde a un elemento deseable de la política industrial rural: que sea el producto de acuerdos entre el sector público y el sector privado, donde cada uno asume un papel activo en el desarrollo productivo del espacio rural.

\section{Bibliografía}

Alvarado, J. y otros (2016), “La cadena de valor de embutidos y otras conservas de carne de cerdo en México", Documentos de Proyectos (LC/MEX/W.17/Rev.1), Ciudad de México, Sede Subregional de la CEPAL en México.

FAO (Organización de las Naciones Unidas para la Alimentación y la Agricultura) (2011), El estado mundial de la agricultura y la alimentación, 2010-2011. Las mujeres en la agricultura: cerrar la brecha de género en aras del desarrollo, Roma.

Gomes, C. y N. Oddone (2017), "Fortalecimiento de la cadena de valor de los lácteos en la República Dominicana", Documentos de Proyectos, Ciudad de México, Sede Subregional de la CEPAL en México.

Ministerio de Agricultura y Ganadería (2014), Encuesta Nacional Agropecuaria de Propósitos Múltiples, 2013-2014, San Salvador.

Oddone, N. y otros (2016), "Fortalecimiento de la cadena de valor de tomate y chile verde dulce en El Salvador", Documentos de Proyectos (LC/MEX/W.13), Ciudad de México, Sede Subregional de la CEPAL en México.

Padilla, R. y N. Oddone (2016), Manual para el fortalecimiento de cadenas de valor (LC/MEX/L.1218), Ciudad de México, Sede Subregional de la CEPAL en México.

Romero, I., V. Díaz y A. Aguirre (2016), “Fortalecimiento de la cadena de valor de los snacks nutritivos con base en fruta deshidratada en El Salvador", Documentos de Proyectos (LC/MEX/W.16), Ciudad de México, Sede Subregional de la CEPAL en México. 


\section{Capítulo VI \\ El fortalecimiento de las cadenas de valor turísticas en los espacios rurales}

Stefanie Garry

Nahuel Oddone

\section{Introducción}

El turismo es un fenómeno social, económico y cultural relacionado con el movimiento de las personas a destinos fuera de su lugar habitual de residencia, ya sea por motivos personales o profesionales. La estructura y gobernanza de las cadenas turísticas suelen ser muy complejas. La demanda se compone de diferentes segmentos y subsegmentos de mercado. El turista viaja por múltiples motivos y busca poder acceder a servicios cada vez más específicos. Por ejemplo, en el ecoturismo se advierte un alto grado de especificidad de la demanda de operadores turísticos, agencias de viajes, excursiones, hoteles y restaurantes. La incorporación de certificaciones y sellos de calidad ha elevado los estándares de los servicios y la exigencia de los turistas.

La actividad turística está conformada por un conjunto de productos y servicios que permiten a los turistas gozar de experiencias tangibles (hoteles, restaurantes, aviones, seguridad) e intangibles o fortuitas (como un buen clima o un lindo atardecer) (Debbage y Daniels, 
1998). Esto es lo que el turista considera "el valor" de la experiencia vivida, que solo se satisface mediante una cadena en la que un conjunto de actores aportan su trabajo para la oferta de esos valores tangibles e intangibles.

La diversificación y el fortalecimiento de la oferta turística podrán lograrse por medio de la articulación de una cadena de valor que recepte las inversiones del sector privado y los apoyos del sector público. El enfoque de cadena permite incorporar nuevos actores y servicios para el turismo, y mejorar la articulación inter- e intraeslabón para la construcción de una mejor experiencia turística. Debido a la naturaleza del turismo, los actores implicados de manera directa o indirecta en la cadena de valor forman parte de un sistema de provisión de servicios en el que la colaboración es clave para lograr una distribución más equitativa de los beneficios.

En este capítulo se hace un análisis transversal del proceso de acompañamiento realizado para diseñar estrategias público-privadas para el escalamiento económico y social en tres cadenas de valor turísticas en El Salvador, Guatemala y la República Dominicana entre mediados de 2014 y mediados de $2016^{1}$.

Las tres cadenas tienen lugar en el espacio rural, bajo distintas modalidades: ecoturismo, turismo rural comunitario e integración de territorios rurales en destinos turísticos consolidados. El fomento de estas actividades es una de las áreas de intervención de la política industrial rural. El desarrollo de la actividad turística en espacios rurales es un factor clave para lograr un cambio estructural progresivo mediante la creación de empleo, la generación de fuentes complementarias de ingresos, la formación de recursos humanos, la mejora de la infraestructura, el fortalecimiento de otras cadenas productivas vinculadas a partir de la provisión de insumos y la integración de grupos excluidos o con mayor vulnerabilidad. Además, genera otros efectos sociales positivos, como el diálogo intercultural entre turistas y locales (Frías, Garry y Oddone, 2016). El enfoque rural del turismo permite incorporar actores no tradicionales, como pequeños agricultores, ganaderos, pescadores y

\footnotetext{
Véanse los documentos completos de las tres cadenas: “Fortalecimiento de la cadena de turismo de Antigua Guatemala y de los municipios rurales del Departamento de Sacatepéquez", Oddone y Alarcón (2016); "Fortalecimiento de la cadena de turismo en el Departamento de La Libertad, El Salvador", Garry y Martínez (2016); Cadenas de Valor Turísticas en el Departamento de la Libertad, San Salvador, Frías, Garry y Oddone (2016), y "Fortalecimiento de la cadena de valor del turismo en Pedernales, República Dominicana. Versión Preliminar", Alvarado, Gil y Oddone (2016) [en línea] http://www.cepal.org/es.
} 
artesanos, que pueden sumarse a la cadena de valor. En este enfoque se busca que la dimensión ambiental ocupe un lugar central.

Los tres territorios sufren algunas restricciones comunes para fortalecer las cadenas turísticas: infraestructura insuficiente, escaso desarrollo de productos y destinos turísticos, falta de capacitación técnica y cultura turística, estrategias limitadas de comercialización y venta, y problemas de coordinación interinstitucional, entre otras. Las estrategias diseñadas para las tres cadenas coinciden en la importancia de contar con una oferta turística de calidad que brinde mayores ingresos y mejores condiciones de vida a la población, al tiempo que se garantice que los productores y oferentes de servicios turísticos locales logren una captura justa del valor agregado generado en la cadena. La protección adecuada de los recursos medioambientales es de especial interés, dado que forma parte esencial del atractivo turístico del destino.

Este capítulo está divido en seis secciones, además de esta Introducción. En la sección A se ofrece un breve panorama del contexto regional del sector turístico y se muestra su evolución durante la última década. En la sección B se destacan los distintos metaobjetivos que se consideraron en cada caso para estimular el fomento productivo de las respectivas cadenas. En la sección $C$ se resumen los principales hallazgos en las estructuras de las cadenas de valor analizadas. En la sección D se presenta un resumen de las restricciones que se enfrentan para el escalamiento en las cadenas estudiadas. En la sección E se brinda un panorama de las estrategias que pueden ser relevantes para resolver los conflictos operativos de las cadenas y en la sección F se concluye el capítulo con algunas reflexiones generales.

\section{A. Contexto regional del turismo}

En 2014, el continente americano recibió más de 180,6 millones de turistas internacionales, según datos de la Organización Mundial de Turismo (OMT). El número de llegadas turísticas internacionales durante la última década mostró un crecimiento medio anual del 7\%. Según los datos estadísticos de la Dirección de Turismo de la Secretaría de Integración Turística Centroamericana (SITCA), en 2014 Centroamérica recibió 9,61 millones de turistas (véase el gráfico VI.1).

Según los datos de la SITCA, los principales emisores de turismo hacia Centroamérica en 2013 fueron: otros países centroamericanos (40\%), América del Norte (36\%), América del Sur (12\%) y Europa (9\%). Los Estados Unidos constituyen el mayor mercado emisor externo hacia Centroamérica. 
El medio de transporte que predomina entre los turistas extranjeros que llegan a la región es el aéreo, seguido por el transporte terrestre, usado sobre todo por los centroamericanos. Según la OMT (2016), la República Dominicana es el principal país de destino del Caribe.

\section{Gráfico VI.1}

Centroamérica y la República Dominicana: llegadas turísticas internacionales, 2007-2014

(En miles de personas)

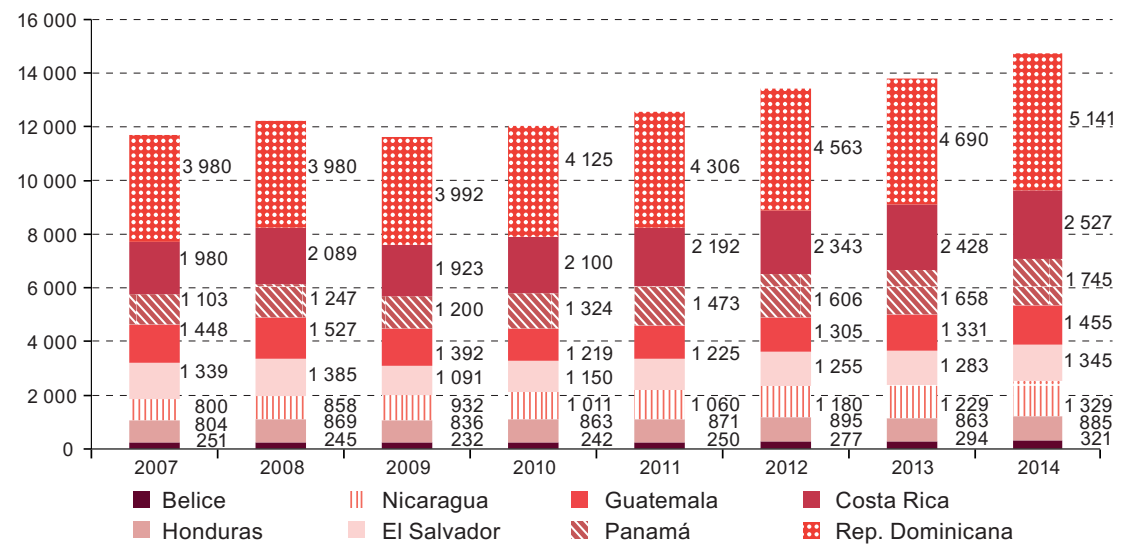

Fuente: Elaboración propia, sobre la base de S. Garry y R. Martínez, "Fortalecimiento de la cadena de turismo en el Departamento de La Libertad, El Salvador", Documentos de Proyectos (LC/MEX/W.18), Ciudad de México, Comisión Económica para América Latina y el Caribe (CEPAL), 2016.

Se observa una diferencia significativa en el número de llegadas de turistas entre los tres países estudiados:

i) Según datos del Instituto Guatemalteco de Turismo (INGUAT), Guatemala recibió 2 millones de visitas en 2013. El país se ha convertido en un destino relativamente accesible para los principales centros emisores de turismo, como el Canadá, los Estados Unidos y Europa.

ii) Según datos de la Corporación Salvadoreña de Turismo (CORSATUR), en 2014 arribaron a El Salvador 1,9 millones de visitantes. Los turistas internacionales representan el 71,3\% del total, mientras que el $28,7 \%$ restante son excursionistas. Un componente esencial es el "hermano lejano": los salvadoreños que viven en el extranjero y regresan para visitar a su familia o conocer la naturaleza, historia y cultura de su terruño.

iii) Los datos del Banco Central indican que en 2015 la República Dominicana recibió un total de 5.599.859 visitantes extranjeros y 
dominicanos no residentes. La Asociación de Hoteles y Turismo de la República Dominicana (ASONAHORES) informa que ese año arribaron 4.832 .956 pasajeros por vía aérea. El aeropuerto de Punta Cana fue el que más turistas recibió, seguido por el de Las Américas de Santo Domingo y el de Puerto Plata.

\section{B. Metaobjetivos}

El primer paso para fortalecer las cadenas de valor es el establecimiento de metaobjetivos (Padilla y Oddone, 2016). Las tres cadenas estudiadas se enfocaron en metaobjetivos específicos, fijados a partir del diálogo con la institución considerada como punto focal en cada experiencia. Si bien cada caso tiene un enfoque particular, el turismo es considerado, de manera común, como un motor de desarrollo económico y social en los territorios. En sus planes nacionales de desarrollo, el turismo es valorado como un sector estratégico.

El departamento de Sacatepéquez (Guatemala) tiene el potencial de incorporar a la actividad turística los pequeños municipios rurales que circundan la ciudad de Antigua, en donde se observa una actividad consolidada. Los metaobjetivos se centraron en la generación de nuevos productos y destinos en municipios rurales seleccionados que rodean la cabecera departamental de Antigua Guatemala: Ciudad Vieja, Jocotenango, Pastores, San Antonio Aguas Calientes, San Juan Alotenango, San Miguel Dueñas, Santa María de Jesús, Sumpango y dos aldeas de Antigua (San Cristóbal el Alto y San Juan del Obispo) (véase el mapa VI.1). El proceso fue producto de una colaboración técnica de la Comisión Económica para América Latina y el Caribe (CEPAL) con el Ministerio de Economía de Guatemala (MINECO) y el Programa Nacional de Competitividad (PRONACOM), y contó con el apoyo del INGUAT.

Elanálisis dela cadena de valor de Pedernales (República Dominicana) se basó en la necesidad de fortalecer la participación de los pequeños productores de bienes y servicios turísticos, todos ellos microempresas y pequeñas empresas, y definir el tipo de destino turístico que se quiere consolidar. En general, los operadores turísticos tradicionales de la Republica Dominicana trabajan con un turismo masivo, principalmente de sol y playa, que demanda paquetes "todo incluido". La cadena analizada plantea desafíos sobre la vocación turística del territorio (véase el mapa VI.2). El proceso se llevó a cabo en conjunto con el Viceministerio de Fomento de las mipymes del Ministerio de Industria Comercio y Mipymes (MICM) y contó con el apoyo de la Dirección de Planificación y Desarrollo del Ministerio de Turismo (MITUR). 


\section{Mapa VI.1 \\ Guatemala: el departamento de Sacatepéquez}

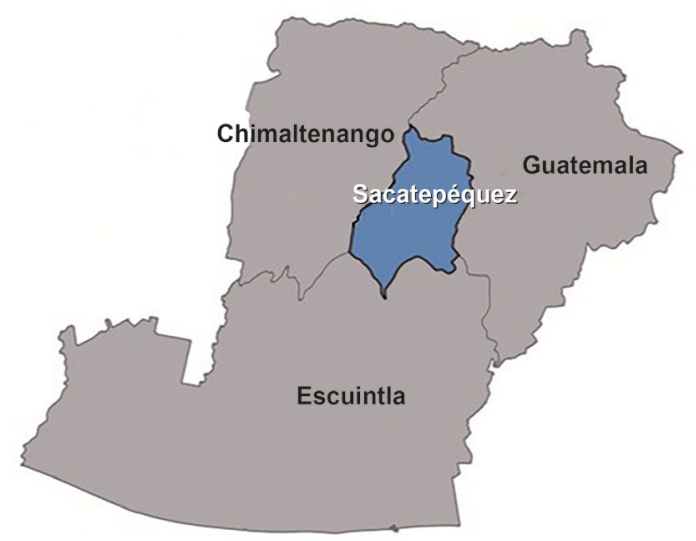

Fuente: N. Oddone y P. Alarcón, "Fortalecimiento de la cadena de turismo de Antigua Guatemala y de los municipios rurales del Departamento de Sacatepéquez", Documentos de Proyectos (LC/MEXM.15), Ciudad de México, Comisión Económica para América Latina y el Caribe (CEPAL), 2016.

Nota: Los límites y los nombres que figuran en este mapa no implican su apoyo o aceptación oficial por las Naciones Unidas.

\section{Mapa VI.2}

\section{República Dominicana: la provincia de Pedernales y su área protegida}

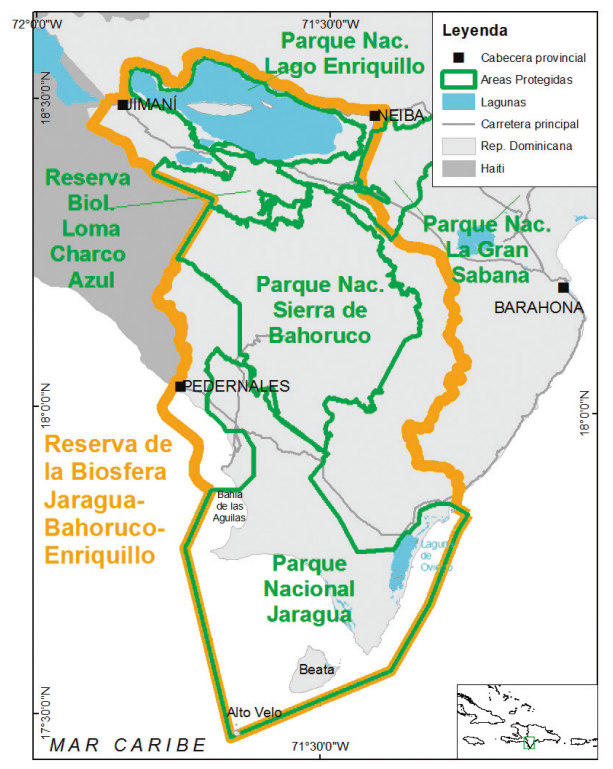

Fuente: J. Alvarado, L. Gil y N. Oddone, "Fortalecimiento de la cadena de valor del turismo en Pedernales, República Dominicana. Versión Preliminar", Documentos de Proyectos, Ciudad de México, Comisión Económica para América Latina y el Caribe/Fondo Internacional de Desarrollo Agrícola (FIDA), 2016.

Nota: Los límites y los nombres que figuran en este mapa no implican su apoyo o aceptación oficial por las Naciones Unidas. 
En el departamento de La Libertad (El Salvador), el trabajo se concentró en fortalecer los enlaces territoriales entre cuatro municipios seleccionados -Chiltiupán, Comasagua, Puerto de La Libertad y Tamanique-, conectando la Ruta de Sol y Playa con la oferta complementaria en la zona rural de la región (véase el mapa VI.3). El estudio tuvo como metaobjetivo la inclusión de productores rurales y locales en la cadena de valor de turismo a través de la incorporación de sus distintos productos o servicios turísticos. Se trató de vincular la oferta de surf, sol y playa ya consolidada de este corredor turístico con la posibilidad de visitar las montañas y las comunidades en el espacio rural. Los socios principales en el proceso de fortalecimiento fueron el Ministerio de Economía (MINEC) y el Ministerio de Turismo (MITUR) a través de la Corporación Salvadoreña de Turismo (CORSATUR)².

\section{Mapa VI.3}

El Salvador: el departamento de La Libertad

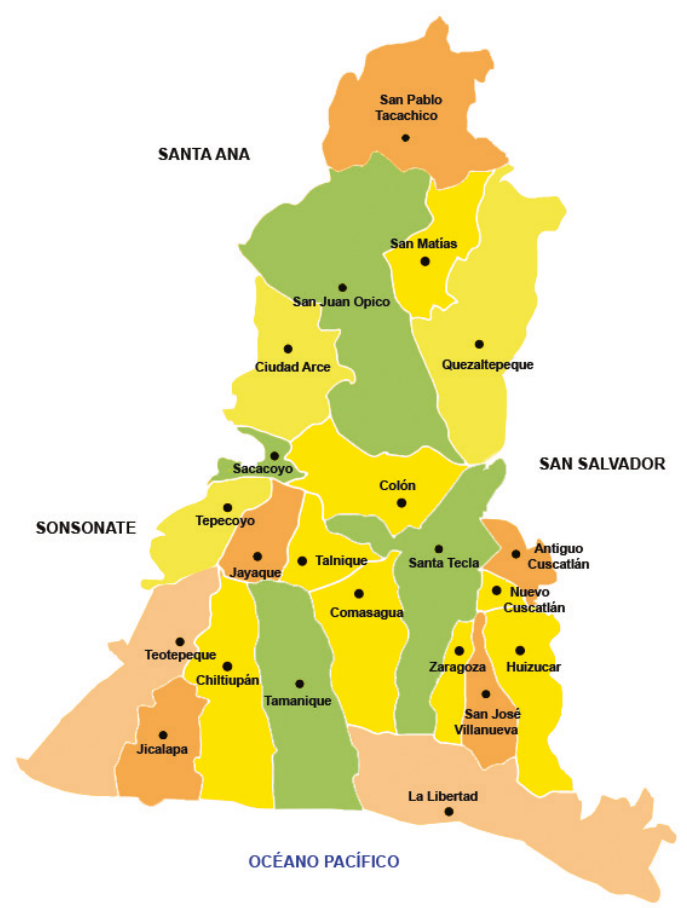

Fuente: S. Garry y R. Martínez, "Fortalecimiento de la cadena de turismo en el Departamento de La Libertad, El Salvador", Documentos de Proyectos (LC/MEX/W.18), Ciudad de México, Comisión Económica para América Latina y el Caribe (CEPAL), 2016.

Nota: Los límites y los nombres que figuran en este mapa no implican su apoyo o aceptación oficial por las Naciones Unidas.

2 Véase un análisis detallado de las instituciones de apoyo vinculadas a cada una de las cadenas analizadas en los estudios publicados y disponibles de manera gratuita en el repositorio de la CEPAL. 
En los tres casos se buscaba crear y vigorizar enlaces con las comunidades y los proveedores locales para fortalecer la identidad y la creación de una marca colectiva. Mediante la construcción de infraestructura o instalaciones para apoyar a la industria turística, el desarrollo del turismo a nivel local en comunidades rurales puede impulsar una situación ventajosa tanto para los turistas como para los residentes de las comunidades. Promover una relación simbiótica entre la sociedad, la cultura y el medio ambiente es fundamental al considerar el adelanto y fortalecimiento de los destinos y productos turísticos, tanto principales como complementarios.

\section{Las cadenas de valor turísticas}

Las cadenas de valor de turismo están conformadas por un conjunto de actividades económicas interrelacionadas. El turista es quien experimenta las distintas actividades a lo largo de la cadena de valor al hacer uso de los bienes y servicios durante su estadía. Para ello, es preciso conocer la complejidad vertical de la actividad, que comprende a los diferentes proveedores que existen para un solo destino (medios de transporte, alojamiento, restaurantes, guías turísticos y demás), los que, a su vez, pueden estar asociados a uno o varios productos y servicios (Oddone y Alarcón, 2016). El turista consume un conjunto de productos y servicios mientras disfruta de una experiencia en contacto con elementos tangibles e intangibles. Las sensaciones provocadas por el valor turístico consumido (la "experiencia turística") son el resultado de una serie de articulaciones entre la oferta y la demanda.

La infraestructura turística se refiere a los elementos físicos - públicos y privados - necesarios para el acceso al destino y su disfrute seguro. Se incluye en este rubro, por ejemplo, la infraestructura de transporte (carreteras, aeropuertos, aparcamientos), de sanidad (hospitales, centros de salud) y de seguridad y protección del turista (policía, protección civil, embajadas, centros de amigos del turista).

En los tres casos estudiados por la CEPAL, a partir de la llegada del turismo al país, las cadenas turísticas se dividen, de manera generalizada, en cuatro eslabones: distribución, transporte nacional, alojamiento y excursiones (véase el diagrama VI.1). Cada uno de estos eslabones, a su vez, tiene encadenamientos con otros insumos y servicios. Además, existen servicios transversales que apoyan la operación de la cadena en su conjunto. Por medio del abastecimiento de insumos y productos primarios, los actores rurales asumen un papel clave en el funcionamiento de la cadena. 
Diagrama VI.1

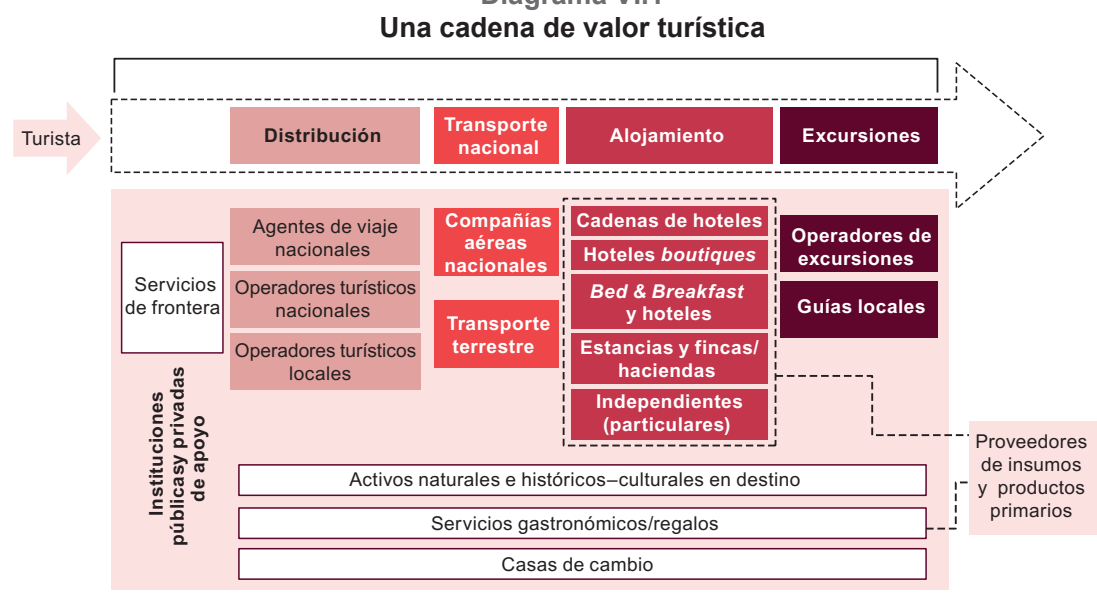

Fuente: S. Garry y R. Martínez, "Fortalecimiento de la cadena de turismo en el Departamento de La Libertad, El Salvador", Documentos de Proyectos (LC/MEX/W.18), Ciudad de México, Comisión Económica para América Latina y el Caribe (CEPAL), 2016.

A continuación se presenta un resumen de las principales características de cada eslabón en las cadenas, partiendo desde que el turista llega al país.

\section{Turista}

Dado que el turismo constituye una experiencia de vida, esta se inicia con el turista que desea conocer un nuevo destino y que compra su pasaje (eslabón de distribución) por medio de una agencia de viajes u otro operador turístico, o de manera independiente por Internet a la compañía prestadora del servicio o a algún grupo mayorista. Otra posibilidad es que el turista simplemente decida viajar al destino por sus propios medios.

En los tres destinos turísticos analizados, los principales consumidores son excursionistas nacionales ${ }^{3}$. No obstante, también se cuenta con presencia de visitantes internacionales. El departamento de La Libertad es uno de los más visitados por turistas internacionales que se acercan a practicar surf (aproximadamente un 40\% del total de turistas internacionales que recibe el país). Antigua, por su parte, capta una tercera parte de los turistas internacionales de Guatemala. En este caso se observa un elevado nivel de visitación por parte de excursionistas internacionales y nacionales, pero la plaza hotelera, a excepción de la temporada alta, muestra un índice de ocupación del $40 \%$, con una pernoctación que en pocos casos excede las 2 noches. Por su distancia de los principales centros urbanos o turísticos de

\footnotetext{
Dependiendo de la duración de su estadía, los visitantes se clasifican en: i) turistas, si se alojan por
} lo menos una noche en el lugar, o ii) excursionistas, si solo lo visitan durante una parte del día. 
la República Dominicana y la falta de infraestructura que facilite la llegada a la provincia, Pedernales ostenta una muy baja presencia de turistas internacionales, pese a contar con las playas de Bahía de las Águilas, Piedra Blanca y Cabo Rojo, el Hoyo de Pelempito y los Parques Nacionales Jaragua y Sierra de Bahoruco. El 68\% del territorio provincial corresponde a áreas naturales protegidas, lo que ofrece un polo de fuerte potencial de atracción.

\section{Distribución}

De la intermediación turística y distribución de servicios turísticos se encargan las empresas de operación turística y las agencias de viajes internacionales, nacionales y, en menor medida, locales y especializadas asentadas en cada país. En cuanto a su distribución, las principales agencias de viajes se concentran en las ciudades más grandes de los países (San Salvador, Santo Domingo y, en el caso de Guatemala, entre Ciudad de Guatemala y Antigua), así como en los principales centros turísticos, como Punta Cana en la República Dominicana. Las agencias de dimensiones menores y locales (en su mayoría con menos de cuatro empleados) utilizan guías locales especializados, así como otros medios de promoción, para ofrecer sus servicios y paquetes. Debido a que existen pocos operadores turísticos que trabajen activamente en la comercialización de las zonas rurales estudiadas como destinos turísticos, en general el visitante arriba por cuenta propia.

En los tres casos analizados, el operador turístico local ejerce un control significativo sobre la gobernanza de la cadena de valor y, por lo tanto, sobre las posibilidades de incorporar otros productos o destinos turísticos como oferta principal o complementaria. Así, el operador turístico de Guatemala es el principal responsable de añadir destinos a la oferta que se encuentra distribuida en torno a la ciudad de Antigua, el operador de El Salvador potencializa el vínculo entre los municipios de la zona de montaña y los operadores de la República Dominicana contribuyen a generar una oferta que pueda consolidarse como un destino ecoturístico. Los atractivos turísticos de Pedernales son muy poco comercializados por agencias de viajes dominicanas, que en algunos casos tienen convenios con intermediarios internacionales y que, por lo general, no ofrecen esta provincia de manera individual, sino en conjunto con las demás provincias del sur del país.

\section{Transporte}

La accesibilidad es indispensable para el desarrollo de los destinos turísticos. El transporte terrestre colectivo o individual es el principal medio de movilidad turística hacia los tres destinos analizados. Tanto La Libertad como Sacatepéquez, ambos cercanos a la ciudad capital de sus respectivos países, enfrentan dificultades de acceso debido al alto volumen de tránsito en las carreteras. En ambos casos se cuenta con un aeropuerto internacional relativamente cerca, aunque en Guatemala las tarifas internacionales son elevadas. El acceso a Pedernales es muy complejo por la distancia a Santo 
Domingo y los problemas de infraestructura en la carretera ${ }^{4}$. Cerca de Pedernales, en Barahona, existe un aeropuerto que por su bajo volumen de operación ha perdido espacio en los vuelos nacionales e internacionales ${ }^{5}$.

Por lo general, los actores de este eslabón de distribución se dividen en tres categorías: i) turoperadores locales, ii) empresas de transporte turístico de pasajeros con itinerarios establecidos y iii) empresas de transporte público extraurbano. Varias agencias y turoperadores en las cadenas de El Salvador y Guatemala disponen de transporte terrestre, como autobuses de enlace, con itinerarios fijos en la región o en viajes privados en microbuses hacia diversos destinos, normalmente sin paradas intermedias. Por ejemplo, desde La Libertad se cuenta con servicio internacional a Antigua (Guatemala) y León (Nicaragua), sitios frecuentes en los recorridos regionales de los turistas, sobre todo los jóvenes y mochileros.

Pese a la existencia de los servicios de transporte enumerados, la articulación y el movimiento en las zonas del estudio siguen siendo limitados por la falta de conexiones locales (en particular a los espacios rurales), la ausencia de horarios fijos para el transporte público y, en algunos casos, el riesgo de seguridad para el turista.

\section{Alojamiento y servicios gastronómicos}

Los servicios de hospedaje y gastronomía constituyen un eslabón central en la creación de valor añadido a la experiencia del viajero. En los tres territorios analizados, en particular en Pedernales, es necesario fortalecer la oferta de estos servicios. Un potencial vínculo vertical valioso para el sector gastronómico es la producción agrícola de los territorios cercanos, así como la pesca en los casos de La Libertad y Pedernales. Entre los principales productos para encadenar se pueden considerar los granos básicos, las hortalizas y las frutas. Las regiones también producen lácteos, aves de corral y pesca artesanal, entre otros productos agropecuarios con potencial.

En 2013, Sacatepéquez tenía una oferta de 154 establecimientos de hospedaje aptos para turismo, con una capacidad de 2.130 habitaciones y

La distancia de Santo Domingo al pueblo de Pedernales por carretera es de aproximadamente $300 \mathrm{~km}$, lo que supone unas 5 horas de viaje. Los primeros $185 \mathrm{~km}$ (Santo Domingo-Barahona) están en buenas condiciones y se recorren en 2 horas y media. Sin embargo, el tramo de Barahona a Pedernales carece de mantenimiento y señalización, además de que algunas partes son peligrosas por el cruce de animales, de modo que el trayecto puede tomar como mínimo otras dos horas y media. Dependiendo de las circunstancias, el trayecto total puede tomar hasta siete $\mathrm{u}$ ocho horas. Por otra parte, las condiciones de los caminos en la provincia, con muchos tramos de terracería, dificultan el acceso a los lugares turísticos.

5 En la región sureste del país existen dos aeropuertos: el de Pedernales y el de Barahona. Actualmente, el Aeropuerto de Pedernales, ubicado en Cabo Rojo, solo está abierto para avionetas y helicópteros de uso militar, y el Aeropuerto Internacional de Barahona, que es categoría 3, está destinado para aeronaves pequeñas, aunque cuenta con la infraestructura suficiente para albergar aeronaves grandes. Este aeropuerto funciona para operaciones privadas y en él se realizan aproximadamente 892 movimientos de aeronaves con unos 500 pasajeros al año, ya que la mayoría de las operaciones son de carga. 
6.225 camas. La oferta de hoteles está dirigida a diversos segmentos del mercado: visitantes nacionales o internacionales que llegan por placer o negocios. Antigua reúne más del $90 \%$ de la capacidad de hospedaje de Sacatepéquez, tanto en establecimientos como en habitaciones y camas. Fuera de esta ciudad, hay dos hoteles en Ciudad Vieja y uno en cada una de las siguientes localidades: San Juan Alotenango, Jocotenango, Santa Lucía Milpas Altas y Sumpango. La oferta gastronómica en Sacatepéquez está conformada por 315 establecimientos registrados como restaurantes o cafeterías, incluidas opciones vinculadas a los hoteles. Aunque la gran mayoría de estos establecimientos se concentran en el casco urbano de Antigua, existe un potencial para desarrollar otras opciones con cocineras locales en las ciudades que rodean a Antigua, como Ciudad Vieja y San Juan del Obispo.

En 2012, el departamento de La Libertad contaba con 51 hoteles que ofrecían 953 habitaciones de varios tamaños (lo que equivale al 12,5\% de la oferta total de hoteles de El Salvador). La gran mayoría se clasifican como hoteles de playa relativamente pequeños, con entre 8 y 20 habitaciones. La región cuenta con restaurantes, comedores y áreas de bar para satisfacer los diversos gustos con una variedad de precios muy amplia y presenta varios retos en materia de calidad. En la playa El Tunco (municipio de Tamanique) la oferta varía desde restaurantes y bares de playa (la mayoría vinculados a un hotel $\mathrm{u}$ hostal), pupuserías, cafés, pizzerías y vendedores ambulantes en la playa, hasta restaurantes internacionales con servicios de comida italiana, japonesa y mexicana, entre otros estilos.

En Pedernales, la mayoría de los establecimientos son casas de huéspedes y hostales que no cumplen los criterios del reglamento de clasificación de estrellas. De acuerdo con el estudio de campo de Alvarado, Gil y Oddone (2016), se detectaron 12 establecimientos que en conjunto disponen de 171 habitaciones. La oferta gastronómica de Pedernales se basa en pescados y mariscos comprados en pescaderías, a pescadores independientes o en el mercado binacional con Haití.

\section{Excursiones}

El operador de excursiones o el guía turístico local es un actor clave para desarrollar diversos destinos turísticos, establecer rutas para visitas y programar actividades aprovechando su conocimiento del lugar. De manera comparativa entre los tres casos, el eslabón de excursiones muestra cierta dispersión en cuanto al nivel de fomento de actividades dentro del proprio eslabón. Los operadores de excursiones en Sacatepéquez han desarrollado cierto grado de madurez y diversificación en su oferta, en comparación con El Salvador y la República Dominicana, donde las excursiones se organizan a demanda y en algunos casos de manera informal. La oferta en Sacatepéquez, no obstante, permanece muy concentrada en Antigua. Este eslabón todavía requiere de mayor formalización para disponer de una oferta de excursiones y visitas hacia diferentes puntos de atracción, tanto naturales como culturales, 
con una programación regular y con un mayor grado de profesionalismo. Los operadores de excursiones y guías locales (incluso los independientes) tienen un gran potencial para gestionar y diseñar recorridos en el ámbito rural y vincular las atracciones menos conocidas a la oferta turística tradicional.

Antigua cuenta con una oferta diversificada de excursiones: a) las que forman parte de los paquetes comprados por el turista desde el exterior, $b$ ) las que se venden a través de agencias de viajes o turoperadores locales, diseñadas y ofertadas para el público en general, y c) las que las empresas turoperadoras locales organizan a medida y en virtud de la demanda del turista. El turista que opte por esta última opción deberá organizar su paseo de manera individual e independiente. Las agencias de excursiones diseñan paquetes hacia diferentes puntos de atracción, tanto en Sacatepéquez (escalada de volcanes, visitas a fincas de café, recorridos culturales, visitas a otros poblados de menor tamaño y demás) como hacia otros destinos dentro y fuera del país.

En El Salvador, el turismo de sol y playa vinculado al surf por lo general forma parte de los paquetes comprados por el turista desde el exterior. Sin embargo, también existen otras experiencias relevantes. En el departamento de La Libertad, por ejemplo, TouRuralEs brinda experiencias turísticas en comunidades principalmente rurales, donde diferentes cooperativas y grupos indígenas planifican, gestionan y cuidan los recursos naturales e históricos que sirven de atractivo. Este tipo de turismo es un complemento de la economía campesina y se distingue, entre otras cosas, por distribuir los ingresos turísticos de manera más equitativa y directamente a las comunidades.

Los operadores turísticos nacionales que organizan viajes en la provincia de Pedernales se centran especialmente en Bahía de las Águilas y en ocasiones incluyen servicios de guías turísticos locales. Si bien la provincia de Pedernales cuenta con una asociación de guías locales que han recibido capacitación del Ministerio de Turismo, su flujo de operaciones es mínimo debido a la poca actividad turística del destino. Entre los servicios que ofrecen se encuentran la observación de aves y el senderismo en el Parque Nacional Sierra de Bahoruco. No cuentan con sistemas de promoción y solo trabajan cuando las dependencias oficiales o los hoteles solicitan sus servicios.

\section{Las restricciones}

Las cadenas de valor turísticas tienen una serie de particularidades, como el papel impulsor del turista o consumidor y la forma de "consumo" de la experiencia obtenida, la gran cantidad de servicios especializados y, en los tres casos analizados, una acusada heterogeneidad intra- e intereslabón. A continuación se presentan las restricciones sistémicas, que son las que afectan a todos los eslabones de una cadena, y una síntesis de las restricciones comunes a nivel de cada eslabón. Las restricciones sistémicas pueden agruparse en tres áreas: de conectividad e infraestructura, de condiciones del mercado y de institucionalidad. 
i) Las cadenas enfrentan restricciones de infraestructura y conectividad aérea y terrestre. Se identificaron dificultades de accesibilidad a los destinos y condiciones de relativa inseguridad como elemento de contexto. Los espacios rurales, en particular, enfrentan dificultades en materia de conectividad por el mal estado de las vías que complica el transporte de materia prima hacía diferentes partes del territorio.

ii) En el aspecto institucional, se identificó una falta de asociatividad entre los actores que conforman los eslabones. Además, los destinos, tanto tradicionales como no tradicionales, en las cadenas estudiadas no compiten bajo una misma marca colectiva. También hay debilidades técnicas en los comités turísticos locales y bajos niveles de comunicación con el gobierno local en acciones productivas relacionadas con el desarrollo turístico y la articulación de la cadena a partir de la consolidación de sus principales proveedores. Asimismo, la información estadística disponible al público para la toma de decisiones sobre actividades turísticas es insuficiente. Faltan datos actualizados y homogéneos a nivel nacional, departamental y local sobre el mercado laboral, la producción local, los flujos de turistas internos e internacionales, y la demanda de servicios, entre otros indicadores.

iii) En cuanto a las restricciones sistémicas del mercado, se observa un relativo desconocimiento del funcionamiento del sector turístico y de la cadena, una baja promoción del destino, sobre todo de destinos y atractivos turísticos en espacios rurales, y poca diversificación de la oferta. No existen estrategias sólidas de mercadotecnia para el posicionamiento de la oferta turística en nuevos mercados y en diversas comunidades no se considera la oferta de esquemas turísticos alternativos, como el ecoturismo. Falta una cultura turística generalizada a nivel local y no se cuenta con programas y normas para garantizar la sostenibilidad del medio ambiente (por ejemplo, dificultades de acceso al agua para la actividad turística y contaminación del territorio y el paisaje). Los proveedores de servicios y productos turísticos no disponen de una oferta de crédito suficiente y tienen un acceso limitado a servicios financieros apropiados. Algunos proveedores de productos y servicios turísticos tienen temor o falta de confianza para endeudarse en el sistema financiero formal.

Las restricciones por eslabón se agrupan en cinco rubros generales (véase el cuadro VI.1): i) distribución, ii) hospedaje y gastronomía, iii) artesanías y regalos, iv) transporte y v) excursiones. Las restricciones específicas por eslabón influyen en la calidad y el éxito de los negocios de las empresas que conforman los distintos eslabones. 


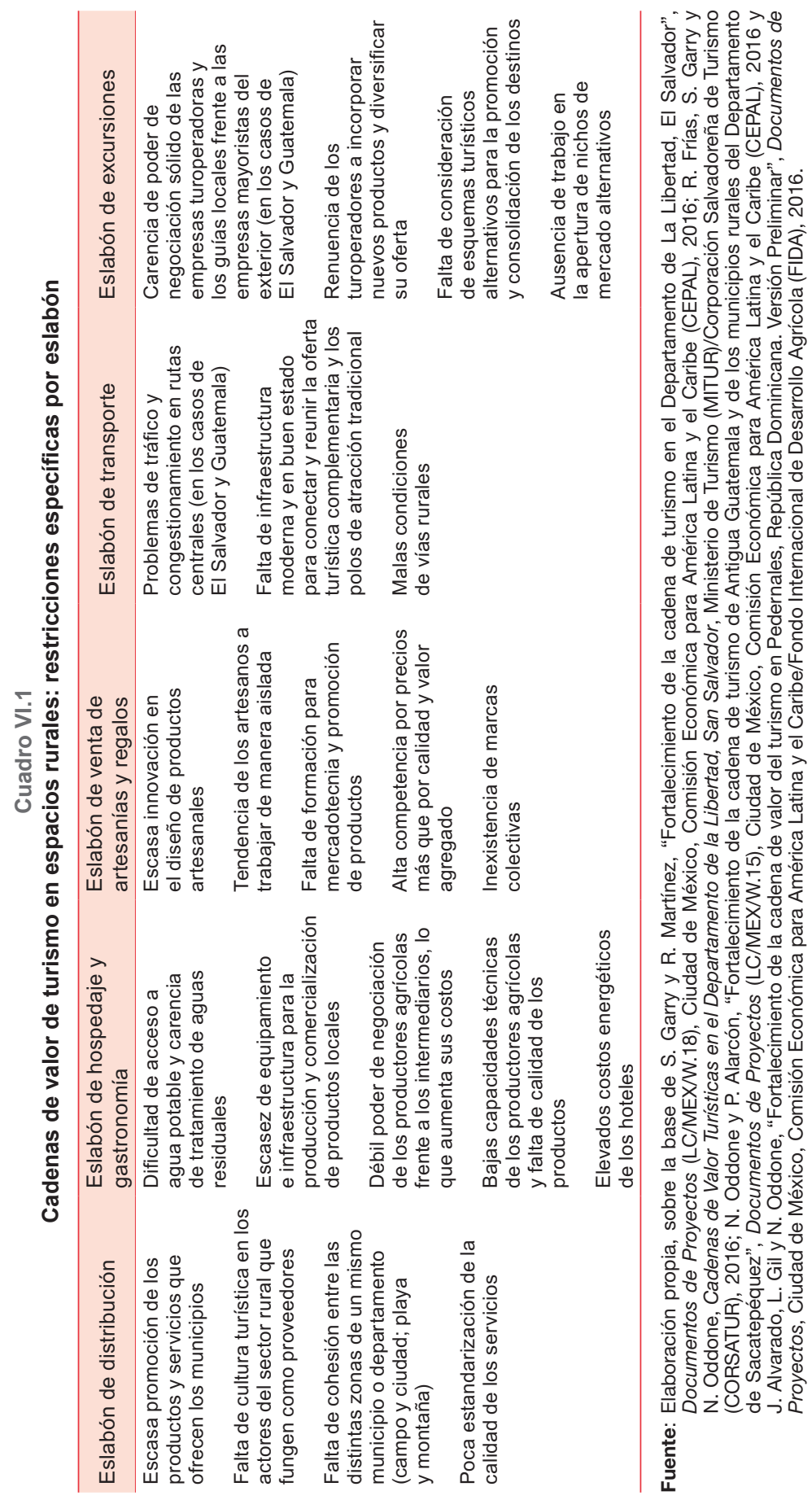


i) Distribución. Uno de los mayores obstáculos que enfrentan las comunidades rurales que han incursionado en el turismo es la distribución, la comercialización y la mercadotecnia adecuada de sus productos y servicios turísticos. Eso suele ser de especial relevancia para la disponibilidad de ofertas turísticas alternativas que podrían ir más allá de las tradicionales, sobre todo en ámbitos rurales. Los turoperadores de menor tamaño enfrentan problemas de escala para acceder a ferias internacionales en las que podrían negociar con los mayoristas internacionales del sector y proponer cambios en esta lógica de gobernanza. Un reto importante para mejorar la distribución de actividades en el medio rural es la carencia de estándares de calidad en la oferta.

ii) Hospedaje y gastronomía. En las cadenas estudiadas, es frecuente que la construcción de los alojamientos, en particular los de menor tamaño, se realice sin considerar los criterios técnicos reglamentarios, de modo que no cumplen con los estándares mínimos de diseño, construcción y operación. Se requiere brindar a los negocios asistencia técnica en materia de capacitación de personal, atención al cliente, administración e higiene, cumplimiento de la normativa y los estándares vigentes, entre otras cuestiones. Se nota una insuficiente formación de recursos humanos en capacidades empresariales y de gestión. Además, hay restricciones particulares relacionadas al vínculo entre el eslabón de hospedaje y gastronomía y los espacios rurales, principalmente a través de la provisión de insumos de materia prima y productos agrícolas. La mayoría de los productores agrícolas y rurales trabajan de manera artesanal, hacen un uso limitado de la tecnología y tienen una baja productividad. Debido a que los productores agrícolas suelen tener un débil poder de negociación frente a los intermediarios, existe una falta de integración del sector comercial con los productores rurales.

iii) Venta de artesanías y regalos. Otro desafío de las comunidades locales es la falta de innovación en nuevos productos artesanales para poder competir en el mercado por diseño, calidad y diferenciación. Además, algunos artesanos trabajan de manera aislada y no reciben la formación necesaria para hacer mercadotecnia y promocionar sus productos a los turistas.

iv) Transporte. Las principales rutas de acceso al polo de atracción turístico presentan problemas de tráfico y congestionamiento, sobre todo en los casos de La Libertad y Sacatepéquez. Además, se constata una falta de infraestructura moderna y en buen estado para conectar los destinos de atracción turística y reunir la oferta complementaria. Como ya se mencionó, el estado de las 
vías rurales complica el acceso a diferentes atractivos turísticos actuales o potenciales fuera del núcleo central de las cadenas.

v) Excursiones. La mayoría de las empresas turoperadoras locales no cuentan con un poder de negociación sólido frente a las empresas mayoristas para negociar en la inclusión de la oferta turística local. Existe una tendencia generalizada en virtud de la cual los operadores turísticos renuncian a incorporar nuevos productos o servicios en la gama de su oferta. Además, en varios casos en las cadenas estudiadas no se consideran esquemas turísticos alternativos en la promoción y el desarrollo de la oferta, como actividades vinculadas al ecoturismo y al turismo comunitario.

\section{E. Estrategias y recomendaciones de política pública para cadenas de valor turísticas}

En los tres países estudiados existe cada vez más interés por la diversificación del mercado turístico. Si la definición de los nuevos productos turísticos se efectúa en el marco de los objetivos y estrategias que forman parte de políticas públicas sectoriales, es más factible delinear acuerdos público-privados para la consolidación del destino (o los destinos) y la elaboración de programas de inversión pública y planes de inversión privada que fortalezcan la cadena.

La OMT (2012), a través del Manual de desarrollo de productos turísticos, ha establecido sugerencias y lineamientos encaminados a una planificación efectiva en la implementación de productos y servicios de turismo en un territorio. En el documento se establece que el desarrollo de productos turísticos debe ajustarse a los siguientes principios:

- Ser auténtico y reflejar los atributos únicos del destino.

- Contar con el apoyo de la comunidad receptora (cultura turística).

- Respetar el entorno natural y cultural sin provocarle un impacto negativo.

- Diferenciarse de los competidores, sin copiar o imitar sus iniciativas.

- Alcanzar una amplitud suficiente para que represente una contribución significativa a la economía, sin llegar a constituirse en una fuga importante de recursos económicos.

Con el objeto de contribuir a la diversificación de fuentes de ingresos y a la creación de empleo, el turismo en el espacio rural —en la forma de turismo comunitario, turismo sostenible o ecoturismo- se ha promovido como alternativa de desarrollo. El turismo comunitario posibilita que un alto nivel de control y una porción considerable de la planificación de la actividad turística y sus beneficios queden en manos de miembros de comunidades 
locales. En la toma de decisiones sobre el desarrollo turístico se contempla la participación de cooperativas u organizaciones comunales, entre otros agentes. El turismo comunitario supone una relación simbiótica, en la que el turista solo representa una parte del sistema, en lugar de ser el centro de atención. El ecoturismo se considera un medio para involucrar a miembros de comunidades rurales en las actividades y servicios del sector turístico y ayudar a la conservación del medio ambiente. El turismo sostenible, creado para reducir las externalidades negativas de la actividad sobre el medio ambiente y el paisaje cultural y social, hace referencia al conjunto de acciones dirigidas a garantizar el mantenimiento de los recursos naturales y las manifestaciones culturales, al tiempo que se proveen beneficios socioeconómicos para los países y las comunidades locales.

Los procesos de certificación son muy comunes en el sector turístico. Por lo general, se busca impulsar en el capital humano local una cultura de excelencia en los servicios por medio de sistemas de capacitación continua enfocados en el incremento de la calidad de los servicios prestados y el mejoramiento de la calidad sistémica del destino. Los servicios profesionales y de soporte - como certificaciones, asistencia técnica e investigación y desarrollo- son cruciales para la modernización tecnológica, el aumento del valor agregado y el acceso a los mercados internacionales. Sin embargo, siempre es necesario considerar el momento oportuno para certificar y quién va a realizar esa tarea, que conviene llevar adelante tras el desarrollo incremental de las capacidades de los actores y el aumento efectivo en la calidad de los servicios (véase el diagrama VI.2).

Diagrama VI.2

Turismo: proceso de certificación
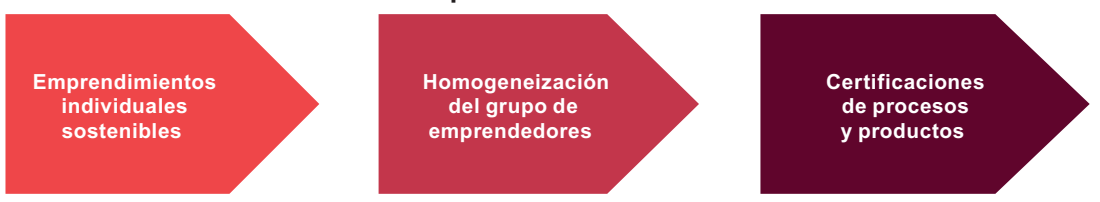

Fuente: Elaboración propia.

El diagrama VI.2 se adapta fácilmente a la realidad de las tres cadenas estudiadas, ya que se parte de la necesidad de contar con un grupo de emprendimientos individuales sostenibles y homogéneos que, gracias al apoyo y la asistencia de la cooperación internacional o los recursos del Gobierno, puedan participar en un proceso de certificación. El desarrollo de este esquema, no obstante, depende de las características que adquieran el proceso y la estructura de gobernanza en las tres cadenas. La gobernanza de las cadenas de turismo es un factor muy relevante para considerar, sobre todo en la formulación de diferentes enfoques de turismo 
alternativos. En las cadenas de turismo, el concepto de gobernanza se refiere a las relaciones y el balance de influencia entre los compradores, los vendedores, los proveedores de servicios y las instituciones reguladoras que operan en la cadena y juegan un papel en los pasos necesarios para llevar un producto o servicio turístico desde su inicio hasta su uso final.

En las cadenas de valor de turismo, como en los casos de los departamentos de Sacatepéquez y La Libertad, el poder suele concentrarse en los turoperadores y las empresas de distribución. Se observa, asimismo, una relativa dependencia de otros actores ubicados en otros eslabones de la cadena, importantes por su poder a la hora de promocionar nuevos destinos y servicios turísticos y vender productos turísticos innovadores. Esto resulta sumamente importante en el caso de los destinos y productos rurales, dado que los actores cuentan con una menor capacidad de promocionar sus servicios. En este sentido, el turista también tiene una relativa dependencia de los operadores turísticos locales para obtener información sobre actividades turísticas alternativas o complementarias, así como el acceso a otros territorios o municipios (véase el diagrama VI.3).

\section{Diagrama VI.3}

Gobernanza en cadenas de valor turísticas: actores clave y su papel en el desarrollo de nuevos destinos o productos

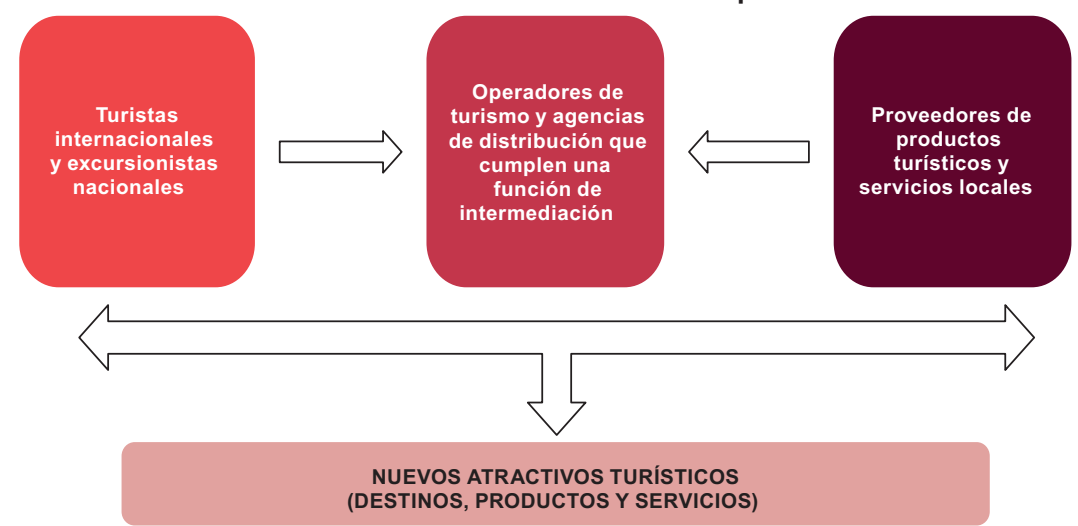

Fuente: Elaboración propia, sobre la base de N. Oddone y P. Alarcón, "Fortalecimiento de la cadena de turismo de Antigua Guatemala y de los municipios rurales del Departamento de Sacatepéquez", Documentos de Proyectos (LC/MEX/W.15), Ciudad de México, Comisión Económica para América Latina y el Caribe (CEPAL), 2016 y S. Garry y R. Martínez, "Fortalecimiento de la cadena de turismo en el Departamento de La Libertad, El Salvador", Documentos de Proyectos (LC/MEXW.18), Ciudad de México, Comisión Económica para América Latina y el Caribe (CEPAL), 2016.

En la provincia de Pedernales, por el contrario, dada la ausencia relativa de agencias de distribución y operadores turísticos maduros, se puede experimentar más con modelos alternativos de promoción turística y gestión del destino (Alvarado, Oddone y Gil, 2016). Ante la ausencia de un eslabón maduro de distribución, los hoteles y 
restaurantes más consolidados juegan un destacado papel en la gobernanza de la cadena local y funcionan como entes rectores en la organización de la cadena de valor.

Las estrategias de escalamiento económico y social para las tres cadenas se diseñaron tomando como referencia buenas prácticas y casos de éxito a nivel internacional, otorgando preferencia a las lecciones de otros países de Centroamérica y América Latina. Las recomendaciones se elaboraron para que su implementación promueva el desarrollo turístico de los destinos a través de una visión de tecnificación de la actividad, la coordinación entre servicios, la vinculación con los mercados, la oferta de nuevos servicios y productos que vinculen al ámbito rural, la proyección y mercadotecnia bajo marcas colectivas y la sostenibilidad de los emprendimientos para que haya una buena distribución del valor agregado de la cadena.

Las recomendaciones en turismo cuentan con un enfoque integral dentro de un marco colectivo de política pública (incluidas la política industrial, rural, de ciencia y tecnología, medio ambiente y otras) que contempla todos los eslabones de la cadena de valor y que considera, por tanto, la complementariedad con otras estrategias nacionales. En el diagrama VI.4 se presentan, de manera sintetizada, las estrategias de política pública para fortalecer el escalamiento de las cadenas turísticas.

\section{Diagrama Vl.4 \\ Estrategias para el fortalecimiento de las cadenas de valor turísticas}

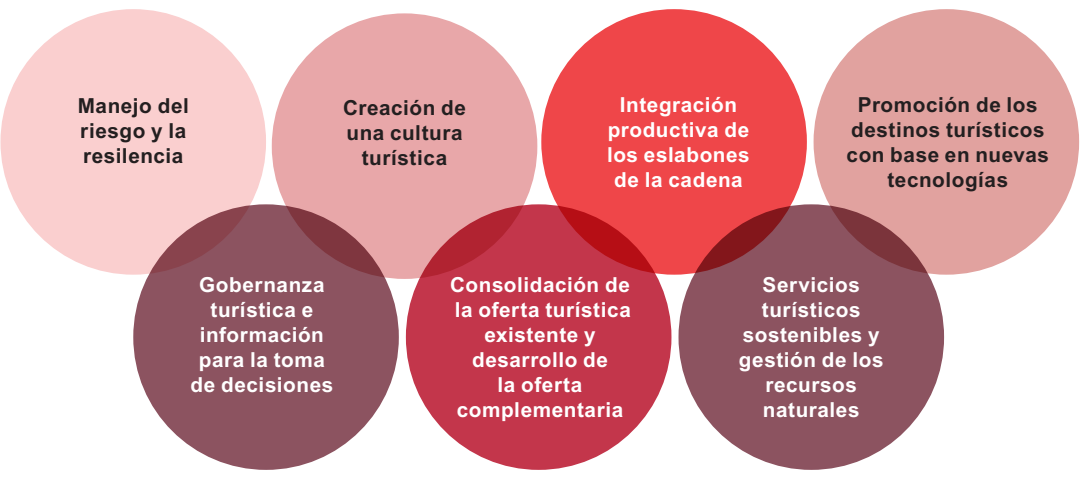

Fuente: Elaboración propia, sobre la base de S. Garry y R. Martínez, "Fortalecimiento de la cadena de turismo en el Departamento de La Libertad, El Salvador", Documentos de Proyectos (LC/MEX/W.18), Ciudad de México, Comisión Económica para América Latina y el Caribe (CEPAL), 2016; R. Frías, S. Garry y N. Oddone, Cadenas de Valor Turísticas en el Departamento de la Libertad, San Salvador, Ministerio de Turismo (MITUR)/Corporación Salvadoreña de Turismo (CORSATUR), 2016; N. Oddone y P. Alarcón, "Fortalecimiento de la cadena de turismo de Antigua Guatemala y de los municipios rurales del Departamento de Sacatepéquez", Documentos de Proyectos (LC/MEX/W.15), Ciudad de México, Comisión Económica para América Latina y el Caribe (CEPAL), 2016 y J. Alvarado, L. Gil y N. Oddone, "Fortalecimiento de la cadena de valor del turismo en Pedernales, República Dominicana. Versión Preliminar", Documentos de Proyectos, Ciudad de México, Comisión Económica para América Latina y el Caribe/Fondo Internacional de Desarrollo Agrícola (FIDA), 2016. 
Con las estrategias de fortalecimiento de la cadena de valor se han identificado oportunidades puntuales de acción por parte del sector privado y se visualizan las áreas estratégicas de gestión y acompañamiento por parte del sector público, a fin de consolidar y robustecer el trabajo de los actores que conforman la cadena. Estos programas y sus estrategias se perfilan como una hoja de ruta para la adecuada integración de los gestores del turismo en los destinos, cada uno desde su perspectiva. Ya sea como autoridad, como pequeño empresario turístico o como proyecto de desarrollo de turismo rural, es necesario que cada actor tome conciencia de su función en la cadena de turismo y comprenda cómo incide su desarrollo individual en el desarrollo colectivo.

A continuación, se resumen las opciones de política pública que pueden considerarse transversales para fortalecer las cadenas de valor turísticas con miras a lograr un turismo más equitativo y sostenible. Las estrategias se agrupan conforme a los siete programas de política pública que ofrecen acciones concretas para resolver las restricciones comunes encontradas en las cadenas estudiadas.

Un programa para fortalecer la creación de una cultura turística puede desarrollarse con base en las siguientes estrategias:

- Identificar o poner en valor recursos naturales y culturales que puedan figurar como principales atractivos turísticos de los destinos. Estimular los emprendimientos turísticos locales, rurales o comunitarios bajo una lógica asociativa.

- Transformar la forma en que las comunidades visualizan el turismo por medio de un proceso de sensibilización. Ejecutar un programa de sensibilización ciudadana y de creación de una cultura turística para comunicar los efectos positivos de la actividad, como la generación de empleo directo e indirecto, la llegada de divisas y el desarrollo económico del territorio. Dicho programa deberá tomar en cuenta los diferentes destinatarios y hacer uso del sistema escolar formal.

- Mejorar las capacidades de la mano de obra calificada organizando un programa de capacitación y profesionalización para artesanos locales que potencie la inserción productiva de jóvenes y mujeres con base en la recuperación de técnicas artesanales del territorio, procesos de innovación en cuanto a los materiales utilizados y técnicas de mercadotecnia y ventas que no respondan solo a la demanda in situ, sino también a la generación de una oferta que pueda comercializarse a escala nacional. Impulsar la formación de capacidades de los trabajadores del sector y los prestadores de servicios, los emprendedores y los gestores turísticos a través de la certificación de competencias laborales. 
En cuanto a la consolidación de la oferta turística existente y el desarrollo de una oferta complementaria se puede considerar estrategias como:

- Construir técnicamente productos turísticos que faciliten la estructuración derutas temáticas y circuitos turísticosinnovadores, de calidad y sostenibles. Generar productos y servicios turísticos locales, rurales y comunitarios complementarios, desarrollados en virtud de un concepto de gestión de calidad y sostenibilidad para prevenir el alto índice de fracaso de los emprendimientos y favorecer el escalamiento social.

- Impulsar de manera sistemática el fortalecimiento de circuitos y rutas de turismo en cada destino. Fomentar la integración de los circuitos y rutas turísticas de los municipios para complementar circuitos y rutas nacionales y regionales. Garantizar una adecuada articulación interprovincial al sur del país.

- Fortalecer el turismo en las comunidades rurales generando productos piloto para garantizar una adecuada gobernanza local orientada al turismo sostenible. Promover la sostenibilidad de los servicios turísticos ofrecidos en la cadena. El enfoque en distintos tipos de turismo - como el ecoturismo, el turismo rural comunitario y otros- diversifica la atracción tradicional de un lugar turístico.

Se destacan opciones de estrategias para el desarrollo de servicios turísticos sostenibles y la gestión de los recursos naturales:

- Avanzar en la construcción de una estructura normativa que permita garantizar una adecuada gestión ambiental; se trata de avanzar a nivel nacional, departamental y local en la elaboración de normas y códigos de operación legales o de zonificación que permitan un escalamiento responsable de la cadena de valor. En lo que respecta a la construcción de la infraestructura necesaria para la expansión de actividades y servicios turísticos, se deben tomar en cuenta principios de construcción que no dañen los recursos naturales existentes.

- Diseñar un programa de sensibilización sobre los aspectos y efectos ambientales asociados con los servicios hoteleros y de restaurantes, resaltando el elevado consumo de agua y energía y la generación de residuos y de aguas residuales. La inversión de largo plazo en infraestructura para la tratamiento de aguas negras y residuales, el manejo de los desechos y el uso de energía de distintas fuentes son aspectos clave de este programa. A nivel más operativo de los eslabones de la cadena también se trata del uso de herramientas o métodos de producción más limpia o que consideran un uso más equitativo de los recursos naturales, 
como el agua en la limpieza de los establecimientos de hoteles y restaurantes, entre otras actividades

Para fomentar la integración productiva de los eslabones de la cadena se puede considerar estrategias basadas en actividades como las siguientes:

- Fortalecer la comercialización y la negociación y promover la participación en ferias locales e internacionales. Estas herramientas incluyen folletos, guías, participación en eventos de promoción y comercialización, viajes de familiarización, alianzas de mercadotecnia y cursos de capacitación focalizados.

- Promover el abastecimiento y la compra de insumos locales a través del establecimiento de una red de negocios turísticos. Fomentar el abastecimiento y la compra de insumos locales mancomunados sobre la base de una planificación escalonada que tome en cuenta la factibilidad de la articulación entre la oferta y la demanda para cada producto.

En cuanto a la promoción de los destinos turísticos con base en nuevas tecnologías, las estrategias clave incluyen:

- Elaborar un plan integral de mercadotecnia turística con el que se pueda potenciar la aplicación general de esta en motores de búsqueda. Las iniciativas de mercadotecnia pueden fortalecerse con la creación de una oficina de mercadotecnia electrónica regional para impulsar las redes sociales y las actividades turísticas en la zona, así como para gestionar alianzas con otros sitios virtuales. Como pasos prácticos se puede diseñar una aplicación móvil a través de un programa de innovación y rediseñar las páginas web de los ministerios de turismo y las promotoras de turismo en los países.

- Facilitar el desarrollo de una marca colectiva que identifique y posicione a la región como un destino que ofrece una riqueza rural/cultural y de naturaleza complementaria a la oferta inicial o el polo de atracción principal. Es importante diseñar una marca turística que represente al destino con el fin de identificar mediante un símbolo las características de la oferta, diferenciarse de otros destinos y dotar de personalidad propia a la oferta turística local, y diseñar y establecer un plan de comunicación.

Como eje central de una política para fortalecer la gobernanza turística y la información para la toma de decisiones se recomienda la siguiente opción:

- Mejorar la recopilación y medición de datos estadísticos relacionados con el turismo (flujos, gastos, empleo y otros) con el apoyo de los bancos centrales, organizaciones nacionales y organismos internacionales. Favorecer el diálogo interinstitucional 
mediante la creación de espacios con información compartida de propuestas, perspectivas y cursos de acción iniciados por diferentes actores. Asimismo, es fundamental el desarrollo de las diversas herramientas de manejo de datos turísticos, como la recolección de datos estadísticos locales a través de la Cuenta Satélite de Turismo. El acceso a información puede fortalecer el sector y empoderar a los encargados de tomar las decisiones turísticas.

Por último, dentro de un programa para el manejo del riesgo y la resiliencia turística se puede considerar estrategias como:

- Diseñar y aplicar un plan integral de manejo del riesgo turístico recopilando información sobre las fuentes de riesgo a partir de datos científicos, registros de eventos pasados y consultas con las partes interesadas y expertos, e incorporando descriptores y a los principales grupos afectados. Estos riesgos pueden provenir de fuentes naturales (desastres, erupciones de volcanes, inundaciones, fuegos), de amenazas sociales (violencia política, cambios de poder del Estado), de la salud (gripe por el virus A (H1N1)) o de situaciones de violencia (terrorismo). Establecer los parámetros e indicadores dentro de los que se realizarán las actividades ligadas al manejo del riesgo turístico.

- Fortalecer el programa de seguridad turística nacional en coordinación con la policía nacional y la policía especializada en turismo. Detectar las preocupaciones y percepciones de riesgo en el destino para establecer los criterios de evaluación del riesgo y, de ser necesario, incrementar la presencia de la policía de turismo.

\section{F. Reflexiones finales}

En este segundo capítulo empírico se ilustra la aplicación de una estrategia de política industrial rural en el sector de los servicios mediante el fortalecimiento de las cadenas de valor de turismo en espacios rurales. La generación de fuentes complementarias de ingresos para la población rural, a través de la participación directa en la provisión de servicios turísticos o en encadenamientos como proveedores de insumos primarios, promueve un desarrollo inclusivo en los territorios.

Reflexionar sobre la constitución de cadenas de valor turísticas y su derrame económico y social remite al análisis de la conformación y delimitación de cada uno de sus eslabones, las estructuras de gobernanza en cada territorio y las posibilidades efectivas de escalamiento. Sin lugar a dudas, implica analizar críticamente las capacidades locales necesarias para la generación y distribución de los beneficios del valor turístico agregado entre la población participante y el estricto cuidado de los recursos naturales y el medio ambiente. De igual forma, vale la pena revisar a nivel territorial 
la articulación de los encadenamientos locales que se pueden generar con actividades económicas consideradas tradicionales, como la agricultura o la pesca, cuyos actores pueden fungir como proveedores de insumos para la cadena o bien como prestadores de servicios turísticos a partir de la visita a sus granjas o de una experiencia de viaje en lancha por la costa o de pesca tradicional, cuando la actividad no se encuentra en veda.

En los tres casos analizados, a pesar de la decidida voluntad de las poblaciones locales de dedicarse al turismo, hay un gran desconocimiento del funcionamiento de las cadenas de valor turísticas y de cómo opera el mercado. En primer lugar, la calidad de los servicios y productos presenta diferentes carencias y anomalías. Los empresarios locales y la población en general no saben cómo tratar a los turistas, no cuentan necesariamente con una cultura turística vinculada a la atención del cliente o del visitante. La mayoría de los emprendimientos son muy empíricos, por lo que más adelante surgirán dificultades debido a sus instalaciones improvisadas y a la falta de habilidades técnicas y administrativas para su operación. La informalidad de los negocios es alta, por lo que el acceso a financiamiento y a programas de apoyo suele ser difícil.

$\mathrm{La}$ afluencia actual y potencial de turistas internacionales que visitan El Salvador, Guatemala y la República Dominicana, así como los excursionistas nacionales, representan una oportunidad para crear nuevas experiencias y diversificar la oferta turística, así como para poner en marcha proyectos específicos del sector turístico vinculados al turismo rural comunitario, al ecoturismo o al turismo sostenible, en un contexto regional caracterizado por una oferta de turismo regional especialmente basada en sol y playas.

El enfoque de cadenas de valor también empodera a las comunidades y territorios para pensar y formular el tipo de desarrollo que quieren tener, ya sea un turismo masivo de sol y playa, un turismo gastronómico con raíces en los productos agrícolas y primarios nativos de la región o un turismo ecológico y sostenible, que considere tanto los recursos naturales como los recursos culturales del lugar. La definición de esta ontología del turismo permite un empoderamiento de los actores a lo largo de la cadena y ayuda a canalizar sus esfuerzos en pro del desarrollo conjunto. Las cadenas de valor turísticas son herramientas útiles para impulsar el escalamiento, tanto social como económico, del territorio, sobre todo en las comunidades rurales.

Si se pretende lograr que los municipios objeto de este estudio también se beneficien del turismo, es necesario trabajar de manera conjunta en la atracción de clientes hacia las áreas que se encuentran fuera de los polos de atracción principal (en los casos de El Salvador y la República Dominicana, el turismo de sol y playa, y en el caso de Guatemala, el núcleo de turismo colonial de Antigua), hacia las zonas y comunidades montañosas y rurales que rodean a ese atractivo principal que puede funcionar como tractor. Para lograrlo, se impone fortalecer las capacidades de los residentes locales para que participen de manera más activa y eficiente en las actividades económicas 
de la cadena. El entrecruzamiento de una segmentación turística acorde con la demanda actual y el diseño de una oferta de productos complementarios del tipo destino/producto contribuiría con el escalamiento de las cadenas de turismo. Resolver las dificultades identificadas respecto del tránsito serviría para consolidar una oferta complementaria para turistas internacionales y nacionales, así como excursionistas que buscan alternativas de recreación en áreas seguras y de calidad.

Las cadenas de valor analizadas permiten la construcción de procesos colectivos multidireccionales. Las acciones del sector privado deben considerarse como complementarias - no como sustitutas- de los esfuerzos y responsabilidades del sector público. Es importante asegurar que el sector privado no interfiera en la esfera de acción gubernamental, sobre todo en los aspectos vinculados al marco regulatorio y, al mismo tiempo, que el sector público ofrezca el espacio y la apertura necesarios para el desarrollo de los privados dispuestos a invertir, con el debido cumplimiento de la normativa vigente. En este sentido, contar con una oferta de financiamiento vinculado a las características que presentan los actores de cada cadena resulta fundamental para el apalancamiento de los proyectos y emprendimientos en curso y la consolidación de una oferta existente que pueda mejorar en términos de calidad.

\section{Bibliografía}

Alvarado, J., L. Gil y N. Oddone (2016), “Fortalecimiento de la cadena de valor del turismo en Pedernales, República Dominicana. Versión Preliminar", Documentos de Proyectos, Ciudad de México, Comisión Económica para América Latina y el Caribe/Fondo Internacional de Desarrollo Agrícola (FIDA).

Debbage, K.G. y P. Daniels (1998), “The tourist industry and economic geography. missed opportunities?", The Economic Geography of the Tourist Industry. A Supplyside Analysis, D. Ioannides y K.G. Debbage (eds.), Londres, Routledge.

Frías, R., S. Garry y N. Oddone (2016), Cadenas de Valor Turísticas en el Departamento de la Libertad, San Salvador, Ministerio de Turismo (MITUR)/Corporación Salvadoreña de Turismo (CORSATUR).

Garry, S. y R. Martínez (2016), "Fortalecimiento de la cadena de turismo en el Departamento de La Libertad, El Salvador", Documentos de Proyectos (LC/MEX/W.18), Ciudad de México, Comisión Económica para América Latina y el Caribe (CEPAL).

Oddone, N. y P. Alarcón (2016), "Fortalecimiento de la cadena de turismo de Antigua Guatemala y de los municipios rurales del Departamento de Sacatepéquez", Documentos de Proyectos (LC/MEX/W.15), Ciudad de México, Comisión Económica para América Latina y el Caribe (CEPAL).

OMT (Organización Mundial del Turismo) (2016), Panorama OMT del turismo internacional Edición 2016, Madrid. (2012), Manual de desarrollo de productos turísticos, Madrid.

Padilla, R. y N. Oddone (2016), Manual para el fortalecimiento de cadenas de valor (LC/MEX/1.1218), Ciudad de México, Comisión Económica para América Latina y el Caribe (CEPAL). 


\section{Capítulo VII \\ Conclusiones}

Ramón Padilla Pérez ${ }^{1}$

En la sección A de este último capítulo se presentan las reflexiones finales sobre el argumento central del libro: el fortalecimiento de cadenas de valor, como un instrumento de la política industrial rural, es una herramienta de gran utilidad para lograr un cambio estructural progresivo. En la sección B se aborda la creación de nuevas cadenas, una variante de la metodología de cadenas también aplicada al espacio rural. Como parte del proyecto de la Comisión Económica para América Latina y el Caribe (CEPAL) y el Fondo Internacional de Desarrollo Agrícola (FIDA), "Crecimiento inclusivo, política industrial rural y fortalecimiento de cadenas de valor participativas en América Latina y el Caribe", se brindó asistencia técnica al Gobierno de Costa Rica para crear una cadena agroindustrial, con fuerte presencia en áreas rurales: chips fritos al vacío. Dado que esta experiencia está sistematizada como documento de proyecto (Cordero y Padilla, 2017a) y en el capítulo VII de Cordero y Padilla Pérez (2017b), aquí se resumen las principales características y el aporte a la formulación de políticas industriales para el espacio rural. Por último, en la sección $C$ se examinan las fortalezas y los retos del enfoque de cadenas, así como las líneas de trabajo futuro.

Ramón Padilla es Jefe de la Unidad de Desarrollo Económico de la sede subregional de la CEPAL en México. 


\section{A. Fortalecimiento de cadenas de valor, política industrial rural y cambio estructural progresivo}

El cambio estructural, entendido como la recomposición de la estructura del valor agregado y el empleo (Krüger, 2008), ha sido ampliamente reconocido como un factor asociado cercanamente a un mayor crecimiento económico en el largo plazo (Harada, 2015; Szirmai, 2012; Lin, 2012; McMillan and Rodrik, 2011). No obstante, el cambio estructural no necesariamente se traduce en mejores condiciones económicas y sociales de la población. La CEPAL (2016) ha añadido el término "progresivo", con lo que reconoce que no todas las formas de cambio estructural tienen los mismos resultados. De esta manera, el cambio estructural progresivo es aquel en el que la transformación deriva en un crecimiento sostenido, inclusivo y ambientalmente sostenible. Para ello se requiere de un conjunto integral de políticas públicas.

$\mathrm{Al}$ igual que en otras regiones, el espacio rural en América Latina y el Caribe ha experimentado grandes transformaciones en las últimas décadas, lo que obliga a repensar las estrategias de desarrollo. En los capítulos I y II se define el espacio rural sobre la base de una combinación de criterios demográficos, sectoriales y territoriales: el espacio geográfico de menor densidad de población en el que ocurren procesos de interacción social y económica compartidos por múltiples actores y que le aportan identidad. Las actividades económicas rurales son multisectoriales; las principales son aquellas que corresponden al sector agropecuario, pero se reconoce la creciente importancia de actividades complementarias de manufactura y servicios como la agroindustria, las artesanías y el turismo rural. En cuanto a los principales cambios, cabe destacar el descenso de la participación del empleo y el valor agregado agropecuario en el total de la actividad económica rural, la mayor interdependencia de lo agropecuario respecto de otros sectores (por ejemplo, manufactura y servicios), la creciente importancia de los procesos de aprendizaje e innovación, el descenso de la población radicada en áreas rurales, los cambios en la conectividad con los centros urbanos y el surgimiento de nuevos actores y las formas de coordinación entre ellos.

Los retos que enfrenta el espacio rural fueron abordados en el capítulo I. El análisis se concentró en los países de Centroamérica y la República Dominicana, dado que allí se llevaron a cabo la mayoría de los procesos de fortalecimiento de cadenas de valor en el marco del proyecto CEPAL-FIDA ya mencionado. En primer lugar, se reconoce el peso significativo que continúa teniendo el espacio rural en estas economías, a pesar de las transformaciones estructurales que se han registrado en las últimas décadas. En 2015, por ejemplo, la población rural representaba 
el $46 \%$ de la población total en Honduras, el $44 \%$ en Guatemala y el $42 \%$ en Nicaragua. También es importante destacar que se observan marcadas diferencias entre lo rural y lo urbano en términos de desarrollo económico y social. Por ejemplo, en Guatemala, la población rural en condición de pobreza alcanza el 77,2\%, mientras que en las áreas urbanas se reduce al $58,1 \%$.

Los desafíos del espacio rural en materia de desarrollo productivo se agruparon en cuatro áreas: institucionales, de sostenibilidad ambiental, de comercialización, y de productividad e innovación. Entre los primeros se identifica el centralismo en el diseño e implementación de políticas públicas, marcos normativos que no favorecen a las unidades de menor tamaño y la ausencia de procesos participativos para la elaboración, implementación y evaluación de políticas públicas para el espacio rural. Entre los retos de sostenibilidad ambiental está la formulación de estrategias para enfrentar las amenazas de origen meteorológico, los efectos del cambio climático en los recursos hídricos y la mitigación del impacto de las actividades productivas en el medio ambiente. Los retos en materia de comercialización están asociados con la alta volatilidad en los precios internacionales de los productos primarios y las barreras que enfrentan los productores para vender sus productos en mercados formales por falta de información de mercados, certificaciones y equipo de transporte, entre otros. En materia de productividad e innovación, la falta de conocimientos técnicos y gerenciales, el limitado acceso al financiamiento y la desarticulación de cadenas de valor son algunos de los retos identificados.

La política industrial rural está dirigida a atender estos desafíos y es entendida como la implementación, por parte del Estado, de instrumentos enfocados al fortalecimiento de las actividades productivas del espacio rural, con el propósito de lograr un cambio estructural a través de actividades de transformación (manufactura) y de servicios, así como la integración y complementariedad con actividades, mercados y sectores de mayor dinamismo e intensidad de conocimiento. Para atender de manera integral los desafíos, la política industrial rural debe coordinarse con otras políticas, como la de desarrollo agropecuario y desarrollo rural. Si bien el término pareciera contener elementos conceptuales contrapuestos, las recientes transformaciones del espacio rural han diluido la aparente contradicción. Es importante señalar que una política industrial rural no supone renunciar a las vocaciones productivas de las localidades, sino escalarlas y complementarlas con actividades secundarias (por ejemplo, agroindustria y artesanías) y terciarias (por ejemplo, turismo rural, servicios ambientales y servicios profesionales). 
La metodología de fortalecimiento de cadenas de valor presentada en el capítulo III es un instrumento para la implementación de la política industrial rural. En primer lugar, sigue un enfoque microeconómico, centrado en los actores que componen los eslabones de la cadena de valor, así como en las relaciones entre ellos, lo que permite identificar las restricciones y formular estrategias focalizadas. En segundo término, comprende el análisis de las instituciones y organizaciones públicas que regulan y apoyan la cadena, por lo que permite la coordinación de los distintos instrumentos públicos dirigidos a su fortalecimiento en diversas áreas. En tercer lugar, un pilar central de esta metodología es la participación activa del sector público, los actores de la cadena y los organismos de apoyo (asociaciones empresariales, universidades y proveedores de servicios especializados, entre otros) en todas las etapas del proceso, a través de mesas de diálogo, grupos de enfoque y un involucramiento cercano en la ejecución de cada etapa. La construcción de espacios de diálogo permite establecer acuerdos entre actores públicos y privados, pero también en los sectores público y privado.

La política industrial rural no necesariamente conduce a un cambio estructural de carácter progresivo. El enfoque y los instrumentos utilizados definen su impacto en materia económica, social y ambiental. El enfoque participativo de la metodología de la CEPAL, así como la incorporación de aspectos ambientales, de género y de inclusión social, permite que las estrategias diseñadas faciliten una transformación de la estructura con una orientación progresiva.

En los capítulos V y VI se analizó de manera transversal la experiencia de fortalecimiento de siete cadenas de valor rurales, agrupadas en dos tipos: primarias y agroindustriales, y de turismo. Ambos casos ilustran la aplicación de instrumentos de política industrial rural. En el primer tipo de cadenas se identificaron estrategias dirigidas a fomentar una cultura de calidad e inocuidad entre los productores agroindustriales, apoyar el desarrollo de capacidades productivas y tecnológicas para incursionar en la transformación de productos primarios, fomentar la asociatividad entre productores, facilitar el acceso de pequeños productos a mercados nacionales e internacionales formales e incentivar la adopción de medidas que mitiguen el impacto ambiental de las actividades de la cadena. En cuanto al fortalecimiento de cadenas de valor de turismo, la política industrial rural se enfoca en la integración productiva de los eslabones de dicha cadena, la promoción de destinos turísticos con base en nuevas tecnologías, el fomento de servicios turísticos sostenibles y la gestión de recursos naturales, la consolidación de la oferta turística existente y el desarrollo de productos y destinos complementarios. 


\section{B. La creación de cadenas de valor}

En 2014, la Promotora del Comercio Exterior (PROCOMER) y el Ministerio de Comercio Exterior (COMEX) de Costa Rica solicitaron la colaboración técnica de la CEPAL para crear cadenas de valor enfocadas en mercados de exportación. En respuesta a esta solicitud, la CEPAL amplió su metodología, sobre la base del trabajo previo realizado en torno al fortalecimiento de cadenas existentes, con conceptos y herramientas de emprendimiento productivo: i) estudio de mercado, ii) análisis de factibilidad técnica y económica, iii) identificación de actores potenciales de la cadena y iv) estrategia de mercadotecnia y ventas ${ }^{2}$.

A fin de contar con una estrategia sólida para la creación de una nueva cadena, se formó un consorcio integrado por cuatro equipos: i) la PROCOMER y el COMEX como representantes del sector público de Costa Rica, interesados en el desarrollo productivo y en la oferta exportadora del país. Ambos organismos aportaron su experiencia en inteligencia comercial y en apoyo a iniciativas empresariales; ii) el Centro Nacional de Ciencia y Tecnología de Alimentos (CITA) de la Universidad de Costa Rica (UCR), que proporcionó los conocimientos tecnológicos para la creación del producto principal de la cadena; iii) Auge, la incubadora de empresas de la UCR, que colaboró en la elaboración del estudio de factibilidad técnica y financiera, en el plan de comercialización y ventas, y en la estrategia de inicio de operaciones. La participación de Auge se concretó a través del proyecto de emprendimiento Sinergia, en el que participan el CITA y la Cámara Costarricense de la Industria Alimentaria (CACIA), y iv) la CEPAL, que cumplió una labor de articulación de los equipos y proporcionó asistencia para implementar la metodología. El consorcio así formado buscó fusionar los conocimientos y la experiencia necesarios para crear la nueva cadena, al tiempo que contribuyó a la consolidación de una estructura nacional que posibilitará la reproducción futura de la experiencia en nuevas cadenas.

En el diagrama VII.1 se ilustran los ocho pasos de la metodología para la creación de cadenas de valor: 1. definición de metaobjetivos, 2. selección de la cadena, 3. estudio de mercado, 4. primera mesa de diálogo, 5. estudio de factibilidad técnica y económica, 6 . segunda mesa de diálogo, 7. selección de empresas y 8. elaboración de estrategias para el inicio de operaciones de la cadena.

Esta sección está basada en el informe completo sobre el trabajo con la cadena (Cordero y Padilla Pérez, 2017a). 
Diagrama VII.1

Metodología para la creación de cadenas participativas

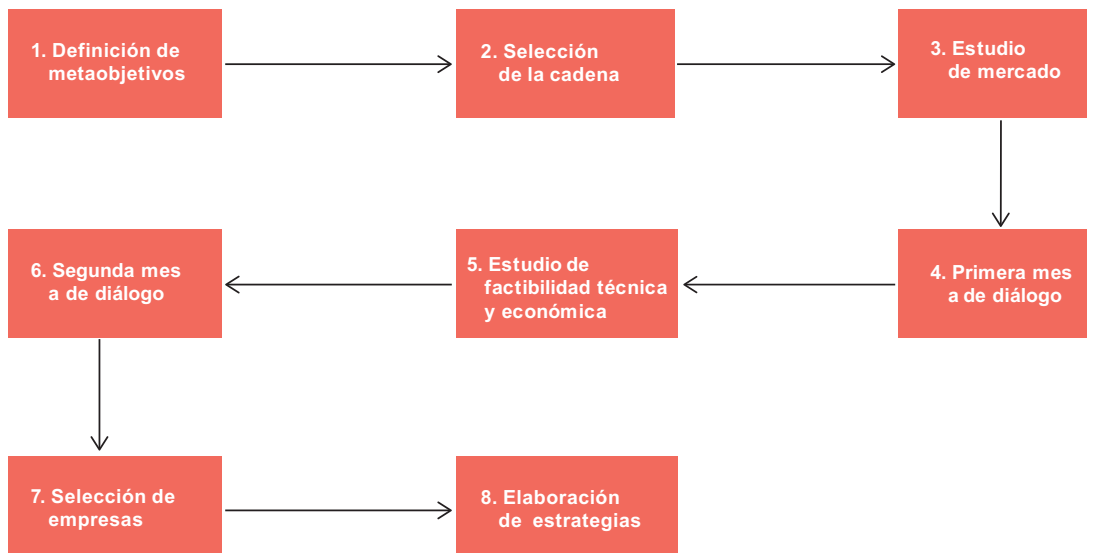

Fuente: M. Cordero y R. Padilla, "Creación de una cadena de valor: chips fritos al vacío en Costa Rica", serie Estudios y Perspectivas-Sede Subregional de la CEPAL en México, № 171 (LC/TS.2017/14; LC/MEX/TS.2017/6), Ciudad de México, Comisión Económica para América Latina y el Caribe (CEPAL), 2017.

A continuación se describen brevemente cada uno de los pasos en el caso de la cadena de chips fritos al vacío.

- Las instituciones encargadas de establecer los metaobjetivos fueron la PROCOMER y el COMEX, que definieron los siguientes: generar empleo; favorecer a las regiones menos desarrolladas (fuera de la Gran Área Metropolitana de San José), es decir, zonas rurales; fomentar las exportaciones, e incrementar el valor agregado mediante la ampliación de los encadenamientos productivos locales.

- El proceso de selección de la cadena comenzó con el análisis de una propuesta de diez productos agroalimentarios desarrollados por el CITA, para lo que se construyó una matriz con indicadores cuantitativos. Se determinó que los chips fritos al vacío tenían el mayor potencial de contribuir a los metaobjetivos.

- El estudio de mercado de la cadena de valor considerada fue realizado por la Dirección de Inteligencia Comercial de la PROCOMER. Se siguió una metodología exploratoria con información tomada de fuentes secundarias, principalmente de bases de datos internacionales, como Euromonitor International y Marketline. El estudio permitió elegir un producto a base de frutas (no de vegetales) y apostar por los mercados con mayor expansión (en particular, los Estados Unidos y el Reino Unido). Dadas las capacidades actuales de producción de frutas 
tropicales de Costa Rica, se consideró que estas deberían ser los insumos para la cadena.

- La primera mesa de diálogo fue convocada por la PROCOMER y se llevó a cabo después de la elaboración del estudio de mercado. Sus objetivos fueron: dar a conocer el proyecto de creación de la cadena y notificar y validar los resultados del estudio de mercado.

- El estudio de factibilidad técnica y económica fue realizado por investigadores del CITA y consultores de la CEPAL. La parte técnica permitió definir las condiciones óptimas para la transformación de los productos primarios (por ejemplo, temperatura, presión de vacío y tiempo de fritura; grosor del rebanado; velocidad de rotación y tiempo de centrifugación; identificación de los parámetros de calidad que determinan la vida útil de los productos, y selección preliminar del material de empaque en función de su vida útil y costo). El estudio económico permitió definir los costos de inversión inicial y los costos directos e indirectos, estimar el costo unitario y calcular los flujos financieros. También se definieron los efectos económicos y ambientales de la creación de la cadena.

- La segunda mesa de diálogo se llevó a cabo al término del estudio de factibilidad técnica y económica y del mecanismo de selección de empresas. Esta mesa tuvo como principal resultado la creación de una agenda para la transferencia de tecnología por empresa y la elaboración de estrategias para la implementación de la cadena.

- La selección de empresas o productores a los que se les transferiría la tecnología y se les brindaría asistencia técnica se hizo de manera objetiva. Para ello, se invitó a un grupo de potenciales interesados a completar un formulario con las siguientes áreas: i) aporte al cumplimiento de los metaobjetivos; ii) experiencia en el área de desarrollo del proyecto; iii) capacidad para cumplir con los requisitos sustentados en el estudio de factibilidad técnica y económica, y iv) nivel de emprendimiento (motivación) para formar parte del proyecto. Como resultado, cuatro empresas fueron seleccionadas por cumplir con los requisitos básicos y obtener los puntajes más altos.

- La última etapa consistió en el apoyo para el inicio de operaciones de la cadena. El primer paso de esta etapa fue una visita de diagnóstico y evaluación a las empresas seleccionadas. Debido a que los derechos de propiedad intelectual de la tecnología de fritura al vacío son de la Universidad de Costa Rica y a que 
las empresas desean proteger su información confidencial, fue necesario negociar un contrato de confidencialidad y otro de licenciamiento entre las partes. Acto seguido, se diseñó un plan de transferencia de tecnología, gestión de recursos financieros e inicio de operaciones.

El apoyo para la creación de la cadena de chips fritos al vacío es un ejemplo de política industrial rural en el que se facilita la transformación de productos primarios en bienes agroindustriales de mayor valor agregado. El enfoque de cadenas fue valioso para sumar a la iniciativa a actores del sector privado (productores, transformadores y proveedores de equipo y maquinaria) y a los diversos organismos públicos y privados encargados de regular y apoyar la nueva cadena.

\section{Fortalezas, retos y líneas de trabajo futuro}

La metodología para el fortalecimiento de cadenas de valor presentada en este libro se distingue por cuatro fortalezas. En primer lugar, se realizan análisis microeconómicos exhaustivos, tanto en el examen de la cadena de valor en el marco del diagnóstico como a la hora de proponer estrategias en el marco de una política industrial rural. También facilita la elaboración de programas para incorporar pequeños productores al proceso productivo, el diseño de herramientas para permitir una captura más equitativa de valor agregado a lo largo de la cadena, la creación de empleo de calidad y la consideración de factores transversales como el género y el medio ambiente. En este sentido, contribuye a lograr un cambio estructural de carácter progresivo.

En segundo término, la metodología se apoya en que todo el proceso sea participativo. Uno de los elementos centrales es la organización de mesas de diálogo para analizar y validar el diagnóstico y las estrategias propuestas. Las mesas ofrecen un mecanismo transparente para el análisis y la toma de decisiones, que favorece la adopción de acuerdos entre los sectores público y privado. Un elemento clave de la propuesta de política industrial rural que aquí se hace es el diseño de estrategias de forma participativa, en cuya formulación e implementación el sector privado asume un papel activo.

En tercer lugar, se apunta al desarrollo de capacidades locales. En todas las etapas del proceso participan activamente funcionarios públicos $\mathrm{y}$, en algunos casos, también representantes de organizaciones privadas, como las cámaras empresariales. Los trabajos con las cadenas involucraron a actores tradicionales del espacio rural (por ejemplo, ministerios de agricultura y ganadería), pero se les invitó a abordar nuevos enfoques: la integración con actividades de transformación y de servicios. También se incorporaron actores que frecuentemente no incluían entre sus prioridades el desarrollo del espacio rural, como los ministerios de industria y de comercio. 
En cuarto lugar, se basa en un enfoque sistémico de la política industrial. El respaldo a las cadenas no se centra exclusivamente en el eslabón principal conformado por los productores de bienes o servicios finales, sino que se extiende a los proveedores de insumos y equipos, a los servicios (control de calidad, difusión de nuevas tecnologías y transporte, entre otros) y a la comercialización. Por ello, es necesaria la integración de la política industrial rural con las políticas de desarrollo rural y desarrollo agropecuario, entre otras.

En la implementación de la metodología de cadenas de valor se han identificado dos retos principales. El primero es la falta de recursos financieros para la puesta en marcha de las estrategias. Con frecuencia, los gobiernos no cuentan con la capacidad financiera para apoyar la implementación, lo que puede causar desánimo entre los actores que participaron en el proceso. Por ello, es importante que en el diagnóstico y la formulación de estrategias se consideren, desde el inicio, posibles fuentes de recursos en los sectores público y privado, y la cooperación internacional. El segundo reto es la posible falta de voluntad y participación por parte de los actores de la cadena y el sector público. Al ser un proceso participativo, una débil respuesta de los actores retrasa las etapas del proceso y reduce el impacto en términos de la elaboración de estrategias conjuntas y la creación de capacidades locales.

El trabajo en cadenas de valor ha permitido a la CEPAL apoyar a los países de la región en sus estrategias de transformación productiva mediante la introducción de nuevos enfoques e instrumentos. La CEPAL continúa recibiendo solicitudes de asistencia técnica para el fortalecimiento de cadenas de valor y reitera su compromiso con los países miembros. Asimismo, se han abierto nuevas líneas de trabajo y colaboración técnica:

- El uso de remesas familiares para el fortalecimiento de cadenas de valor. Las remesas son un recurso valioso para facilitar la inclusión financiera de pequeños productores. Las estrategias diseñadas para el fortalecimiento de cadenas pueden implementarse mediante el uso productivo de estos recursos financieros.

- El análisis de cadenas de valor transfronterizas es una línea de trabajo para estimular el crecimiento inclusivo y la transformación productiva a través de procesos de integración regional.

- La asistencia técnica para el desarrollo de eslabones específicos de la cadena. Por ejemplo, el fortalecimiento de capacidades de productores de bienes primarios para abastecer a grandes cadenas de hoteles o la identificación de productos agroindustriales potenciales a partir del fortalecimiento de cadenas de valor primarias. 


\section{Bibliografía}

CEPAL (Comisión Económica para América Latina y el Caribe) (2016), Horizontes 2030: la igualdad en el centro del desarrollo sostenible (LC/G.2660/Rev.1), Santiago.

Cordero, M. y R. Padilla (2017a), "Creación de una cadena de valor: chips fritos al vacío en Costa Rica", serie Estudios y Perspectivas-Sede Subregional de la CEPAL en México, No 171 (LC/TS.2017/14; LC/MEX/TS.2017/6), Ciudad de México, Comisión Económica para América Latina y el Caribe (CEPAL).

(2017b), "Creación de una cadena de valor: chips fritos al vacío en Costa Rica", Fortalecimiento de cadenas de valor rurales, N. Oddone y R. Padilla (eds.), Documentos de Proyectos (LC/TS.2017/24), Santiago, Comisión Económica para América Latina y el Caribe (CEPAL), en prensa.

Harada, T. (2015), "Structural change and economic growth with relation-specific investment", Structural Change and Economic Dynamics, vol. 32.

Krüger, J. (2008), "Productivity and structural change: a review of the literature", Journal of Economic Surveys, vol. 22, N 2.

Lin, J. (2012), New Structural Economics. A framework for rethinking development and policy, Washington. D.C., Banco Mundial.

McMillan, M. S. y D. Rodrik (2011), "Globalization, structural change and productivity growth", NBER Working Paper, $\mathrm{N}^{\mathrm{o}} 17143$.

Szirmai, A. (2012), "Industrialisation as an engine of growth in developing countries, 1950-2005", Structural Change and Economic Dynamics, vol. 23. 


\section{Publicaciones recientes de la CEPAL ECLAC recent publications}

\section{www.cepal.org/publicaciones}

\section{Informes periódicos / Annual reports}

También disponibles para años anteriores / Issues for previous years also available

- Estudio Económico de América Latina y el Caribe 2016, 236 p. Economic Survey of Latin America and the Caribbean 2016, 232 p.

- La Inversión Extranjera Directa en América Latina y el Caribe 2016, 170 p. Foreign Direct Investment in Latin America and the Caribbean 2016, 164 p.

- Anuario Estadístico de América Latina y el Caribe 2016 / Statistical Yearbook for Latin America and the Caribbean 2016, $132 p$.

- Balance Preliminar de las Economías de América Latina y el Caribe 2016, 132 p. Preliminary Overview of the Economies of Latin America and the Caribbean 2016, 124 p.

- Panorama Social de América Latina 2015, 226 p. Social Panorama of Latin America 2015, 222 p.

- Panorama de la Inserción Internacional de América Latina y el Caribe 2016, 174 p. Latin America and the Caribbean in the World Economy 2015, 170 p.

\section{Libros y documentos institucionales / Institutional books and documents}

- Panorama fiscal de América Latina y el Caribe 2017: la movilización de recursos para el financiamiento del desarrollo sostenible, 2017, $115 \mathrm{p}$.

Fiscal Panorama of Latin America and the Caribbean 2017: Mobilizing resources to finance sustainable development, 2017, 108 p.

- ECLAC Thinking. Selected Texts (1948-1998), 2016, 520 p.

- La matriz de la desigualdad en América Latina, 2016, 96 p. The social inequality matrix in Latin America, 2016, 94 p.

- Autonomía de las mujeres e igualdad en la agenda de desarrollo sostenible, 2016, 184 p. Equality and women's autonomy in the sustainable development agenda, 2016, 168 p. Autonomia das mulheres e igualdade na agenda de desenvolvimento sustentável. Sintese, 2016, $106 \mathrm{p}$.

- La Unión Europea y América Latina y el Caribe ante la Agenda 2030 para el Desarrollo Sostenible: el gran impulso ambiental, 2016, 112 p.

The European Union and Latin America and the Caribbean vis-à-vis the 2030 Agenda for Sustainable Development: The environmental big push, 2016, 112 p.

- Horizontes 2030: la igualdad en el centro del desarrollo sostenible, 2016, $176 \mathrm{p}$. Horizons 2030: Equality at the centre of sustainable development, 2016, 174 p. Horizontes 2030: a igualdade no centro do desenvolvimento sustentável, 2016, 176 p.

- 40 años de agenda regional de género, 2016, 130 p. 40 years of the regional gender agenda, 2016,128 p.

- La nueva revolución digital: de la Internet del consumo a la Internet de la producción, 2016, 100 p. The new digital revolution: From the consumer Internet to the industrial Internet, 2016, 100 p. 


\section{Libros de la CEPAL / ECLAC books}

144 Desde el gobierno abierto al Estado abierto en América Latina y el Caribe, Alejandra Naser, Álvaro Ramírez-Alujas, Daniela Rosales (eds.), 2017, 466 p.

143 Protección social en América Latina: la desigualdad en el banquillo, Ana Sojo, 2017, 246 p.

142 Consensos y conflictos en la política tributaria de América Latina, Juan Carlos Gómez Sabaini, Juan Pablo Jiménez y Ricardo Martner (eds.), 2017, 446 p.

141 Brechas y transformaciones: la evolución del empleo agropecuario en América Latina, Jürgen Weller (ed.), 2016, $274 \mathrm{p}$.

140 Protección y formación: instituciones para mejorar la inserción laboral en América Latina y Asia, Alberto Isgut, Jürgen Weller (eds.), 2016, 428 p.

Protection and training: Institutions for improving workforce integration in Latin America and Asia, Alberto Isgut, Jürgen Weller (eds.), 2016, 428 p.

139 Hacia una nueva gobernanza de los recursos naturales en América Latina y el Caribe, Hugo Altomonte, Ricardo J. Sánchez, 2016, 256 p.

138 Estructura productiva y política macroeconómica: enfoques heterodoxos desde América Latina, Alicia Bárcena, Antonio Prado, Martín Abeles (eds.), 2015, 282 p.

\section{Páginas Selectas de la CEPAL / ECLAC Select Pages}

- Planificación y prospectiva para la construcción de futuro en América Latina y el Caribe. Textos seleccionados 2013-2016, Jorge Máttar y Mauricio Cuervo (comps.), 2016, 222 p.

- Desarrollo inclusivo en América Latina. Textos seleccionados 2009-2016, Ricardo Infante (comp.), 2016, $294 \mathrm{p}$.

- Globalización, integración y comercio inclusivo en América Latina. Textos seleccionados 2010-2014, Osvaldo Rosales (comp.), 2015, 326 p.

- El desafío de la sostenibilidad ambiental en América Latina y el Caribe. Textos seleccionados 2012-2014, Carlos de Miguel, Marcia Tavares (comps.), 2015, 148 p.

\section{Copublicaciones / Co-publications}

- El imperativo de la igualdad, Alicia Bárcena, Antonio Prado, CEPAL/Siglo Veintiuno, Argentina, 2016, 244 p.

- Gobernanza global y desarrollo: nuevos desafíos y prioridades de la cooperación internacional, José Antonio Ocampo (ed.), CEPAL/Siglo Veintiuno, Argentina, 2015, 286 p.

- Decentralization and Reform in Latin America: Improving Intergovernmental Relations, Giorgio Brosio and Juan Pablo Jiménez (eds.), ECLAC/Edward Elgar Publishing, United Kingdom, 2012, 450 p.

- Sentido de pertenencia en sociedades fragmentadas: América Latina desde una perspectiva global, Martín Hopenhayn y Ana Sojo (comps.), CEPAL/Siglo Veintiuno, Argentina, 2011, 350 p.

\section{Coediciones / Co-editions}

- Perspectivas económicas de América Latina 2017: Juventud, Competencias y Emprendimiento, 2016, 338 p. Latin American Economic Outlook 2017: Youth, Skills and Entrepreneurship, 2016, 314 p.

- Desarrollo e integración en América Latina, 2016, 314 p.

- Hacia un desarrollo inclusivo: el caso del Uruguay, 2016, 174 p.

- Perspectivas de la agricultura y del desarrollo rural en las Américas: una mirada hacia América Latina y el Caribe 2015-2016, CEPAL/FA0/IICA, 2015, 212 p. 


\section{Documentos de Proyectos / Project Documents}

- La transversalización del enfoque de género en las políticas públicas frente al cambio climático en América Latina, Marina Casas Varez, 2017, 101 p.

- Financiamiento para el cambio climático en América Latina y el Caribe en 2015, Joseluis Samaniego y Heloísa Schneider, 2017, 76 p.

- El cambio tecnológico y el nuevo contexto del empleo: tendencias generales y en América Latina, Sebastian Krull, 2016, 48 p.

- Cambio climático, políticas públicas y demanda de energía y gasolinas en América Latina: un meta-análisis, Luis Miguel Galindo, Joseluis Samaniego, Jimy Ferrer, José Eduardo Alatorre, Orlando Reyes, 2016, 68 p.

- Estado de la banda ancha en América Latina y el Caribe 2016, 2016, 46 p.

\section{Cuadernos Estadísticos de la CEPAL}

44 Las cuentas de los hogares y el bienestar en América Latina. Más allá del PIB, 2016.

43 Estadísticas económicas de América Latina y el Caribe: Aspectos metodológicos y resultados del cambio de año base de 2005 a 2010

\section{Series de la CEPAL / ECLAC Series}

Asuntos de Género / Comercio Internacional / Desarrollo Productivo / Desarrollo Territorial / Estudios Estadísticos / Estudios y Perspectivas (Bogotá, Brasilia, Buenos Aires, México, Montevideo) / Studies and Perspectives (The Caribbean, Washington, D.C.) / Financiamiento del Desarrollo / Gestión Pública / Informes y Estudios Especiales / Macroeconomía del Desarrollo / Medio Ambiente y Desarrollo / Población y Desarrollo / Política Fiscal / Políticas Sociales / Recursos Naturales e Infraestructura / Seminarios y Conferencias.

\section{Manuales de la CEPAL}

5 Estimación de las erogaciones sociales a partir del sistema de cuentas nacionales: una propuesta para las funciones de educación, salud y protección social, María Paz Colinao, Federico Dorin, Rodrigo Martínez y Varinia Tromben, 2016, 63 p.

4 Territorio e igualdad: planificación del desarrollo con perspectiva de género, 2016, 84 p.

3 Manual de formación regional para la implementación de la resolución 1325 (2000) del Consejo de Seguridad de las Naciones Unidas relativa a las mujeres, la paz y la seguridad, María Cristina Benavente R., Marcela Donadio, Pamela Villalobos, 2016, 126 p.

2 Guía general para la gestión de residuos sólidos domiciliarios, Estefani Rondón Toro, Marcel Szantó Narea, Juan Francisco Pacheco, Eduardo Contreras, Alejandro Gálvez, 2016, 212 p.

\section{Revista CEPAL / CEPAL Review}

La Revista se inició en 1976, con el propósito de contribuir al examen de los problemas del desarrollo socioeconómico de la región. La Revista CEPAL se publica en español e inglés tres veces por año.

CEPAL Review first appeared in 1976, its aim being to make a contribution to the study of the economic and social development problems of the region. CEPAL Review is published in Spanish and English versions three times a year. 


\title{
Observatorio demográfico / Demographic Observatory
}

Edición bilingüe (español e inglés) que proporciona información estadística actualizada, referente a estimaciones y proyecciones de población de los países de América Latina y el Caribe. Desde 2013 el Observatorio aparece una vez al año.

Bilingual publication (Spanish and English) proving up-to-date estimates and projections of the populations of the Latin American and Caribbean countries. Since 2013, the Observatory appears once a year.

\section{Notas de población}

Revista especializada que publica artículos e informes acerca de las investigaciones más recientes sobre la dinámica demográfica en la región. También incluye información sobre actividades científicas y profesionales en el campo de población. La revista se publica desde 1973 y aparece dos veces al año, en junio y diciembre.

Specialized journal which publishes articles and reports on recent studies of demographic dynamics in the region. Also includes information on scientific and professional activities in the field of population. Published since 1973, the journal appears twice a year in June and December.

\section{Las publicaciones de la CEPAL están disponibles en: ECLAC publications are available at: www.cepal.org/publicaciones}

\section{También se pueden adquirir a través de: They can also be ordered through: www.un.org/publications}

\author{
United Nations Publications \\ PO Box 960 \\ Herndon, VA 20172 \\ USA
}

\section{Tel. (1-888)254-4286 \\ Fax (1-800)338-4550}

Contacto / Contact. publications@un.org

Pedidos / Orders: order@un.org 


\section{Política industrial rural y fortalecimiento de cadenas de valor}

\section{RAMÓN PADILLA PÉREZ}

Editor
El espacio rural ha sufrido grandes transformaciones en el curso de las últimas décadas, como la disminución de la participación del

empleo y el valor agregado agropecuario en el total de la actividad económica, una mayor interdependencia del sector agropecuario con otros sectores como la manufactura y los servicios, y una creciente importancia de los procesos de aprendizaje e innovación. No obstante estas transformaciones, el espacio rural sigue teniendo un gran peso en la estructura económica de la región.

En este libro se plantea la necesidad de contar con una política industrial rural que promueva un cambio estructural basado en la innovación, un mayor valor agregado, mejores condiciones de empleo y de vida, y en armonía con el medio ambiente. La propuesta parte de la experiencia de la Comisión Económica para América Latina y el Caribe (CEPAL) en el fortalecimiento de cadenas de valor rurales, y ofrece un enfoque novedoso de la política industrial y el desarrollo del espacio rural, temas que tradicionalmente han sido tratados por separado. En el libro también se presenta la metodología de la CEPAL en materia de cadenas de valor, y se analizan de manera comparada los procesos de fortalecimiento de las cadenas rurales en torno a productos primarios y agroindustriales y al turismo rural. 